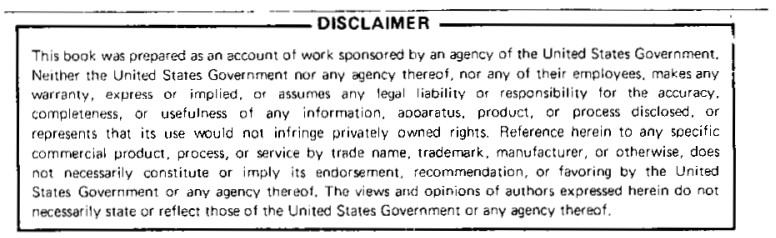

\title{
HEAT TRANSFER TO ISOBUTANE FLOWING INSIDE A \\ HORIZONTAL TUBE AT SUPERCRITICAL PRESSURE
}

Ike Chiao-Wen Hsu

Ph.D. Thesis

\section{Lawrence Berkeley Laboratory \\ University of California \\ Berkeley, California 94720}

November 1979

Distribution of thls aocumet is unumited 


\section{DISCLAIMER}

This report was prepared as an account of work sponsored by an agency of the United States Government. Neither the United States Government nor any agency Thereof, nor any of their employees, makes any warranty, express or implied, or assumes any legal liability or responsibility for the accuracy, completeness, or usefulness of any information, apparatus, product, or process disclosed, or represents that its use would not infringe privately owned rights. Reference herein to any specific commercial product, process, or service by trade name, trademark, manufacturer, or otherwise does not necessarily constitute or imply its endorsement, recommendation, or favoring by the United States Government or any agency thereof. The views and opinions of authors expressed herein do not necessarily state or reflect those of the United States Government or any agency thereof. 


\section{DISCLAIMER}

Portions of this document may be illegible in electronic image products. Images are produced from the best available original document. 


\section{ABSTRACT}

An experimental measurement of heat transfer coefficient of isobutane at $4.14 \mathrm{MPa}(600 \mathrm{psia})$ has been performed using the experimental system developed by the Sea Water Conversion Laboratory. The experimental system simulates a geothermal power plant utilizing a binary cycle with isobutane as the working fluid. In this system, isobutane is heated inside a horizontal tube with steam condensing on the outside.

The heat transfer coefficient was deduced from the measurements at the heater using the equation: $h=\frac{q_{\text {STEAM }}}{\left(T_{w}-T_{b}\right)_{A V G}}$. The heat flux $q_{\text {STEAM }}$ was determined by collecting the steam condensate in four pans placed underneath the heater tube and measuring the condensate rate by four specially-designed flow meters. The inside wall temperature of the heater tube was calculated using the temperatures obtained from the best fit curves drawn through the measurements of the thermocouples located at $x / 0=14 ., 45.9,77.6,109.4$ and 141.1. At each axial location, there were at least two thermocouples located at known radial locations inside the tube wall and positioned at either $+45^{\circ}$ or $-45^{\circ}$ about the vertical plane through the tube. The inside wall temperature calculated was assumed to be the peripherally-averaged value. The bulk temperature of isobutane was measured by a travelling temperature probe.

The resulting heat transfer coefficient was estimated to be accurate to $\pm 20 \%$ over the range of Reynolds number from $2.2 \times 10^{4}$ to $2.5 \times 10^{5}$ and $4.3<\operatorname{Pr}<11.1$.

For those runs, when $E=\frac{T_{p} \cdot c \cdot-T_{b}}{T_{w}-T_{b}}>1$ and the property variation 
was least severe, the experimental Nusselt numbers were found to be correlated by Petukhov's correlation to $\pm 15 \%$. Free convection showed little apparent effect on the heat transfer coefficient that was measured.

Experimental runs with bulk fluid temperature approaching or passing through the pseudocritical temperature along the length of the heat exchanger were considered in two parts.

(a) The results for $0.1<E<1.0$ were correlated to $\pm 15 \%$ by the Sieder-Tate correlation.

(b) For those results with $0.1>E>-3.0$, none of the proposed correlations could correlate the results to any satisfaction. However, there was some evidence that, when $0.1>E>-0.1$, a reduction in the experimental Nusselt number with respect to the prediction by Sieder-Tate correlation was dependent on $E$. 


\section{ACKNOWLEDGMENT}

I would like to express my gratitude to Professor R. A. Seban for his guidance in this research along with his helpful suggestions in the writing of this thesis. I also want to thank Professors A. D. K. Laird and C. J. King for their careful review and comments on the manuscript. I am also indebted to:

Mr. B. W. Tleimat for designing the SWCL experimental system and for inviting me to join the Binary Fluid Experiment Project. Mr. Tleimat's helpful advice and supervision during the experiments are deeply appreciated.

Mr. H. Rie for working together to obtain the experimental data and his contribution in the data reduction.

Dr. L. Silvester for providing the data on the properties of isobutane.

Messrs. J. C. Hensley, G. Schwab of SWCL and R. E. Whiteman of Lawrence Berkeley Laboratory for their help in the improvement and maintenance of the system.

Mrs. M. Ragsdale for her effort and patience in typing the manuscript and making the changes.

Mrs. G. Arneson and Mrs. R. Kirby for their kind encouragement and help during the years I spent at Sea Water Conversion Laboratory. My parents, Anling, uncle, aunt and Wayne for their encouragement and support through all of my graduate work.

This work was supported by the Division of Geothermal Energy of the U. S. Department of Energy, under contract No. W-7405-ENG $=48$. 
TABLE OF CONTENTS

Page

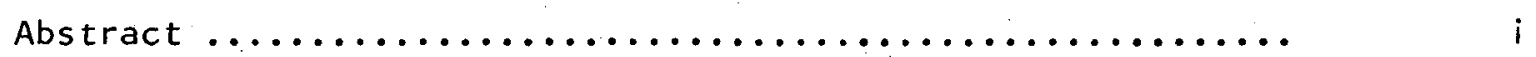

Acknowledgement $\ldots \ldots \ldots \ldots \ldots \ldots \ldots \ldots \ldots \ldots \ldots \ldots \ldots \ldots \ldots \ldots \ldots \ldots \ldots \ldots$

Table of Contents $\ldots \ldots \ldots \ldots \ldots \ldots \ldots \ldots \ldots \ldots \ldots \ldots \ldots \ldots$ iv

Chapter 1. Introduction $\ldots \ldots \ldots \ldots \ldots \ldots \ldots \ldots \ldots \ldots \ldots \ldots \ldots$

1-1. Heat Transfer to Fluids at Supercritical

Pressure ............................ 2

1-1-1. Available Experimental Data ........... 3

I-1-2. Available Analytical Results ........... 4

1-2. Identification of Effects That May Influence

Heat Transfer .......................... 5

1-3. Thes is Outline ........................ 6

Chapter 2. Experimental system $\ldots \ldots \ldots \ldots \ldots \ldots \ldots \ldots \ldots \ldots \ldots \ldots$

$2-1$. The Isobutane Loop ........................ 12

2-2. The Heater and Condenser Tubes and Location

of Thermocouples ......................... 14

2-3. Measurement of Bulk Temperature of Isobutane .... 16

2-4. Measurement of Flow Rate of Isobutane $\ldots \ldots \ldots \ldots .18$

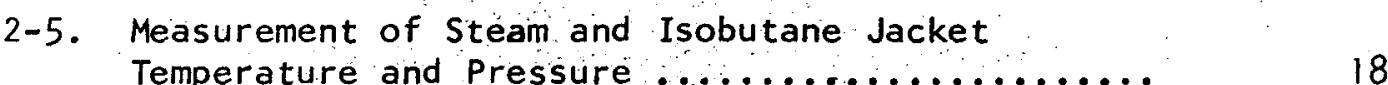

2-6. Measurement of the Condensation Rate .......... 19

Chapter 3. Experimental Measurements and Evaluation of Heat Transfer Coefficients ............... 21

3-1. The Specification of the Local Heat Transfer Coefficients .................... 21

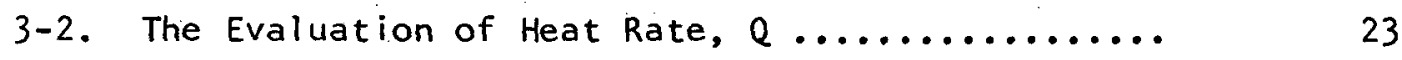


Page

3-3. The Evaluation of Bulk Temperature of

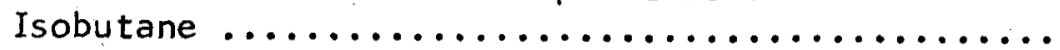

3-4. The Evaluation of the Inside Wall Temperature....

3-5. The Evaluation of the Steam Temperature .........

3-6. The Evaluation of Local Heat Transfer Coefficient.

3-6-1. The Error in the Evaluation of $h$

from Eq. $(3-1) \ldots \ldots \ldots \ldots \ldots \ldots \ldots \ldots . . . \ldots \ldots$

3-6-2. The Error in the Evaluation of $h$

from Eq. $(3-2) \&(3-3)$

3-6-3. Comparison of the Value of $h$ Evaluated

by the Two Methods ..................

3-7. The Heat Transfer Coefficient Obtained In

This Study $\ldots \ldots \ldots \ldots \ldots \ldots \ldots \ldots \ldots \ldots \ldots \ldots$

Chapter 4. The Effect of Buoyancy on Heat Transfer to Isobutane at Supercritical Pressure Flowing

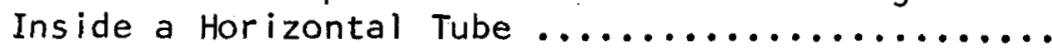

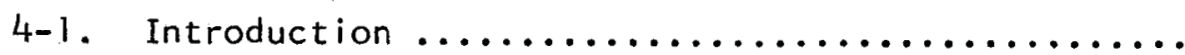

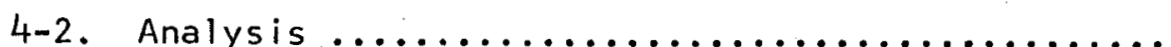

4-3. The Experimental Nusselt Numbers ............. 57

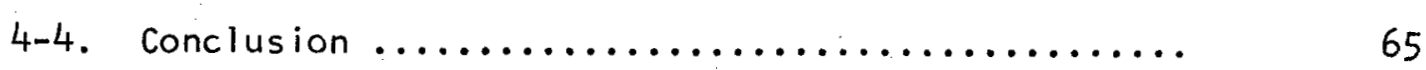

Chapter 5. Effect of Variation of Properties on Heat

Transfer to Isobutane Flowing Inside a Horizontal Tube at Supercritical Pressure ........

5-1. Introduction $\ldots \ldots \ldots \ldots \ldots \ldots \ldots \ldots \ldots \ldots \ldots \ldots \ldots \ldots$

5-2. Available Experimental Results .................. 68

5-2-1. Results of Adebiyi and Hall ........... 68

5-2-2. The Results of Yamagata, et al, For Water at Supercritical Pressure .........

5-2-3. Experimental Results of 0ther Investigators on Heat Transfer to Fluids at Supercritical Pressure for Vertical Flow ................... 


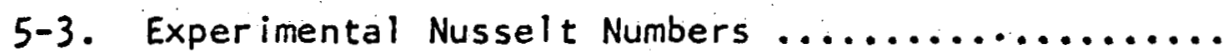

5-3-1. Runs with $0.01 \leq E \leq 1$ Along the Whole Length of the Heater Tube ......

5-3-2. Runs with Eckert Number Changing from Positive to Negative along the Length of the Heater Tube ...................

5-3-3. Comparison of NuEXP/NuS-T with

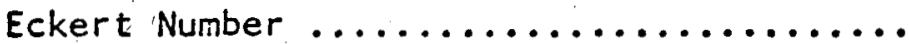

5-3-4. Reclassification of Experimental

Nusselt Numbers .................... 108

5-4. Conclusion ............................ 108

Chapter 6. Conclusions .......................... 116

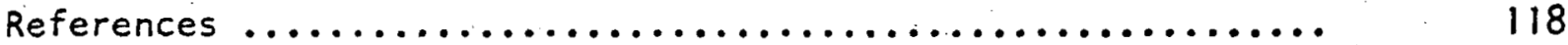

List of symbols ............................... 121

Appendix A. Thermodynamic and Transport Properties of

Isobutane at $4.14 \mathrm{MPa}(600$ psia) $\ldots \ldots \ldots \ldots \ldots$

Appendix B. Experimental Data ...................... 135

Appendix C. Derivation of Equations for Data Reduction ......

C-1. The Calculation of the Inside and outside Heater Tube Wall Temperature from

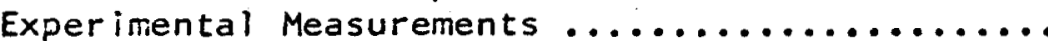

C-2. Calculation of Steam Condensate Rate and

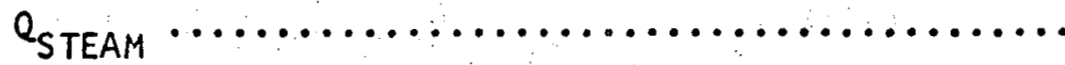

C-3. Calculation of Heat Rate, $Q_{\text {ISOB }} \ldots \ldots \ldots \ldots \ldots \ldots \ldots$

C-4. Calculation of Local Heat Transfer Coefficient ..........................

C-5. Calculation of Heat Transfer Coefficient of Condensing Steam Using Nusselt's Equation ....

Appendix D. Experimental Results for Low Grashof

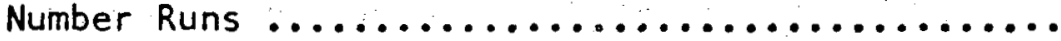

Appendix E. Preliminary Results on the Condensation of Isobutane on a Horizontal Tube. 
Appendix F. Locations and Configurations of Imbedded 
CHAPTER 1

\section{INTRODUCTION}

A binary cycle power generating plant has been proposed in the feasibility study of a $10 \mathrm{MW}$ experimental geothermal power generation facility. In this system, low-salinity intermediate temperature (150$230^{\circ} \mathrm{C}$ ) geothermal brine is used to heat a secondary fluid. This secondary fluid acts as the working fluid of a turbo-generator power cycle similar to an ordinary steam power plant. The selection of the secondary working fluid depends on the obtainable temperature range of the brine and other considerations. Studies prepared for Lawrence Berkeley Laboratory [1] selected isobutane at supercritical pressure as one of the candidate working fluids for use in the binary cycle system. Accurate specification of heat transfer coefficient for isobutane at supercritical pressure can affect the practicality of utilizing geothermal brine as a viable source of energy, since the cost of heat transfer equipment accounts for approximately half of the capital cost of the plant. In specifying the heat transfer coefficient for a novel working fluid, a design engineer has to rely on the available heat transfer coefficient predictions when information on the performance of the working fluid under similar or identical conditions are not available. These generalized empirical correlations involve the thermodynamic and transport properties of the fiuid and give the mean, or most probable value of a large amount of experimental data. Often the correlations might not have taken certain minor influences into account because such influences were not important under the experimental conditions on which the correlation was based. Thus the accuracy of such correlations 
diminishes even more. Because of this circumstance, a decision was made by Lawrence Berkeley Laboratory to fund at the Sea Water Conversion Laboratory. (SWCL) an experimental study to determine the value of heat transfer coefficient of isobutane at the proposed operating conditions for the geothermal power plant.

\section{1-i. Heat Transfer to Fluids at Supercritical Pressure.}

In the experimental system developed for the measurement of heattransfer coefficient to isobutane by the SWCL, isobutane is pressurized to $4.14 \mathrm{MPa}(600 \mathrm{psia})$, and heated inside an instrumented horizontal tube by steam condensing on the outside. This pressure is above the critical pressure of isobutane, $3.65 \mathrm{MPa}(529.1 \mathrm{psia})$. The temperature of the isobutane in the experiments performed on this system ranged from $62^{\circ} \mathrm{C}$ to $176^{\circ} \mathrm{C}$, with the critical temperature being $135^{\circ} \mathrm{C}$. The mass flow rate of isobutane ranged from 0.044 to $0.150 \mathrm{~kg} / \mathrm{sec}(350$ to $1200 \mathrm{lbm} / \mathrm{hr}$ ) giving the Reynolds numbers from $2.5 \times 10^{4}$ to $3.0 \times 10^{5}$ in the heated tube of $19.2 \mathrm{~mm}(0.756 \mathrm{in.})$ inside diameter. These Reynolds numbers are in the "fully turbulent" range.

With the experimental values of heat transfer coefficient for isobutane under various flow conditions at supercritical pressure thus made available, the focus of this study is the comparison of those experimental data to various predictions of the heat transfer coefficients, particularly for pressures above the critical. Such information has been available since the early 1960's in the application of supercritical fluids in boiler design and cooling rocket motors. Surveys of forced convective heat transfer to fluids at supercritical pressure have been made by Hall and Jackson, 1978 [2], and by Hsu and Graham [3]. 
Available information can be classified into two categories, experimental data and analytical results.

1-1-1. Available Experimental Data.

Most of the information on heat transfer to fluids at supercritical pressure involves experimental data for both vertical flow and horizontal flow, mostly for constant heat flux along the length of the tube.

Experimental data for vertical upflow and downflow have been given by Yamagata, et al [4] for water, by Bourke, et al [5] and Shiralkar and Griffith [6] for carbon dioxide, and by Brassington and Cairns [7] for helium. Yamagata and Brassington correlated their experimental data in terms of dimensionless parameters similar to a standard Dittus-Boelter correlation with

$$
\mathrm{Nu}=\mathrm{C} \operatorname{Re}_{b}^{\mathrm{m}} \operatorname{Pr}_{b}^{n} \mathrm{Fc}
$$

where

$$
\mathrm{Nu}=\frac{\mathrm{hD}}{\mathrm{k}}=\text { Nusselt number }
$$$$
\operatorname{Re}_{b}=\frac{\rho u_{m} D}{\mu_{b}}=\text { Reynolds number based on bulk temperature }
$$$$
\operatorname{Pr}_{b}=\left(\frac{\mu c p}{k}\right)_{b}=\operatorname{Prand} t \mathrm{l} \text { number based on bulk temperature }
$$

$F C=$ Correction factor based on the properties of the fluid

$C=a$ constant, e.g. $C=0.023$ for Dittus-Boelter correlation

Experimental data for horizontal flow have been reported by Adebiyi and Hall [8] for carbon dioxide and in part of Yamagata's work [4] for water. Both teams of investigators reported temperature measurements on the top and bottom along the axial direction of the test section. Adebiyi and Hall measured the peripheral variation of temperature at 
various axial locations as well. None of them attempted to correlate their experimental data for horizontal flow.

\section{1-1-2. Available Analytical Results.}

Hsu and Smith [9] examined the effect of density variation on the heat transfer in the critical region and compared their results with the experimental measurements of Bringer and Smith [10] for carbon dioxide at 1200 psia, at which the reduced pressure, $P_{r}$, is 1.12 . The effect of buoyancy on the heat transfer to the fluid at supercritical pressure was also considered analytically, but Hsu did not have sufficient experimental data to assess the result.

Hess and Kunz [11] made an analysis based on fully developed pipe flow with variable fluid properties and showed that their analysis could predict the heat transfer to hydrogen at supercritical pressure without postulating a new mechanism for heat transfer, such as a pseudo-film-boiling hypothesis. They obtained an empirical correlation based on their heat transfer data on supercritical hydrogen which in general form was similar to the sieder-Tate correlation.

$$
N u_{f}=0.0208 \operatorname{Re}_{f}^{0.8} \operatorname{Pr}_{f}^{0.4}\left(1+0.01457 \frac{\nu_{w}}{\nu_{b}}\right)
$$

The fluid properties were evaluated at film temperature, $T_{f}=\frac{T_{w}+T_{b}}{2}$. Hess and Kunz did not specify that their analytical model would be affected by the orientation of the heat transfer section because free convection was not accounted for.

Schnurr, et al [12], used an implicit finite difference numerical method to calculate the heat transfer coefficients of water at 
supercritical pressure under various wall heat fluxes. Their numerical method incorporated the variation of properties of the fluid into calculation. Schnurr also reported that for water, as heat flux was increased, the thermal development length became shorter. Their results showed a thermal development length of 30 diameters or less for hydrogen and water. To compare their results, Schnurr selected the experimental data obtained by Swenson, et al [13], on heat transfer to supercritical water in vertical upward flow for comparison.

\section{1-2. Identification of Effects That May Influence Heat Transfer.}

In the SWCL experimental arrangement, isobutane at supercritical pressure is heated while flowing through a horizontal tube. A length of about $4.7 \mathrm{in.} \mathrm{(} 6$ diameters) precedes the heating section for hydrodynamic development. The Reynolds number of isobutane at the inlet of the heated section is always greater than $2 \times 10^{4}$ based on the inside diameter of the tube (I.D. $=0.756 \mathrm{in.}$ ) so that the flow can be considered as "fully turbulent."

The isobutane is heated by condensing steam on the outside of the horizontal tube, simulating a constant outside wall temperature boundary condition. Thus the heat transfer to isobutane is by forced convective heat transfer inside a horizontal tube with relatively constant wall temperature.

The possible effects on the heat transfer to isobutane are:

(a) Buoyancy effect due to temperature difference between the bulk of the fluid and the wall. 
(b) The effect of significant variation of thermodynamic and transport properties which occur near the pseudocritical temperature of isobutane. The pseudocritical temperature is defined as the temperature at which the specific heat, $c_{p}$, exhibits a maximum value at a specified pressure. For isobutane at $4.14 \mathrm{MPa}$, this temperature is $142.5^{\circ} \mathrm{C}\left(288.5^{\circ} \mathrm{F}\right)$.

To assess those two effects on the heat transfer to isobutane, the experimental data are divided into three groups, as suggested by Yamagata, based on the magnitude of the Eckert number, $E=\frac{T_{p} \cdot c \cdot T_{b}}{T_{w}-T_{b}}$. Group A. This group contains data selected from experimental runs with $E>1$ at almost all the temperature measurement stations. These data are listed on Table B-I, Appendlx B.

Group B: This group contains data selected from experimental runs with $0.01<E<1$ at all the temperature measurement stations. These data are listed on Table B-2, Appendix B.

Group C: This group contains data from experimental runs where the inlet bulk temperature is less than the pseudocritical temperature, $T_{p . c .}$, but the exit temperature is greater than $T_{p . c} \cdot$ In such case, the value of $E$ changes from positive to negative along the heated tube and these results are given by Table B-3, Appendix B.

1-3. Thes is Outline.

Chapter 2 describes the experimental apparatus used in obtaining the present results for the heat transfer to isobutane using the SWCL system. 
Chapter 3 describes the experimental measurements, and the evaluation of heat transfer coefficients of isobutane. Before describing the evaluation of the heat transfer coefficient, a discussion on the comparison of the heat absorbed by the isobutane and the heat produced by the condensation of the steam is presented.

In Chapter 4 , the experimental results for heat transfer to isobutane at supercritical pressure are assessed with respect to the effect of buoyancy. The data selected are those of Group A for which $E>1$ so that in this consideration the properties are relatively constant across the cross section of the tube. This is evidenced by an approximate temperature and Prandtl number variation of isobutane in the radial direction for a case of $E>1$, as shown on Fig. 1-1. For this illustration, the temperature and Prandt 1 number profiles were calculated using the constant property solution of Table 9-3 and Fig. 9-6 of McAdams [14] together with the properties of isobutane. Fig. $1-1$ shows by the variation of the Pr numbers, that the viscosity, the property that is most sensitive to temperature variation, is almost invariant across the tube, so that for $E>1$ the major effect on the heat transfer coefficient ought to be that of free convection.

Chapter 5 assesses the effect of significant variation of properties of isobutane near the pseudocritical temperature region on the measured heat transfer data. The data selected are those in Groups $B$ and $C$ for which $0<E<1$ and $E$ changes from positive to negative. Using the same illustrative basis as for $E>1$, the temperature and Prandtl number variation in the radial direction are shown for $0<E<1$ on Fig. 1-2. In this case, $T_{w}$ exceeds $T_{p_{0} c}$ and a sharp peak of $\operatorname{Pr}$ occurs near the wall. Fig. $1-3$ shows when $E$ is slightly negative and both $T_{w}$ 


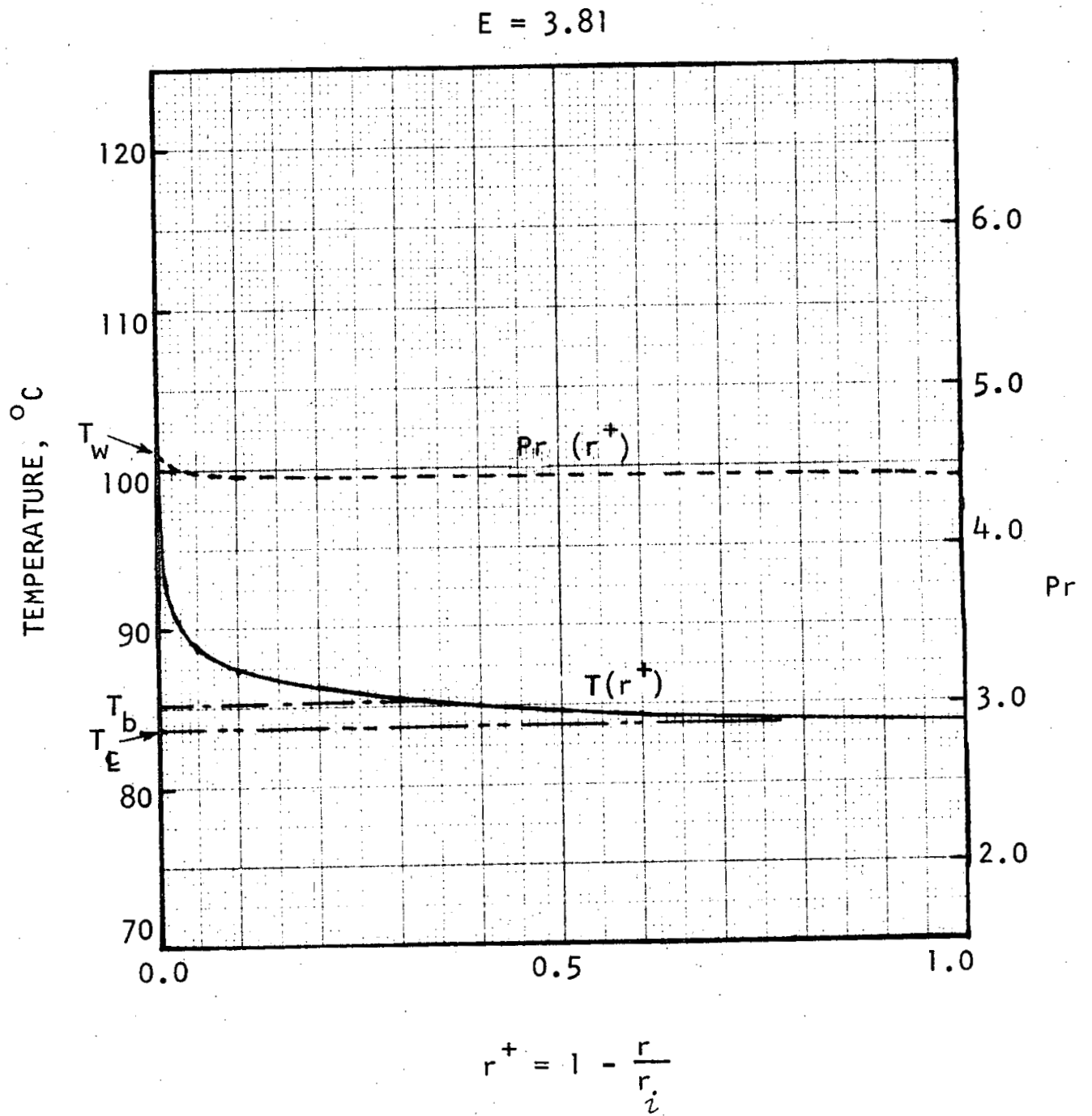

FIG. 1-1. ILLUSTRATION OF VARIATION OF TEMPERATURE AND PRANDTL NUMBER WITH RADIUS OF HEATER TUBE FOR ECKERT NUMBER GREATER THAN UNITY. $E=\frac{T_{p \cdot c \cdot}-T_{b}}{T_{w}-T_{b}}>1$ 


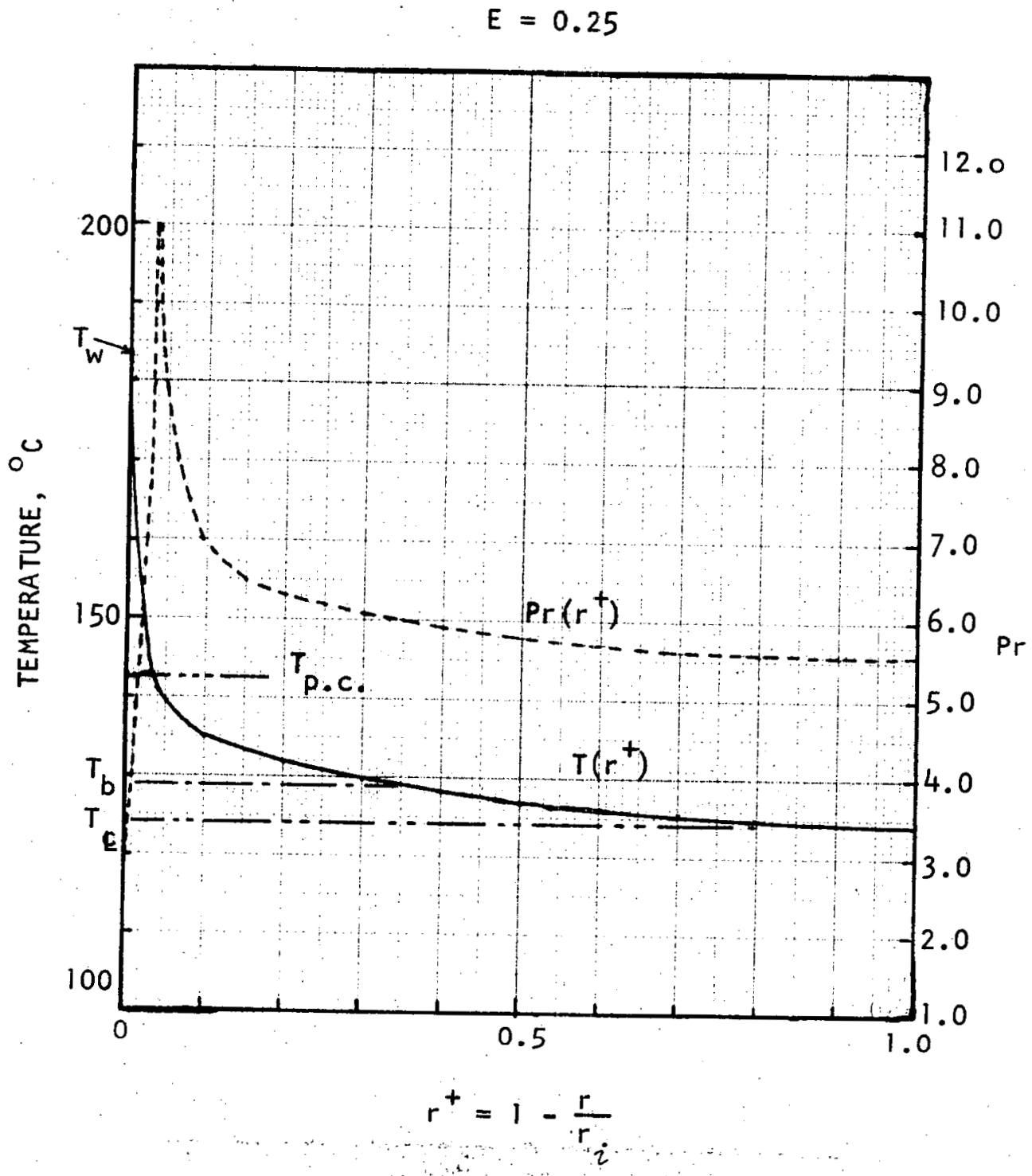

FIG. 1-2. ILLUSTRATION OF TEMPERATURE AND PRANDTL NUMBER VARIATION WITH RAD IUS OF THE TUBE FOR $0<E<I$. 


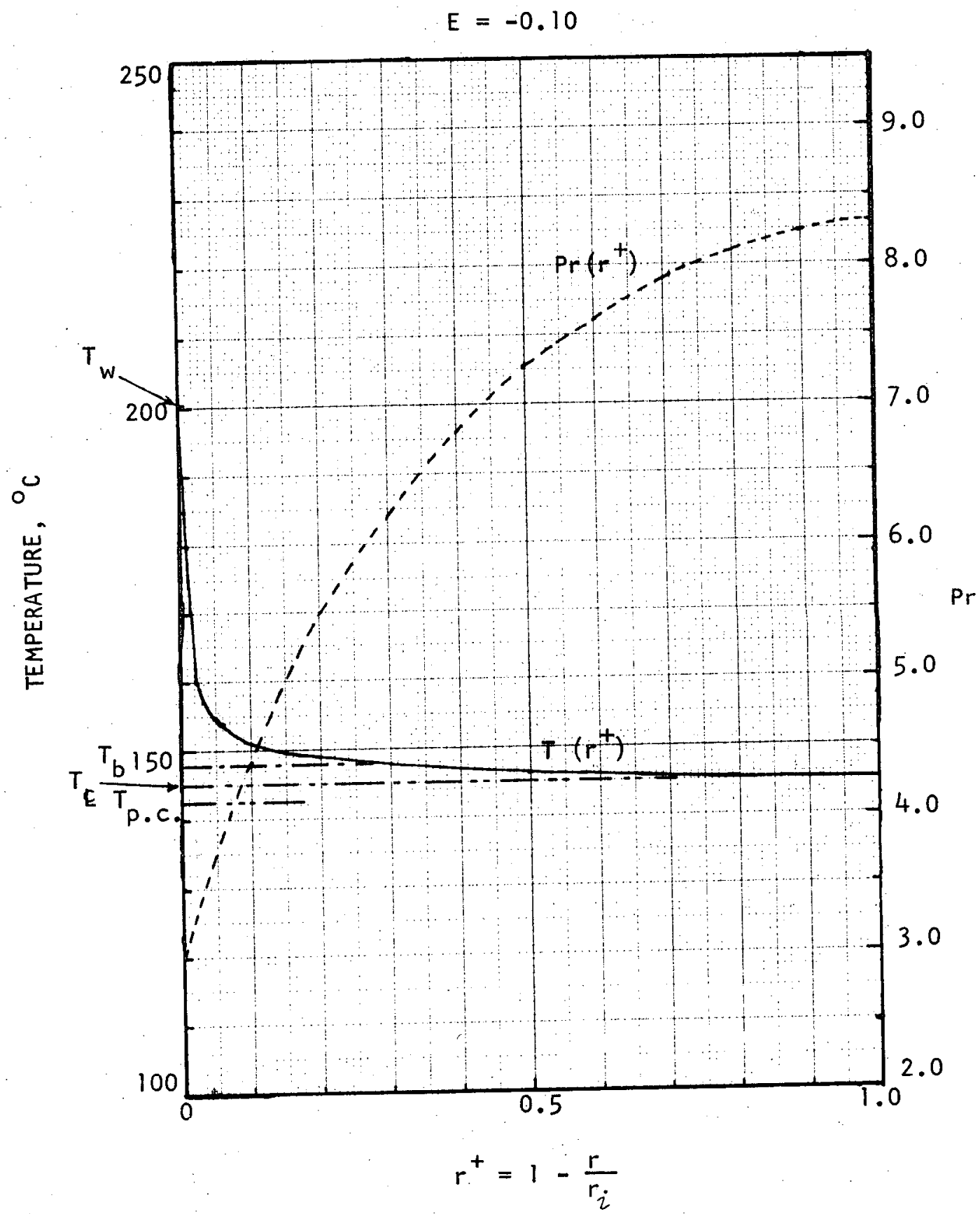

FIG. 1-3. ILLUSTRATION OF TEMPERATURE AND PRANDTL NUMBER VARIATION WITH RADIUS OF THE TUBE FOR ECKERT NUMBER LESS THAN ZERO. 
and $T_{b}$ are greater than $T_{p . c .}$, substantial property variation occurs across the tube cross-section. The severity of the property variation that is indicated by the two figures leads to the expectation of substantial effect on the heat transfer due to property variation alone. Appendix A contains a review and graphical presentation of thermodynamic and transport properties of isobutane at $4.14 \mathrm{MPa}$, as they were developed from various sources, for use in data reduction and various correlation equations.

Appendix $B$ contains the tabulation of the experimental data.

Appendix $C$ contains the equations used for data reduction and presents a sample data reduction for a run using a Texas Instruments TI-59 calculator.

Appendix $D$ includes data on runs with low temperature difference between the condensing steam and the inlet isobutane buik temperature.

Appendix E presents some of the heat transfer coefficients measured for the condensation of isobutane over a horizontal tube and compares these to the Nusselt solution for laminar condensation on a horizontal tube.

Appendix $F$ presents a tabulation of axial locations, wall thickness and radii at the imbedded thermocouples of the instrumented tubes. 


\section{CHAPTER 2}

\section{EXPER IMENTAL SYSTEM}

The experimental system, developed by the Sea Water Conversion Laboratory, was designed to simulate a geothermal power plant using a binary cycle. The thermodynamic cycle of the working fluid, isobutane, was a closed Rankine cycle but with the turbine replaced by a throttling valve. A schematic flow diagram of the system is shown on Fig. 2-1.

\section{2-1. The Isobutane Loop.}

Starting from the heater, pressurized isobutane flows through a horizontal tube containing thermocouples imbedded in the wall and the isobutane is heated by steam condensing on the outside of the tube. The thermocouples imbedded inside the tube wall indicate temperatures along the tube at five locations, $x / D=14.14,45.89,77.63,109.38$ and 141.12. After leaving from the heater tube, the isobutane expands through a throttling valve and is introduced into either a direct contact desuperheater or surface desuperheater by means of two threeway valves, depending on the state of isobutane after expansion. If the isobutane is in the superheated vapor region, then it is routed to the surface desuperheater where it is cooled to the saturated vapor state before entering into the condenser. The surface desuperheater is a shell-and tube-counterfiow heat exchanger with isobutane vapor on one side and cooling water on the other side. If isobutane is in the twophase region, then it is introduced into the direct-contact desuperheater which acts as a separator and separates the liquid and vapor phases. In either case, the nature of the heat transfer experiment is unaffected, 


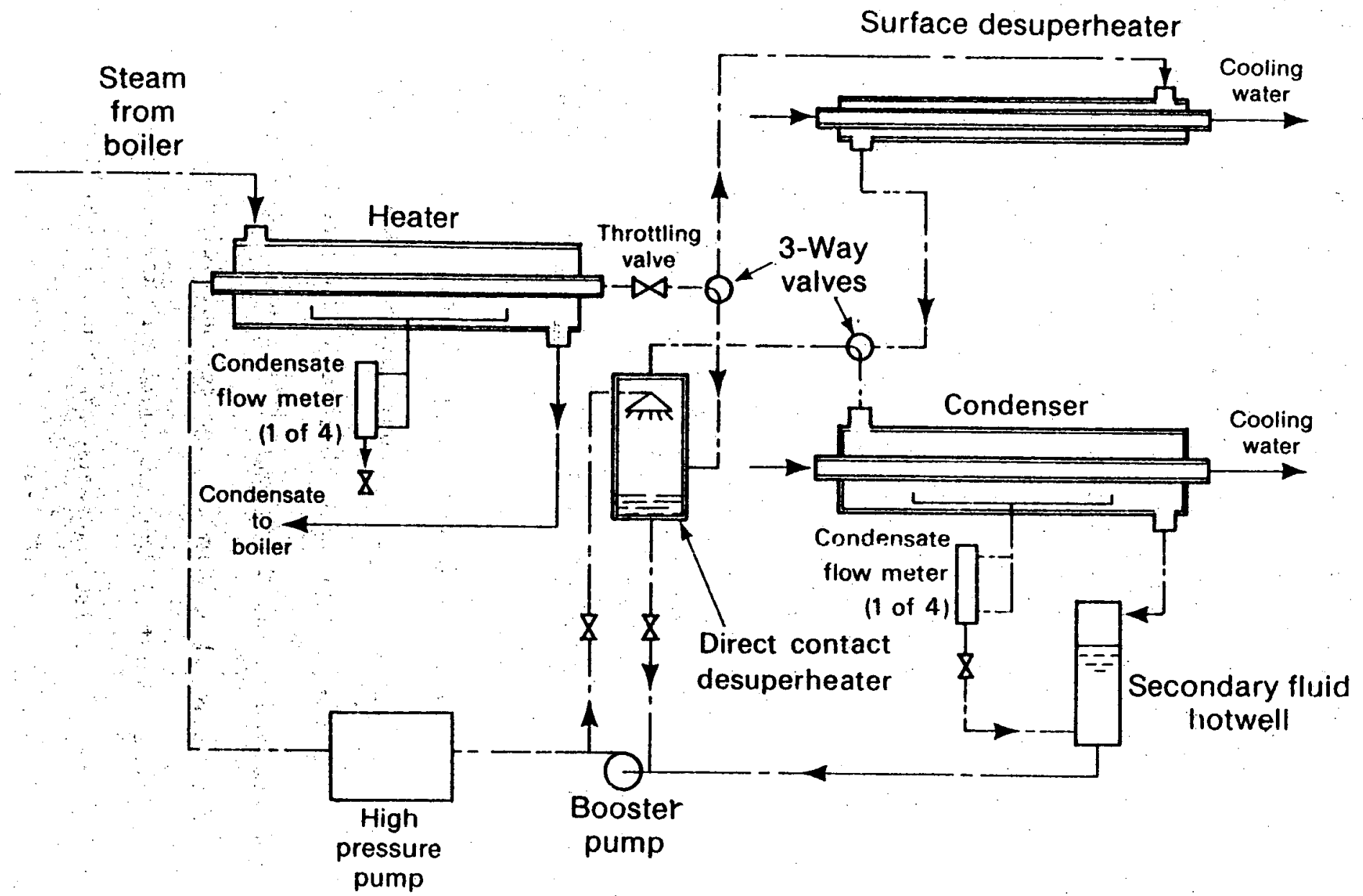

Fig. 2-1. Schematic Flow Diagram of the Sea Water Conversion

XBL $783-7893$ Laboratory's Binary Fluid Experimental System. 
but saturated vapor enters the condenser in amounts equal to or less than the isobutane flow rate through the heater and condenses on the outside of a single horizontal tube identical to the tube in the heater, including the locations of the imbedded thermocouples. The condenser is cooled by cooling water flowing through the tube. The condensed isobutane is metered by four specially-designed condensate flow meters and collected in the isobutane hotwells. From there it passes through a booster pump to pressurize it slightly before it enters the highpressure variable-capacity diaphragm-type pump. After leaving the pump, the pressurized isobutane passes through a turbine flow meter and then into a steam preheater before entering the main heater to complete the loop. During operation.with the direct-contact desuperheater, a portion of the liquid isobutane is diverted into the desuperheater to assist the separation of the vapor from liquid isobutane inside. The excess isobutane is returned to the suction side of the booster pump.

\section{2-2. The Heater and Condenser Tubes and Location of Thermocouples.} The tube in the heater and condenser were made from a $31.8 \mathrm{~mm}(1.25 \mathrm{in.})$ 0.D. and $19.1 \mathrm{~mm}(0.75 \mathrm{in.})$ I.D. type 316 stainlesssteel tube that was cut into two equal pieces about $2.7 \mathrm{~m}$ (106 in.) long. In order to obtain uniform wall thickness, the two pieces were honed to an inside diameter of $19.2 \mathrm{~mm}(0.756 \mathrm{in.})$, then the outside diameter was reduced to $30.2 \mathrm{~mm}(1.189 \mathrm{in.})$. The concentricity was then checked by ultrasonic measurement of the tube-wall thickness at $101.6 \mathrm{~mm}$ ( $4 \mathrm{in.}$ ) intervals along the axis. At each location, the wall thickness was measured at four points, $90^{\circ}$ apart. These measurements were used to calculate the precise locations for the thermocouples that were imbedded in the wall of each tube. Table F-l of Appendix F is a tabulation of 
the radii and wall thickness of the tube at the locations where the thermocouples are imbedded.

Fig. $2-2$ is a cross-sectional view of the tube showing the location of the thermocouples and the definition of the radii used in Table F-l. There were a total of fifteen thermocouples imbedded in the wall of each tube at five stations. These thermocouple indications produced a prediction for the inside and outside surface temperatures of the tube at each station based on the assumption of steady-state radial heat conduction with a uniform peripheral heat flow.

The angular location of the set of thermocouples imbedded in both instrumented tubes at an axial location were changed during the period of data collection. Before June 20, 1978, the set of thermocouples at $x / 0=14.14,77.63$ and 141.12 (Stations 1,3 and 5) were located at the top of the tube and the thermocouples at $x / 0=45.89$ and 109.38 (Statiuns 2 and 4 ) were located at the horizontal $90^{\circ}$ plane of the tube. This was called Configuration A, shown in Fig. F-l, Appendix F. After June 20,178 , both heater and condenser tubes were rotated by $45^{\circ}$ so that all the sets of thermocouples were $45^{\circ}$ about the vertical plane through the axis of the tube. This was called Configuration B, shown in Fig. F-2. The data collected in Configuration $A$ are considered as preliminary data and they are not used in this work. The data collected in Configuration $B$ are considered as experimental data and tabulated in Appendix $B$.

\section{2-3. Measurement of Bulk Temperature of Isobutane.}

The bulk temperature of isobutane inside the heater tube was measured by a traveling probe which consisted of a $6.35 \mathrm{~mm}(0.25 \mathrm{in}$. 


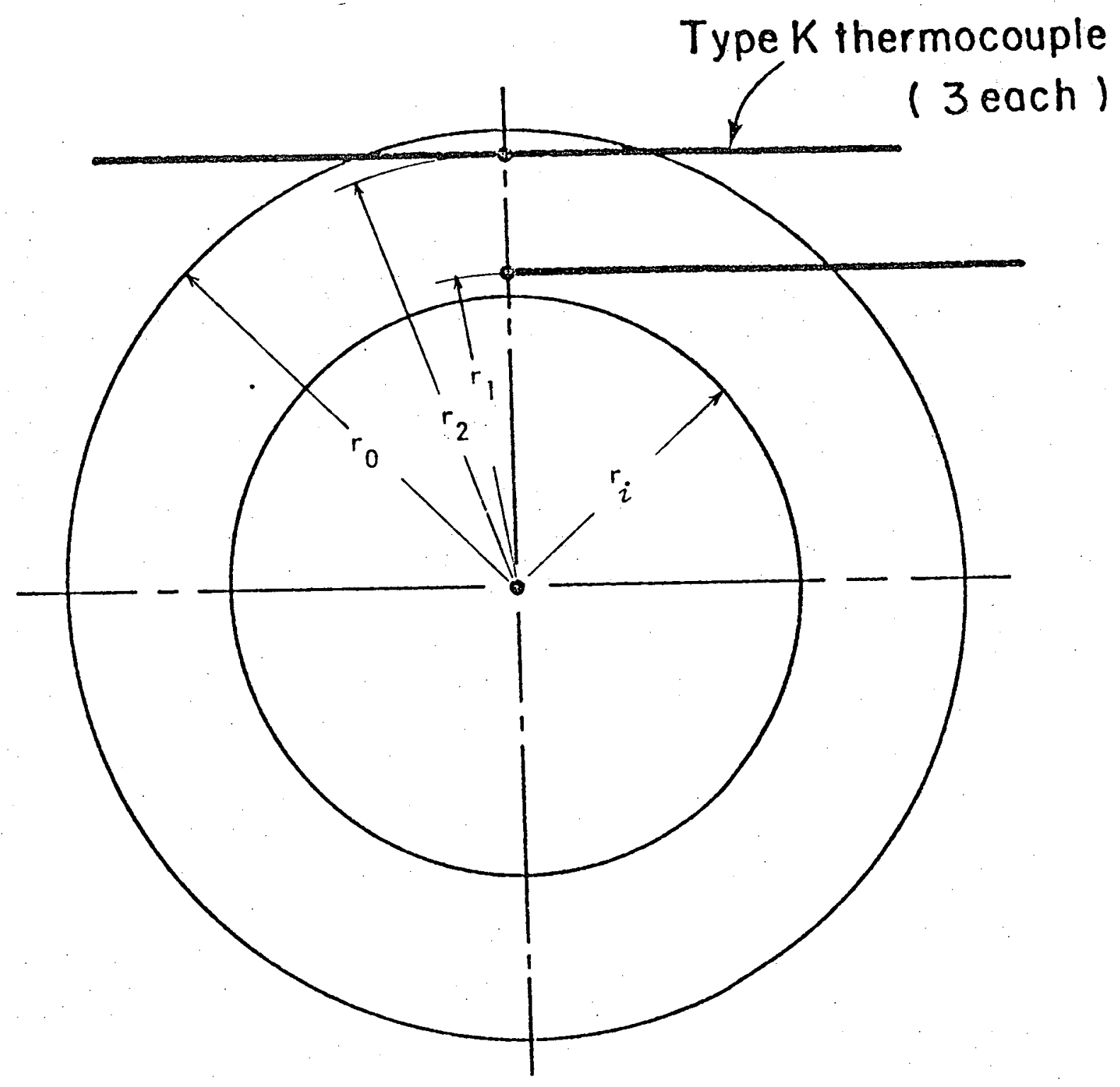

Fig. 2-2. Tube Cross Section Showing Location of Thermocouples.

XBL 783-417 
dia. $\times 2.54 \mathrm{~m}$ (100 in.) long stainless steel sheathed platinum resistance thermometer (RTD) equipped with a "mixing head" at its tip and illustrated on Fig. 2-3. The "mixing head" had a four-bladed stationary propellor at its front end and a mixing chamber behind the propellor. The propellor was used to disturb the flow stream of isobutane before entering the mixing chamber where the tip of the RTD temperature sensor was located. It was hoped that this mixing was sufficient for the measurement of the mixed-mean temperature of isobutane. This is discussed further in Chap. 3 .

\section{2-4. Measurement of Flow Rate of Isobutane.}

The volumetric flow rate of iscbutane was measured by a turbine flow meter placed downstream of the high pressure pump. By measuring the temperature of isobutane with the RTD located a short distance downstream of the flow meter, the mass flow rate could be determined by deducing the density of isobutane. The turbine flow meter was calibrated with water before installation and its calibration was checked using isobutane with a volumetric tank, not shown on Fig. 2-1, placed upstream from the high pressure pump.

2-5. Measurement of Steam and Isobutane Jacket Temperature and Pressure. The temperature of the condensing vapor, steam in the heater and isobutane in the condenser was measured by a calibrated platinum resistance thermometer (RTD) and three calijbrated type $K$ thermocouples located in the vapor space. At the heater, the RTD was located at the opposite end from the steam inlet. One of the thermocouples was located at the steam inlet, the second one at the middle of the heater shell and the third close to the RTD. These three thermocouples were 


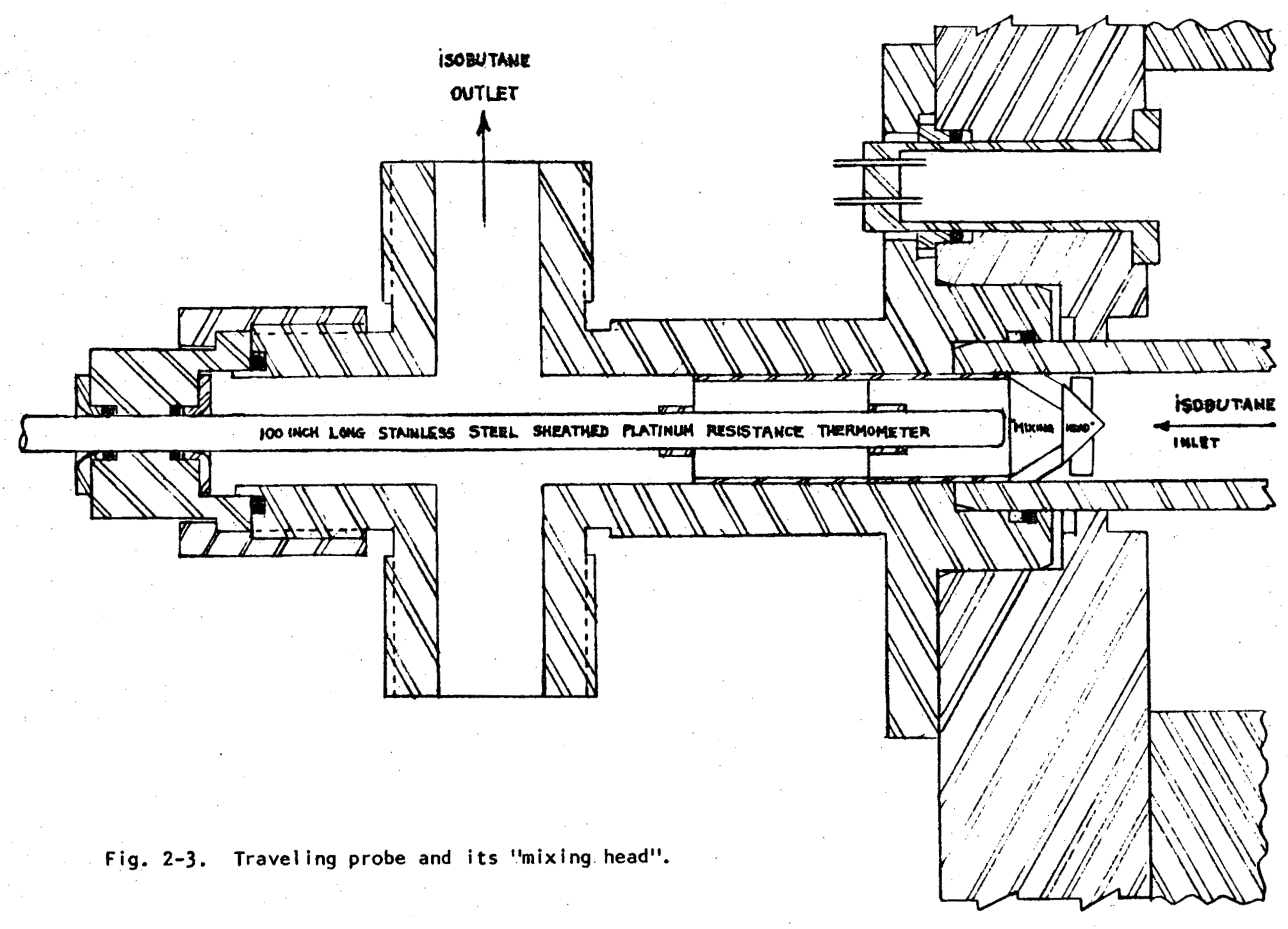

XBL 7911-12840 
used to check the reading of the RTD and to indicate the presence of superheated steam as well. In the condenser, the locations of the RTD and the three thermocouples were similar to those in the heater.

The pressure in the vapor space was measured by a calibrated pressure transducer and by a high accuracy Bourdon-type pressure gauge in both the heater and condenser.

\section{2-6. Measurement of the Condensation Rate.}

The rate of heat input to isobutane in the heater or the rate of heat released by the isobutane vapor in the condenser was determined by measuring the rate of condensation by the condensing vapor on the outside of the tube. This was done by placing a pan, $2.43 \mathrm{~m}$ (96 in.) long and divided into four equal sections of $0.61 \mathrm{~m}$ (24 in.), underneath each tube. The three dividers plus the two end plates of the pan were aligned to be directly below the five imbedded thermocouple stations. Thus, the condensate formed on the outside of the tube dripped into the separate sections of the pan and drained into four specially-designed vapor-traced condensate flow meters. Each meter consisted of a calibrated volume, a pneumatically operated valve, and a timer to measure the time required to fill the calibrated volume. This timer was operated by photocells to detect the rising condensate surface between two predetermined levels in the meter.

Fig. 2-4 shows a cross-section of the heater. It shows the external shell, the instrumented tube with thermocouples at $45^{\circ}$ from the vertical plane (Configuration B), the condensate collecting pan, and a hood placed above the tube to prevent any condensate forming on the inside surface of the shell from dripping into the pan. 


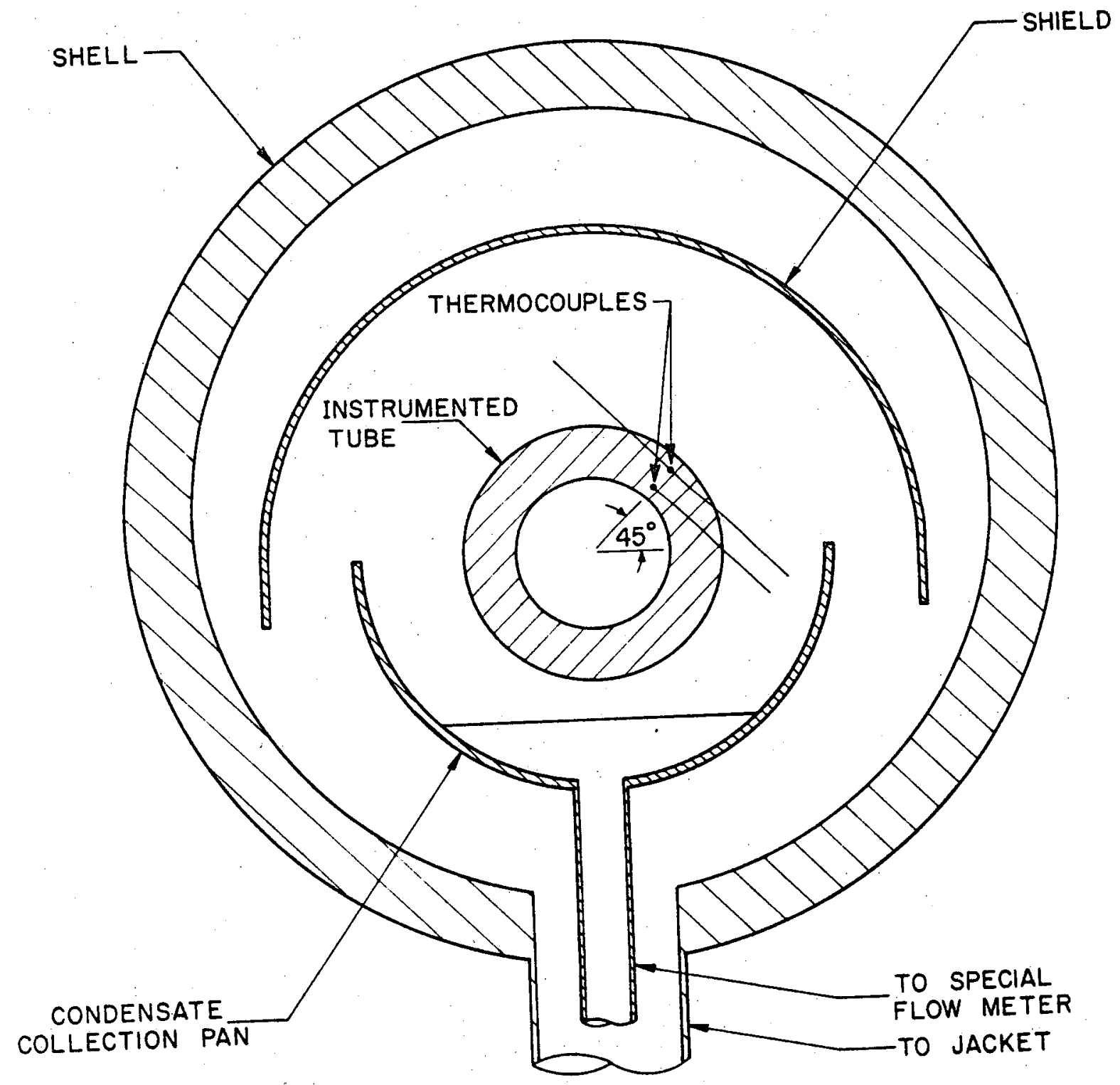

Fig. 2-4. Heater Cross Section Showing Tube, Condensate Tray, Drip Shield and Outer Shell. 


\section{CHAPTER 3}

\section{EXPER IMENTAL MEASUREMENTS AND EVALUATION}

OF HEAT TRANSFER COEFFICIENTS

The experimental system, developed by the Sea Water Conversion Laboratory, is designed to measure the heat transfer coefficient of the working fluids for binary cycle during heating and condensation. This chapter reports on the experimental measurements and the heat transfer coefficient evaluation for isobutane in the heater unit of the experimental system. The evaluation used for measurements associated with the condenser of that system are contained in Appendix E.

3-1. The Specification of the Local Heat Transfer Coefficients.

From the experimental measurements of temperature, pressure and condensate mass flow rate, the local heat transfer coefficients of isobutane, $h$, can be evaluated using:

$$
h=\frac{Q / A_{i}}{\left(T_{w}-T_{b}\right)_{A V G}}
$$

where

$$
\begin{aligned}
\quad 0 / A_{i}= & \text { Heat flux per unit inside tube area. } \\
A_{i}= & \text { Inside heater tube area for a } 2 \mathrm{ft} .(61 \mathrm{~cm}) \text { section = } \\
& 0.396 \mathrm{ft}^{2}=367.75 \mathrm{~cm}^{2} \\
\left(T_{W}-T_{b}\right) A V G= & \text { Averaged temperature difference between the inside } \\
& \text { wall temperature of the tube, } T_{w} \text {, and the bulk } \\
& \text { temperature of isobutane, } T_{b}, \text { in the } 2 \mathrm{ft} \text {. section of } \\
& \text { tube length for which the evaluation was made. }
\end{aligned}
$$


As an alternative to the above, the overall heat transfer coefficient, U, can be evaluated from:

$$
u=\frac{Q / A_{i}}{\left(T_{\text {STEAM }}-T_{b}\right)_{A V G}}
$$

This overall heat transfer coefficient is related to the local heat transfer coefficient of isobutane inside the tube as:

$$
\frac{1}{U}=\frac{1}{h}+\frac{A_{i} \ln \left(r_{0} / r_{i}\right)}{2 \pi k L}+\frac{A_{i}}{A_{0}} \frac{1}{h_{0}}
$$

where $\quad U=$ Overall heat transfer coefficient based on $A_{i}$.

$A_{0}=$ Outside heater tube area for a $2 \mathrm{ft}$. section $=0.623 \mathrm{ft}^{2}=$ $578.41 \mathrm{~cm}^{2}$.

$r_{0}=$ Outside radius of the heater tube. The values of $r_{0}$ are tabulated in Appendix F.

$r_{i}=$ Inside radius of the heater tube.

$k=$ Thermal conductivity of the stainless steel heater tube. The value of $k$ is not sensitive to temperature and is $10 \frac{\mathrm{Btu}}{\mathrm{hr}-\mathrm{ft}-\mathrm{F}}$ or $0.173 \frac{\mathrm{W}}{\mathrm{cm}-\mathrm{C}}$ between $100^{\circ} \mathrm{C}$ to $200^{\circ} \mathrm{C}$ according to [26].

$L=$ Length of heater section $=2 \mathrm{ft}=61 \mathrm{~cm}$.

$h_{0}=$ Heat transfer coefficient of condensing steam on the outside surface of heater tube.

Thus, the local heat transfer coefficient can be calculated from Eq. (3-3) if $h_{0}$ is predicted for the condensation side. 


\section{3-2. The Evaluation of Heat Rate, $Q$.}

The heat rate $Q$ was measured by two methods.

(1) By measuring the time required for the steam condensate collected in each pan to fill a known volume in the condensate flow meter, the heat rate, $Q_{S T E A M}$, can be deduced.

(2) From the bulk temperature measurement of isobutane by the travelling RTO probe at the five stations (refer to Table F-l of Appendix $F$ for the locations of these stations), the heat rate $Q_{I S O B}$ can be calculated from:

$$
Q_{I S O B}=\dot{m}_{I S O B} \Delta i=\dot{m}_{I S O B}\left(i_{n+1}-i_{n}\right)
$$

where

$$
\begin{aligned}
\dot{m}_{I S O B}= & \text { Mass flow rate of isobutane through the heater } \\
& \text { tube. } \\
i_{n+1,} i_{n}= & \begin{array}{l}
\text { Enthalpy of isobutane corresponding to the bulk } \\
\text { temperature measured at station }(n+1) \text { or } n .
\end{array}
\end{aligned}
$$

To exhibit the consistency between $Q_{\text {STEAM }}$ and $Q_{\text {ISOB }}$, three runs performed under very similar conditions are examined. The results are contained as items 4 and 7 of Table 3-2.

Some conclusions can be drawn from Tables $3-1$ and 3-2:

(a) The values of Q Q STEAM show the expected monotonic decrease in condensate rate along the length of the tube.

(b) The values of $Q_{\text {ISOB }}$ deduced from the travelling probe measurement extibit less of a decreasing trend and the values of the $Q_{I S O B}$ for Run 150 are particularly irregular. This irregularity implies that the mixed mean temperature was not 


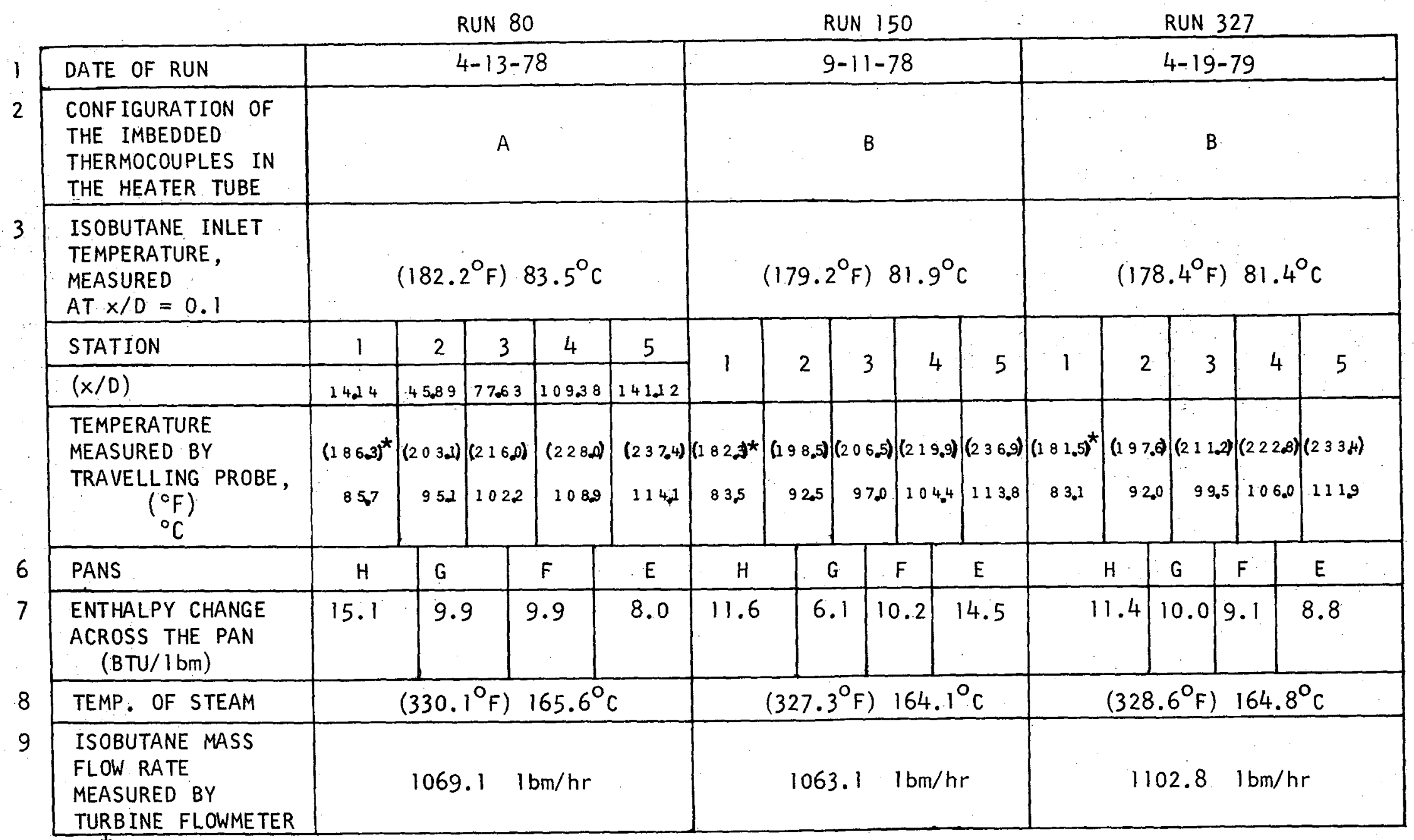

\footnotetext{
* Temperature interpolated from graph.
}

Note: The Pseudocritical Temperature of Isobutane at $4.14 \mathrm{MPa}$ (600 Psia) is $142.5^{\circ} \mathrm{C}\left(288.5^{\circ} \mathrm{F}\right)$

TABLE 3-1. EXPERIMENTAL CONDITIONS AND MEASUREMENTS FOR THREE RUNS

USED FOR HEAT RATE, Q, COMPARISON IN TABLE 3-2. 
RUN 80

RUN 150

RUN 327

ISOBUTANE

FLOW DIRECTION $\rightarrow$

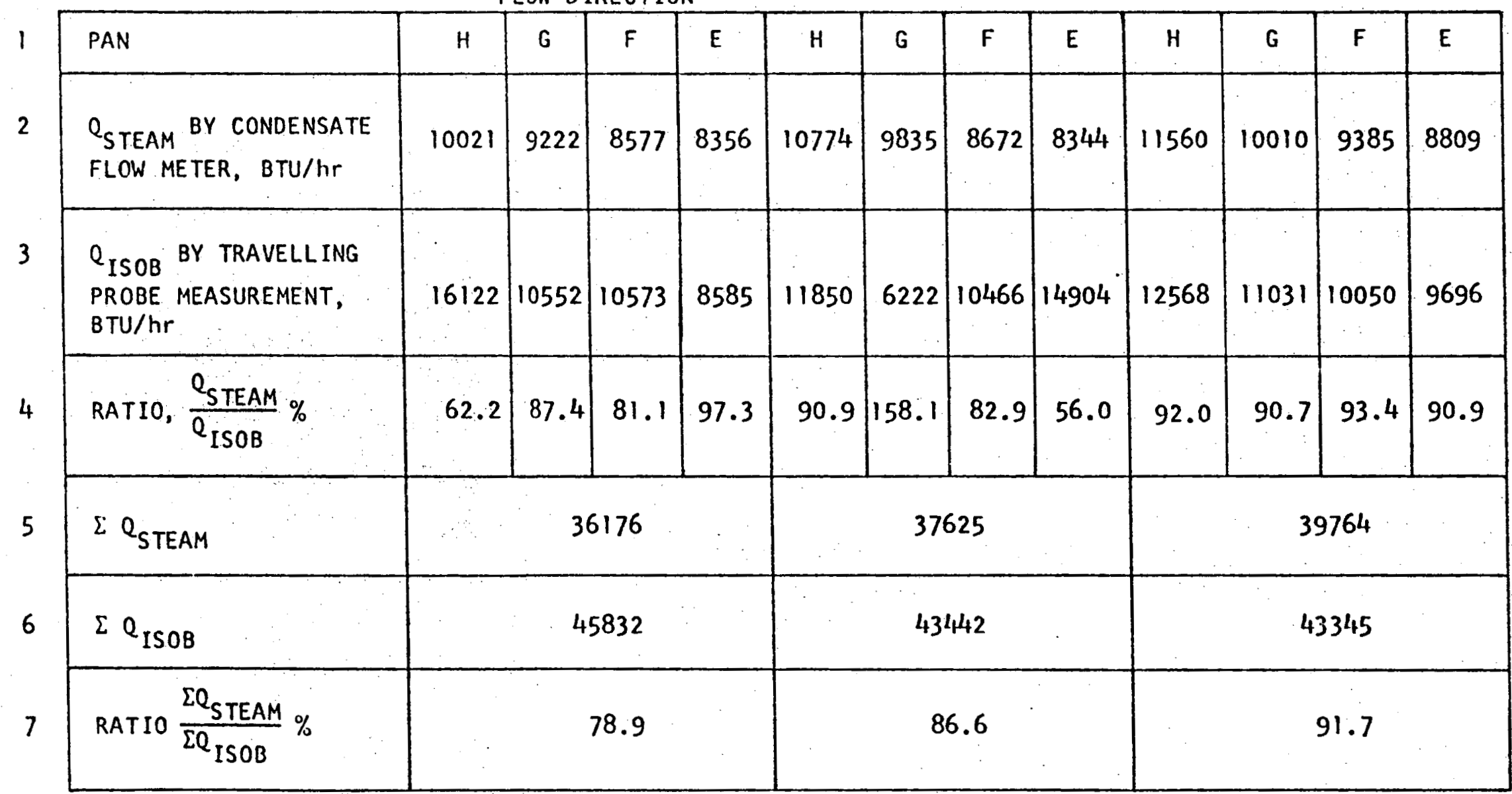

TABLE 3-2. COMPARISON OF HEAT RATE, Q, FOR THREE RUNS UNDER SIMILAR CONDITIONS. 
measured properly but there is not even a trend that can be used to try to rationalize the possible error. During March 1979, the experimental system was disassembled for overhaul and the "mixing head" of the travelling probe was found to be detached from the tip of the probe, and stuck near the entrance of the heater tube. The last time the "mixing head" was assembled onto the probe was in early September 1978 before Run 150 was performed, and the exact time when the head became separated could not be determined.

(c) The overall energy balances $\Sigma Q_{\text {STEAM }} / \Sigma Q_{\text {ISOB }}$ are not encouraging (refer to Row 7 of Table 3-2).

(d) The lack of correspondence between $Q_{\text {STEAM }}$ and $Q_{\text {ISOB }}$ is charged to the ineffectiveness of the travelling probe to measure the bulk temperature of isobutane properly. Consequently the heat rate, $Q$, to isobutane is evaluated from the condensate rate of steam using the condensate flow meters.

The error in the condensate rate is appraised in Table 3-3 for the Runs 150 and 327. In this table, $\tau_{1}, \tau_{2}$ and $\tau_{3}$ are three successive times needed to fill the volumes of the condensate flow timers. Row 6 of the Table indicates the ratio of $\frac{\Delta T}{T_{A V G}}$, where $\Delta T$ is the maximum time increment from the average time, $T A V G$. The maximum value of $\frac{\Delta T}{{ }^{T} A V G}$ is indicated to be $2 \%$. The heat rate $Q_{\text {STEAM }}$ is related to ${ }^{T}$ AVG by:

$$
Q_{\text {STEAM }}=\frac{\rho V h_{f g}}{T_{A V G}}
$$

where $V=$ Volume of the calibrated flow meter.

$\mathrm{h}_{\mathrm{fg}}=$ Latent heat of condensation of steam. 


\begin{tabular}{|c|c|c|c|c|c|c|c|c|c|}
\hline \multirow[b]{2}{*}{1} & & \multicolumn{4}{|c|}{ RUN 150} & \multicolumn{4}{|c|}{ RUN 327} \\
\hline & PAN & $H$ & $G$ & $\mathrm{~F}$ & $E$ & $H$ & G & $F$ & $E$ \\
\hline 2 & $\begin{array}{l}\text { TIME TO FILL } \\
\text { FLOWMETER, } T_{1} \text {, sec }\end{array}$ & 229.3 & 245.0 & 282.6 & 294.1 & 212.3 & 242.7 & 260.5 & 277.6 \\
\hline 3 & $\begin{array}{l}\text { TIME TO FILL } \\
\text { FLOWMETER, }{ }_{2}, \mathrm{sec}\end{array}$ & 229.7 & 248.6 & 285.3 & 294.1 & 212.7 & 242.3 & 257.4 & 278.3 \\
\hline 4 & $\begin{array}{l}\text { TIME TO FILL } \\
\text { FLOWMETER, } T_{3}, \mathrm{sec}\end{array}$ & 227.5 & 249.5 & 275.5 & 292.9 & 213.6 & 243.7 & 259.9 & 277.1 \\
\hline 5 & $\begin{array}{l}\text { AVERAGED TIME } \\
\text { TO FIL FLOWMETER } \\
\text { TAVG }\end{array}$ & 228.8 & 247.7 & 281.1 & 293.7 & 212.9 & 242.9 & 259.3 & 277.7 \\
\hline 6 & $\left|\left(\frac{\Delta T}{T A V G}\right)\right|_{\text {MAX }} \%$ & 0.6 & 1.1 & 2.0 & 0.3 & 0.3 & 0.3 & 0.7 & 0.2 \\
\hline
\end{tabular}

TABLE 3-3. TABULATION OF TIME RECORDED TO FILL CONDENSATE FLOW METERS. 
Therefore: $d Q=\frac{-\rho V h_{f g} d \tau}{\tau_{A V G}^{2}}$

$$
\begin{aligned}
& \frac{d Q}{Q}=\frac{-d T}{T_{A V G}} \\
& \left|\frac{\Delta Q}{Q}\right|=\frac{\Delta T}{T_{A V G}}
\end{aligned}
$$

Therefore, the condensate flow meters can measure the condensate rate, $Q_{\text {STEAM, }}$ to within $2 \%$ at worst.

3-3. The Evaluation of Bulk Temperature of Isobutane.

From Table 3-1 and 3-2 plus the discussion in the previous section, the bulk temperature of isobutane is recalculated using two methods:

(a) By assuming the inlet temperature of isobutane at $x / D \approx 0.1$ is correct and the bulk temperature of isobutane downstream is computed using $Q_{S T E A M}$ obtained from each pan. The equation used is similar to Equation (3-4):

$$
Q_{\text {STEAM }}=\dot{m}_{\text {ISOB }}\left(i_{\text {DNSTRM }}-i_{\text {UPSTRM }}\right)
$$

(b) By assuming that the temperature measured by the travelling probe at Station 5 is correct and the bulk temperatures upstream is computed using $Q_{S T E A M}$

The computed bulk temperatures for Run 150 are shown on Fig. 3-1. The largest temperature difference between the computed bulk temperature and the measured temperature is about $5^{\circ} \mathrm{C}$. Thus, for the error in measurement of bulk temperature for Run 150 is:

$$
\frac{\Delta T_{b}}{T_{b}} \approx \frac{5^{\circ} \mathrm{C}}{80^{\circ} \mathrm{c}} \times 100=6 \%
$$




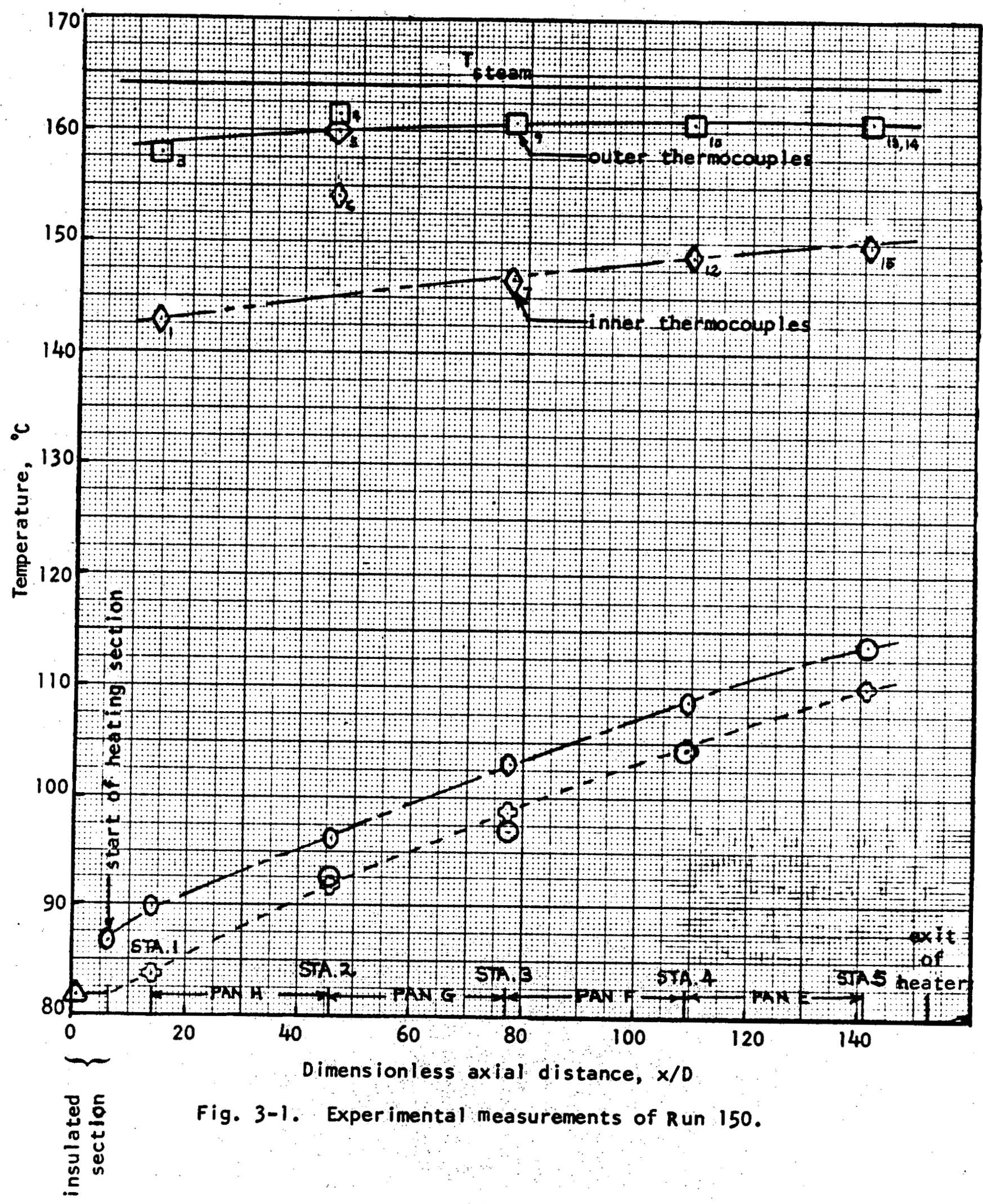


(Continuation of figure 3-1

from previous page)

( ) Bulk temperature of isobutane measured

$\odot$ Bulk temperature of isobutare calculated assuming temp. at STA. 5 was correct.

B Bulk temp. of isobutane calculated assuming inlet temp. was correct. 
Run 150 represents one of the worst cases for the measurement of isobutane bulk temperature as exhibited on Table 3-2. Therefore, the best estimate is that the measured bulk temperature of isobutane is within $\pm 5^{\circ} \mathrm{C}$ of the actual temperature.

3-4. The Evaluation of the Inside Wall Temperature.

The imbedded thermocouples in the wall of the heater tube are used to deduce the inside and outside surface wall temperatures. The equations used for the deduction are given in Appendix $C$. The temperatures at the thermocouples inside the wall of the tube are plotted on Fig. 3-1 and 3-2 for two runs, 150 and 327. For each plot of inside and outside thermocouple readings, a curve best fitting the points is drawn. The inside and outside wall temperatures were specified from this kind of curve fit. The largest difference between a temperature point and the curve is only $2^{\circ} \mathrm{C}$. The temperature reading of thermocouple \#6 was never used in the drawing of the best fitting curves for almost all of the runs in this study. Therefore for Run 327 , the largest error in reading the inside wall temperature is about $2^{\circ} \mathrm{C}$.

$$
\frac{\Delta T_{W}}{T_{W}}=\frac{2^{\circ} \mathrm{C}}{140^{\circ} \mathrm{C}} \times 100=1.4 \%
$$

Another appraisal of the accuracy of the imbedded thermocouple readings is by comparing the heat flux through the wall of the heater tube measured by the thermocouples and the heat flux $Q_{S T E A M} / A_{0}$ between two stations. The heat flux through the wall is calculated by:

$$
q_{W A L L}=\frac{Q}{A_{0}}=\frac{k}{r_{0}} \cdot \frac{\left(T_{2}-T_{1}\right)}{\ln \left(\frac{r_{2}}{r_{1}}\right)}
$$




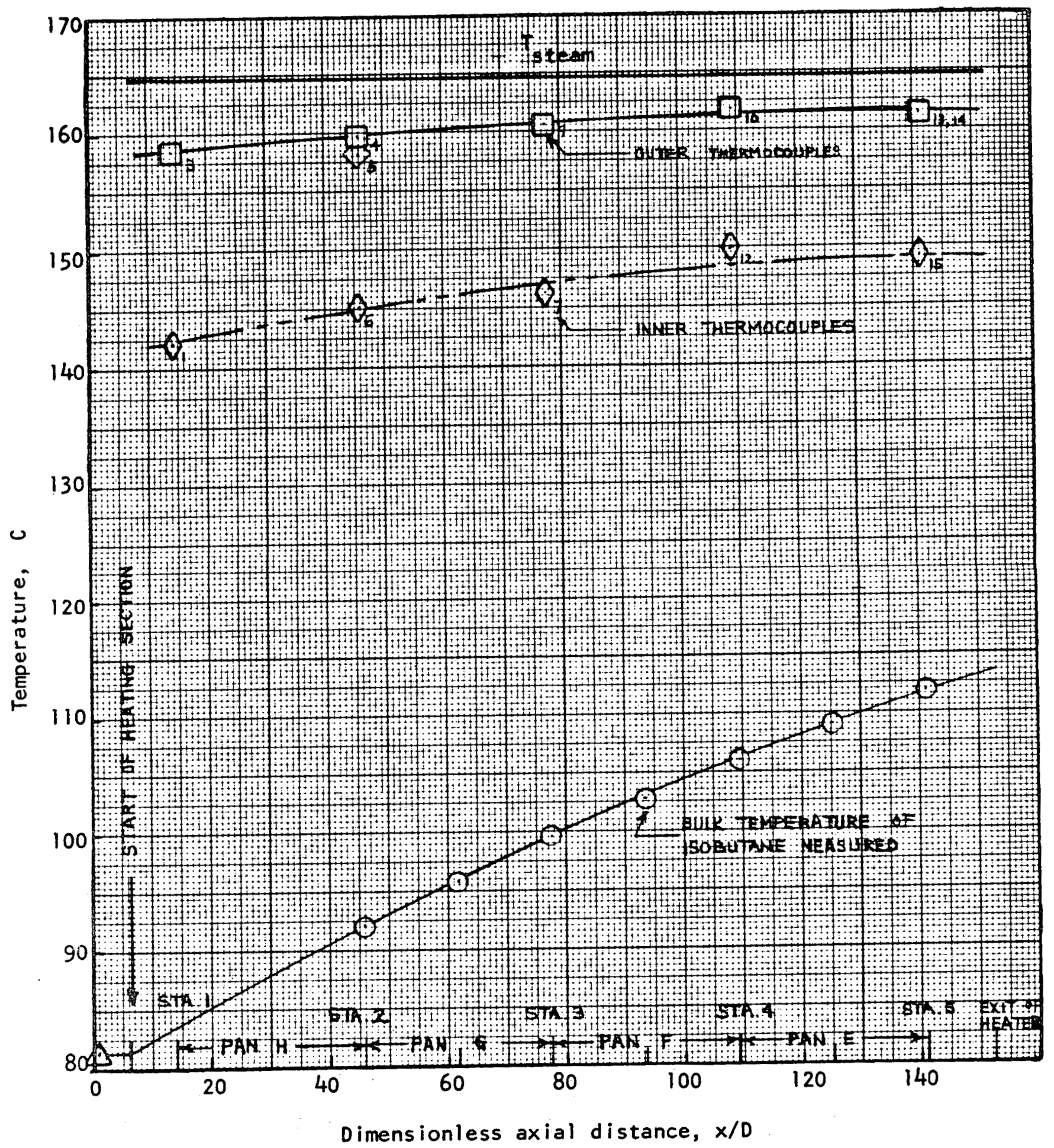

Fig. 3-2. Experimental measurements of run 327 
where $T_{2}=$ Temperature measured by the thermocouple located at $r_{2}$.

$T_{1}=$ Temperature measured by the thermocouple located at $r_{1}$.

$r_{0}=$ Outer radius of the heater tube.

$r_{1}$ and $r_{2}=$ Radial locations of imbedded thermocouples and listed on Table F-1, Appendix F.

Table 3-4 shows the comparison of the two heat fluxes. The averaged $\left(\frac{Q}{A_{0}}\right)_{W A L L}$, T.C. between two stations agrees very well with the heat given off by the condensing steam on the outside of the heater tube. The slight difference of $5 \%$ at most may be because the heat

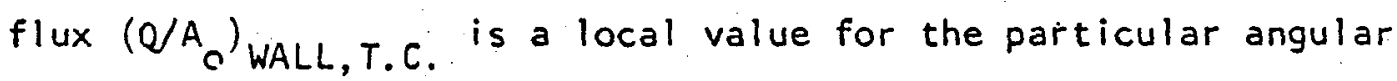
position of the thermocouples, whereas ( $\left./ A_{0}\right)$ STEAM is the peripherally averaged heat flux over the $2 \mathrm{ft}$. section.

The implication of the close agreement of $\left(U_{0} A_{0}\right)_{W A L L}, T . C$. with $\left(Q / A_{0}\right)_{\text {STEAit }}$ is as follows:

(1) The temperatures read from the curves drawn through the piot of imbedded thermocouple measurements are good.

(2) This reaffirms the choice of $Q_{S T E A M}$ as the correct heat rate for the evaluation of heat transfer coefficient.

\section{3-5. The Evaluation of the Steam Temperature.}

To determine the thermodynamic state of the steam and detect the presence of non-condensable gas in the heater jacket, a pressure transducer and a Bourdon-type Heise gauge were installed near the steam inlet of the heater jacket. Three thermocouples and a platinum resistance temperature probe were also located in the jacket as described in Chapter 2-5. 


\begin{tabular}{|c|c|c|c|c|c|c|c|c|c|c|c|c|c|}
\hline & & & \multicolumn{5}{|c|}{ RUN 150} & \multicolumn{6}{|c|}{ RUN 327} \\
\hline 1 & \multicolumn{2}{|l|}{ STATION } & 1 & 2 & 3 & 4 & 5 & 1 & 2 & \multicolumn{2}{|c|}{3} & 4 & 5 \\
\hline 2 & \multicolumn{2}{|c|}{$\begin{array}{l}\text { ANGULAR LOCATION } \\
\text { OF THERMOCOUPLES, } \\
\text { DEGREES FROM TOP } \\
\text { OF TUBE }\end{array}$} & $+45^{\circ}$ & $-45^{\circ}$ & $+45^{\circ}$ & $-45^{\circ}$ & $+45^{\circ}$ & $+45^{\circ}$ & $-45^{\circ}$ & \multicolumn{2}{|c|}{$+45^{\circ}$} & $-45^{\circ}$ & $+45^{\circ}$ \\
\hline & $\left(\frac{Q}{A_{0}}\right)$ & $\frac{B T U}{h r-f t^{2}}$ & 16314 & 15324 & 14140 & 13093 & 12007 & 18286 & 16910 & \multicolumn{2}{|c|}{15387} & 14368 & 14167 \\
\hline 3 & WALL,T.C. & $\frac{\mathrm{kW}}{\mathrm{m}^{2}}$ & 51.422 & 48.301 & 44.5 & 41.269 & 37.846 & 57.637 & 53.300 & \multicolumn{2}{|c|}{48.500} & 45.288 & 4.4 .654 \\
\hline \multirow{2}{*}{4} & \multirow{2}{*}{$\begin{array}{l}\text { AVERAGED } \\
\left(\frac{Q}{A_{0}}\right)_{\text {WALL, T.C. }}\end{array}$} & $\frac{\text { BTU }}{h r-f t^{2}}$ & 15819 & \multicolumn{2}{|c|}{14732} & 13617 & $\begin{array}{l}12550 \\
\ldots \ldots\end{array}$ & 17598 & \multicolumn{2}{|c|}{16149} & \multicolumn{2}{|c|}{14878} & 14268 \\
\hline & & $\frac{k W}{m^{2}}$ & 49.861 & \multicolumn{2}{|c|}{46.435} & 42.921 & 39.558 & 55.469 & \multicolumn{2}{|c|}{50.902} & \multicolumn{2}{|c|}{46.895} & 44.973 \\
\hline \multirow{2}{*}{5} & \multirow{2}{*}{$\left(\frac{Q}{A_{0}}\right)_{\text {STEAM }}$} & $\frac{B T U}{h r-f t^{2}}$ & 16462 & \multicolumn{2}{|c|}{15026} & 13250 & 12748 & 18568 & \multicolumn{2}{|c|}{16078} & \multicolumn{2}{|c|}{15076} & 14150 \\
\hline & & $\frac{\mathrm{kW}}{\mathrm{m}^{2}}$ & 51.888 & \multicolumn{2}{|c|}{47.362} & 41.764 & 40.182 & 58.526 & \multicolumn{2}{|c|}{50.678} & \multicolumn{2}{|c|}{47.520} & 44.601 \\
\hline 6 & \multicolumn{2}{|c|}{ 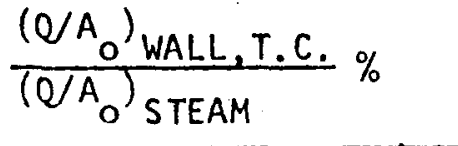 } & $96 \%$ & \multicolumn{2}{|c|}{$98 \%$} & $103 \%$ & $98 \%$ & $95 \%$ & \multicolumn{2}{|c|}{$100.4 \%$} & \multicolumn{2}{|r|}{$99 \%$} & $101 \%$ \\
\hline 7 & \multicolumn{2}{|l|}{ PANS } & H & G & 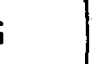 & $\mathrm{F}$ & E & $H$ & G & & & $\mathrm{F}$ & $\mathrm{E}$ \\
\hline
\end{tabular}

TABLE 3-4. COMPARISON OF HEAT FLUX MEASURED BY WALL THERMOCOUPLES AND CONDENSATE FLOW METERS. 
At the beginning of the experimental program, non-condensable gas, such as air, was detected to be accumulating in the steam jacket. Vent $l$ ines were added to the system, one at the top side of the jacket near the steam exit, another at the top of the steam hotwell below the heater. A moderate amount of steam was vented out of the jacket and hotwell during the experiments by opening the 1/4-in. diameter vent valves by less than a quarter of a turn. The venting did not solve the problem completely because the feed water to the boiler was not deaerated. The boiler was modified to return some steam to the boiler's water hotwell and heat the water to nearly $100^{\circ} \mathrm{C}$. This reduced the amount of dissolved air in the boiler feed water and thus minimized the amount of non-condensable air in the steam loop.

Table 3-5 presents a history of the temperature and pressure measurements taken in the steam jacket. From the tabulation, the following assessment on the temperature and pressure measurement of steam can be stated:

(1) The pressure transducer did not provide consistent or accurate readings of pressure of steam.

(2) The pressure measured by the Heise gauge was closer to but larger than the saturated pressure corresponding to the temperature measured by the temperature probe (RTD). The He ise gauge could be read to \pm 0.1 bar or \pm 1.4 Psi.

(3) At times when the pressure indicated by the Heise gauge was significantly higher than the saturation pressure corresponding to the RTD, it was believed that non-condensable air had accumulated in the steam jacket. 


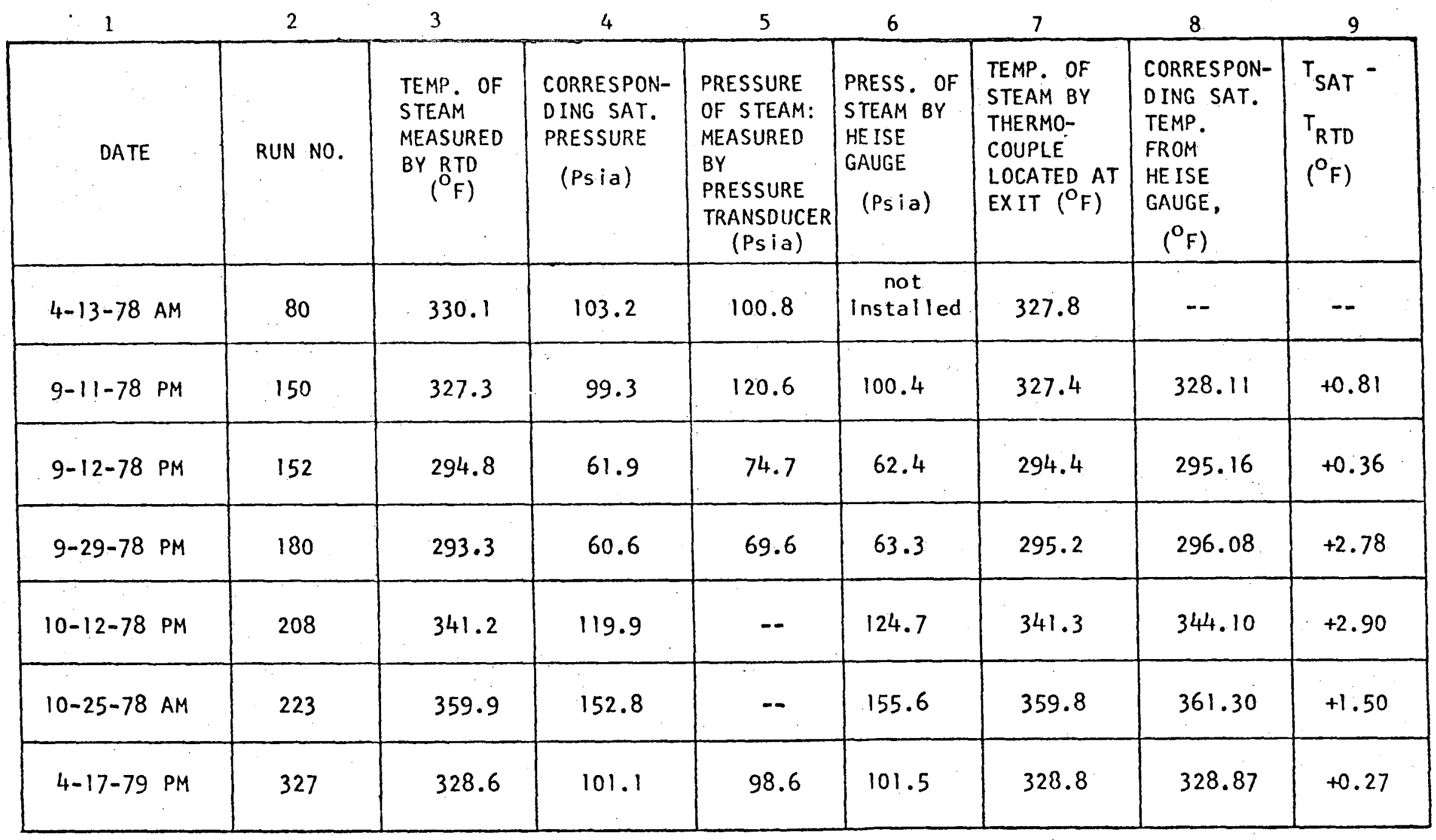

TABLE 3-5. TEMPERATURE AND PRESSURE MEASUREMENTS IN THE STEAM JACKET WITH RESPECT TO SATURATED STATE. 
(4) By comparing the difference between the saturated temperature corresponding to the Heise gauge and the temperature measured by the RTD, the largest difference was about $3^{\circ} \mathrm{F}$. This difference may be attributed to the presence of non-condensable gas in the jacket or error in measuring temperature by the RTD. Thus the largest error in temperature measurement can be $\frac{\Delta T_{\text {STEAM }}}{T_{\text {STEAM }}}=\frac{3^{\circ} \mathrm{F}}{341^{\circ} \mathrm{F}} \times 100=0.9 \%$

3-6. The Evaluation of Local Heat Transfer Coefficient.

The equations used for the specification of heat transfer coefficients of isobutane are Equations $(3-1)$, or $(3-2)$ and $(3-3)$. The individual terms of these equations that are experimentally measured have been evaluated in the previous sections. Thus the total error in the evaluation of heat transfer coefficient, $h$, can be calculated.

3-6-1. The Error in the Evaluation of $h$ from Eg. $(3-1)$.

Equation $(3-1)$ is restated here:

$$
\begin{aligned}
& h=\frac{Q_{i}{ }_{i}}{\left(T_{w}-T_{b}\right)_{A V G}}=\frac{q_{\text {STEAM }}}{\left(T_{w}-T_{b}\right)_{A V G}} \\
& \frac{d h}{h}=\frac{1}{h}\left[\frac{d q_{\text {STEAM }}}{\left(T_{w}-T_{b}\right)_{A V G}}-\frac{q_{\text {STEAM }}\left(d T_{w}-d T_{b}\right)}{\left(T_{w}-T_{b}\right)_{A V G}^{2}}\right]
\end{aligned}
$$

* In the data reduction, the term $\left(T_{W}-T_{b}\right)_{A V G}$ was taken as the logarithic mean for each of the pan sections. Refer to Appendix $C$ for the definition of $\left(T_{w}-T_{b}\right)_{L M T D}$. 


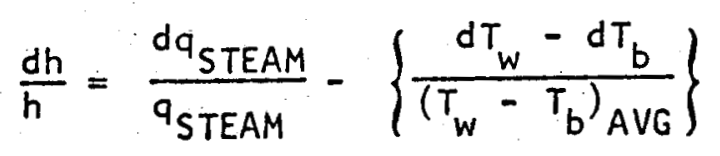

From Table 3-3

$$
\frac{d q_{\text {STEAM }}}{q_{\text {STEAM }}}=0.02
$$

From Section 3-4, the largest error in reading the inside wall temperature is about $\pm 2{ }^{\circ} \mathrm{C}$ for Run 327. From Section 3-3, the bulk temperature can be measured to $\pm 5^{\circ} \mathrm{C}$.

From Run 327, $\left(T_{w}-T_{b}\right)_{A V G}$, is about $40^{\circ} \mathrm{C}$.

: Therefore, the largest error in the evaluation of $h$ is:

$$
\frac{\mathrm{dh}}{\mathrm{h}}=0.02-\left\{\frac{-2-5}{40}\right\}=0.20
$$

or $\frac{d h}{h}=20 \%$

so that based on the condition of Run 327 the maximum possible error in the heat-transfer coefficient is $\pm 20 \%$.

Further examination of the results of this study tabulated in Appendix $B$ indicates that the value of $\left(T_{w}-T_{b}\right)$ AVG has the following range:

(1) Table $B-1$ indicates that $\left(T_{w}-T_{b}\right)$ AVG varies from $55^{\circ} \mathrm{C}$ to $9^{\circ} \mathrm{C}$.

(2) Table $8-2$ indicates that $\left(T_{w}-T_{b}\right)$ AVG varies from $86^{\circ} \mathrm{C}$ to $17^{\circ} \mathrm{C}$. 
(3) Table $B-3$ indicates that $\left(T_{w}-T_{b}\right)_{A V G}$ varies from $77^{\circ} \mathrm{C}$ to $13^{\circ} \mathrm{C}$.

3-6-2. The Error in the Evaluation of $h$ from Eq. $(3-2) \varepsilon(3-3)$.

Equations $(3-2)$ and $(3-3)$ are restated here:

$$
U=\frac{Q / A_{i}}{\left(T_{\text {STEAM }}-T_{b}\right)_{\text {AVG }}}=\frac{q_{\text {STEAM }}}{\left(T_{\text {STEAM }}-T_{b}\right)_{A V G}}
$$

and $\frac{1}{h}=\frac{1}{U}-\frac{A_{i} \ln \left(r_{0} / r_{i}\right)}{2 \pi k L}-\frac{A_{i}}{A_{0}} \frac{1}{h_{0}}=\frac{1}{U}-r_{w}-\frac{A_{i}}{A_{0}} \frac{1}{h_{0}}$

Evaluating $U$ first

$$
\begin{aligned}
& \frac{d U}{U}=\frac{1}{U}\left[\frac{d q_{\text {STEAM }}}{\left(T_{\text {STEAM }}-T_{b}\right)_{\text {AVG }}}-\frac{q_{\text {STEAM }}\left(d T_{\text {STEAM }}-d T_{b}\right)}{\left(T_{\text {STEAM }}-T_{b}\right)_{\text {AVG }}}\right] \\
& \frac{d U}{U}=\frac{d q_{\text {STEAM }}}{q_{\text {STEAM }}}-\left\{\frac{d T_{\text {STEAM }}-d T_{b}}{\left(T_{\text {STEAM }}-T_{b}\right)}{ }_{\text {AVG }}\right\}
\end{aligned}
$$

From Section 3-5, the steam temperature can be measured to $\pm 3^{\circ} \mathrm{F}$ or $\pm 1.7^{\circ} \mathrm{C}$.

From Run 327, ( $\left.T_{\text {STEAM }}-T_{b}\right)_{\text {AVG }}$ is about $65^{\circ} \mathrm{C}$ at the middle of the heater tube.

In the data reduction, the term ( $\left.T_{S T E A M}-T_{b}\right)$ was not used, instead a log-mean temperature difference, $\Delta T_{L M T D}$, between the $T_{S T E A M}$ and $T_{b}$ for the section was used. Refer to Appendix $c$ for definition of $\triangle T_{\text {LMTD }}$ for the section. 
Therefore, the largest error in the evaluation of $U$ is:

$$
\begin{aligned}
& \frac{d U}{U}=0.02-\left\{\frac{-1.7-5}{65}\right\}=0.12 \\
& \text { or } \frac{d U}{U}=12 \%
\end{aligned}
$$

Evaluating $h$ from $U$ :

$$
\begin{aligned}
& \frac{1}{h}=\frac{1}{U}-r_{w}-\frac{A_{i}}{A_{0}} \frac{1}{h_{0}} \\
& -\frac{d h}{h^{2}}=-\frac{d U}{U^{2}}-\frac{A_{i}}{A_{0}}\left(-\frac{d h_{0}}{h^{2}}\right) \\
& \frac{d h}{h}=\frac{d U}{U^{2}} h-\frac{A_{i}}{A_{0}} \frac{d h_{0}}{h^{2}} h \\
& \frac{d U}{U}=0.12 \text { from previous calculation } \\
& \frac{d h_{0}}{h_{0}}=-0.5
\end{aligned}
$$

based on the assumption that the presence of non-condensable gas in the steam jacket can decrease value of heat-transfer coefficient of condensing steam, ho, by $50 \%$. 
Then $\frac{d h}{h}=h\left(\frac{0.12}{U}+\frac{0.5}{h_{0}}\right)$

From the experimental results of Run 327, for Pan $F$

$$
\begin{gathered}
h \approx 316 \frac{B T U}{h r=f t^{20} F} \\
U \approx 181 \frac{B T U}{h r=f t^{20} F} \\
h_{0} \approx 3175 \frac{B T U}{h r \cdot f t^{20} F} \\
\text { Thus } \frac{h}{U} \approx 1.8 \\
\frac{h}{h_{0}} \approx 0.1 \\
\frac{d h}{h} \approx 0.21+0.05=0.26 \text { or } 26 \%
\end{gathered}
$$

3-6-3. Comparison of the Value of $h$ Evaluated by the Two Methods.

The heat transfer coefficients, $h$; calculated using Equation $(3-1)$ and Equations $(3-2)$ and $(3-3)$, are tabulated on Table 3-6 for comparison.

The table indicates that:

(1) The values of $h$ calculated from the two methods agree with each other.

(2) The variation of $h$, due to the different $T_{B U L K}$ used for the calculation, is $\pm 8 \%$ at most. 


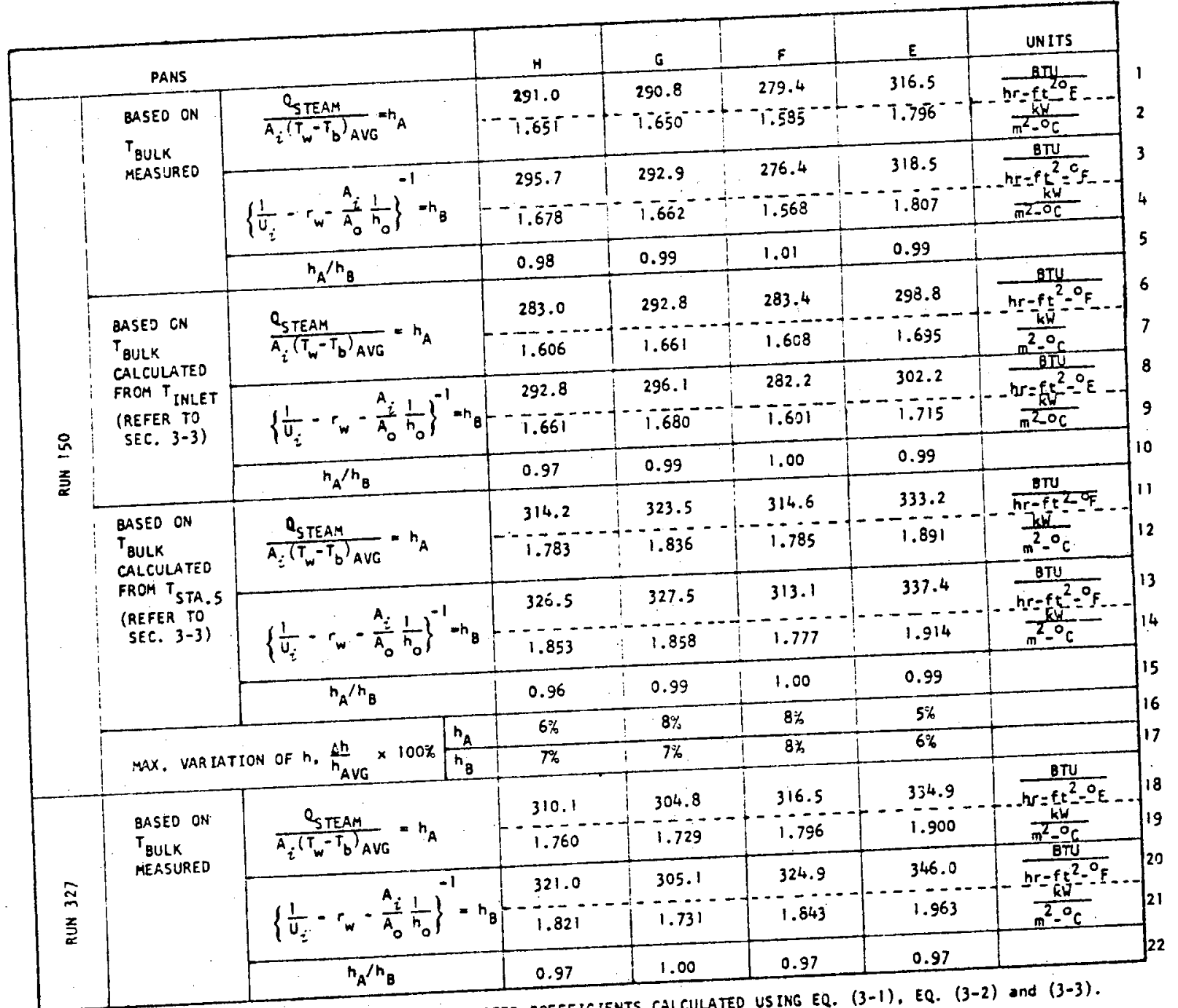

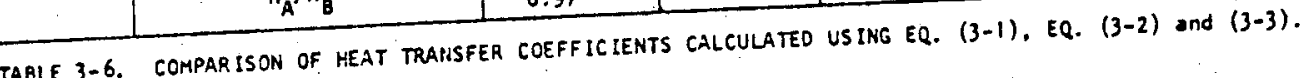


(3) The values of $h$ calculated for Run 327 are within the range of values of $h$ calculated for Run 150. Since Run 327 is a repeat of Run 150, the results indicate that any fouling resistance caused by the isobutane has not become significant over time.

3-7. The Heat Transfer Coefficient Obtained in This Study.

From the evaluation of the heat transfer coefficient in Section $3-6$, the values of $h$ calculated by Eq. $(3-1)$ are selected to represent the experimental data, and tabulated as dimensionless Nusselt numbers in the tables of Appendix B.

In Chapter 4, the experimental Nusselt numbers from Table B-1 are compared with those correlations given by Dittus-Boelter on Fig. 4-4, Sieder-Tate on Fig. 4-5, and Petukhov on Fig. 4-6. The worst case of data scatter is on Fig. 4-4 when the data are compared with the Dittus-Boelter correlation. If the constant of Dittus-Boelter correlation is increased from 0.023 to 0.028 , the data can be specified to $\pm 20 \%$. From Section $3-6-1$, the estimation of error in the $h$ evaluated from Eq. $(3-1)$ is about $=20 \%$ also. It should be noted that the plot of experimental Nusselt numbers on Fig. $4-4$ also incorporates the uncertainties in the evaluation of properties, $\rho, \mu$ and $k$ of isobutane at $600 \mathrm{Psia}$. Therefore, the actual experimental measurement of the heat transfer coefficient, $h$, must have been better than $\neq 20 \%$. 


\section{CHAPTER 4}

THE EFFECT OF BUOYANCY ON HEAT TRANSFER TO ISOBUTANE AT

SUPERCR ITICAL PRESSURE FLOWING INS IDE A HOR IZONTAL TUBE

\section{4-1. Introduction.}

Chapter 1 suggested that the experimental runs could be divided into three groups based on the values of Eckert number obtained for the runs. From these groups of runs, the group having data with $E>1$ listed on Table B-I of Appendix B are selected for assessment of possible effect of buoyancy on heat transfer to isobutane at supercritical pressure. When $E>1$, the temperature of isobutane across the tube is in the subcritical range and the properties of isobutane all vary monotonically with temperature. From the graphs of properties of isobutane in Appendix $A, C_{p}$ and $\mathrm{Pr}$ increase slightly with temperature while $k, \mu$ and $\rho$ decrease with temperature. Thus the effect of variable properties on the heat transfer should be minimal and the only additional effect is possibly that due to free convection.

\section{4-2. Analysis.}

Analytical and experimental results for heat transfer to air by combined forced and free convection in turbulent flow through an inclined or horizontal tube was reported by Futagami and Abe [15]. Similarly, heat transfer with turbulent flow in a horizontal tube under substantial influence of thermogravitational forces was investigated by Petukhov, et al [16]. In both cases, air was heated at a constant heat flux as it passed through the heater tube. Both of these sets of results differed from the data obtained by the present experiment during which the outside wall temperature of the heated tube 
was constant. In addition, in the analytical part of the cited references, the physical properties of air were assumed constant except for variation of density with temperature.

(a) Results by Petukhov, et al.

Petukhov gave an equation specifying the analytical results

for the peripheral variation of local Nusselt number ratio,

$\left(\mathrm{Nu} / \mathrm{Nu}_{\mathrm{o}}\right)$, as a function of dimensionless parameters:

$$
\left.\frac{N u_{\phi}}{N u_{0}}=1-\frac{340 G r_{b}^{*} \operatorname{Cos} \phi}{\operatorname{Re}_{b}^{2.75} \operatorname{Pr}_{b}^{0.5}} \frac{1}{\left\{1+2.4 \operatorname{Re}_{b}^{-1 / 8}\left(\operatorname{Pr}^{2 / 3}-1\right)\right.}\right\}
$$

Where $N u_{\phi}=\frac{h_{\phi} D}{k_{b}}=\frac{q_{w} D}{k_{b}\left(T_{w, \phi} T_{b}\right)}$ $\begin{aligned} \mathrm{Nu}_{\mathrm{O}}= & \text { Nusselt number obtained for turbulent } \\ & \text { forced convection without the influence } \\ & \text { of buoyancy effect. }\end{aligned}$

$$
\begin{aligned}
& G_{b}^{*}=\frac{\rho_{b}-\rho_{w}}{\rho_{b}} \frac{g D^{4}}{v 2} \frac{q_{w}}{\left(T_{w}-T_{b}\right)}=G r_{b} N u \\
& G r=\frac{\rho_{b}-\rho_{w}}{\rho_{b}} \frac{g D^{3}}{v_{b}^{2}}
\end{aligned}
$$

$\phi=$ angle measured from the upper generatrix

$$
\begin{aligned}
& \operatorname{Re}_{b}=\frac{\rho u_{m} D}{\mu_{b}}=\frac{4}{\pi} \frac{\dot{m}}{D \mu_{b}} \\
& \operatorname{Pr}_{b}=\frac{\mu_{b} c_{p_{b}}}{k_{b}}
\end{aligned}
$$




$$
\begin{aligned}
& \text { Petukhov also specified } \mathrm{Nu}_{\mathrm{o}} \text { as } \\
& \mathrm{Nu}_{\mathrm{O}}=\frac{(f / 8) \operatorname{Re} \operatorname{Pr}}{1.07+12.7 \sqrt{f / 8}\left(\operatorname{Pr}^{2 / 3}-1\right)} \\
& \text { where } f=\left(1.82 \log _{10} \operatorname{Re}-1.64\right)^{-2}
\end{aligned}
$$

From Eq. (4-1), a criterion for $10 \%$ variation of Nusselt number on the upper (lower) generatrices from $\mathrm{Nu}_{0}$ in a horizontal tube is

$$
\mathrm{Gr}_{b}^{*} \operatorname{Re}_{b}^{-2.75} \operatorname{Pr}_{b}^{-0.5}\left[1+2.4 \operatorname{Re}_{b}^{-1 / 8}\left(\operatorname{Pr}_{b}^{2 / 3}-1\right)\right]^{-1}>2.9 \times 10^{-4}
$$

Introducing equation (4-2) into (4-5) and assuming $\mathrm{Nu}=\mathrm{Nu}_{0}$ as the 1 imiting value at the onset of buoyancy effect, equation $(4-5)$ becomes

$$
\begin{gathered}
\operatorname{Gr}_{b} \operatorname{Nu}_{o} \operatorname{Re}_{b}^{-2.75} \operatorname{Pr}_{b}^{-0.5}\left[1+2.4 \operatorname{Re}_{b}^{-1 / 8}\left(\operatorname{Pr}_{b}^{2 / 3}-1\right)\right]^{-1}=2.9 \times 10^{-4} \\
\text { or } \\
\operatorname{Gr}_{b} \frac{(f / 8) \operatorname{Re}_{b} \operatorname{Pr}_{b}}{1.07+12.7\left(\operatorname{Pr}^{2 / 3}-1\right) \sqrt{f / 8}}=2.9 \times 10^{-4} \operatorname{Re}_{b}^{2.75} \operatorname{Pr}_{b}^{0.5}\left[1+2.4 \operatorname{Re}_{b}^{-1 / 8}\left(\operatorname{Pr}_{b}^{2 / 3}-1\right)\right]
\end{gathered}
$$

Thus the Rayleigh number at the onset of a free convection effect is

$$
\begin{aligned}
\operatorname{Ra}_{b}=G r_{b} \operatorname{Pr}_{b} & =\frac{C}{f} \operatorname{Re}_{b}^{1.75} \operatorname{Pr}_{b}^{0.5}\left[1+2.4 \operatorname{Re}_{b}^{-1 / 8}\left(\operatorname{Pr}_{b}^{2 / 3}-1\right)\right]\left[1.07+12.7\left(\operatorname{Pr}_{b}^{2 / 3}-1\right) \sqrt{(f / 8)}\right] \\
f & =\left(1.82 \log \operatorname{Re}_{b}-1.64\right)^{-2} \\
C & =2.4 \times 10^{-3}
\end{aligned}
$$


Equation (4-1) gives the local variation of $\frac{\mathrm{Nu} \phi}{\mathrm{Nu}_{0}}$ about the circumference of the heater tube at any axial location. However, an appraisal of the influence of free convection on the averaged heat transfer coefficient by integrating Eq. (4-1) from $\phi=0$ to $\pi$ gives:

$$
\frac{N u_{\phi}}{N u_{0}}=1-A \operatorname{Cos} \phi
$$

where $A$ represents the remaining factors in the second term of Eq. $(4-1)$.

$$
\begin{aligned}
& \frac{\overline{N u}}{\mathrm{Nu}}=\frac{1}{\pi} \int_{0}^{\pi}[1-\mathrm{A} \cos \phi] \mathrm{d} \phi=1 \\
& \overline{\mathrm{Nu}}=\text { the peripheral averaged Nusselt number }
\end{aligned}
$$

Thus the analytical result of Petukhov indicates that the circumferentially averaged heat transfer coefficient is not affected by the free convection at all. Petukhov has confirmed the indication of Eq. (4-1) for weak thermogravitational effect by measurement of the coefficient for air at $\phi=0^{\circ}, 90^{\circ}$ and $180^{\circ}$ as shown of Fig. 6 of his paper.

(b) Results of Futagami and Abe.

Futagami and Abe analyzed the combined forced and free convective heat transfer with turbulent flow inside a tube inclined at angle $\alpha$. They presented their result graphically, for $v / \alpha=0.70$ and 0,72 , in terms of $\frac{\overline{N u}}{\mathrm{Nu}_{0}} v s_{0}: \operatorname{Ra}_{b}^{*} \operatorname{Cos} \alpha / \operatorname{Re}_{b}{ }^{5 / 4}$ and compared that with their experimental result for turbulent flow of air inside a horizontal tube. Upon further examination of their paper, they seemed to indicate the relationship 


$$
\begin{aligned}
& \text { between } N u_{b} / N u_{0} \text { and } R a_{b}^{*} \cos \alpha^{\prime} / \\
& \frac{\overline{N u_{b}}}{N u_{0}}=c_{1}\left(\frac{R a_{b}^{*} \operatorname{Cos} \alpha^{\prime}}{R e_{b}^{5 / 4}}\right)^{1 / 11} \\
& \text { for } \frac{R a^{*} \operatorname{Cos} \alpha}{R e^{5 / 4}}>10^{-2}
\end{aligned}
$$

Where $\overline{\mathrm{Nu}}$ 列 $=$ the peripheral averaged Nusselt No.:

$$
=\frac{q_{w} D}{k\left(T_{w}-T_{b}\right)}
$$

$\mathrm{Nu} \mathrm{O}_{0}=$ the Nusselt No. obtained under the buoyancyfree condition, which Futagami and Abe gave in terms of the empirical correlation as

$$
=0.03876 \mathrm{Re}^{3 / 4} \mathrm{Pr}^{1 / 3}
$$

$$
\begin{aligned}
R_{b}^{*} & =\text { Raleigh No. defined by Futagami as } \\
& =\frac{g B_{b} r^{4}\left|\frac{d T}{d x}\right|}{\alpha_{b} \nu_{b}}=\frac{G r_{b} N u_{b}}{4 R e_{b}} \\
\alpha^{\prime} & =\text { angle of inclination of the tube, thus } \\
c_{1} & \alpha^{\prime}=0 \text { for horizontal tube. } \\
& 1.536 \text {. This was obtained from curve fitting } \\
& \text { and Abe, as illustrated on Fig. (4-1). }
\end{aligned}
$$




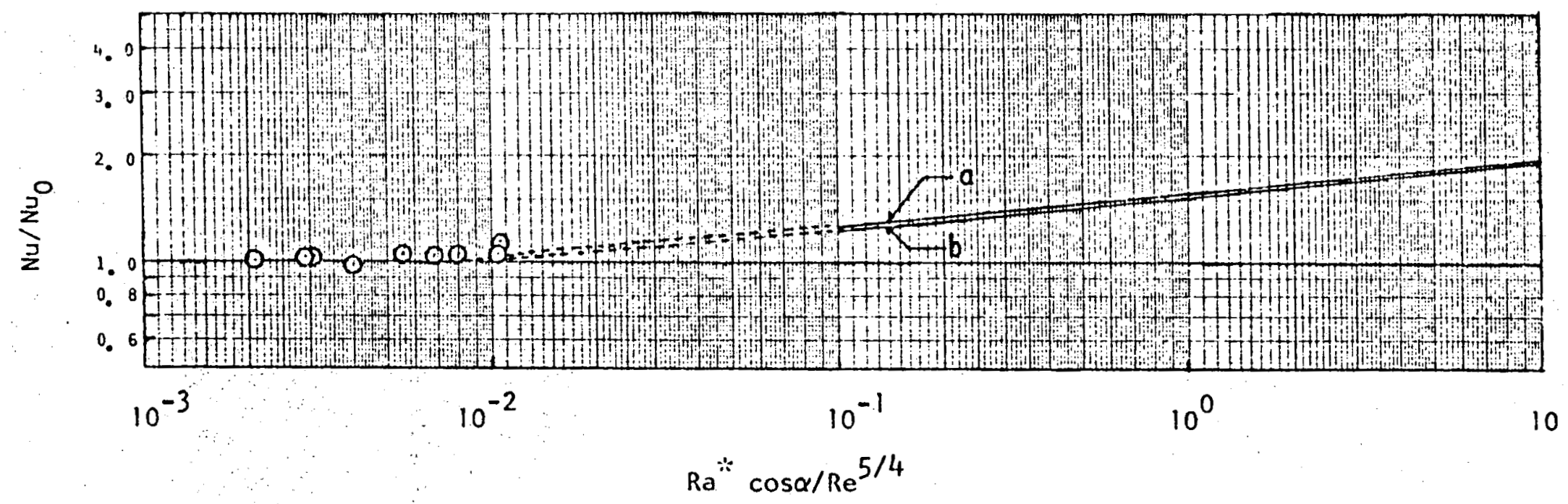

Fig. 4-1. Illustration of the results obtained by Futagami and Abe for $\mathrm{Nu}^{\mathrm{Nu}} \mathrm{Nu}_{0}$ vs. $R a^{*} \cos \alpha / R e^{5 / 4}$.

Experimental data of Futagami and Abe: $\odot$

curve a: $\operatorname{Pr}=0.72$

b: $\operatorname{Pr}=0.70$ 
Figure 13 of Futagami and Abe al so contained some experimental data which indicated that for air, at least, for values of $\mathrm{Ra}^{*} \cos \alpha / \mathrm{Re}^{5 / 4}$ less than $10^{-2}$, the values of $\mathrm{Nu} / \mathrm{Nu}$ o were about unity. Thus a criterion can be established for the onset of buoyancy effect as when $\overline{\mathrm{Nu}}$ is $10 \%$ greater than $\mathrm{Nu}_{0}$ and Eq. $(4-8)$ becomes:

$$
\operatorname{Ra}_{b}^{*} / \operatorname{Re}_{b}^{5 / 4} \geq 2.3 \times 10^{-2}
$$

for a horizontal tube.

The Raleigh number defined by Futagami was based on the constant wall heat flux boundary condition of his analysis. To relate Futagami's Raleigh number to the isothermal wall boundary condition applicable to present study, the following conversion has to be performed.

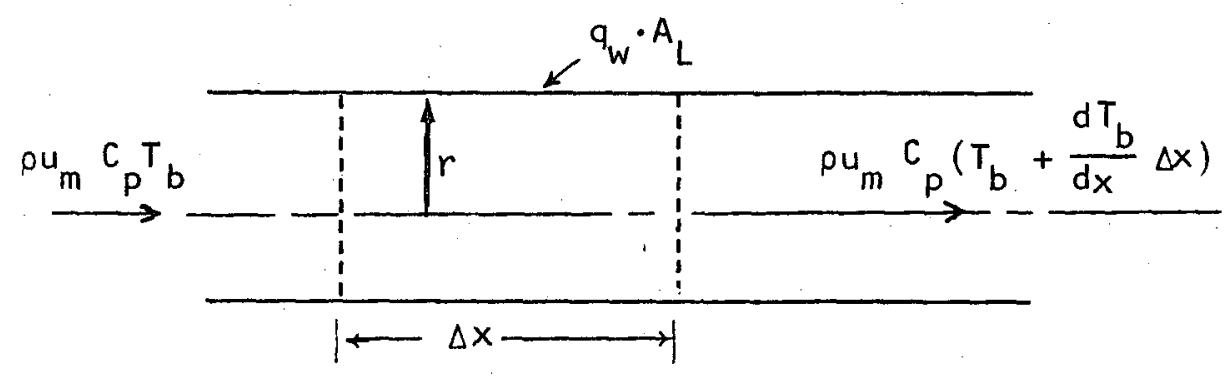

FIGURE $4-2$ 
By energy balance:

Assuming constant $C_{p}$ over the distance $\Delta z$ and constant wall heat flux heating:

$$
\begin{gathered}
\pi r^{2} \rho u_{m} C_{p} \frac{d T_{b}}{d x} \Delta x=2 \pi r q_{w} \Delta x \\
\frac{d T_{b}}{d x}=\frac{2 q_{w}}{r \rho u_{m} C_{p}}
\end{gathered}
$$

For a fully developed temperature profile inside the tube:

$$
\frac{d T_{b}}{d x}=\frac{d T_{w}}{d x}=\frac{2 q_{w}}{r \rho u_{m} c_{p}}
$$

Therefore Futagami's definition of Ra* becomes:

$$
\begin{aligned}
R_{b}^{*} & =\frac{g \beta_{b} r^{4}\left|\frac{d T w}{d x}\right|}{\alpha_{b} \nu_{b}}=\frac{g \beta_{b} r^{4}}{\alpha_{b} \nu} \quad \frac{2 q_{w}}{r \rho u_{m} c_{p}} \\
& =\frac{2 g \beta_{b} r^{3} q_{w}}{\left(\rho \alpha \sim C_{p}\right)_{b} u_{m}}
\end{aligned}
$$

Usually Raleigh No. is defined as

$$
\begin{aligned}
R_{b} & =G r_{b} P_{b} \\
& =\frac{\rho_{b}^{2} g B_{b}\left(T_{w}-T_{b}\right)\left(2 r_{b}\right)^{3}}{\mu_{b}^{2}}\left(\frac{\nu}{\alpha}\right)_{b}
\end{aligned}
$$

Relating Eq. $(4-10)$ and $(4-11)$

$$
\begin{aligned}
& R_{b}{ }_{b}=\frac{\left.b_{b}^{g \beta_{b} \Delta T(2 r}\right)^{3}}{{ }_{b}^{2}} \frac{\mu_{b}}{4} \frac{q_{w}}{k_{b} \rho_{b} u_{m} \Delta T} \\
& \text { where } \Delta T=\left(T_{w}-T_{b}\right)
\end{aligned}
$$


Thus

$$
R a_{b}^{* *}=\operatorname{Gr}\left\{\frac{q_{w}(2 r)}{k_{b} \Delta T}\right\}\left\{\frac{\mu_{b}}{4 p_{b} u_{m}(2 r)}\right\}=\frac{G r_{b} N u_{b}}{4 R e_{b}}
$$

Substituting this into Eq. (4-8) and $\cos \alpha=1$ for horizontal tube

$$
\begin{aligned}
& \frac{\overline{N u_{b}}}{N u_{0}}=1.536\left(\frac{R_{b}^{*}}{\operatorname{Re}_{b}^{5 / 4}}\right)^{1 / 11}=1.536\left(\frac{1 / 4 G r_{b}^{N u_{b}}}{R e_{b}^{9 / 4}}\right)^{1 / 11} \\
& \left.\frac{\overline{N u}_{b}}{N u_{0}}\right)^{10 / 11}=1.354\left(\frac{G r_{b}}{\operatorname{Re}_{b}^{9 / 4}}\right)^{1 / 11}\left(N u_{0}\right)^{1 / 11} \\
& \frac{N u_{b}}{N u_{0}}=(1.354)^{11 / 10}\left(\frac{G r_{b}}{\operatorname{Re}_{b}^{9 / 4}}\right)^{1 / 10}\left(N_{0}\right)^{1 / 10}
\end{aligned}
$$

Substituting in the expression for $\mathrm{Nu}_{0} g$ iven by Futagami:

$$
\begin{aligned}
& \frac{\overline{N u_{b}}}{N u_{0}}=(1.354)^{11 / 10}\left(\frac{G r_{b}^{1 / 10}}{\operatorname{Re}_{b}^{3 / 2}}\right)\left(0.03876 \operatorname{Re}_{b}^{3 / 4} P_{b}^{1 / 3}\right)^{1 / 10} \\
& \frac{\overline{N u_{b}}}{N u_{0}}=1.008\left(\frac{G r_{b} P_{b}^{1 / 3}}{\operatorname{Re}_{b}^{3 / 2}}\right)^{1 / 10}=1.008\left(\frac{\operatorname{Ra}_{b}}{\operatorname{Pr}_{b}^{2 / 3} \operatorname{Re}_{b}^{3 / 2}}\right)^{1 / 10}
\end{aligned}
$$

Note that Equation $(4-12)$ is quite different from the results of Petukhor given by Equation (4-7). Since we are also interested in the limiting value of $\frac{\mathrm{Ra}^{*}}{\mathrm{Re}^{5 / 4}}$ for buoyancy-free forced convection inside the horizontal tube, the Nusselt 
number should correspond to Nu given by Futagami. Thus. Eq. (4-9) becomes

$$
\begin{aligned}
& \frac{\operatorname{Ra}_{b}^{*}}{R e_{b}^{5 / 4}}=\frac{G r_{b}\left(0.03876 \operatorname{Re}_{b}^{3 / 4} \operatorname{Pr}_{b}^{1 / 3}\right)}{4 R e_{b}^{9 / 4}} \\
&=0.00969 \frac{G r_{b} P r_{b}}{\operatorname{Re}_{b}^{3 / 2} \operatorname{Pr}^{2 / 3}} \leq 2.3 \times 10^{-2} \\
& \text { or } \quad G_{b} \operatorname{Pr}_{b}=\operatorname{Ra}_{b} \leq 2.395 \operatorname{Re}_{b}^{3 / 2} \operatorname{Pr}_{b}^{2 / 3}
\end{aligned}
$$

Table 4-1 presents a summary of the equations for variation of Nusselt number under the influence of buoyancy effect and criteria for onset of buoyancy effect as given by Petukhov and Futagami. In addition, expressions given by them for $\mathrm{Nu}_{0}$ or buoyancy free forced convection are compared with those standard correlations by Dittus-Boelter:

$$
N u_{b}=0.023 \operatorname{Re}_{b}^{0.8} \operatorname{Pr}_{b}^{0.4}
$$

and of Sieder and Tate

$$
N_{b}=0.027 \operatorname{Re}_{b}^{0.8}{ }_{P_{r}} 1 / 3\left(\frac{\mu_{b}}{\mu_{w}}\right)^{0.14}
$$

on Fig. 4-3.

The figure shows that Petukhov's correlation predicts $10 \%$ to $20 \%$ higher Stanton number than Dittus-Boelter correlation over $3 \times 10^{4}<\operatorname{Re}<4 \times 10^{5}$ at $\mathrm{Pr}=4.0$. In contrast, Futagami's correlation indicates a $10 \%$ to $25 \%$ 
PETUKHOV, et al

FUTAGAMI \& ABE

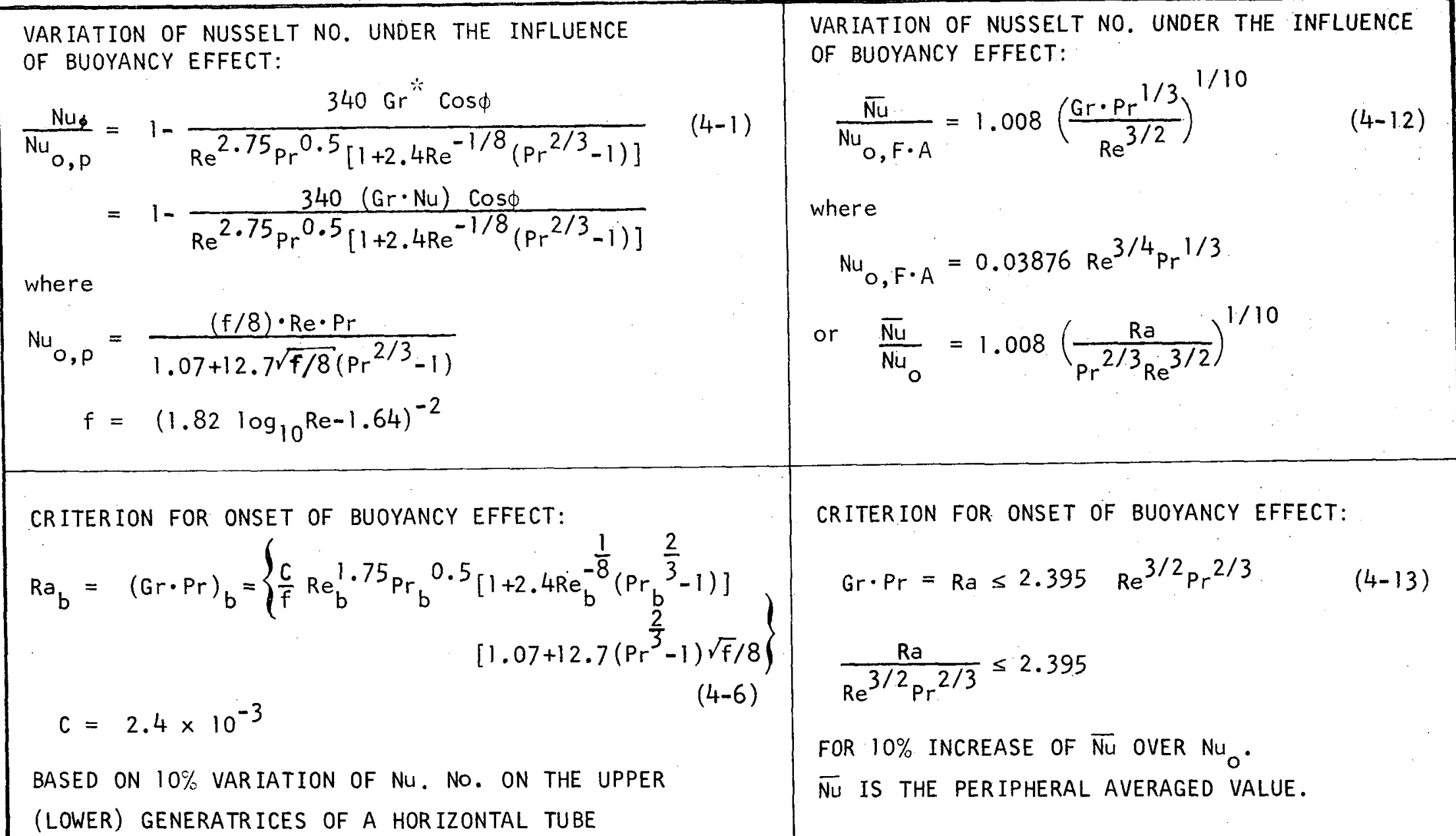

TABLE 4-1. SUMMARY OF EQUATIONS GIVEN FOR VARIATION OF NUSSELT NUMBER UNDER THE INFLUENCE OF BUOYANCY EFFECT AND CRITERION FOR ONSET OF BUOYANCY EFFECT. 


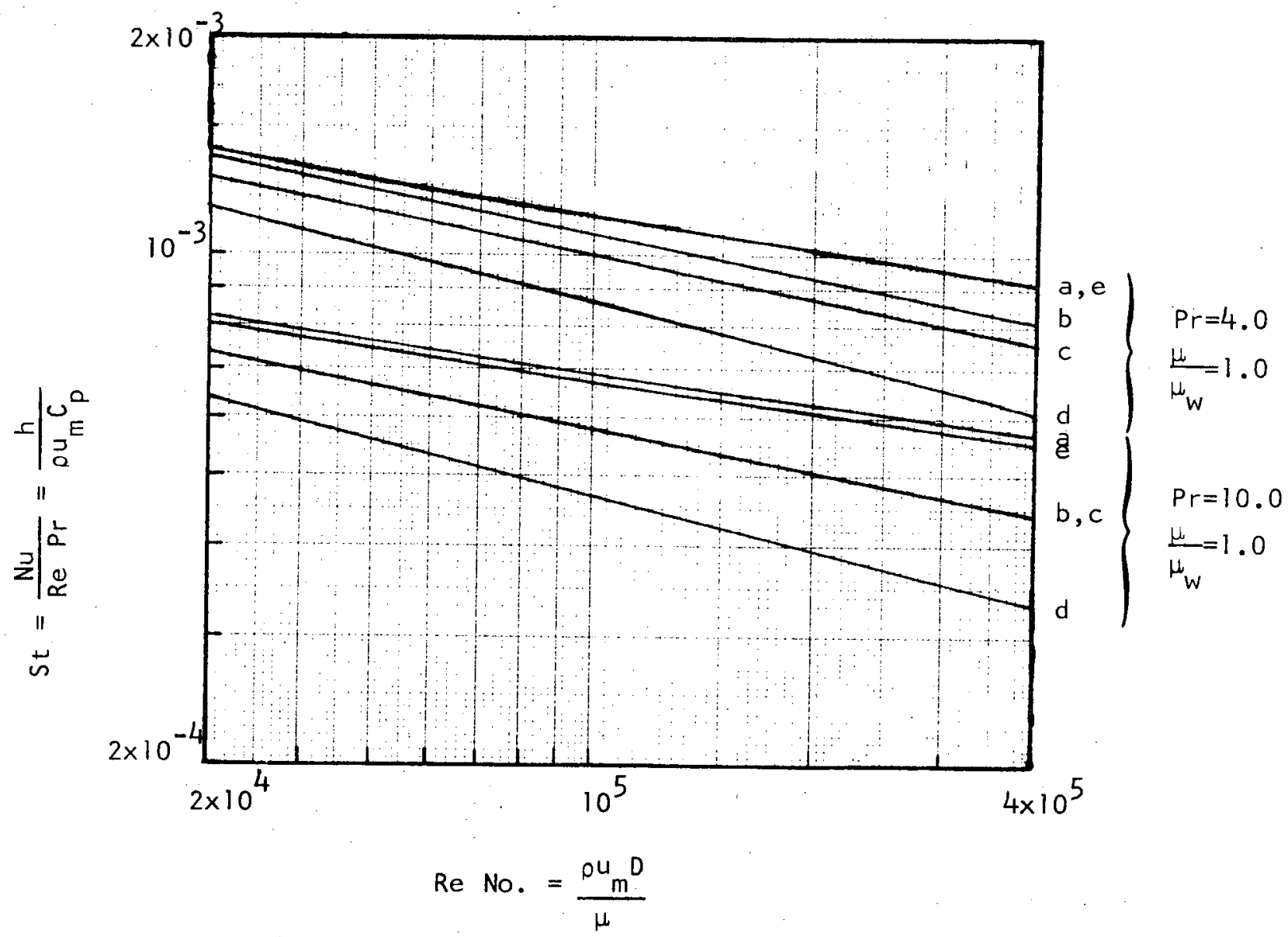

Fig. 4-3. Comparison of correlations for turbulent forced convective heat transfer inside a tube.

Curve a: Petukhov correlation; St. $=\frac{(f / 8)}{1.07+12.7 \sqrt{f / 8}\left(\operatorname{Pr}^{2 / 3}-1\right)}$

$$
f=(1.82 \log \operatorname{Re}-1.64)^{-2}
$$

Curve b: Sieder-Tate correlation;

$$
\text { St. }=0.027 \operatorname{Re}^{-0.2} \operatorname{Pr}^{-2 / 3}\left(\frac{\mu}{\mu_{w}}\right)^{0.14}
$$

Curve c: Dittus-Boelter correlation;

$$
\text { St. }=0.023 \mathrm{Re}^{-0.2} \mathrm{Pr}^{-0.6}
$$

Curve d: Futagami-Abe

$$
\text { St. }=0.03876 \operatorname{Re}^{-\frac{1}{4}} \mathrm{Pr}^{-2 / 3}
$$

Curve e: Sleicher \& Rouse, Eq. 4-16. 
lower Stanton number than Dittus-Boelter correlation over the same range of $\operatorname{Re}$ number and at $\mathrm{Pr}=4.0$. Therefore, the difference between the correlations given by Petukhov and Futagami for $\mathrm{Nu}_{0}$ is about $20 \%$ to $50 \%$ at $\operatorname{Pr}=4.0$.

At $\operatorname{Pr}=10.0$, the difference between the correlations by Petukhov and Futagami becomes $30 \%$ to $72 \%$ over $3 \times 10^{4}$ $<\operatorname{Re}<4 \times 10^{5}$.

In 1975 sleicher and Rouse [27] proposed a correlation for variable property fluid over a wide range of $\operatorname{Re}$ and $\mathrm{Pr}$ as :

$$
\begin{aligned}
& N u_{b}=5+0.015 \operatorname{Re}_{f}^{a} \operatorname{Pr}_{w}^{b} \\
& a=0.88-0.24 /\left(4+\operatorname{Pr}_{w}\right) \\
& b=1 / 3+0.5 e^{-0.6 \operatorname{Pr}_{w}}
\end{aligned}
$$

The Prandtl number $\operatorname{Pr}$ is evaluated at the wall temperature and Reynolds number is evaluated at the film temperature $T_{f} \equiv\left(T_{w}+T_{b}\right) / 2$.

Equation (4-16) is then compared with Eq. (4-3) by Petukhov on Fig. 4-3 also. Except for the difference on the basis for the evaluation of $\operatorname{Pr}$ and Re, Equation (4-16) is almost identical to Eq. $(4-3)$ at $\operatorname{Pr}=4.0$ and about $3 \%$ less than Eq. (4-3) at $\operatorname{Pr}=10.0$. 
4-3. The Experimental Nusselt Numbers.

The experimental data are tabulated on Table $B-1$ of Appendix $B$ with the listing in order of increasing $R_{b}$, column 8, at Section $H$. The experimental Nusselt numbers are compared with those correlations given by Dittus-Boelter on Fig. 4-4; Sieder-Tate on Fig. 4-5 and Petukhov on Fig. 4-6. Each data point on the figures represents a heat transfer coefficient evaluated from one pan section, therefore there are four data points for each run. Although the tabulation on Table B-1 is for runs with $E>1$, a few runs in which $E$ changes to $E<1$ when traversing through the heater tube are included.

Figure 4-4 shows that the data points are all above the DittusBoelter correlation and they exceed that specification by as much as $50 \%$. If the constant of Dittus-Boelter's correlation is increased from 0.023 to 0.028 , the data can be specified to within $\pm 20 \%$.

Alternatively a new correlation with

$$
N u_{b}=0.022 \operatorname{Re}_{b}^{0.82} \operatorname{Pr}_{b}^{0.4}
$$

correlates the data to within $\pm 20 \%$ also.

Figure $4-5$ shows the comparison with sieder-Tate correlation. This involves the evaluation of properties for $\mathrm{Nu}, \mathrm{Re}$ and $\mathrm{Pr}$ at the bulk temperature and includes the factor $\left(\frac{\mu_{b}}{\mu_{w}}\right)^{0.14}$ to account for the variation of viscosity with temperature. The data points are moved closer to the prediction line though the majority of them still lie above it. A $10 \%$ increase in the Sieder-Tate constant to 0.03 will correlate the data to within $\pm 18 \%$.

Finally, on Fig. 4-6, the data points are compared to the Petukhov prediction as calculated from Equations (4-3) and (4-4). Referring to Fig. 4-3, it is noted that Eq. (4-3) gives a higher prediction of Stanton 


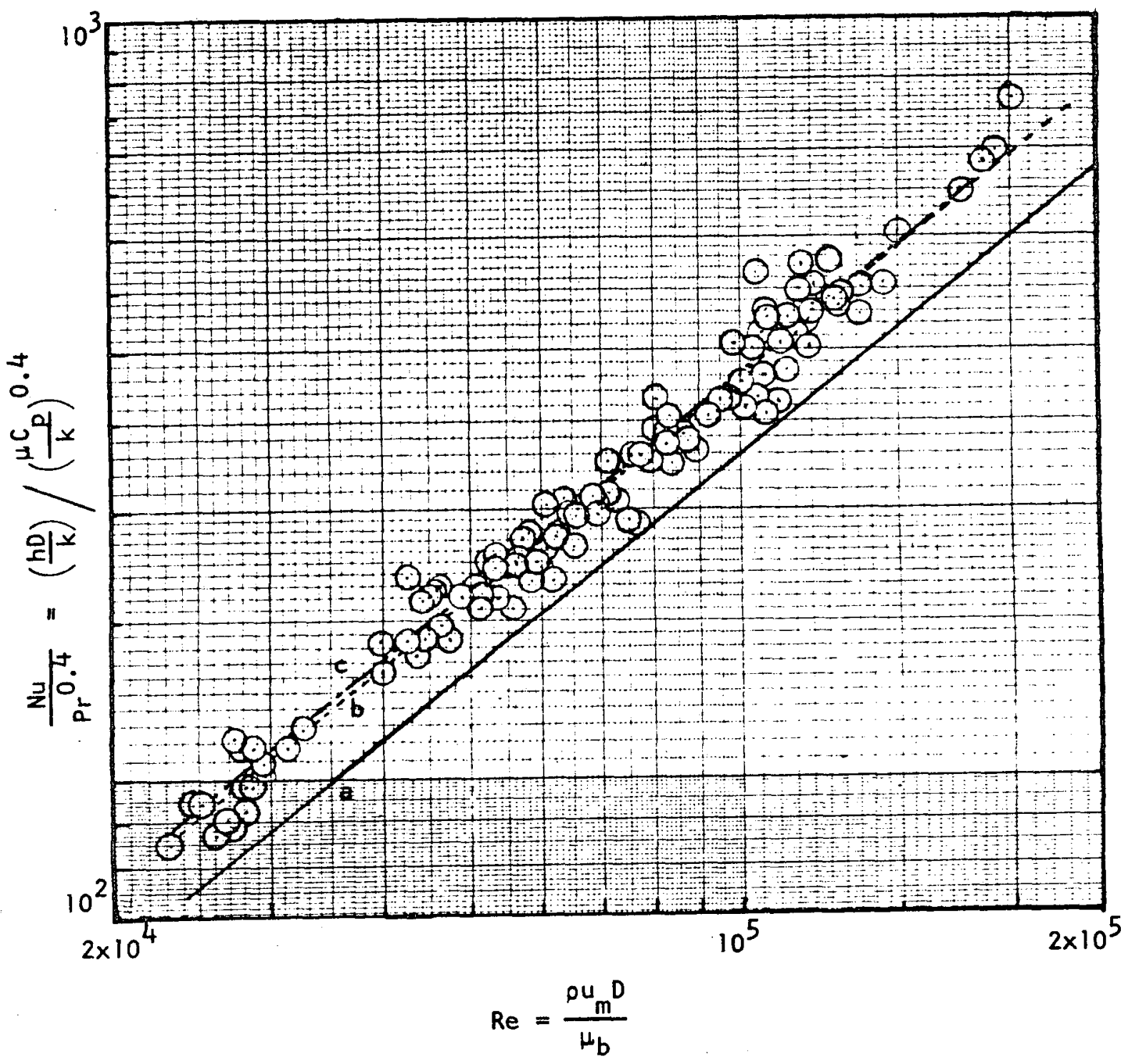

FIG. 4-4. COMPARISON OF DATA WITH DITTUS-BOELTER CORRELATION. DATA WITH E > 1

$$
\begin{aligned}
\text { Line } a: \quad N u & =0.023 \operatorname{Pr}_{b}^{0.4} \operatorname{Re}_{b}^{0.8} \\
b: \quad N u & =0.022 \operatorname{Pr}_{b}^{0.4} \operatorname{Re}_{b}^{0.82} \\
c: \quad N u & =0.028 \operatorname{Pr}_{b}^{0.4} \operatorname{Re}_{b}^{0.8}
\end{aligned}
$$




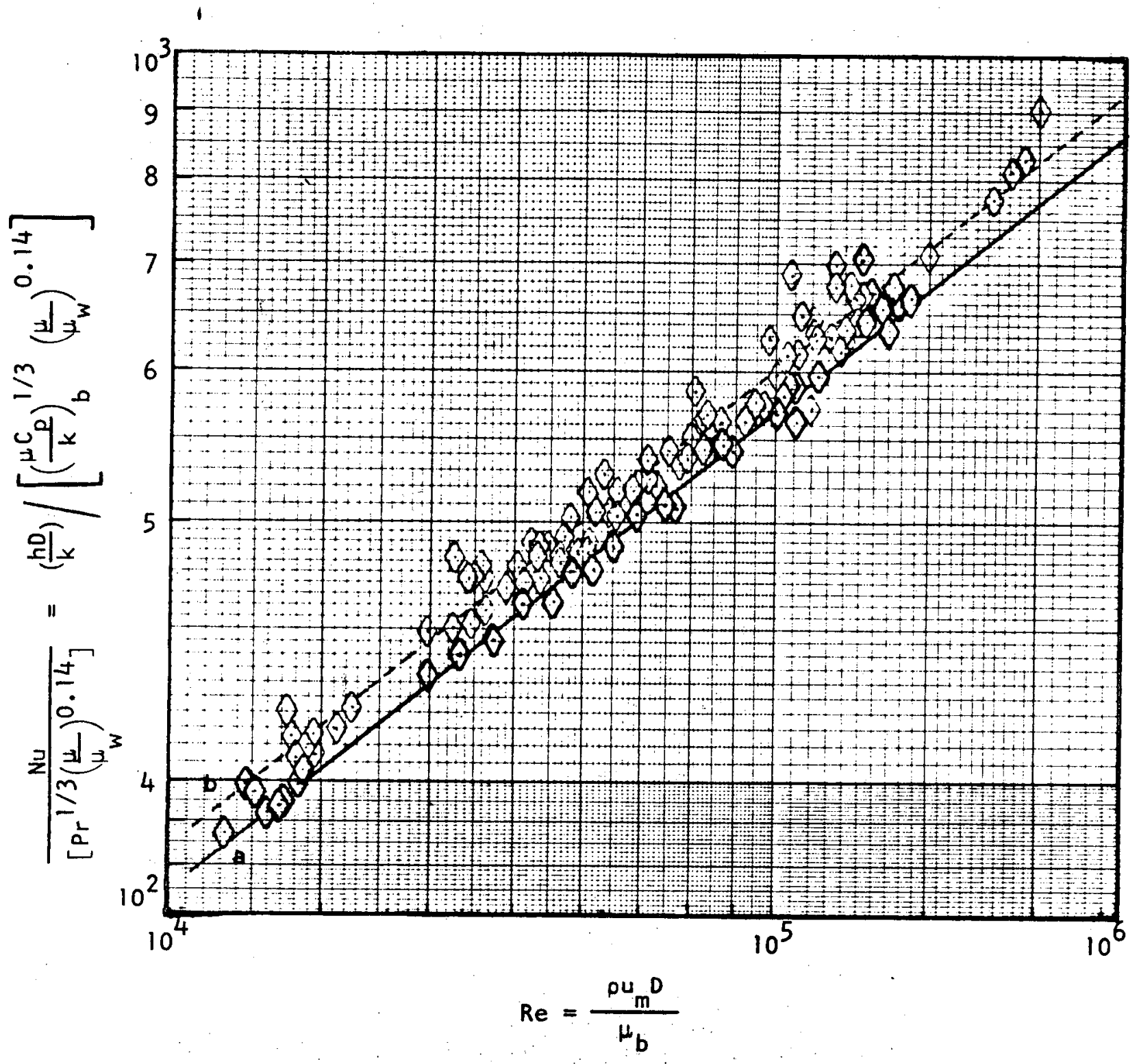

FIG. 4-5. COMPARISON OF DATA WITH SIEDER-TATE CORRELATION. DATA WITH E $>1$

$\begin{aligned} \text { Line } a: N u & =0.027 \operatorname{Re}_{b}^{0.8} \operatorname{Pr}_{b}^{1 / 3}\left(\frac{\mu_{w}}{\mu_{w}}\right)^{0.14} \\ b: \quad N u & =0.030 \operatorname{Re}_{b}^{0.8} \operatorname{Pr}_{b}^{1 / 3}\left(\frac{\mu}{\psi_{w}}\right)^{0.14}\end{aligned}$ 


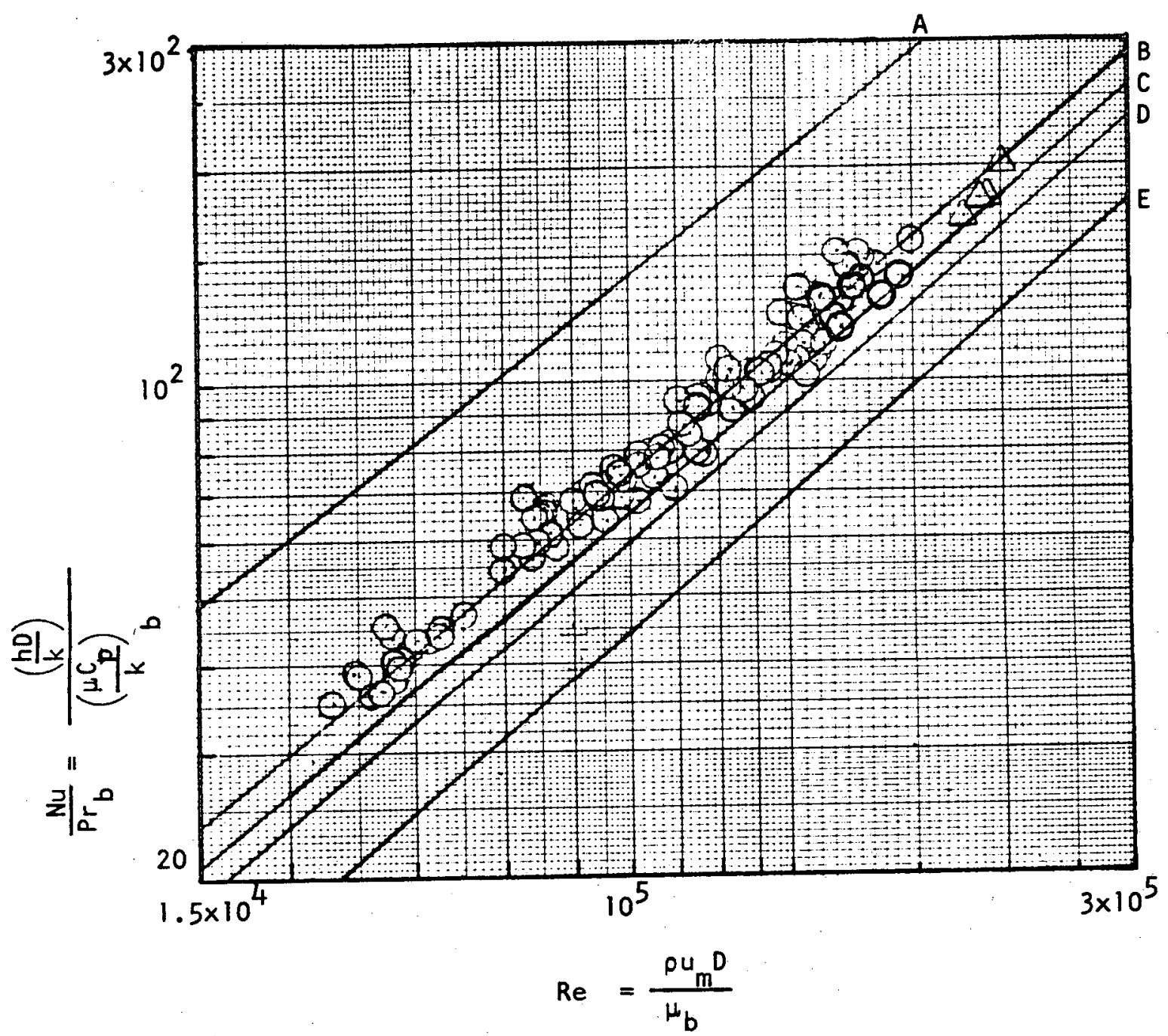

FIG. 4-6. COMPARISON OF DATA WITH PETUKHOV CORRELATION.

Line $\begin{aligned} A: & \operatorname{Pr}=1.0 \\ B: & \operatorname{Pr}=4.0 \\ C: & \operatorname{Pr}=5.0 \\ D: & \operatorname{Pr}=6.0 \\ E: & \operatorname{Pr}=10.0\end{aligned}$

○ $4.0<\operatorname{Pr}<5.0$

$\triangle 5.0<\operatorname{Pr}<6.0$

$$
\begin{aligned}
\frac{N u}{\operatorname{Pr}} & =\frac{(f / 8) \operatorname{Re}}{\left[1.07+12.7\left(\operatorname{Pr}^{2 / 3}-1\right) \sqrt{f / 8}\right]} \\
f & =(1.82 \log \operatorname{Re}-1.64)^{-2}
\end{aligned}
$$


number than either Sieder-Tate or Dittus-Boelter correlations as discussed in Sec. 4-2. Since the Reynolds number is so imbedded in this formulation of Nusselt number, the data are represented as Nu vs. Re on Fig. 4-6, and the Petukhov relation is shown by 1 ines for various values of $\operatorname{Pr}$. The range of $\operatorname{Pr}$ for the data is distinguished by the point designation as shown on Fig. 4-6. For $4<\operatorname{Pr}<5$, the Petukhov relation gives a difference of $12.5 \%$ in the Nusselt numbers. The data encompasses a band of about $\pm 15 \%$ in the Nusselt number about the prediction for $\operatorname{Pr}=4.0$.

The data for $5.0<\operatorname{Pr}<6,0$ are few and they 1 ie within the same error band as the data for $4.0<\operatorname{Pr}<5.0$ with respect to the prediction for the range of Prandt 1 numbers.

At this point it can be concluded that:

(a) The Dittus-Boelter correlation gives a lower prediction with respect to data. An increase of $22 \%$ in the constant coefficient is needed to correlate data within $\pm 20 \%$.

(b) The Sieder-Tate correlation is also low. An increase of the constant by $10 \%$ will correlate the data within $\pm 18 \%$.

(c) Plotting the data in terms of $\left(\mathrm{Nu} / \mathrm{Pr}_{b}\right)$ vs. $\mathrm{Re}_{b}$ actually diminishes the scatter of the data. The scatter of data points is approximately $\pm 15 \%$ about the prediction line for $\operatorname{Pr}=4.0$. Any further conclusions are impaired by the relatively large scatter of data.

At this point the experimental results is reassessed for the possible effect of buayancy on the augmentation of heat transfer coefficient over the prediction by Dittus-Boelter and Sieder-Tate 
correlation. In this respect it is noted that:

(a) Equation (4-7) indicates that Petukhov's appraisal gives no influence of free convection on the average heat transfer coefficient but rather just changes the peripheral distribution of the coefficients.

(b) On the other hand, the appraisal by Futagami and Abe indicates that $\overline{\mathrm{Nu}} /\left(\mathrm{Nu}_{\mathrm{O}}\right)_{\mathrm{F}-\mathrm{A}}$ is dependent on the dimensionless free convection parameter $\left(\frac{\operatorname{Ra}}{\mathrm{Pr}^{2 / 3} \mathrm{Ra}^{3 / 2}}\right)$, Equations $(4-12)$.

The ratio of experimental Nusselt numbers to that specified by Sieder-Tate, Eq. (4-15), $\frac{\mathrm{Nu}_{b}}{\mathrm{Nu} S-\mathrm{T}}$ is plotted against (GrNu) ${ }_{b}$ on Fig. 4-7. Also, the ratio $\frac{\mathrm{Nu}_{b}}{\left(\mathrm{Nu} u_{0}\right)}$ is plotted $v \cdot(\mathrm{GrNu})_{b}$ on Fig. 4-8.

Fig. 4-7 indicates that $\frac{\mathrm{Nu}_{b}}{\mathrm{Nu} S-\mathrm{T}}$ is about 1.10 over the range of $8 \times 10^{9}<(\mathrm{GrNu})_{\mathrm{b}}<4 \times 10^{11}$ with a scatter of $\pm 20 \%$.

Fig. 4-8 indicates similar results as for Fig. 4-7. Therefore, this confirms Petukhov's appraisal that free convection does not have any effect on the averaged heat transfer coefficient. Furthermore, four curves based on Eq. (4-1) for $\phi=\frac{\pi}{4}$ and the values of Re and $\operatorname{Pr}$ encompassing the range of experimental data are added. Petukhov's analysis shows that due to the free convection effect, the ratio of local Nusselt number at $\phi=\frac{\pi}{4}$ with respect to $\mathrm{Nu}_{0}$ becomes

$$
\frac{N u_{\phi}=\frac{\pi}{4}}{N u_{0}}=1-A \cos \frac{\pi}{4}
$$

and this indicates that $\mathrm{Nu}_{\phi}=\frac{\pi}{4}<\mathrm{Nu}_{0}$ always. Thus the four curves are decreasing functions of $\left(\mathrm{GrNu}_{b}\right)$. Nonetheless, the experimental data do not exhibit such a trend even though the heat transfer 


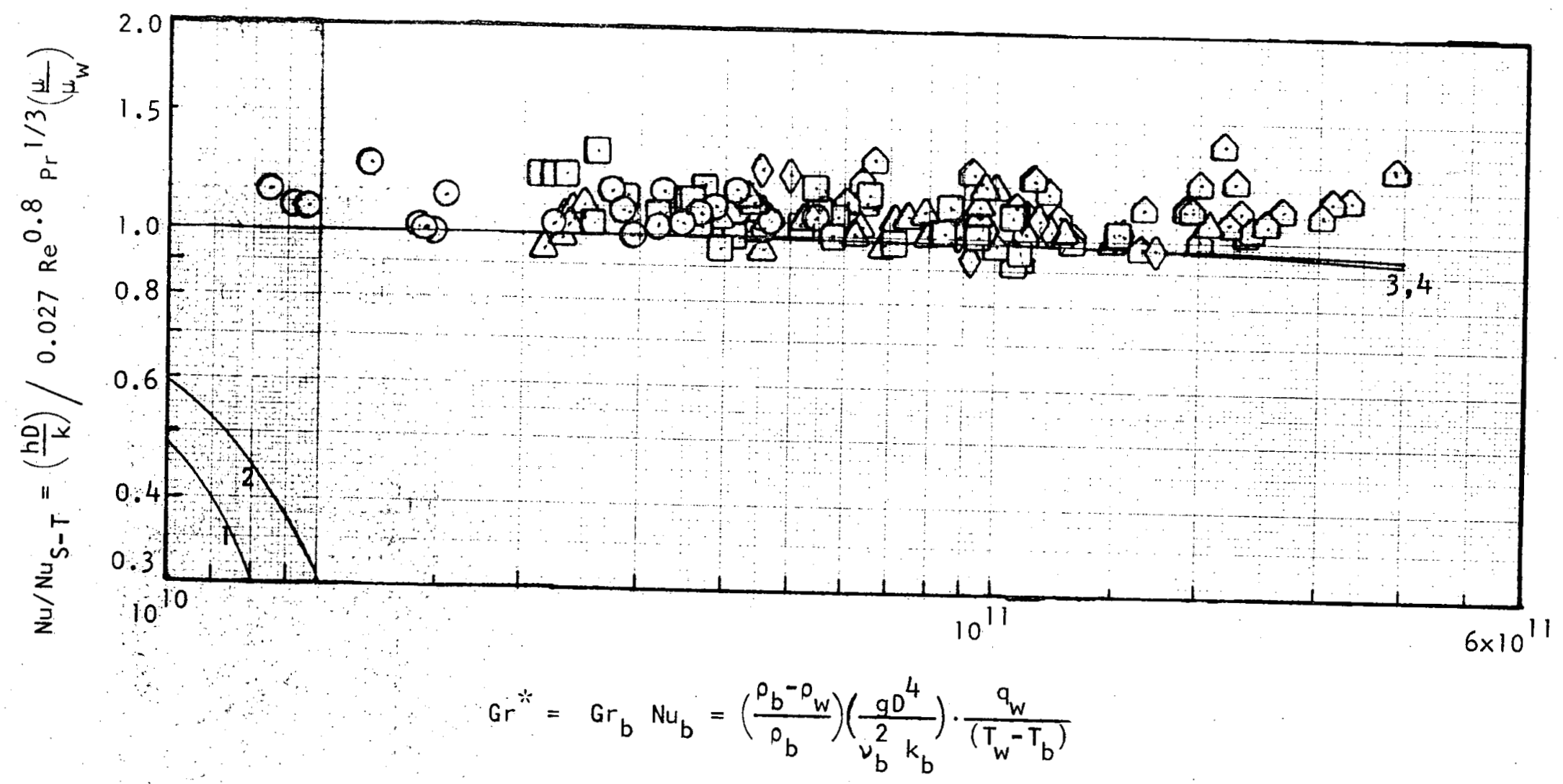

FIG. 4-7. EFFECT OF BUOYANCY ON EXPERIMENTAL DATA FOR E $>1$.

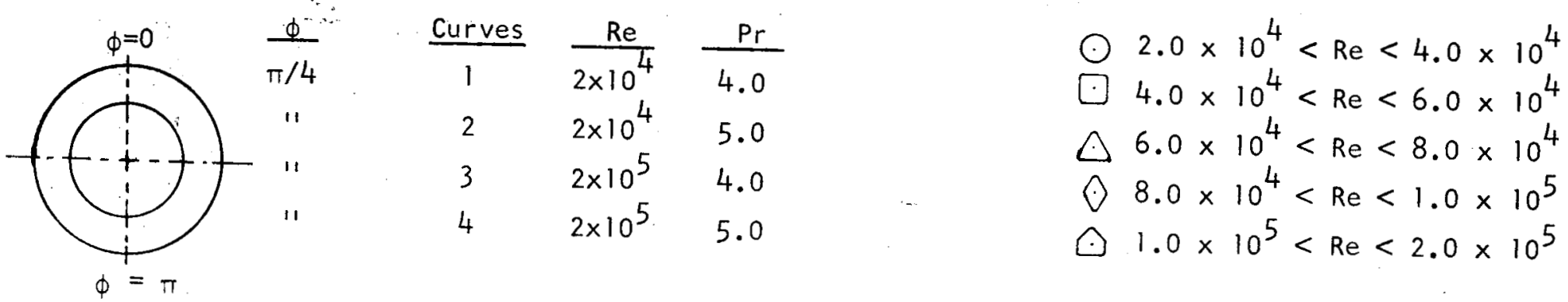




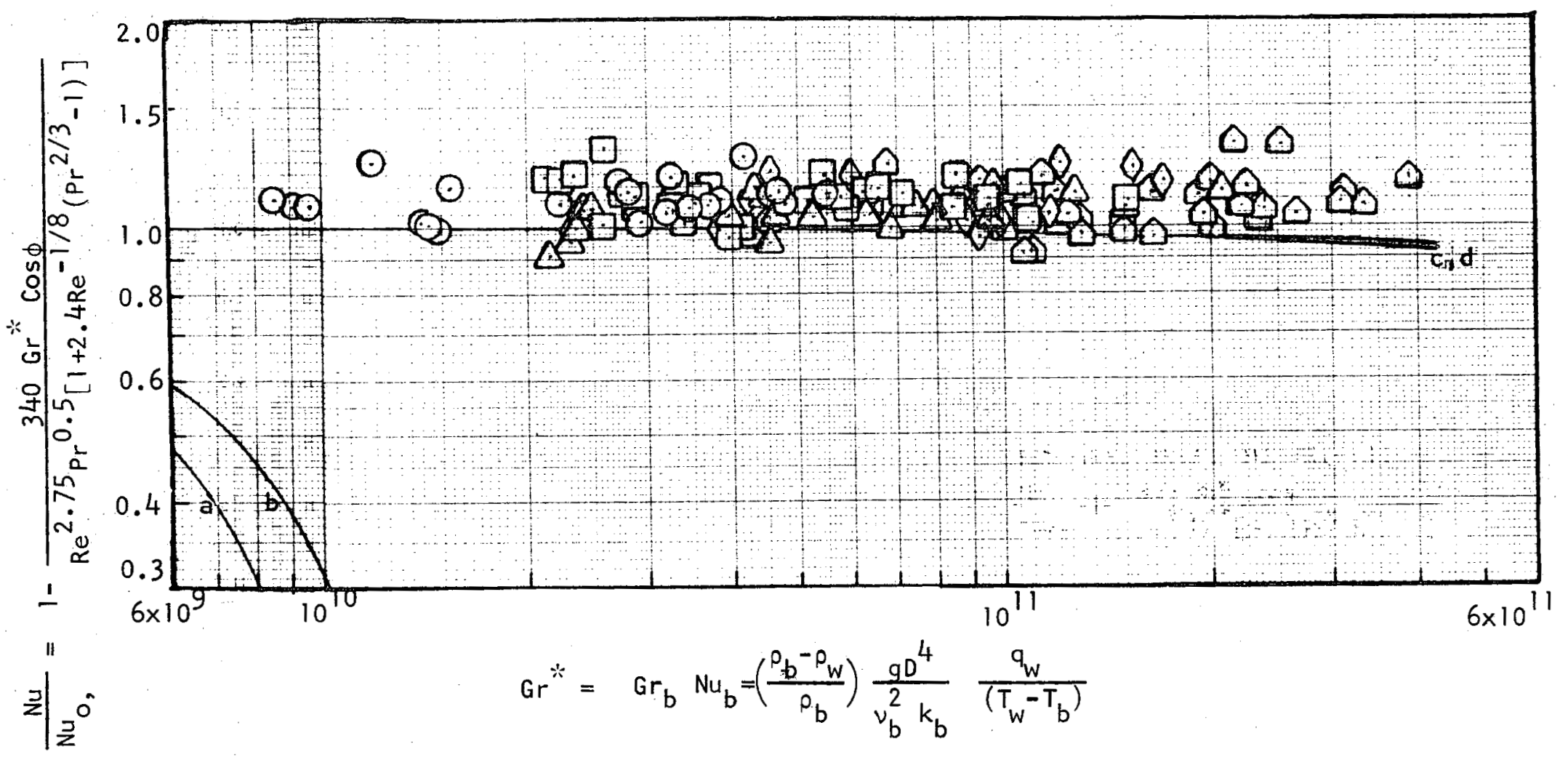

FIG. 4-8. EFFECT OF BUOYANCY ON EXPERIMENTAL DATA FOR E > 1 USING EQUATION GIVEN BY PETUKHOV, et al.

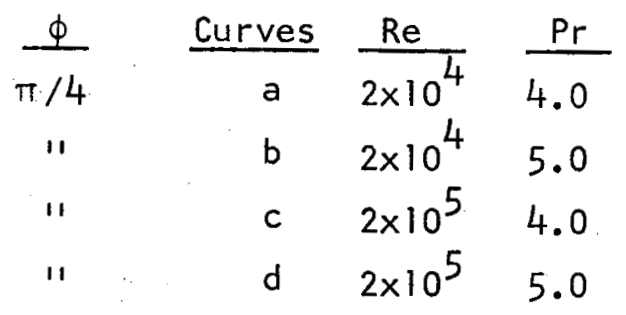
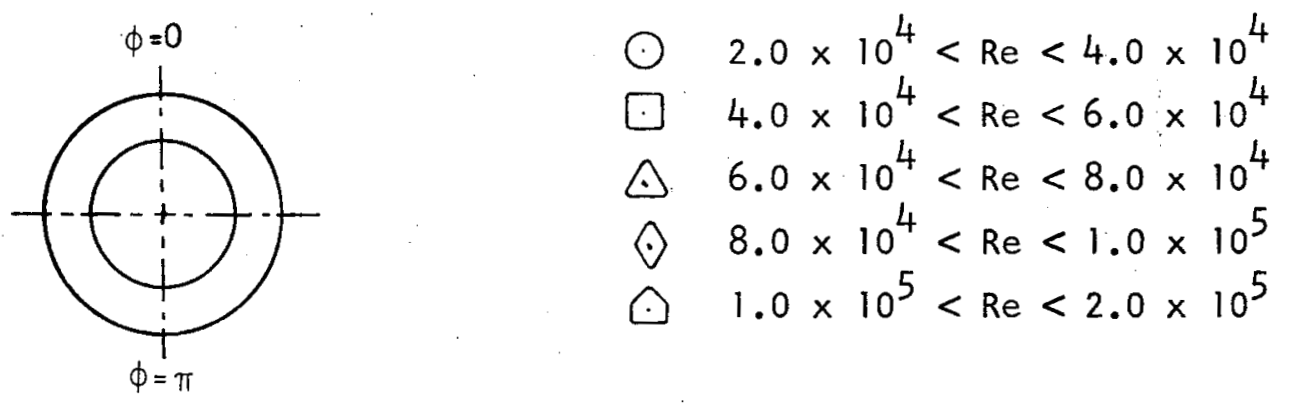

$\stackrel{n}{f}$ 
coefficients are calculated from $\frac{{ }^{q} \text { STEAM }}{\left(T_{w, \phi}=\frac{\pi}{4}-T_{b}\right)}$ AVG and where $T_{w}$ is inside wall temperature measured at $\phi=\frac{\pi}{4}$ (refer to Section 3-4).

Figure 4-9 shows the plot of experimental data in terms of $\frac{\mathrm{Nu}}{\mathrm{Nu} \mathrm{o}_{\mathrm{FA}}}$ against $\left(\frac{\mathrm{Ra}}{\mathrm{Pr}^{2 / 3} \mathrm{Re}^{3 / 2}}\right)$. The value of $\frac{\mathrm{Nu}}{(\mathrm{Nu})_{\mathrm{F}} \mathrm{A}}$ is about 1.45 over a range of $3.5<\left(\frac{\operatorname{Ra}}{\operatorname{Pr}^{2 / 3} \operatorname{Re}^{3 / 2}}\right)<80$ with a scatter of $\pm 20 \%$. All the data points exceed the specification by Futagami for the lower limit value of $\frac{\mathrm{Ra}}{\mathrm{Pr}^{2 / 3} \mathrm{Re}^{3 / 2}}$ for the onset of buoyancy effect, Eq. (4-13). The analysis by Futagami, Eq. (4-12), indicates an increasing function of

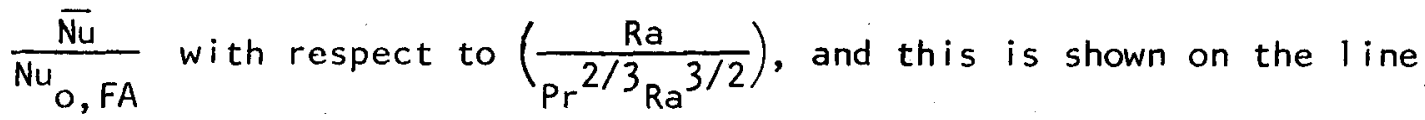
drawn on the figure. The experimental data failed to follow this trend.

4-4. Conclusion.

The experimental data exceed the prediction by both Dittus-Boelter and Sieder-Tate correlations.

Petukhov's prediction line for $\mathrm{Pr}=4.0$ correlates the data to within $\pm 15 \%$.

There is little apparent dependence of data on Grashof number. Petukhov's analysis indicates that local heat transfer coefficient is dependent on the peripheral location after the onset of free convection effect. Thus, if his analysis is correct, and if the data measured for $\phi=45^{\circ}$ were truly a peripherally local value, then there should have been a significant departure of $\frac{\mathrm{Nu}}{\left(\mathrm{Nu}_{\mathrm{O}}\right)_{p}}$ from unity for given Re and Pr. This is not apparent in the data.

Futagami and Abe's indication of a free convection effect is not confirmed. Their analysis is hard to appraise because their "isothermal" correlation ( $\left.\mathrm{Nu}_{\mathrm{O}}\right)_{\mathrm{FA}}$ is so low. 


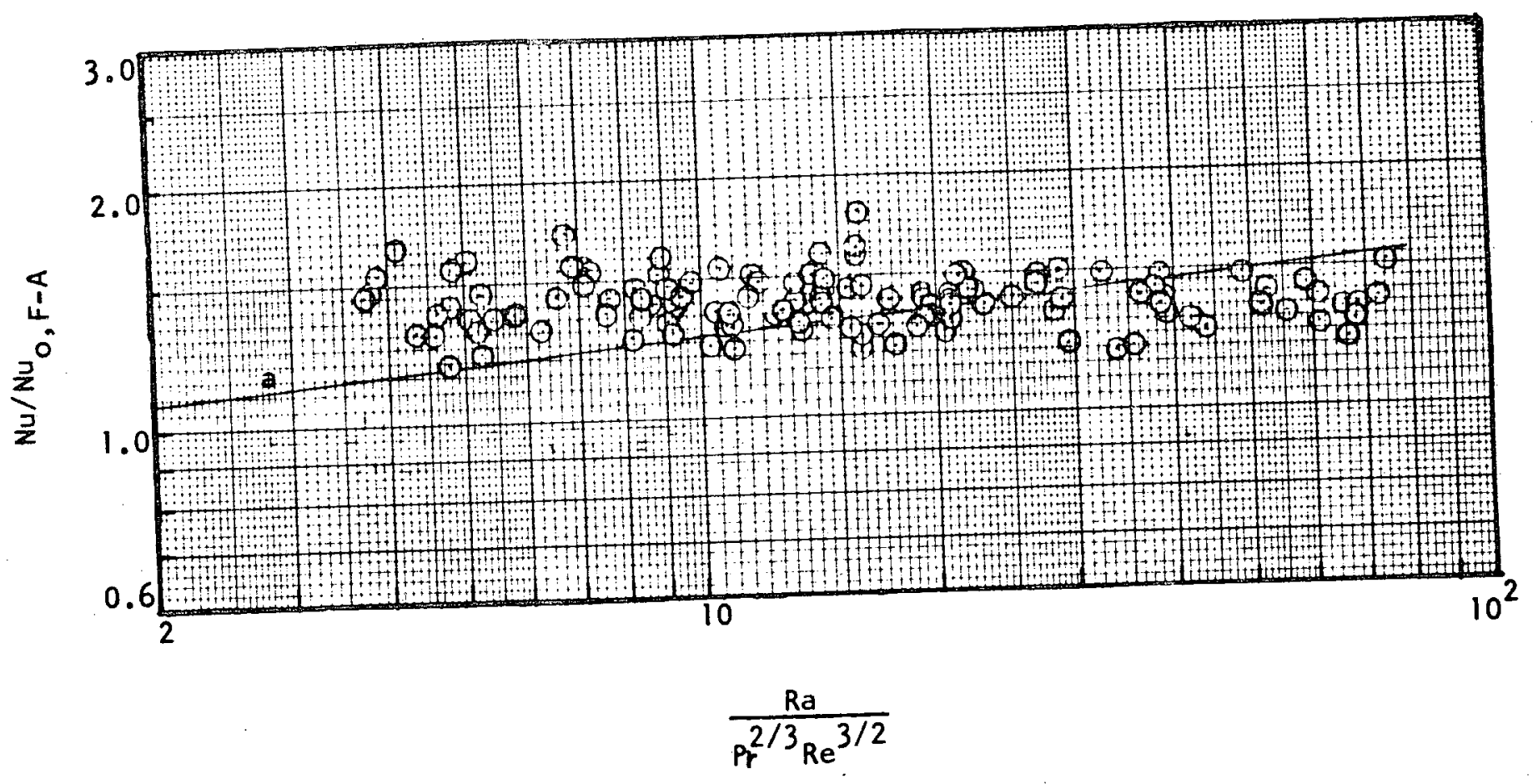

FIG. 4-9. COMPARISON OF DATA WITH E>I WITH CORRELATION GIVEN BY FUTAGAMI \& ABE FOR VARIATION OF NUSSELT NUMBER UNDER THE INFLUENCE OF BUOYANCY EFFECT.

Line $a: \frac{\overline{N u}}{N_{O}, F-A}=1.008\left(\frac{R a}{P r^{2 / 3} R^{3 / 2}}\right)^{0.1}$ 
CHAPTER 5

EFFECT OF VARIATION OF PROPERTIES ON HEAT TRANSFER TO ISOBUTANE FLOW ING INS IDE A HOR IZONTAL TUBE AT SUPERCR ITICAL PRESSURE

5-1. Introduction.

In the previous chapter, heat transfer to isobutane results obtained for Eckert number, $E=\frac{T_{p . c}-T_{b}}{T_{w}-T_{b}}$, greater than unity were compared with available results. In addition, the effect of free convection was assessed.

In this chapter, the second set of data for runs with $0 \leq E \leq 1$ and runs with Eckert number transitioning from positive to negative will be assessed. In this range of Eckert number, the pseudocritical temperature of isobutane, $T_{p . c}$, is either $T_{b}<T_{p . c}<T_{w}$ when $0 \leq E \leq 1$ as illustrated on Fig. $1-2$ or $T_{w}>T_{b}>T_{p . c}$. when $E$ is negative as shown on Fig. 1-3. Because the runs with $E$ being negative throughout the heater tube are few, they are combined with the other runs for assessment. For both ranges of Eckert number, significant variation of properties occurs across the section of the tube even for small temperature differences.

The general conclusion drawn by most of the recent investigators of heat transfer to fluids at supercritical pressure has been that the large variation of physical properties of the fluid in the pseudocritical temperature region causes the widely divergent heat-transfer coefficients that are obtained from experiments. None of the models such as pseudonucleate boiling, and pseudo-film boiling has fully succeeded in explaining the phenomena of heat transfer found by means of experimentation. Therefore, the experimental results obtained in this study will be 
compared with the available results of those investigators which support the hypothesis that it is the large variation of properties that causes the divergent heat transfer coefficients that are obtained.

\section{5-2. Available Experimental Results.}

5-2-1. Results of Adebiyi and Hall.

Adebiyi and Hall investigated the heat transfer to carbon dioxide at supercritical pressure using an electrically-heated horizontal tube. They obtained the following results:

(i) The temperature of the wall along the horizontal tube was not uniform circumferentially.

(ii) Their experimental data indicated a lower value of $h=\frac{g / A}{T_{w}-T_{b}}$ at the top of the tube and a higher value at the bottom.

(iii) They tested two criteria for onset of buoyancy effects in horizontal flow using their experimental results. The criteria were:

(a) $\operatorname{Gr}_{b} \operatorname{Re}_{b}^{-2}\left(\frac{\rho_{b}}{\rho_{w}}\right)\left(\frac{x}{D}\right)^{2}<10$ with $G r_{b}=\frac{\rho_{b}-\rho_{w}}{\rho_{b}} \frac{g D^{3}}{2}$

(b) $\operatorname{Gr}_{b}^{*} \operatorname{Re}_{b}^{-2.75} \operatorname{Pr}_{b}^{-0.5}\left[1+2.4 \operatorname{Re}_{b}^{-1 / 8}\left(\operatorname{Pr}^{2 / 3}-1\right)\right]^{-1}<3 \times 10^{-5}$ with $\mathrm{Gr}^{*}=\mathrm{GrNu}$

The results of their experiment had all exceeded the values given by those criteria, so they concluded that their data did not constitute a test of these criteria. 
One major deficiency of their data presentation was the lack of presentation of data in terms of heat transfer coefficients or Nusselt numbers with dimensionless axial distance, $x / D$. For one test condition reproduced on Fig. 5-1, Test code 3.3, they presented temperature distributions at five angular locations along the heater tube at $x / D=8,21,34,49,62,76$ and 89 . From these temperatures, a circumferentially averaged temperature, $T_{W}$, at each axial location was calculated and plotted on Fig. 5-2. On the same figure, the wall temperatures at $\phi=0^{\circ}, 45^{\circ}$ and $180^{\circ}$ were also plotted. Since only the inlet and outlet bulk temperatures of the carbon dioxide were given, a straight line bulk temperature distribution was plotted with the assumption that the specific heat $C_{p}$ was constant along the tube. This assumption might be justified because the bulk temperature was below the pseudocritical temperature, $T_{p . c .}$, of carbon dioxide at the test pressure along the length of the tube. In addition, Adebiyi and Hall gave a bulk temperature at $x / D=100$ for the run based on their heat balance calculation and this temperature was only slightly higher than the temperature obtained from the assumed bulk temperature profile: By using the averaged wall temperature and bulk temperature, the value of $E$ along the axis locations were calculated al so and the range of $E$ decreased from 0.60 at inlet to 0.13 at $x / 0=89$. 


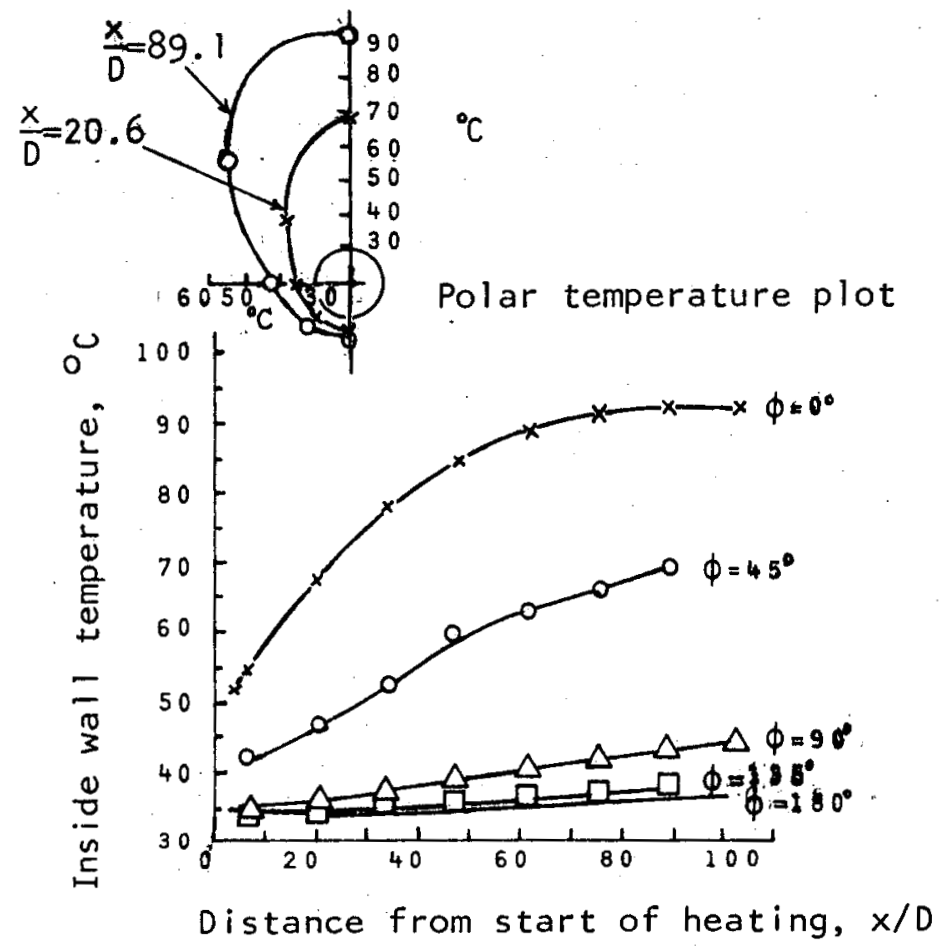

EXPER IMENTAL COND ITIONS

\begin{tabular}{|c|c|c|c|c|c|}
\hline $\begin{array}{l}\text { Test } \\
\text { code } \\
\end{array}$ & $\begin{array}{l}\text { Mass } \\
\text { flow } \\
\text { rate } \\
(\mathrm{kg} / \mathrm{s})\end{array}$ & $\begin{array}{c}\text { Inlet } \\
\text { bulk } \\
\text { tem- } \\
\text { perature } \\
\left({ }^{\circ} \mathrm{C}\right)\end{array}$ & $\begin{array}{c}\text { Average } \\
\text { heat } \\
\text { flux } \\
\left(\mathrm{kW} / \mathrm{m}^{2}\right)\end{array}$ & $\begin{array}{c}\text { Outlet } \\
\text { bulk } \\
\text { tem- } \\
\text { perature } \\
(\mathrm{C})\end{array}$ & $\begin{array}{c}\text { Test } \\
\text { pressyre } \\
\left(\mathrm{MN} / \mathrm{m}^{2}\right)\end{array}$ \\
\hline 3.3 & 0.0776 & 21.1 & 21.4 & 30.8 & $\therefore 7.607$ \\
\hline
\end{tabular}

Fig. 5-1. Experimental axial and circumferential temperature distribution and experimental conditions for test 3.3 of Adebiyi and Hall [8]. 


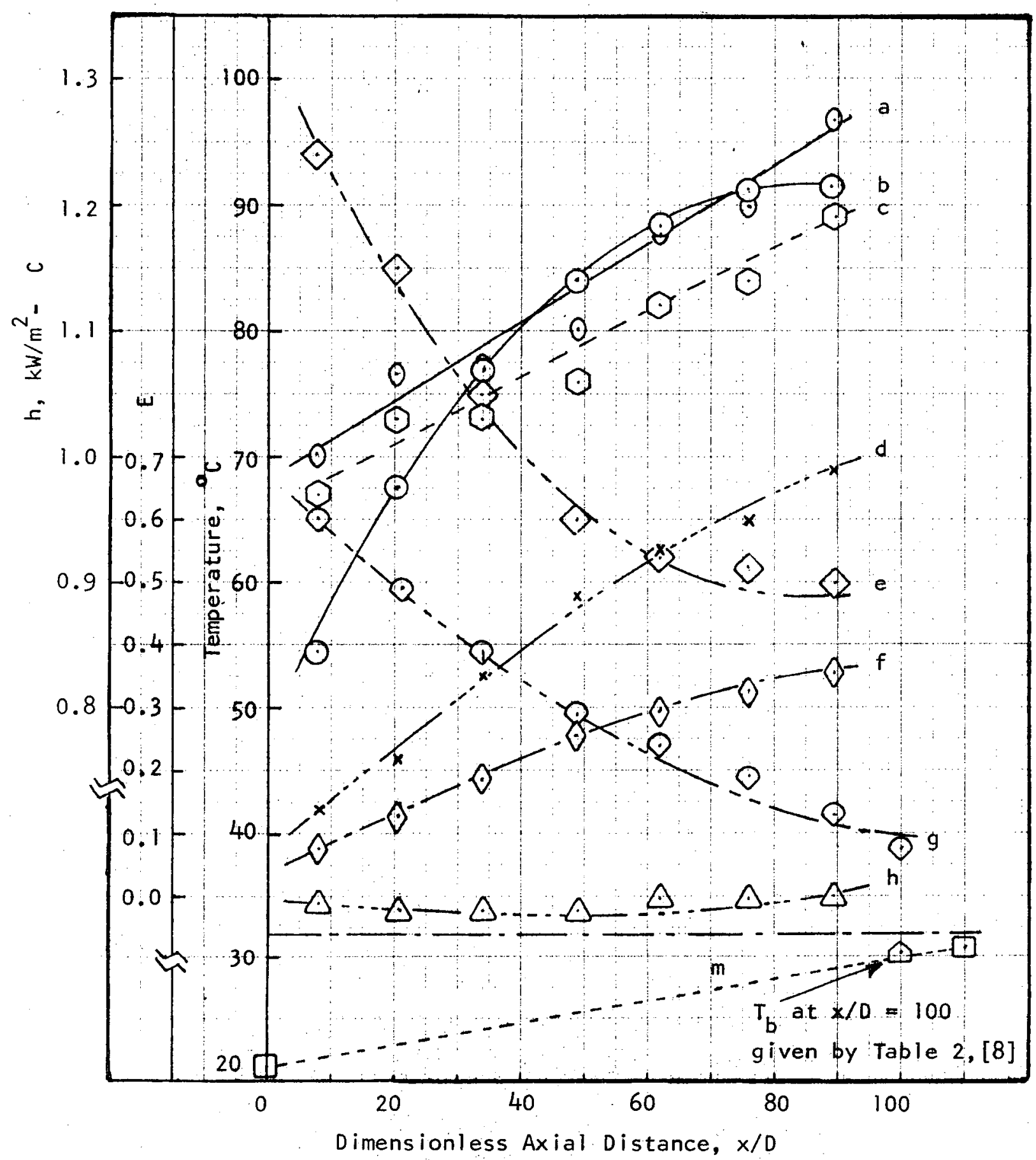

Fig. 5-2. Experimental Results of Test Code 3.3 of Adebiyi and Hall [8]. 


\section{(Continuation of Figure 5-2}

from previous page)

Comparison of local heat transfer coefficient measured with the predicted values:

Curve a: Jackson's correlation without the correction terms;

$$
\mathrm{Nu}=0.0183 \operatorname{Re}_{\mathrm{b}}^{0.82} \operatorname{Pr}_{\mathrm{b}}^{0.5}
$$

Curve c: Dittus-Boelter correlation.

Curve e: Experimental heat transfer coefficient, $h=\frac{q_{w}}{\left(\bar{T}_{w}-T_{b}\right)}$.

Temperature distribution along the tube:

Curve b: $T_{w}$ at the top of the tube, $\phi=0^{\circ}$.

Curve $d: T_{W}$ at $\phi=45^{\circ}$.

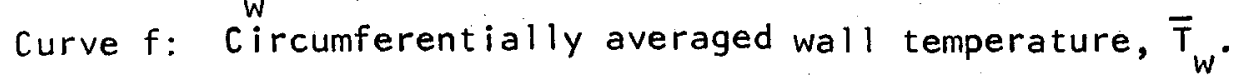

Curve $h: T_{W}$ at the bottom of the tube, $\phi=180^{\circ}$.

Curve m: Bulk temperature, $T_{b}$, based on the constant $C_{p}$ assumption.

Curve g: Variation of Eckert number, E, along the tube. 
The heat transfer coefficients for their experiments, though not presented in Hall's paper, could be calculated for Test Code 3.3 for which the peripheral variation of wall temperature was given as shown on Fig. 5-1. Taking the peripheral average of the wall temperature at a location, the heat transfer coefficient can be evaluated as:

$$
\begin{aligned}
& h_{E X P}=\frac{q_{W A L L}}{\bar{T}_{W}-T_{b}} \\
& \bar{T}_{W}=\text { Peripherally averaged wall temperature. }
\end{aligned}
$$

The coefficient, $h_{\text {Exp }}$ is plotted on Fig. $5-2$ and it decreases along the length of the heated section as expected.

In addition, the heat transfer coefficient, $h_{D-B}$, based on the Dittus-Bcelter correlation is calculated and plotted on Fig. $5-2$. Since the properties of $\mathrm{CO}_{2}$ at $7.6 \mathrm{mN} / \mathrm{m}^{2}(1102 \mathrm{psia})$ are not readily available to the author, the properties at 1200 psia as plotted on Fig. 5 and 6 of Bringer and Smith [10] for the temperature range of $70^{\circ} \mathrm{F}$ to $120^{\circ} \mathrm{F}\left(21.1^{\circ} \mathrm{C}\right.$ to $\left.48.9^{\circ} \mathrm{C}\right)$ are used for the calculation. Therefore, $\mathrm{Re}_{b}$ and $\mathrm{Pr}_{b}$ are approximate values based on the properties at 1200 psia. The resulting $h_{D-B}$ is shown to increase with $x / 0$.

Hall also introduced an equation given by Jackson for the specification of heat-transfer coefficient to water and $\mathrm{CO}_{2}$ in which the buoyancy effects are not present. This equation is:

$$
N_{0}=0.0183 \operatorname{Re}_{b}^{0.82} \operatorname{Pr}_{b}^{0.5}\left(\frac{\rho_{w}}{\rho_{b}}\right)^{0.5}\left(\frac{\bar{c}_{p}}{c_{P_{b}}}\right)^{0.4}
$$




$$
\text { where } \begin{aligned}
\bar{C}_{p} & =\frac{i_{w}-i_{b}}{T_{w}-T_{b}} \\
i_{w} & =\text { Enthalpy of the fluid at the wall. } \\
i_{b} & =\text { Enthalpy of the fluid at bulk temperature. }
\end{aligned}
$$

The available information on the properties of $\mathrm{CO}_{2}$ from Bringer and Smith is insufficient to evaluate $\bar{c}_{p}$, therefore, Jackson's correlation without the factors, $\left(\rho_{w} / \rho_{b}\right)^{0.5}\left(\bar{c}_{p} / c_{p_{b}}\right)^{0.4}$, is used to predict the heat-transfer coefficient along the length of the heated section. The calculated h Jackson, uncorrected is also plotted on Fig. 5-2 and exceeds $h_{D-B}$ by about $5 \%$.

For Test Code 3.3, Hall calculated a wall temperature, $T_{w, 0^{\prime}}$ at $x / D=100$, which would satisfy Eq. 5-4 when the bulk temperature was $30.3^{\circ} \mathrm{C}$ at the same location. The temperature $T_{W, 0}$ was $47.9^{\circ} \mathrm{C}$ and the heat-transfer coefficient calculated from Eq. $5-3$ is $1.22 \mathrm{~kW} / \mathrm{m}^{2}-{ }^{\circ} \mathrm{C}$. This value is quite close to the prediction by Dittus-Boelter correlation and much higher than the extrapolated experimental value which is $0.895 \mathrm{~kW} / \mathrm{m}^{2}-{ }^{\circ} \mathrm{C}$, as shown on Fig. 5-2. Therefore the results of Hall's experiment indicated that for Test Code 3.3 at $x / D=100$, the total reduction in the heat transfer coefficient was $31 \%$, of which $5 \%$ could be attributed by the factors $\left({ }^{\rho_{w}} / \rho_{b}\right)^{0.5}\left(\bar{c}_{p} / c_{p_{b}}\right)^{0.4}$ and $26 \%$ was due to buoyancy effect.

5-2-2. The results of Yamagata, et al, for water at supercritical pressure.

Yamagata, et al, investigated the heat transfer to supercritical water flowing inside an electrically heated tube for 
horizontal, vertically upward and downward flows. Two kinds of results were obtained from their experiment:

(i) At low or moderate heat fluxes, a peak in the heat transfer was obtained near the neighborhood of the pseudocritical temperature of water for both horizontal and vertically upward and downward flows. Thus the peak value is not associated with a free convection effect. The peak value of the heat transfer coefficient decreased with increasing heat flux at constant pressure and mass flow rate. Yamagata, et al, obtained a correlation for the heattransfer coefficient based on their results for vertically upward flow with low and moderate ratios of heat fluxes to mass flow rate. The correlation was based on a DittusBselter type of correiation with an additional correction factor, $F_{c}$. The correction factor $F_{c}$ depended on the value of Eckert Number, E.

$$
E=\frac{T_{p \cdot c \cdot}-T_{b}}{T_{w}-T_{b}}
$$

This dimensionless number could be employed to designate the state of the supercritical fluid over a cross section of the tube.

For $E>1$, the fluid could be assumed to be liquid over a cross section.

For $E<0$, the fluid could be considered as vapor over a cross section, if the variation of properties was small. 
For $0 \leq E \leq 1$, the fluid could be considered in the pseudocritical region with large variation of properties within a small temperature range. The state of the fluid could not be clearly defined across the tube.

The correlation obtained was:

$$
\begin{aligned}
& N u_{b}=0.0135 \operatorname{Re}_{b}^{0.85} \mathrm{Pr}_{b}^{0.8} \mathrm{~F}_{c} \\
& F_{c}=1.0 \text { for } E>1 \\
& F_{c}=0.67 \operatorname{Pr}_{p . c .}^{-0.05}\left(\frac{\bar{c}_{p}}{c_{p_{b}}}\right)^{n_{1}} \text { for } 0 \leq E \leq 1 \\
& F_{c}=\left(\frac{\bar{c}_{p}}{\bar{c}_{p_{b}}}\right)^{n_{2}} \text { for } E<0 \\
& n_{1}=-0.77\left(1+\frac{1}{p r_{\text {p.c. }}}\right)+1.49 \\
& n_{2}=1.44\left(1+\frac{1}{\operatorname{Pr}_{\text {p.c. }}}\right)-0.53 \\
& \operatorname{Pr}_{\text {p.c. }}=\text { Prandt number evaluated at the pseudocritical } \\
& \text { temperature. } \\
& \bar{C}_{p}=\text { the integrated average specific heat over the } \\
& \text { cross section of the tube. } \\
& =\frac{i_{w}-i_{b}}{T_{w}-T_{b}} \\
& i_{w}=\text { enthalpy of the fluid at the wall. } \\
& i_{b}=\text { enthalpy of the fluid at the bulk temperature. }
\end{aligned}
$$


Yamagata, et al, presented a plot of $\left(\mathrm{Nu}_{b} / 0.0135 \mathrm{Re}_{b}^{0.85}\right.$ $\left.\operatorname{Pr}_{b}^{0.8}\right)$ vs. $\bar{C}_{p} / C_{p_{b}}$ for their experimental results for supercritical water on Fig. 11 of their paper. Referring to that figure, the values of $F_{c}$ are less than unity when $\leq E \leq 1$ and $E<0$. The reduction in the value of $\mathrm{Nu}_{b}$ for data with $\mathrm{E}<1$ with respect to the $\mathrm{Nu}_{\mathrm{b}}$ obtained from data with $E>1$ did not imply corresponding reduction in the value of heat transfer coefficient, $h$. With $\mathrm{Nu}_{b}$ equaling $\frac{h D}{k_{b}}$ and the value of $k_{b}$ exhibiting a sharp decrease in the neighborhood of pseudocritical temperature, the value of $h$ may still increase despite decreasing values of $\mathrm{Nu}_{b}$ for $0<E<1$. Yamagata reported that this correlation, Eq. (5-4), correlated most of their data to within $\pm 20 \%$, except for a few data points near $E=0$ or $E=1$.

(ii) At high heat flux compared to flow rate and for vertically upward flow, the measured wall temperature fluctuated along the axis of the tube. The wall temperatures were also higher than the predicted values using the correlation, Eq. $(5-4)$, obtained in Part (i). Thus a significant reduction in heat transfer coefficient was observed. Yamagata obtained a relationship between the limiting heat flux with mass velocity for deterioration in heat transfer to supercritical water and vertically upflow as

$$
q_{c}=0.20 G^{1.2}
$$

where $q_{c}=$ Heat flux per unit area.

G = Mass velocity per unit area. 
This correlation was also validated by the results of Shitsman, Vikrev and Ackerman, as shown on Fig. 5-3. For horizontal flow, the results on heat transfer to water at supercritical pressure were presented as variation of $T_{w}$ with bulk enthalpy and heat transfer coefficient in relation to bulk temperature and wall temperature. Under conditions of constant pressure and mass flow rate, the temperatures at the top did not differ from those at the bottom of the horizontal tube when the heat flux was lowest. At moderate heat fluxes, the temperature difference between the top and bottom of the tube increased for increasing heat flux. In terms of variation of heat transfer coefficient, $\frac{q_{w}}{\left(T_{w}-T_{b}\right)}$, with the bulk temperature, the heat transfer coefficient exhibited a peak value in the neighborhood of the pseudocritical temperature for all the low or moderate heat flux runs. At the lowast heat flux, the values of heat transfer coefficient were almost equal for horizontal flow and vertically upward and downward flows. At moderate heat flux, the highest heat transfer coefficient occurred at the bottom of the horizontal tube and the lowest at the top of the tube. Intermediate between these two values were the heat transfer coefficients of vertically downward and upward flow obtained under the same conditions, as shown on Fig. $5-4$. 


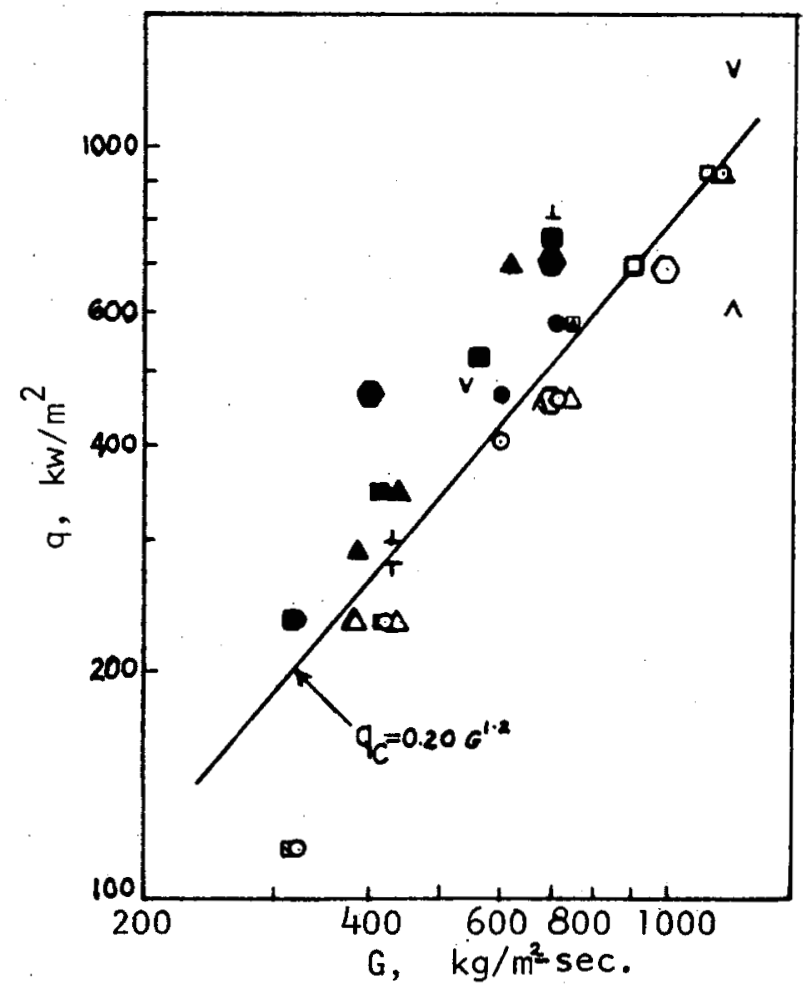

Fig. 5-3. RESULT OF YAMAGATA, et al, FOR LIMITING HEAT FLUX VS. MASS VELOCITY FOR DETERIORATION IN HEAT TRANSFER.

\begin{tabular}{lccc} 
& P bar & DETER IORATION & NO \\
& DETER IORATION \\
\hline Yamagata & 226 & $\Delta$ & $\Delta$ \\
& 245 & - & 0 \\
Shitsman & 294 & $\mathbf{0}$ & $\square$ \\
Vikrev & $226-293$ & $\mathbf{1}$ & $\mathbf{T}$ \\
Ackerman & 228,310 & $\mathbf{v}$ & $\Lambda$ \\
\hline
\end{tabular}



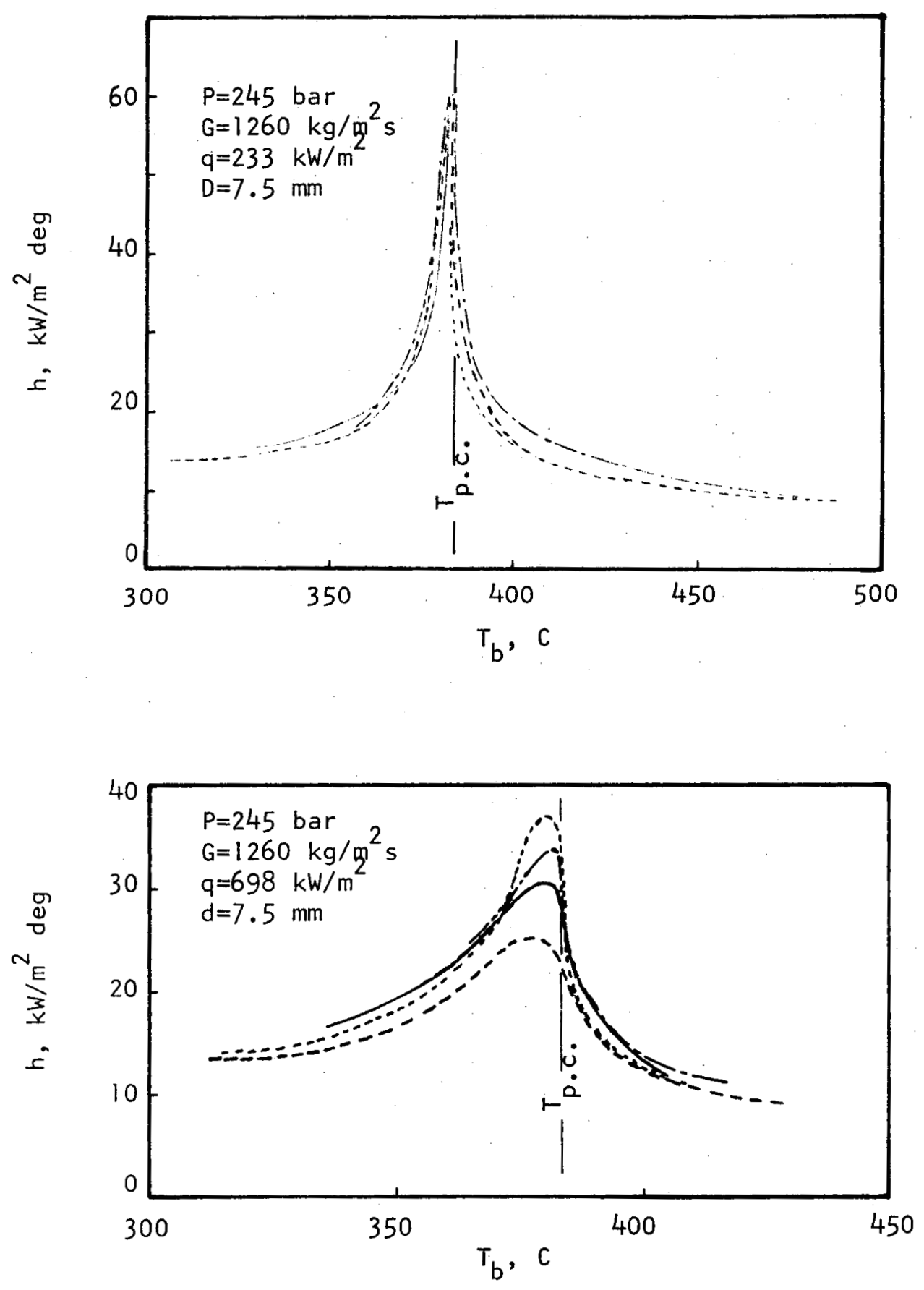

Fig. 5-4. An illustration of the results by Yamagata, et al, on the comparison of heat transfer coefficients for flows in various directions: (top) at low heat flux, (bottom) at high heat flux.

Vertically upward Vertically downward $-\quad$ Horizontal $\begin{cases}\text { Top } & -\cdots- \\ \text { Bottom } & \cdots-\cdots\end{cases}$ 
5-2-3. Experimental Results of Other Investigators on Heat Transfer to Fluids at Supercritical Pressure for Vertical Flow.

Almost all of the recent experimental investigations on heat transfer to fluids at supercritical pressure employed a verticallyoriented electrically-heated tube as test section. The results reported for vertically upflow indicated that a peak in the wall temperature occurred as heat flux was increased relative to the mass flow rate $[5,6]$. However, this peak in wall temperature was not observed by Bourke, et al, for vertically downward flow for the same variation of wall heat flux.

Brassington and Cairns [7] reported their experimental data for supercritical helium in vertically upward flow, showing a peak in wall temperature was measured whenever

$$
\mathrm{Gr} / \operatorname{Re}^{2.7}>2.4 \times 10^{-5}
$$

Hall [8] suggested that buoyancy effect induced the degradation in heat transfer, consequently a peak in wall temperature occurred. His criterion for the onset of buoyancy effect in vertical upflow iș

$$
\frac{G r}{R e^{2.7}}>1.2 \times 10^{-5}
$$

Griffith and Shiralkar [6] reported that they could not observe any difference between upward and downward flow for carbon dioxide at supercritical pressure flowing in a $1 / 8$ in. diameter tube. They showed that for both upward or downward flow, a peak in wall temperature was always measured in the neighborhood of the pseudocritical enthalpy at various heat fluxes. Thus, the reduction in 
heat transfer coefficient measured for vertical flow could not be due to buoyancy effect alone, but to the large variation in properties in the pseudocritical temperature region as well.

A summary of the equations discussed so far on the available experimental results are listed on Table $5-1$.

Fig. 5-5 compares Yamagata's correlation with $F_{c}=1$ against the correlations specified by Dittus-Boelter, Sieder-Tate, Petukhov and Jackson.

\section{5-3. Experimental Nusselt Numbers.}

5-3-1. Runs with $0.01 \leq E \leq 1$ Along the Whole Length of the Heater Tube.

The experimental data for runs with $0.01 \leq E \leq 1$ along the length of the heater tube are tabulated on Table B-2 of Appendix B. The experimental Nusselt numbers are compared with DittusBoelter correlation on Fig. 5-6, Sieder-Tate correlation on Fig. 5-7, and the correlation given by Yamagata on Fig. 5-8.

Fig. 5-6 shows that the data points are all above the DittusBoelter correlation line when the constant coefficient is taken to be 0.023 . If the constant is increased to 0.028 , which is the value recommended in Section 4-3 for data with $E>1$, then the data points can be specified to within $\pm 18 \%$. The experimental data obtained by Hall and Adebiyi are also plotted on Fig. 5-6. As already implied by the heat transfer coefficients that are shown on Fig. 5-2, Hall's experimental Nusselt numbers are at first above and then at greater $x / D$ below the Dittus-Boelter 


\begin{tabular}{|c|c|c|c|c|}
\hline & ADEBIYI \& HALL & YAMAGATA, et al. & $\begin{array}{l}\text { BRASS INGTON } \\
\text { CAIRNS }\end{array}$ & BOURKE, et al. \\
\hline $\begin{array}{l}\text { OR IENTATION OF } \\
\text { TEST SECTION }\end{array}$ & HORIZONTAL & VERTICAL & VERTICAL & VERTICAL \\
\hline $\begin{array}{l}\text { NU, } \\
\text { NUSSELT NUMBER }\end{array}$ & - & $\begin{array}{l}\mathrm{Nu}_{0}=\mathrm{C}_{1} \mathrm{Re}^{0.85} \mathrm{Pr}^{0.8} \mathrm{Fc} \\
C_{1}=0.0135 \\
\mathrm{~F}_{\mathrm{c}} \text { is dependent on the } \\
\text { value of Eckert No. }\end{array}$ & $\begin{array}{l}N u=0.0931 \mathrm{Re}_{\mathrm{b}}^{0.687} \overline{\mathrm{Pr}}^{0.63} \\
\text { FOR DOWNFLOW } \\
N u=0.0602 \mathrm{Re}_{\mathrm{b}}^{0.718} \overline{\operatorname{Pr}}^{0.5}\left(\frac{\mathrm{T}_{\mathrm{w}}}{\mathrm{T}_{\mathrm{b}}}\right)^{-0.48} \\
\text { FOR UPFLOW }\end{array}$ & $\begin{array}{l}\text { Nu }=0.023 \mathrm{Re}^{0.8} \mathrm{Pr}^{0.3} \\
\text { (Away from critical } \\
\text { region) }\end{array}$ \\
\hline $\begin{array}{l}\text { Nu, HEAT TRANSFER } \\
\text { WITHOUT BUOYANCY } \\
\text { EFFECT }\end{array}$ & $\begin{aligned} H_{0}= & 0.0183 \operatorname{Re}_{b}^{0.82} \operatorname{Pr}_{b}^{0.5} \\
& \times\left(\frac{p_{w}}{\rho_{b}}\right)^{0.5}\left(\frac{\bar{c}_{p}}{c_{0}}\right)^{0.4}\end{aligned}$ & - & - & $\div$ \\
\hline $\begin{array}{l}\text { CRITERIA FOR } \\
\text { ABSENCE OF } \\
\text { BUOYANCY EFFECT } \\
\vdots\end{array}$ & $\begin{array}{l}\text { OV JACXSSON: } \\
\operatorname{Gr}_{b} R_{b}^{-2}\left(\frac{D}{\rho_{w}}\right)\left(\frac{x}{D}\right)^{2}<10 \\
\text { OY PETUKHOV: } \\
G r^{2} \operatorname{Re}_{b}^{-2.75} \operatorname{Pr}_{b}^{0.5} \\
\times\left[1+2.4 R_{b}^{-1 / 8}\left(\operatorname{Pr}_{b}^{2 / 3}-1\right)\right]^{-1} \\
<3 \times 10^{-5}\end{array}$ & - & $\begin{array}{l}\text { FOR VERTICAL UPFLOW } \\
\frac{\mathrm{Gr}}{\mathrm{Re}^{2.7}}<2.4 \times 10^{-5}\end{array}$ & - \\
\hline $\begin{array}{l}\text { CR ITER IA FOR } \\
\text { DE TER IORATION OF } \\
\text { HEAT TRANSFER }\end{array}$ & 一 & $\begin{array}{l}\text { FOR VERTICAL UPFLOW } \\
a_{c}=0.2 G^{1.2}\end{array}$ & - & - \\
\hline
\end{tabular}

Table 5-1. Summary of the Equations Discussed in Section 5-2. 


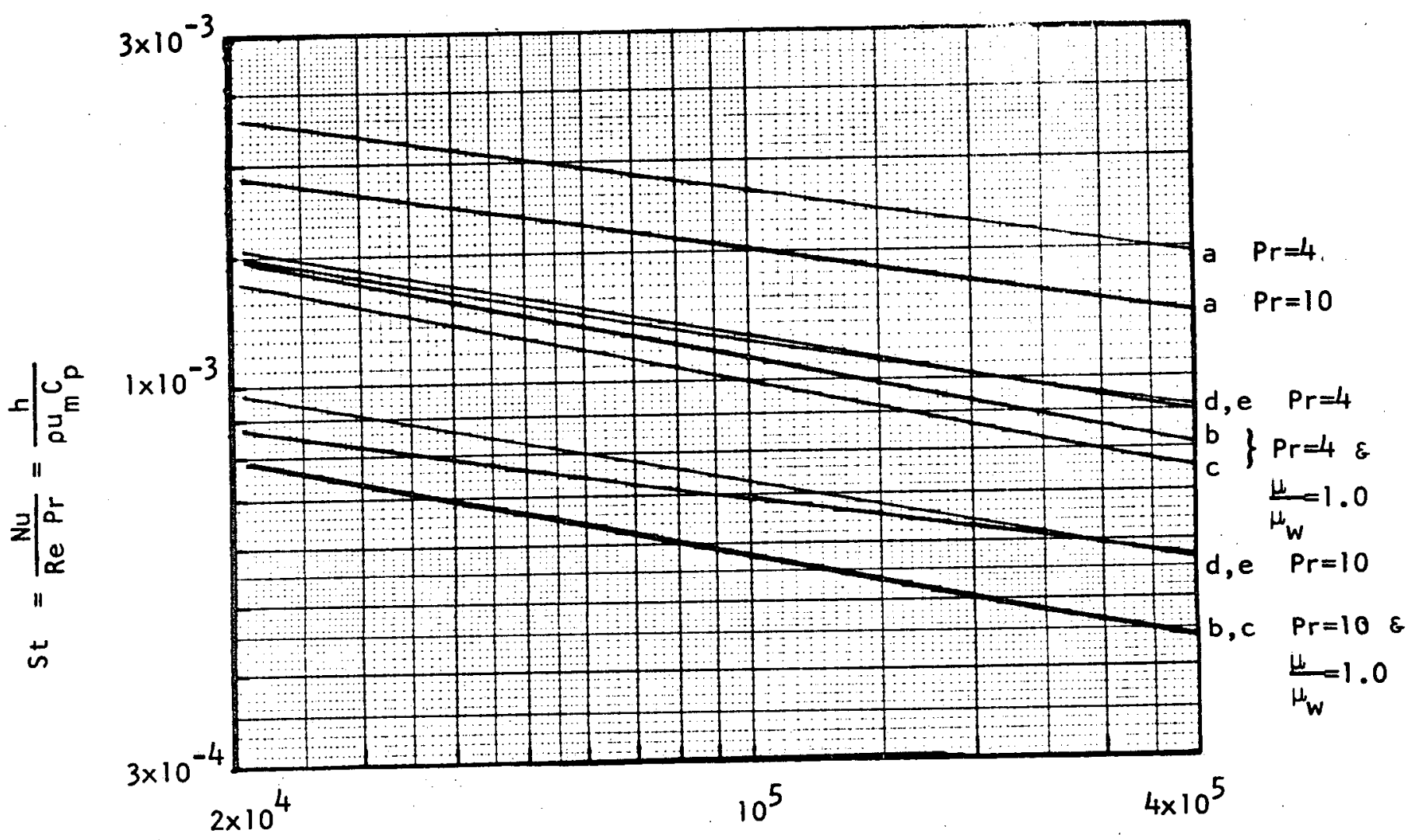

$$
\operatorname{Re} \text { No. }=\frac{\rho u_{m} D}{\mu_{b}}
$$

Fig. 5-5. Comparison of correlation obtained by Yamagata on heat transfer to water at supercritical pressure with other correlations used in Section 5-2.

Curve a: Yamagata correlation for $E>1$;

$$
\text { St }=0.0135 \operatorname{Re}_{b}{ }^{-0.15} \operatorname{Pr}_{b}-0.2
$$

Curve b: Sieder-Tate correlation;

$$
\text { St }=0.027 \operatorname{Re}^{-0.2} \operatorname{Pr}^{-2 / 3}\left(\frac{\mu}{\mu_{W}}\right) 0.14
$$

Curve c: Dittus-Boelter correlation;

$$
\text { St }=0.023 \mathrm{Re}^{-0.2} \mathrm{Pr}^{-0.6}
$$




\section{(Continuation of figure 5-5 \\ from previous page)}

Curve d: Petukhov correlation;

$$
\begin{aligned}
& S t=\frac{(f / 8)}{1.07+12.7 \sqrt{f / 8}\left(P r^{2 / 3}-1\right)} \\
& f=(1.82 \log \operatorname{Re}-1.64)^{-2}
\end{aligned}
$$

Curve e: Jackson uncorrected;

$$
\text { St }=0.0183 \mathrm{Re}^{-0.18} \mathrm{Pr}^{-0.5}
$$




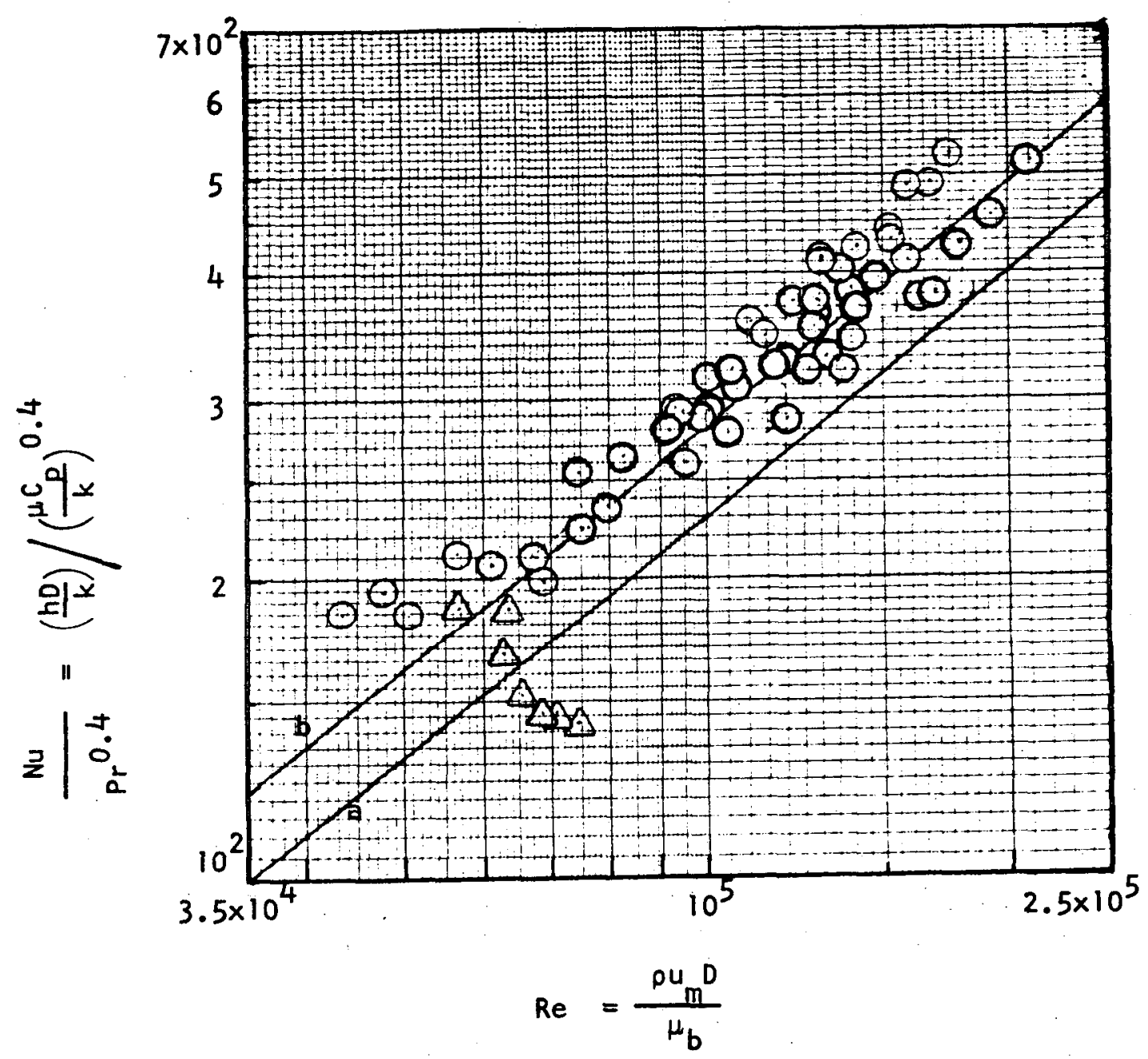

FIG. 5-6. COMPARISON OF DATA WITH DITTUS-BOELTER CORRELATION. DATA WITH $0<E<1$

$$
\begin{gathered}
\text { Line a: }{ }^{N u_{D-B}}=0.023 \operatorname{Re}^{0.8} \operatorname{Pr}^{0.4} \\
\text { b: } \mathrm{Nu}=0.028 \mathrm{Re}^{0.8} \operatorname{Pr}^{0.4}
\end{gathered}
$$

$\odot$ EXPERIMENTAL DATA FOR ISOBUTANE

$\triangle \quad$ HALL \& ADEBIYI'S DATA FOR $\mathrm{CO}_{2}$ CALCULATED BY AUTHOR 
correlation. The reduced pressure, $P_{r}$, for $\mathrm{CO}_{2}$ of Hall's experiment was 1.03 and the reduced pressure for this experiment with isobutane was 1.13 .

Figure 5-7 shows that Sieder-Tate correlation, which includes the factor $\left(\frac{\mu_{b}}{\mu_{w}}\right)^{0.14}$, to account for the variation of viscosity with temperature, predicts the data quite well. A new Sieder-Tate correlation 1 ine with the constant coefficient as 0.03 recommended in Section 4-3 does not predict the data points as well. The scatter of data points about the lower line on Fig. 5-7 is about $\pm 15 \%$

At this point it should be noted that Yamagata also compared his data for water with the Dittus-Boelter correlation by plotting his data as $\mathrm{Nu}_{b} / \mathrm{Re}_{b}^{0.8}$ vs. $\mathrm{Pr}_{b}$ and encountered a large scatter of data.

On Fig. 5-8, the experimental data are compared with Yamagata's correlation for $0 \leq E \leq 1$. This comparison is justified because the experimental heat flux, " STEAM" when plotted on Fig. 5-9 against mass velocity, $G$, is less than the limiting heat flux for deterioration of heat transfer and within the region for which Yamagata recommends the use of Eq. (5-4) to (5-9). From Fig. 5-8, alnost all the data points lie below the prediction line. The data occupy a narrow range of $\left(\bar{C}_{p} / C_{p_{b}}\right)$ and the scatter is greater than in the two previous figures. Therefore the equation proposed by Yamagata for $0 \leq E \leq 1$ does not improve the correlation of these experimental data over the sieder-Tate equation. 


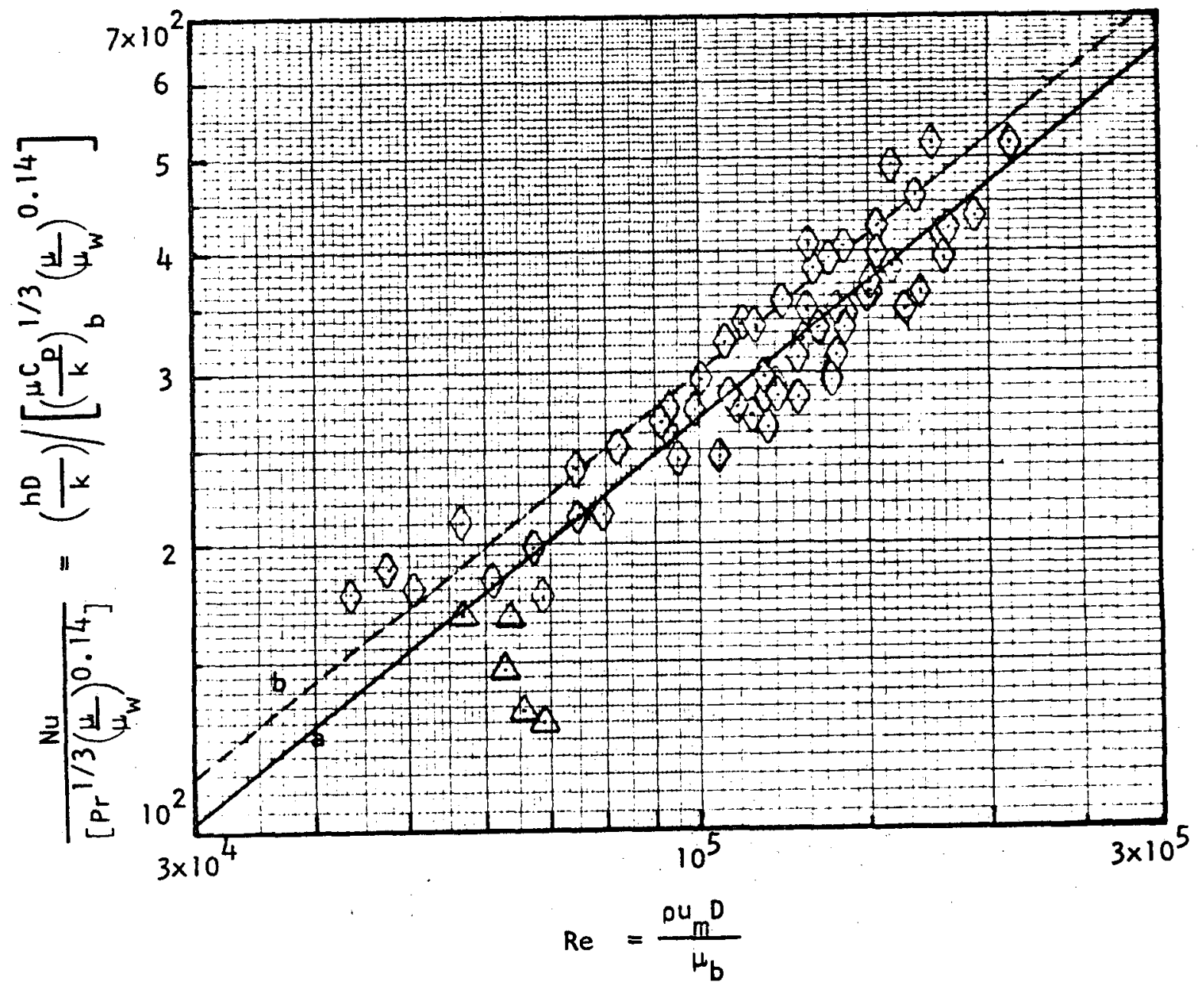

FIG. 5-7. COMPARISON OF DATA WITH SIEDER-TATE CORRELATION. DATA WITH $0<$ E $<1$.

Line $a: N_{S}-T=0.027 \operatorname{Re}_{b}^{0.8} \operatorname{Pr}_{b}^{1 / 3}\left(\frac{\mu}{\psi_{w}}\right)^{0.14}$
$b: N u=0.030 \operatorname{Re}_{b}^{0.8} \operatorname{Pr}_{b}^{1 / 3}\left(\frac{\mu}{\psi_{w}}\right)^{0.14}$

$\odot$ EXPER IMENTAL DATA

$\triangle$ DATA OBTAINED BY HALL \& ADEBIYI, TEST CODE 3.3 


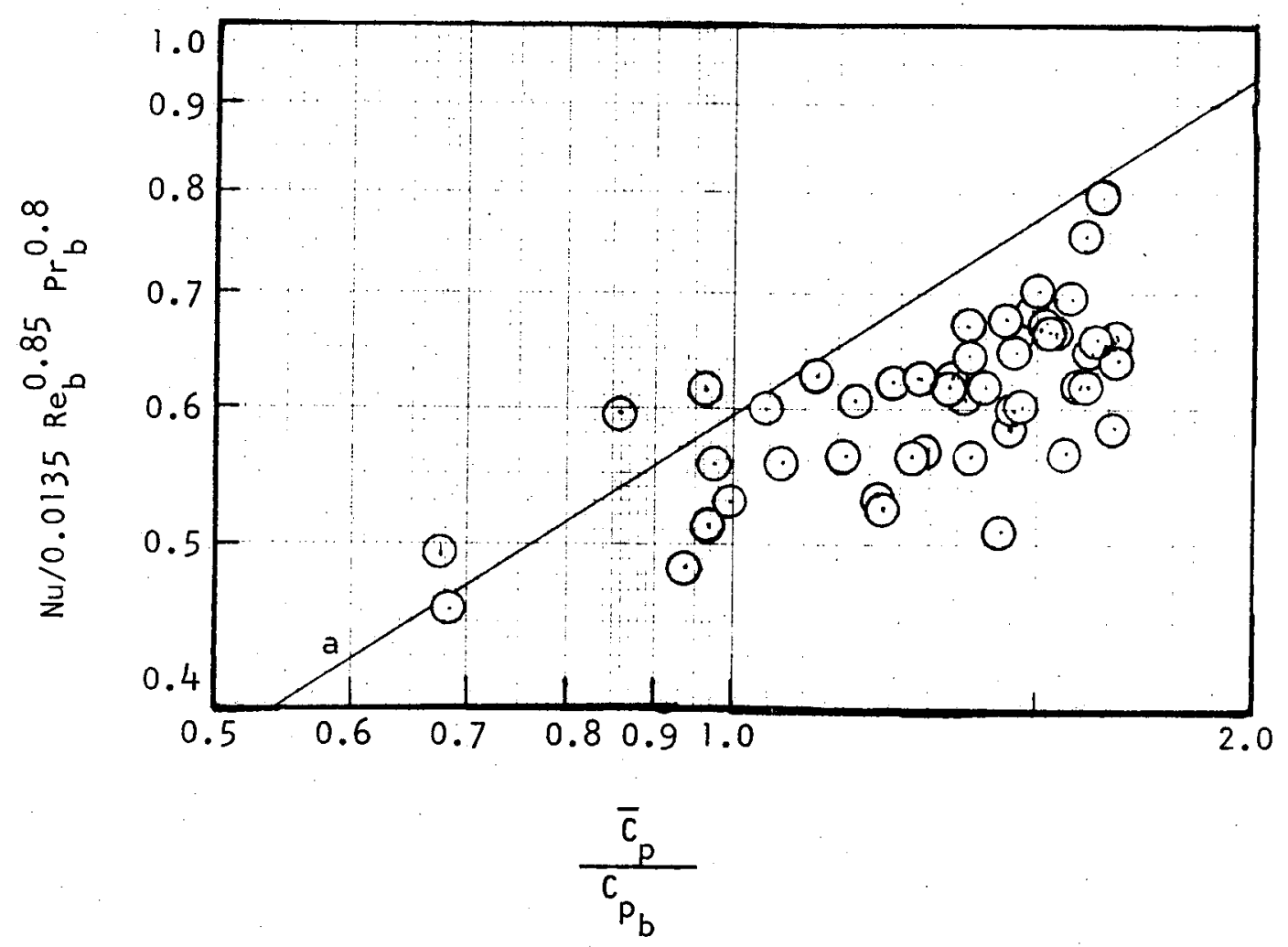

FIG. 5-8. COMPARISON OF EXPERIMENTAL DATA FROM TABLE B-2 WITH YAMAGATA'S CORRELATION.

Line a: Yamagata's correlation for $0<E<1$. 


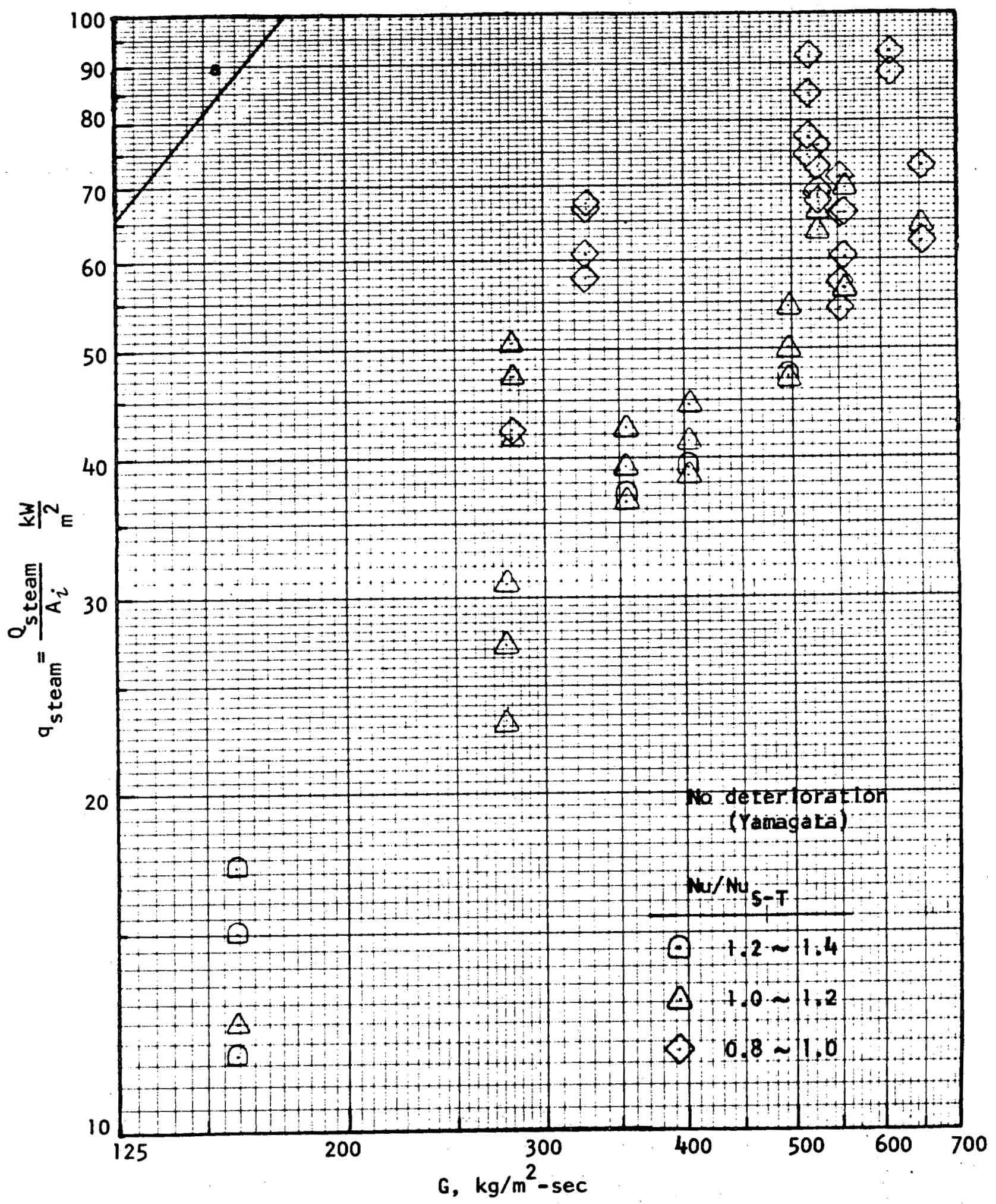

Fig. 5-9. Comparison of experimental data for 0sEsl with Yamagata's specification of limiting heat flux vs. mass velocity for deterioration in heat transfer. Curve a: $q_{c}=0.20 G^{1.2}$ (Yamagata) 
5-3-2. Runs with Eckert Number Changing from Positive to Negative along the Length of the Heater Tube.

In this set of experimental runs, the temperature of isobutane passes through the pseudocritical temperature, 'Tp.c.' inside the heater tube. Correspondingly, the Eckert number of isobutane changes from positive to negative along the length of the heater tube. This set of experimental data is tabulated on Table B-3 of Appendix B.

From Table B-3, Run 218 is selected for more detailed discussion and the experimental measurements for this run are plotted on Fig. 5-10. The Eckert number for the run changes from 0.25 near the inlet to -0.62 at station 5 . The figure shows that experimental bulk temperature, $T_{b}$, increases at a slower rate in the pseudocritical temperature region than away from it. This implies that the specific heat, $C_{p}$, has a larger value at the pseudocritical temperature region.

The experimental heat transfer coefficients, $h_{\text {EXP, for this }}$ run are compared with those heat transfer coefficients, $h$, calculated by the following correlations on Fig. 5-11:

(a) Yamagata's correlation with correction factor:

$$
\begin{array}{ll}
\mathrm{Nu} & =0.0135 \operatorname{Re}_{b}^{0.85} \operatorname{Pr}_{b}^{0.8} F(c) \\
F_{c}=0.67 \operatorname{Pr}_{p . c}^{-0.05}\left(\frac{\bar{c}_{p}}{c_{p_{b}}}\right)^{n_{1}} & 0 \leq E \leq 1 \\
F_{c}=\left(\bar{c}_{p} / C_{P_{b}}\right)^{n_{2}} & E<0
\end{array}
$$




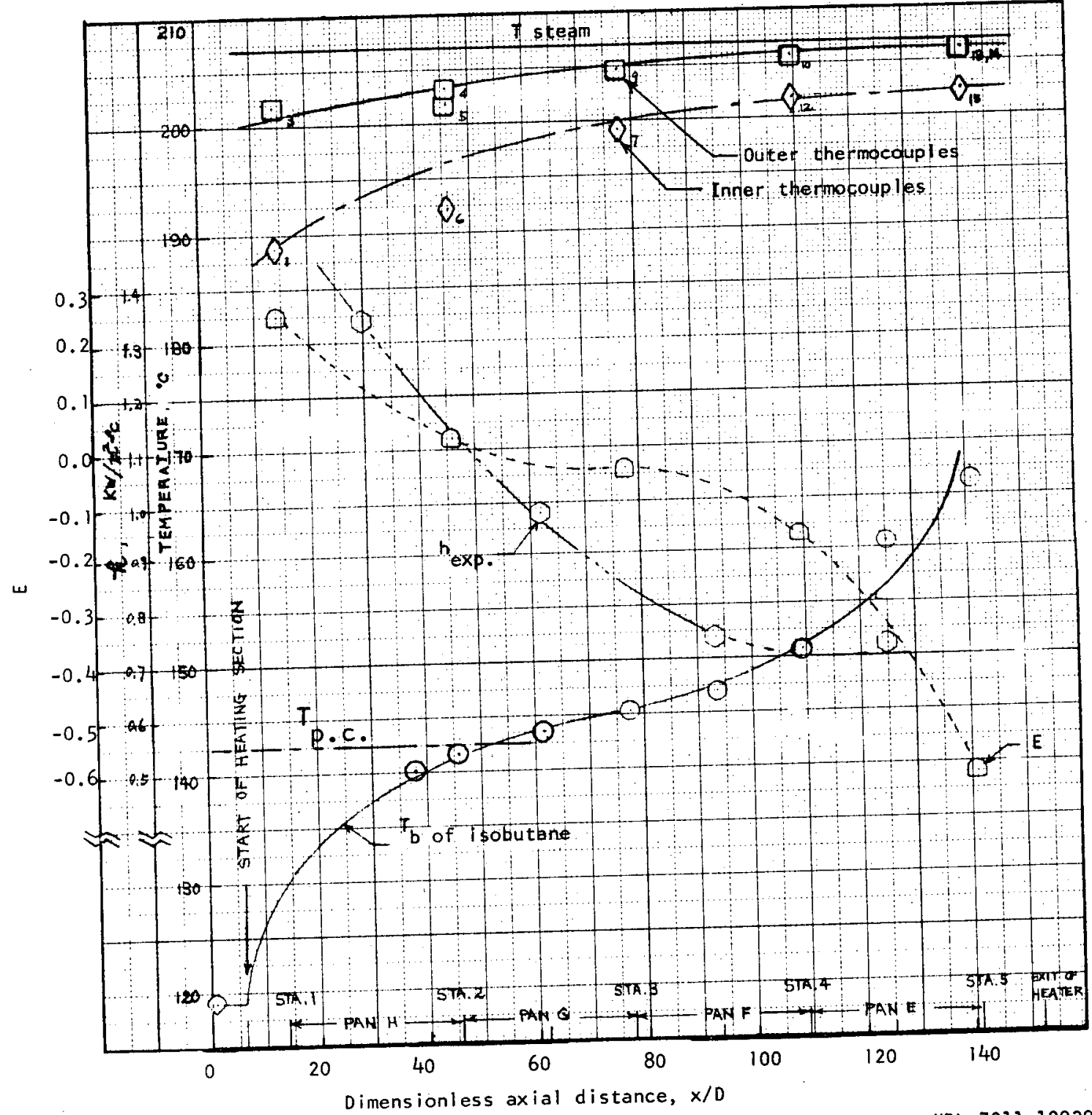

Fig. 5-10. Experimental measurements for run 218 .

XBL 7911-12838 
where $n_{1}=-0.77\left(1+\frac{1}{\operatorname{Pr}_{\text {p.c. }}}\right)+1.49=0.650$

$$
n_{2}=1.44\left(1+\frac{1}{\operatorname{Pr}_{\text {p.c. }}}\right)-0.53=1.041
$$

(b) Yamagata's correlation without correction factor:

$$
\mathrm{Nu}=0.0135 \operatorname{Re}_{b}^{0.85} \operatorname{Pr}_{b}^{0.8}
$$

(c) Jackson's correlation with correction factor:

$$
\mathrm{Nu}=0.0183 \operatorname{Re}_{b}^{0.82} \operatorname{Pr}_{b}^{0.5}\left(\frac{{ }^{0} w}{o_{b}}\right)^{0.5}\left(\frac{\bar{c}_{p}}{c_{P_{b}}}\right)^{0.4}
$$

(d) Jackson's correlation without correction factor:

$$
\mathrm{Nu}=0.0183 \operatorname{Re}_{b}^{0.82} \operatorname{Pr}_{b}^{0.5}
$$

(e) Dittus-Boelter correlation:

$$
\mathrm{Nu}=0.023 \operatorname{Re}_{b}^{0.82} \operatorname{Pr}_{b}^{0.4}
$$

(f) Sieder-Tate's correlation:

$$
\mathrm{Nu}=0.027 \mathrm{Re}_{\mathrm{b}}^{0.8} \mathrm{Pr}^{1 / 3}\left(\frac{\mu_{b}}{\mu_{w}}\right)^{0.14}
$$

(g) Petukhov's correlation:

$$
\begin{aligned}
& \mathrm{Nu}=\frac{\operatorname{Re} \operatorname{Pr}(f / 8)}{1.07+12.7\left(\operatorname{Pr}^{2 / 3}-1\right) \sqrt{f / 8}} \\
& f=(1.82 \log \operatorname{Re}-1.64)^{-2}
\end{aligned}
$$

From Fig. $5-11$, the experimentally measured heat transfer coefficients indicate a decreasing trend along the length of 


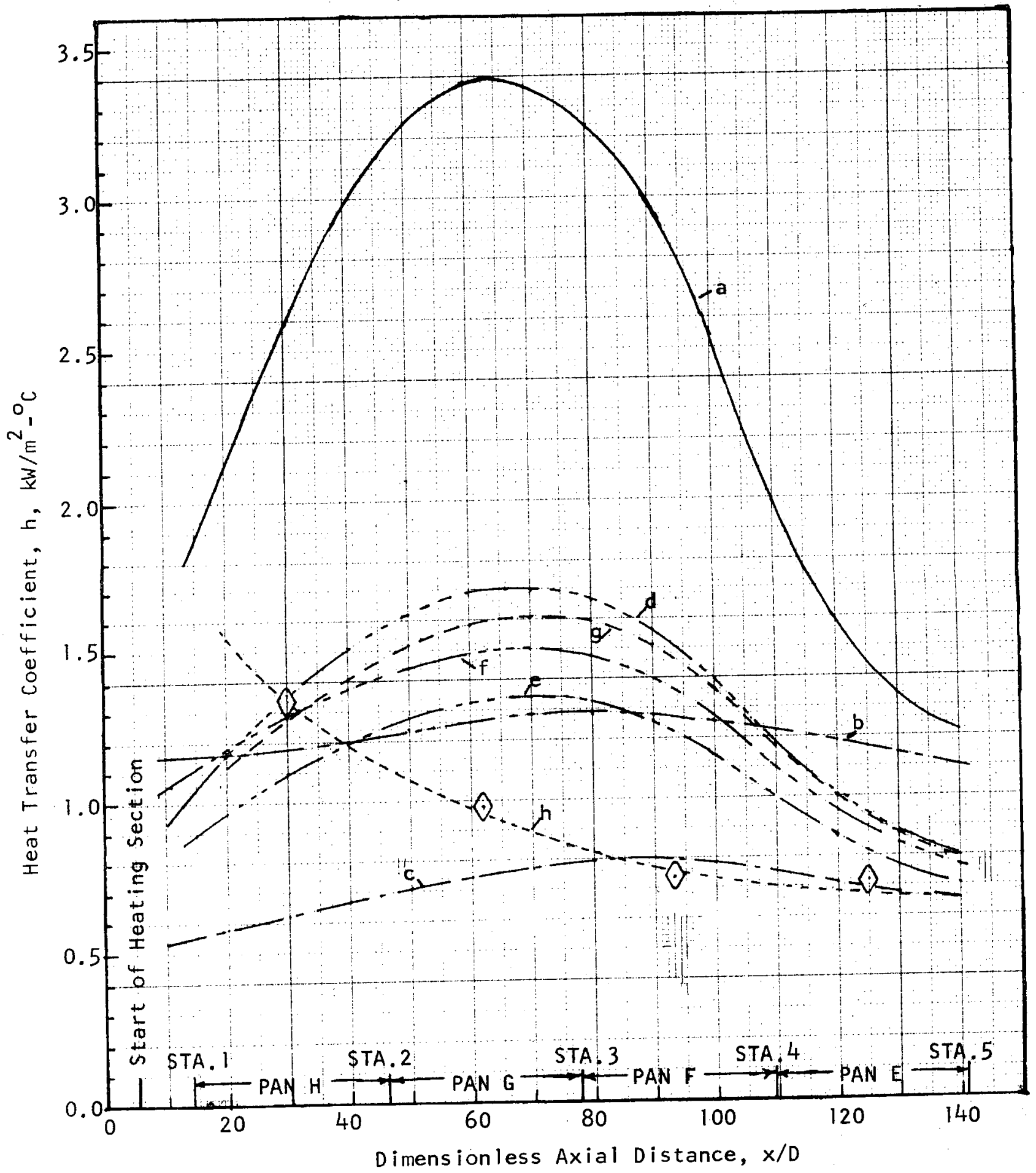

Fig. 5-11. Variation of Heat Transfer Coefficient Along the Heater Length Calculated by Various Correlations and Based on Experimental Measurements of Run 218. 


\section{(Continuation of Figure 5-11 \\ from previous page)}

Curve a: Yamagata's correlation with correction factor.

b: Yamagata's correlation without correction factor.

c: Jackson's correlation with correction factors.

d: Jackson.'s correlation without correction factor.

e: Dittus-Boeltor correlation.

f: Sieder-Tate's correlation.

g: Petukhov's correlation.

h: Experimental measurement, Run 218. 
the heater tube, whereas the calculated coefficients show a peak value within the heater length. This peak in value of heat transfer coefficient is largest for those correlations without the correction factors for properties variation. so that $h$, or $\mathrm{Nu}$, is proportional to $\mathrm{Pr}^{\mathrm{m}}$. Consequently, when $\mathrm{Pr}_{b}$ has a maximum value as $T_{b}$ passes through $T_{p . c}$, a peak value in $h$ is observed along the length of the heater tube. When the correction factor is applied to Yamagata and Jackson's equations, the value of $h$ is reduced and the peak is almost flattened out. Jackson's equation with the correction factors seems to predict the experimental results at $x / D>90$ very well. On the other hand, Yamagata's equation with a single correction factor for variation of $C_{p}$ with temperature predicts a higher value of $h$ than Jackson's equation. Therefore, the additional correction factor for density variation with temperature in Jackson's equation is necessary.

The experimental Nusselt numbers are again compared with the Dittus-Boelter correlation on Fig. 5-12, and with the SiederTate correlation on Fig. 5-13, and the Yamagata's correlation on Fig. $5-15$.

On Fig. 5-12, the data points are scattered about the prediction 1 ine by $\pm 55 \%$. The data points are separated into two groups according to their positive or negative $E$ value and they are distinguished by the point designation as shown on Fig. 5-12. The data points for E being positive lie predominately above the Dittus-Boelter 1 ine and the data points for $E$ being negative are mostly below the line. Thus for most of the runs a deterioration of heat transfer occurs after the 


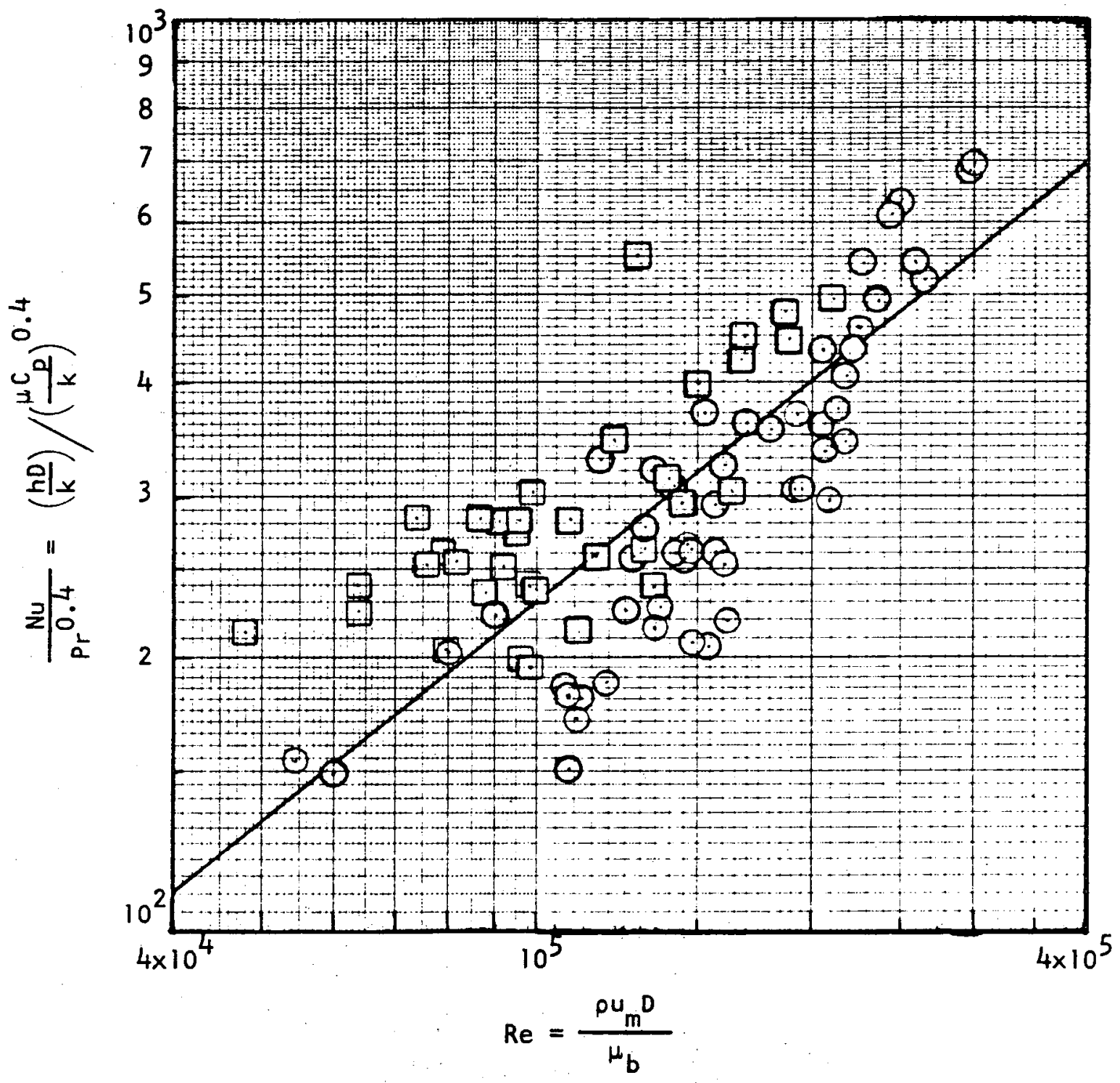

FIG. 5-12. COMPARISON OF EXPER IMENTAL DATA FROM TABLE B-3 WITH DITTUS-BOELTER CORRELATION.

Line a: $\mathrm{Nu}=0.023 \operatorname{Pr}_{\mathrm{b}}^{0.4} \operatorname{Re}_{\mathrm{b}}^{0.8}$

EXPER IMENTAL DATA

$\bigcirc \quad 0<E<1$

$\odot \quad E<0$ 
bulk temperature exceeds the pseudocritical temperature. Due to the large scatter of experimental data, the Dittus-Boelter correlation cannot be used to specify the data.

Fig. 5-13 compares the experimental data with the Sieder-Tate correlation. Most of the data points are below the prediction line and some are as much as $60 \%$ below the line. With such a large scatter of data points, the Sieder-Tate correlation also cannot be used to specify the data.

Before comparing the experimental data with Yamagata's correlation, the experimental heat fluxes, 9STEAM, tabulated on columns $12,20,28$ and 36 of Table $8-3$ are plotted against the isobutane mass velocity, $G$, on Fig. 5-14. The data points all lie within the region for which Yamagata recommends the use of his correlation. The ratio of $\mathrm{Nu}_{\text {ExP }} / \mathrm{Nu}_{S-T}$ for each experimental data point is also included on the figure and represented by the point designation.

On Fig. 5-15, the data points are compared with Yamagata's correlations for $0 \leq E \leq 1$ and $E<0$. The experimental data are predominately scattered about the line for $0 \leq E \leq 1$ and they failed to follow the prediction line for $E<0$. There is also a lack of data in the range when $E<0$.

At this point, it can be concluded that for those data with E passing through zero along the length of the heater: 


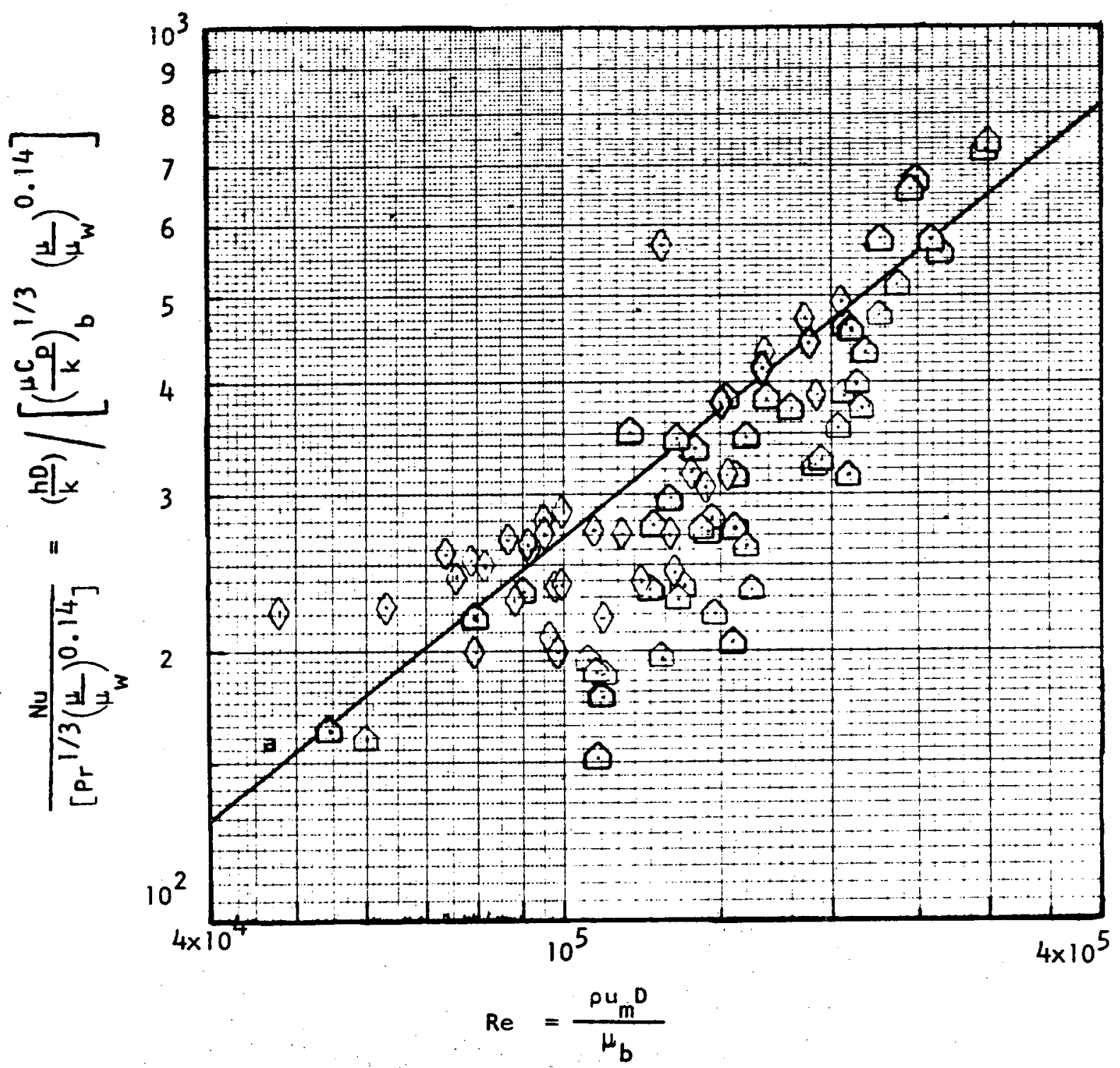

FIG. 5-13. COMPARISON OF EXPER IMENTAL DATA FROM TABLE B-3 WITH SIEDER-TATE CORRELATION.

Line a: $N u=0.027 \mathrm{Re}^{0.8} \operatorname{Pr}^{1 / 3}\left(\frac{\mu}{\mu_{W}}\right)^{0.14}$

$\begin{array}{rr}\ominus & 0<E<1 \\ \odot & E<0\end{array}$ 


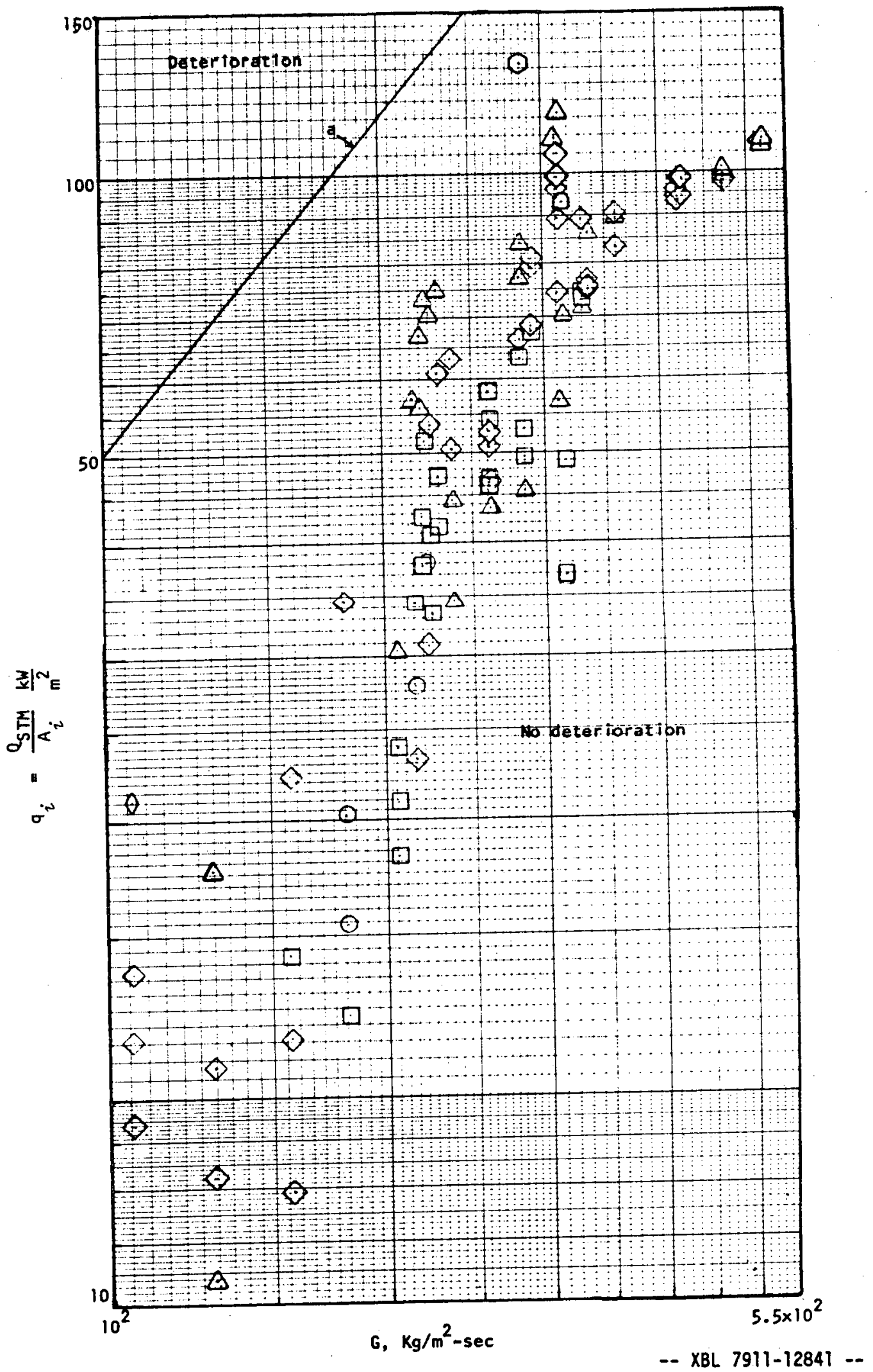

FIG. 5- H. COMPARISON OF EXPERIMENTAL DATA WITH YAMAGATA'S SPECIF ICATION OF LIMITING HEAT FLUX VS. MASS VELOCITY FOR DETERIORATION IN HEAT TRANSFER. DATA TAKEN FROM TABLE B-3. 


\section{(Continuation of Figure 5-14 \\ from previous page)}

Line a: $q_{C}=0.20 G^{1.2}$
$\mathrm{Nu} / \mathrm{Nu}_{\mathrm{S}-\mathrm{T}}$
- 1.6 to 1.8
$01.4 \sim 1.6$
C $1.2 \sim 1.4$
$\triangle 1.0 \sim 1.2$
$\odot 0.8 \sim 1.0$
$0.6 \sim 0.8$
$\odot 0.4 \sim 0.6$ 


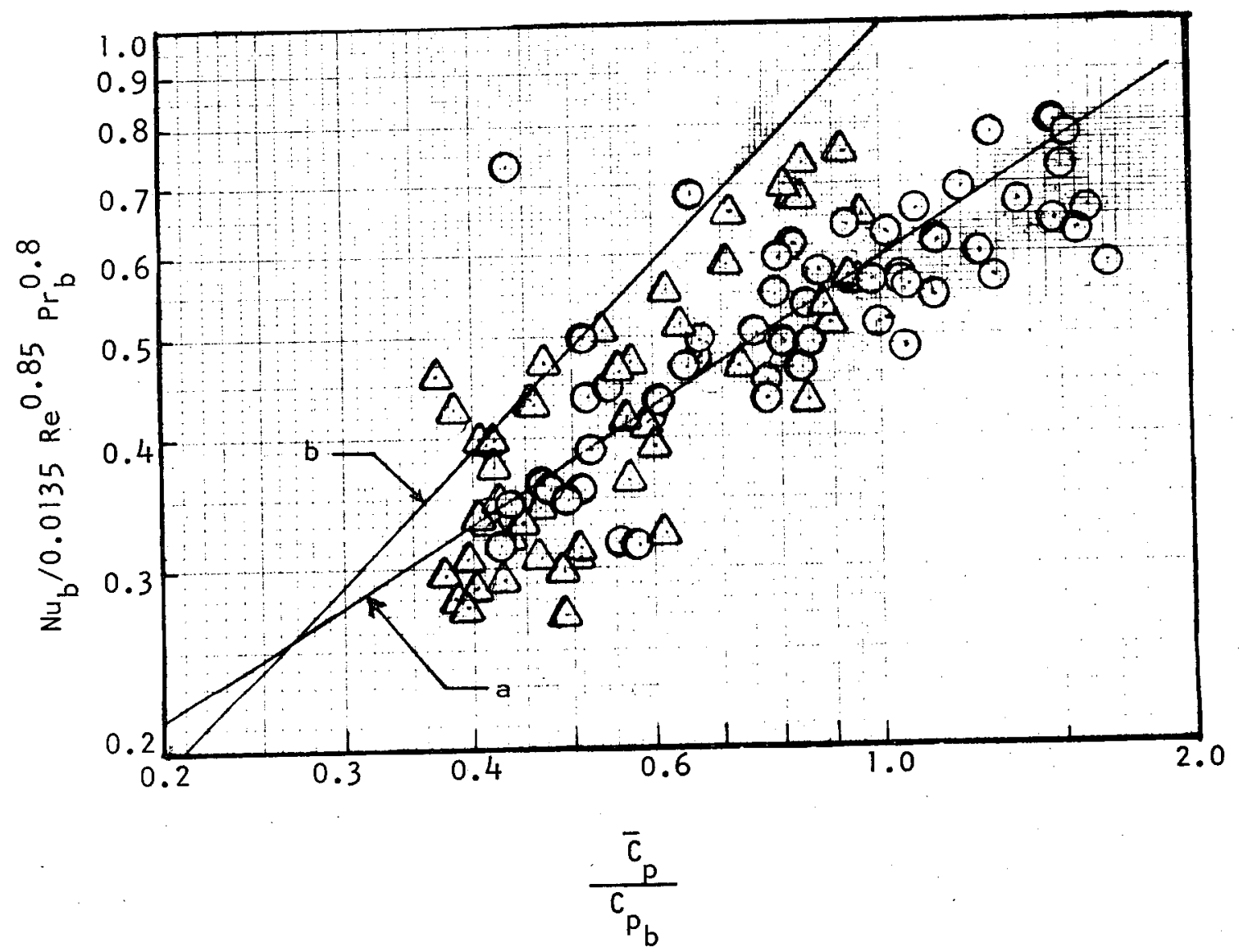

FIG. 5-15. COMPARISON OF EXPER IMENTAL DATA FROM TABLE B-3 WITH YAMAGATA'S CORRELATION.

Line a: Yamagata's correlation for $0<E<1$ $b$ : Yamagata's correlation for $E<0$

EXPERIMENTAL DATA POINTS:

$\begin{array}{rr}\odot & 0<E<1 \\ \triangle & E<0\end{array}$ 
(a) Correlating the experimental data by the Dittus-Boelter or Sieder-Tate correlations is impracticable due to large scatter, up to $\pm 55 \%$ or more, of data points.

(b) Plotting the data points as suggested by Yamagata has not reduced the scattering of data points. This indicates that the data points do not show much dependence on $\left(\bar{C}_{p} / C_{P_{b}}\right)$.

5-3-3. Comparison of $\mathrm{Nu}_{\text {EXP }} / \mathrm{Nu}_{S-T}$ with Eckert Number.

On Fig. 5-16, the ratio of experimental Nusselt number with ${ }^{\mathrm{Nu}} \mathrm{S}-\mathrm{T}$ by Sieder-Tate correlation is plotted against $\mathrm{E}$ for all the runs discussed so far. The scatter of data is reduced as compared with Fig. 5-8 and Fig. 5-15.

When $0.1<E<1$, the data points are within $\pm 25 \%$ about unity. As $-0.1<E<0.1$, the value of $\mathrm{Nu} / \mathrm{Nu}_{S}-\mathrm{T}$ shows a decreasing trend towards a minimum value of 0.5 , though the scatter of data is almost $\pm 37 \%$. As $E$ becomes more negative, the data seem to return towards unity again, but there is insufficient data for $E$ more negative than -0.5 to substantiate this trend.

Figure 5-16 suggests that the deterioration in heat transfer as observed in this experimental study seems to be dependent on the Eckert number: The Eckert number is an indication of how close the bulk temperature is relative to the pseudocritical temperature, $T_{P . C .}$ In the region when $-0.1<E<0.1$, the bulk temperature is in the neighborhood of T $T_{p . c .}$ and large variation of properties of isobutane occurs across the cross-section of the 


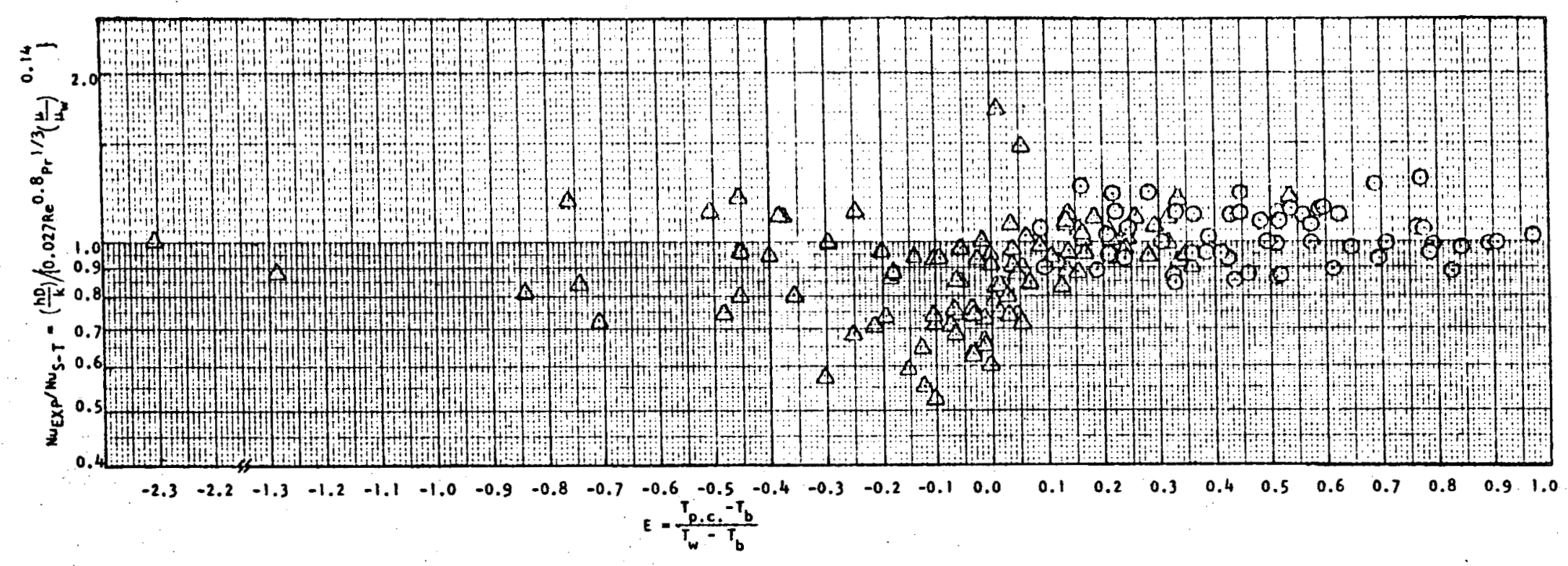

Fig. 5-16. Plot of Wu Exp $/$ Mts S-T against Eckert twumber, E.

$\odot$ Date from Table o-2

$\triangle$ Data from Table B-3 
heater tube. Consequently, deterioration of heat transfer was measured.

On Fig. 5-11, Jackson's correlation with the correction factors predicted the heat transfer coefficients very well for Run 218 when $x / 0>90$. Therefore, the experimental Nusselt numbers for the data listed on Table B-3 are also compared with Nusselt numbers by Jackson's correlation and plotted against $E$. The result shown on Fig. $5-17$ indicates that for $E>0.1$, the ratio of $\mathrm{Nu}_{\text {EXP }} / \mathrm{Nu}$ Jackson is about 2 and for $-0.1<E<0.1$, the same ratio decreases to unity. The scatter of data is slightly less than Fig. $5-16$, but the result is still not satisfactory to make a definite conclusion.

From Chapter 4, the experimental Nusselt numbers were correlated to $\pm 15 \%$ by Petukhov's correlation. Thus, the experimental Nusselt numbers considered in this chapter are also compared with Petukhov's correlation, and this is shown on Fig. 5-18. The data points are very similar to Fig. 5-16, with those points in the range of $1.0>E>0.1$ scattered about $\mathrm{Nu}_{\text {EXP }}{ }^{\prime}$ $\mathrm{Nu}_{\text {Petukhov }}=1.12$. When $-0.1<E<0.1$, the data points also exhibit a decreasing trend towards 0.5 . For $E<-0.1$, the data points seem to return to unity but this is not conclusive due to lack of data points. 


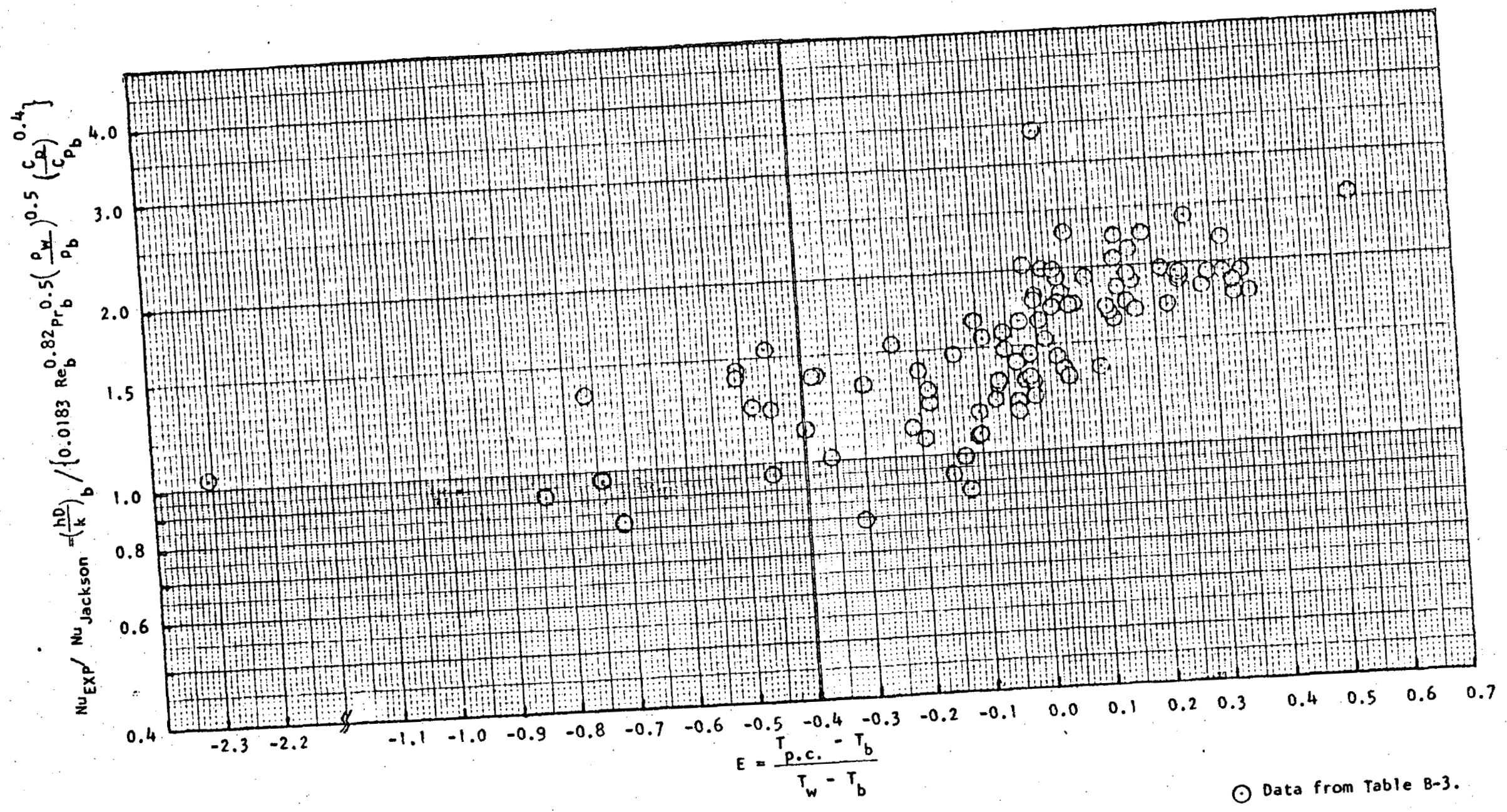

Fig. 5-17. Plot of Nu Exp thu jackson as a function of Eckert Number, E, for data tabulated on Table B-3. 


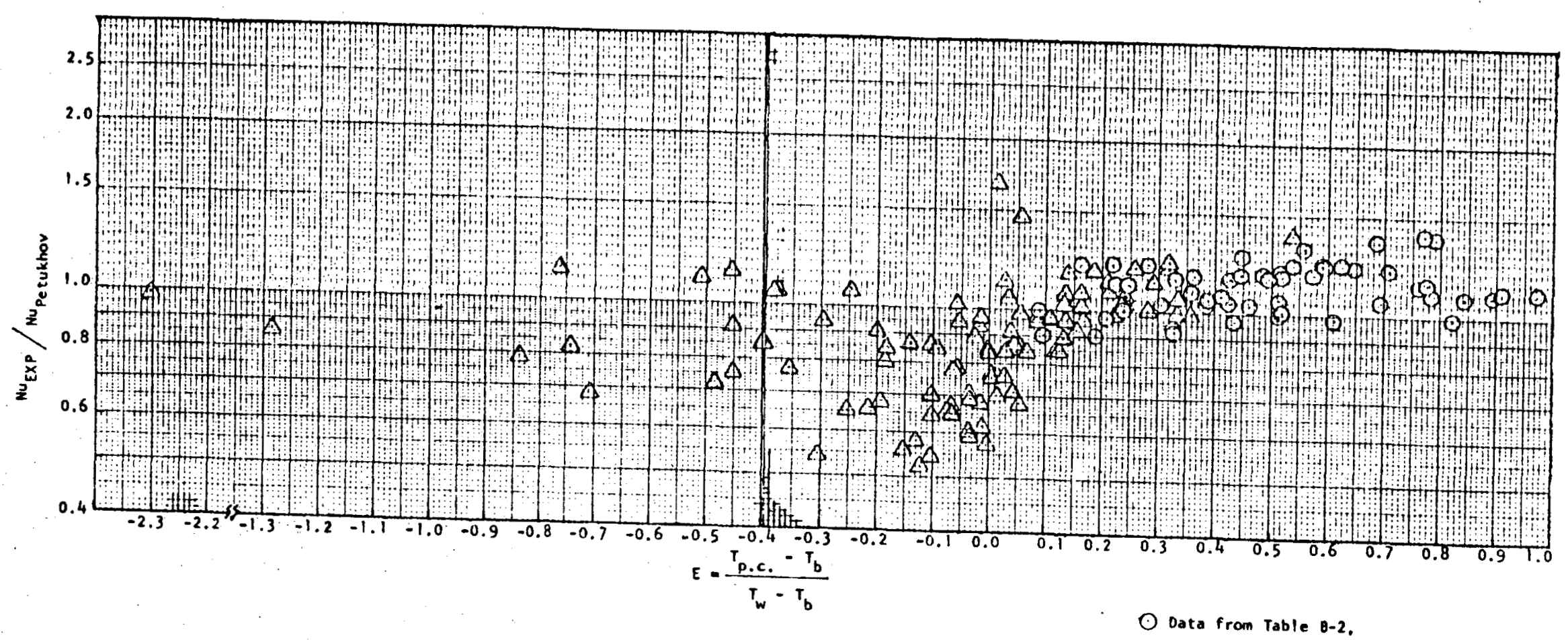

Fig. 5-18. Plot of Nu Exp' Nu Petukhov as a function of Eckert Number, E.

$\triangle$ Data from Table B-3. 
5-3-4. Reclassification of Experimental Nusselt Numbers.

Figs 5-16 to 5-18 suggest that an alternative method of classifying the experimental Nusselt numbers considered in this chapter is possible. Those experimental Nusselt numbers with $1.0>E>0.1$ constitute one group of data that can be prescribed by the Sieder-Tate correlation. Those experimental Nusselt numbers with $E<0.1$ constitute a second group of data which exhibited a reduction in the range of $0.1>E>-0.1$ and large scatter of experimental data when compared with Sieder-Tate or Dittus-Boelter correlations.

Thus, the experimental data are reclassified according to the above and compared with Dittus-Boelter, Sieder-Tate and Petukhov correlations on Fig. 5-19 to Fig. 5-24. Fig. 5-19 shows a scatter of data points of $\pm 20 \%$ when compared with Dittus-Boelter correlation with the constant coefficient being 0.028 . Fig. 5-20 shows a scatter of data points of about $\pm 15 \%$ when compared with Sieder-Tate correlation. Fig. 5-21 shows that except for some data points in the low Reynold number range, the data points are within $\pm 15 \%$ of Petukhov's prediction.

When $E<0.1$, the scatter of data points is still too large to make a definite conclusion, as shown on Fig. 5-22 to 5-24.

5-4. Conclusion.

For the runs with $1.0>E>0.1$, the experimental Nusselt numbers can be specified by the Sieder-Tate correlation to $\pm 15 \%$. The DittusBoelter correlation with constant coefficient of 0.028 as recommended in Chapter $4-3$ correlates the data to $\pm 18 \%$. Petukhov's correlation 


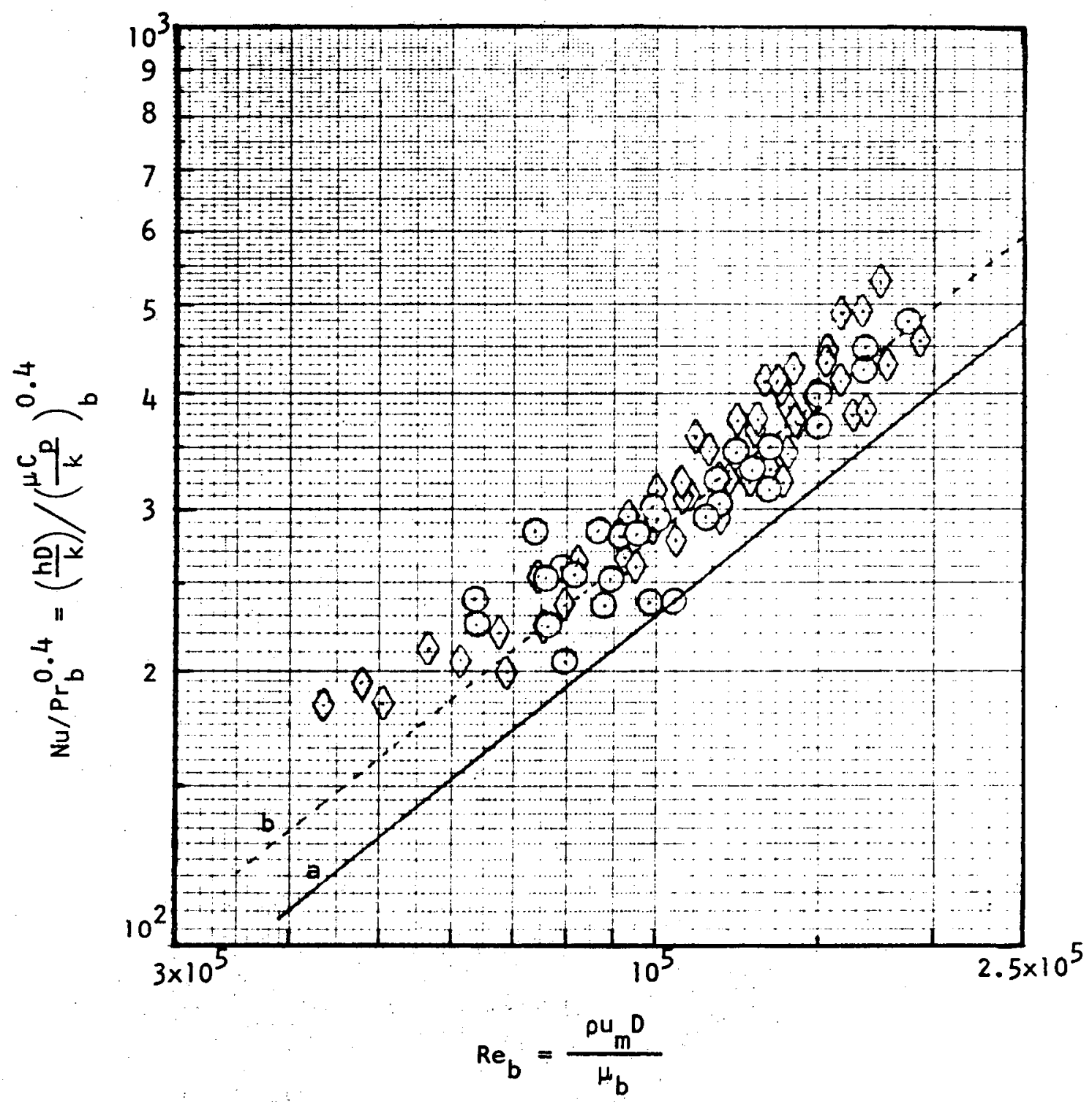

FIG. 5-19. COMPARISON OF DATA WITH DITTUS-BOELTER CORRELATION. DATA WITH $0.1<E<1.0$
Line a: ${ }^{N U_{D-B}}=0.023 \operatorname{Re}_{b}^{0.2} \operatorname{Pr}_{b}^{0.4}$
Line b:
$=0.028 \operatorname{Re}_{b}^{0.8} \operatorname{Pr}_{b}^{0.4}$

- data from table b-2

$\odot$ DATA FROM TABLE B-3 


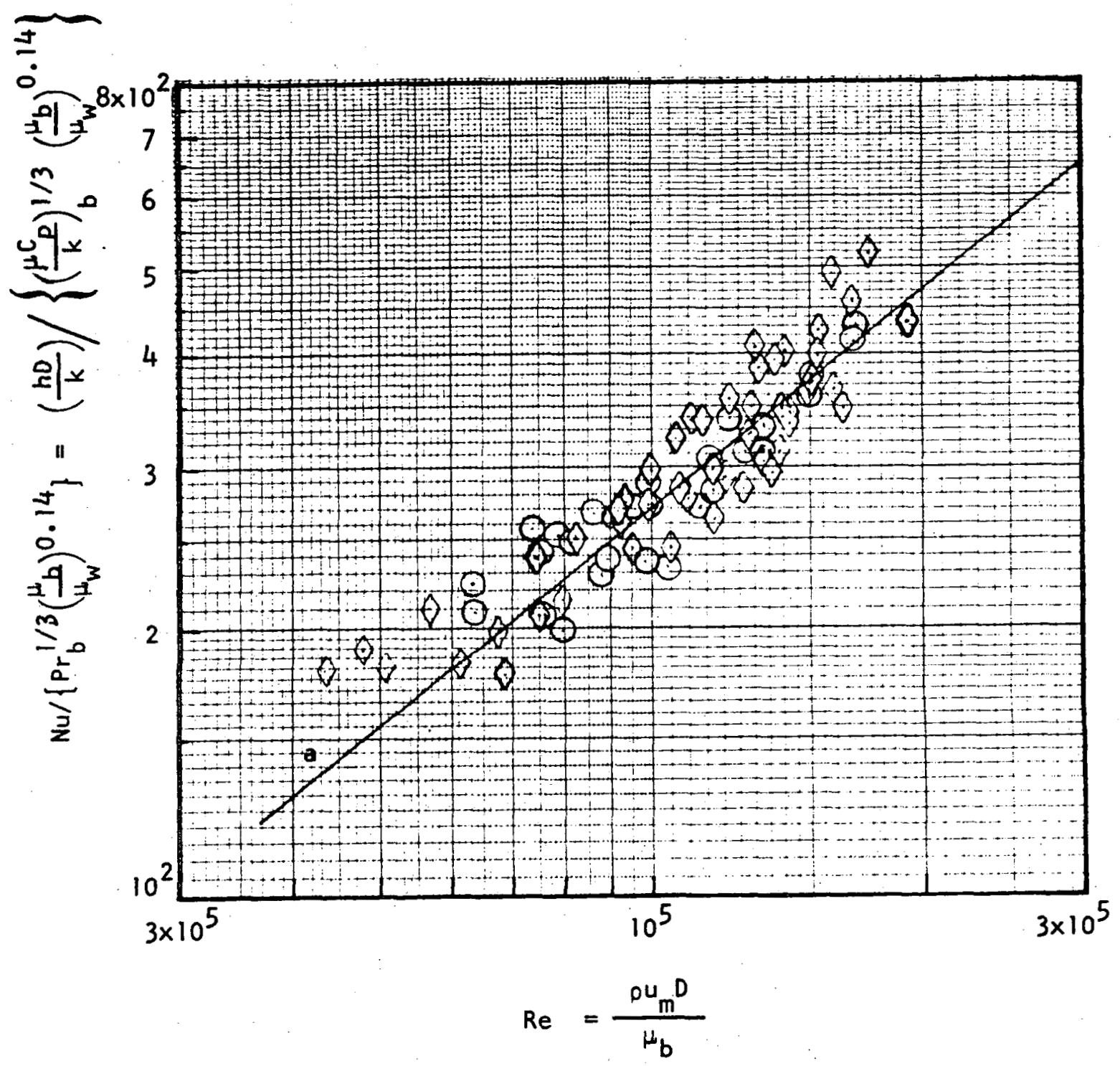

FIG. 5-20. COMPARISON OF DATA WITH $0.1<$ E $<1.0$ AGAINST SIEDER-TATE CORRELATION.

Line a: $N_{S-T}=0.027 \operatorname{Re}^{0.8} \mathrm{Pr}^{1 / 3}\left(\frac{\mu_{b}}{\mu_{w}}\right)^{0.14}$

$\odot$ DATA FROM TABLE B-2

$\odot$ DATA FROM TABLE $B-3$ 


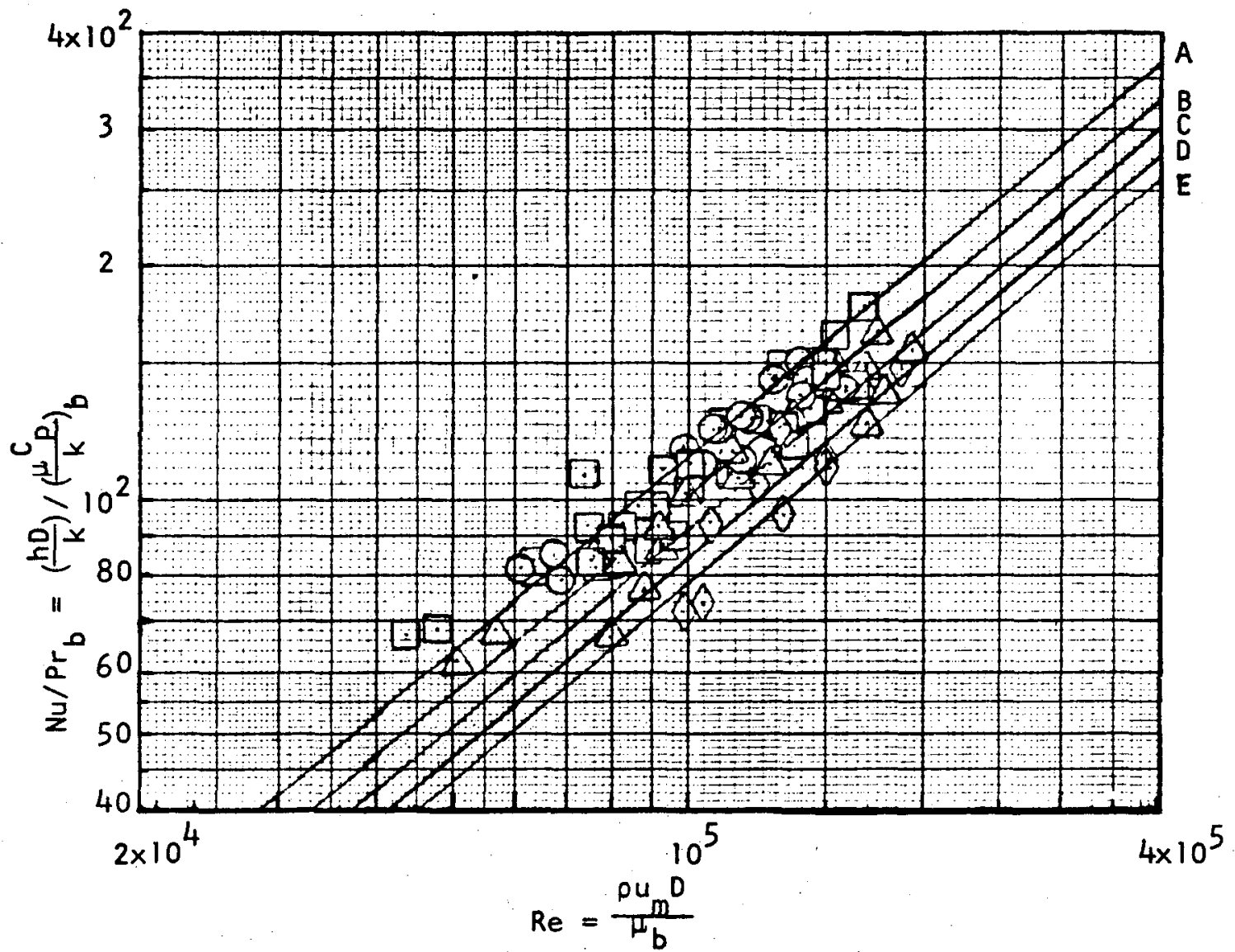

Fig. 5-21. Comparison with Petukhov's correlation. Data with $0.1<E<1.0$.

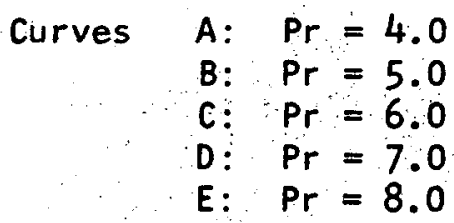

$\odot 4.0<\operatorname{Pr}<5.0$

$5.0<\operatorname{Pr}<6.0$

6.0<Pr<7.0

$87.0<\operatorname{Pr}<8.0$

$88.0<\operatorname{pr}<9.0$

Petukhov's correlation:

$$
\begin{aligned}
\mathrm{Nu} & =\frac{(f / 8) \operatorname{Re}_{b} \operatorname{Pr}_{b}}{\left[1.07+12.7\left(\operatorname{Pr}_{b}^{2 / 3}-1\right)^{\sqrt{f / 8}}\right]} \\
f & =(1.82 \log \operatorname{Re}-1.64)^{-2}
\end{aligned}
$$




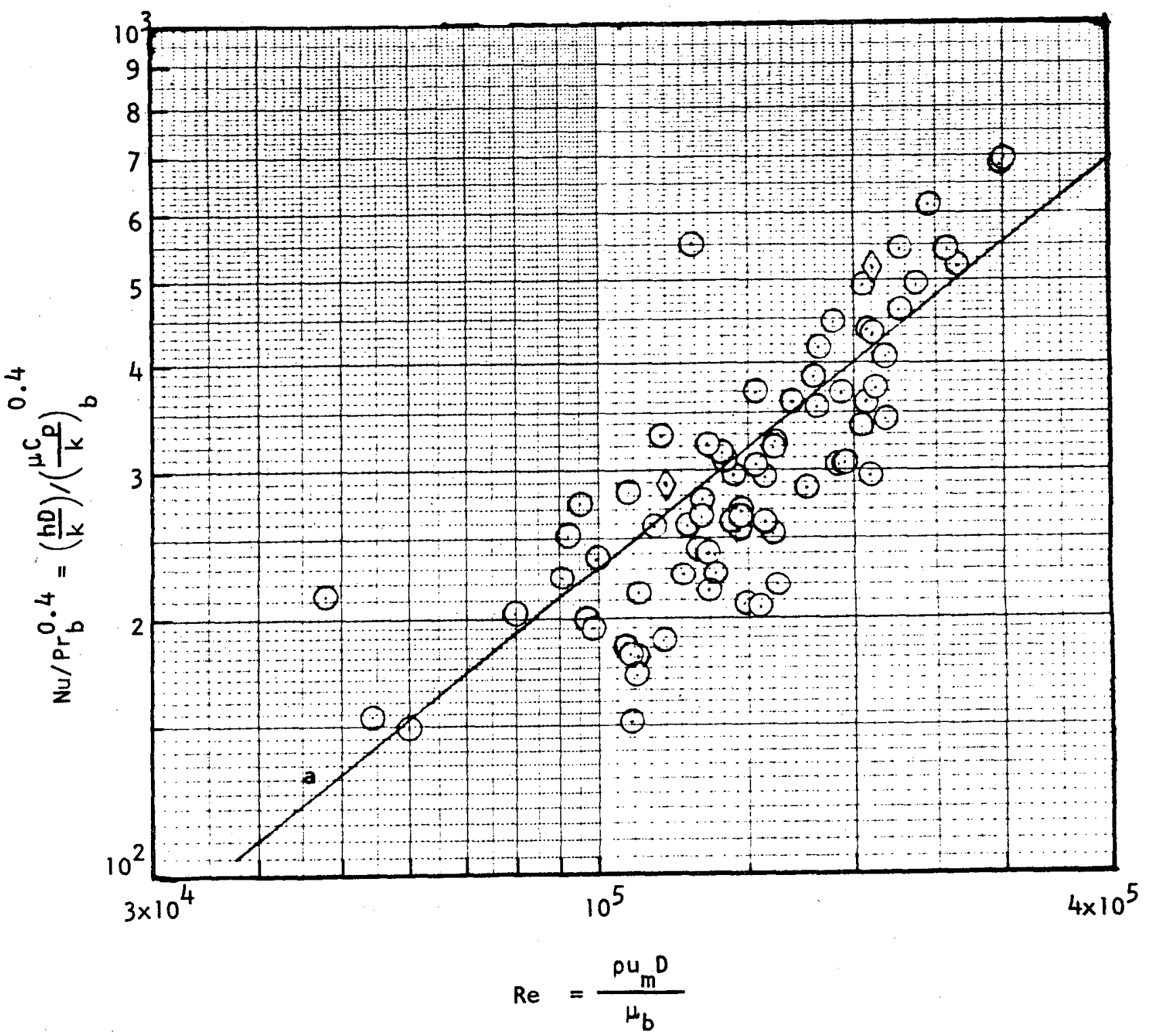

FIG. 5-22. COMPARISON WITH DITTUS-BOELTER CORRELATION. DATA WITH $0.1>E>-3.0$

Line a: $\quad N u_{D-B}=0.023 R e^{0.8} \operatorname{Pr}^{0.4}$

$\odot$ DAta From table $B-2$
() data from table $B-3$ 


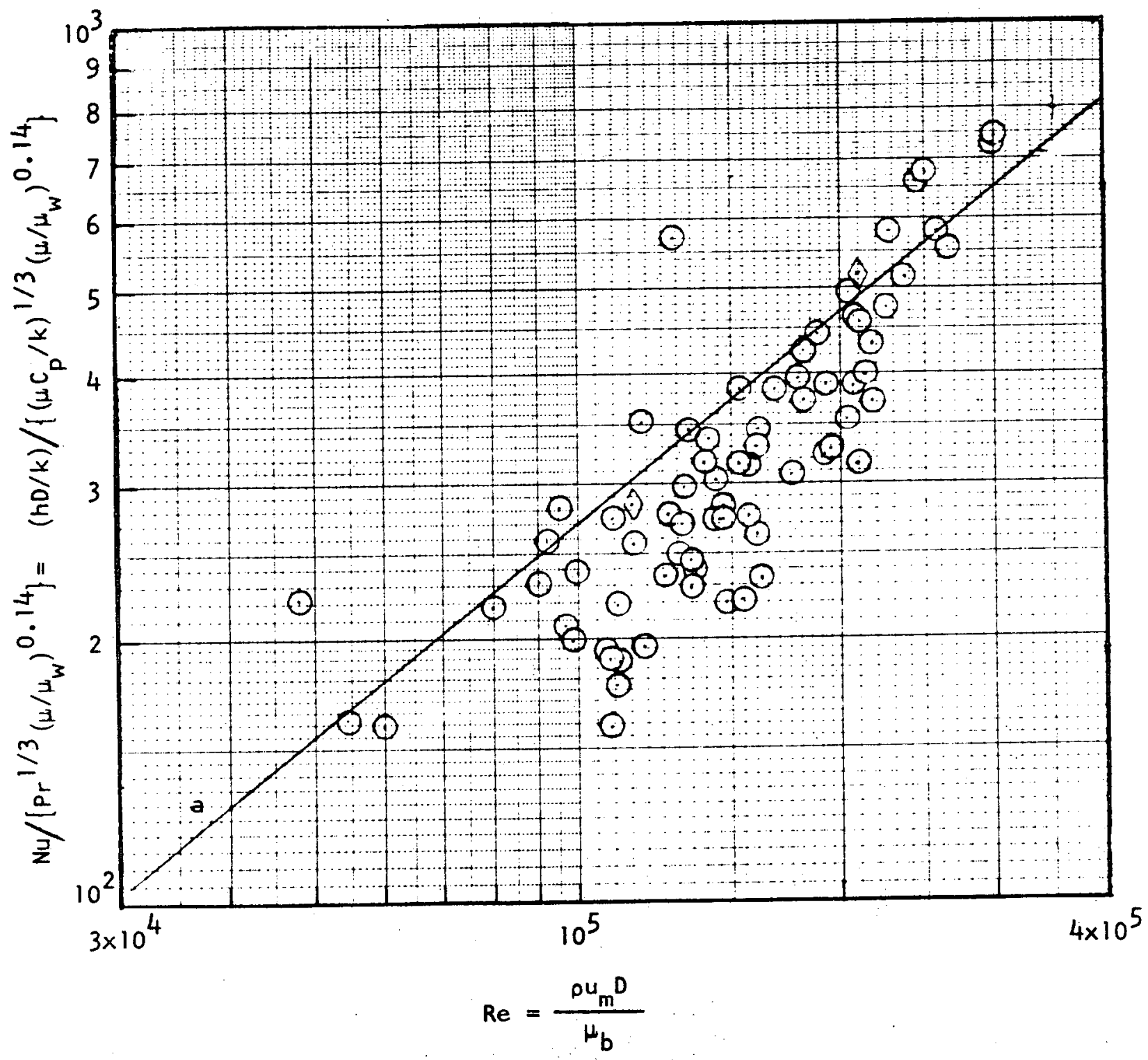

FIG. 5-23. COMPARISON OF DATA WITH SIEDER-TATE CORRELATION. DATA WITH $0.1>E>-3.0$.

Line a: ${ }^{N u_{S}-T}=0.027 \operatorname{Re}^{0.8} \operatorname{Pr}^{1 / 3}\left(\frac{\mu}{\mu_{w}}\right)^{0.14}$

$\odot$ DATA from table b-2
$\odot$ DAta from table $B-3$ 


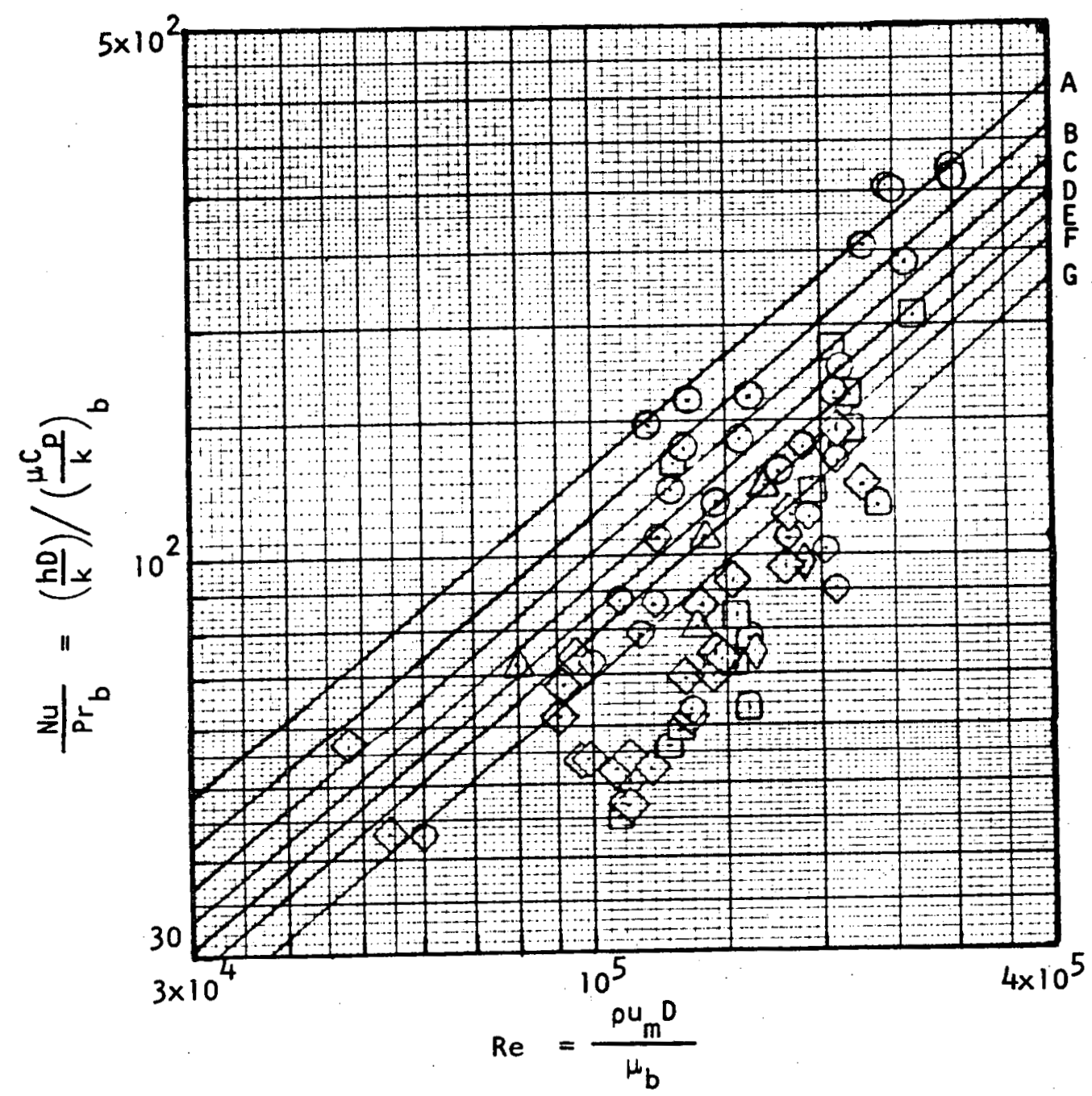

FIG. 5-24. COMPARISON OF DATA WITH PETUKHOV CORRELATION. DATA WITH $0.1>E>3.0$

$$
\text { Line } \begin{aligned}
A: & \operatorname{Pr}=3.0 \\
B: & \operatorname{Pr}=4.0 \\
C: & \operatorname{Pr}=5.0 \\
D: & \operatorname{Pr}=6.0 \\
E: & \operatorname{Pr}=7.0 \\
F: & \operatorname{Pr}=8.0 \\
\text { G: } & \operatorname{Pr}=10.0
\end{aligned}
$$

Petukhov's correlation:

$$
\begin{aligned}
\mathrm{Nu} & =\frac{(f / 8) \operatorname{Re}_{b} \operatorname{Pr}_{b}}{\left[1.07+12.7\left(\operatorname{Pr}_{b}^{2 / 3}-1\right) \sqrt{f / 8}\right]} \\
f & =(1.82 \log \operatorname{Re}-1.64)^{-2}
\end{aligned}
$$

( $3.0<\operatorname{Pr}<4.0$

$\square 4.0<\operatorname{Pr}<5.0$

$\triangle 5.0<\operatorname{Pr}<6.0$

$\odot 6.0<\operatorname{Pr}<7.0$

$\odot 7.0<\operatorname{Pr}<8.0$

$\Leftrightarrow 8.0<\operatorname{Pr}<10.0$

(-) $\operatorname{Pr}>10.0$ 
correlates the data to $=15 \%$ also.

For those runs with $E$ less than 0.1 , both Sieder-Tate and DittusBoelter correlation cannot be used to correlate the experimental data due to large scatter of data.

The scatter of experimental data is caused by a deterioration in heat transfer when the bulk temperature passes through the pseudocritical temperature region. This is substantiated by the plot of $\mathrm{Nu}_{\text {EXP }} / \mathrm{Nu}_{S-T}$ against $\mathrm{E}$ on Fig. 5-13, which exhibited a trend of decreasing $\mathrm{Nu}_{\text {EXP }} / \mathrm{Nu}_{S-T}$ in the range of $-0.1<E<0.1$.

When the experimental data for both $0 \leq E \leq I$ and $E<0$ are compared with Yamagata's correlation, the scatter of data about the correlation line is as much as $=35 \%$ when $0 \leq E \leq 1$, but the data failed to follow the $I$ ine for $E<0$. Yamagata's correlation was based on his experimental data on supercritical water for vertical upflow and his data had a scatter of $\pm 20 \%$ about the correlation line. Thus, Yamagata's correlation is not quite applicable to the present experimental data.

Before ending this chapter, it should be pointed out that experimental data points of large negative values were few because the experimental runs designed to obtain such data points required very high steam temperatures. However, the highest temperature of steam allowable in the steam jacket was set at $230^{\circ} \mathrm{C}\left(446^{\circ} \mathrm{F}\right)$. In addition, the preheater also required steam from the boller to heat the isobutane. Therefore, only a few data points were obtained with $E<-0.5$ in this study. 


\section{CHAPTER 6}

\section{CONCLUS IONS}

1. Experimental measurements of heat transfer to isobutane at $4.14 \mathrm{MPa}$ (600 psia) have produced values of heat-transfer coefficients accurate to $=20 \%$. The overall range of Reynolds number for the experiment was from $2.2 \times 10^{4}$ to $2.5 \times 10^{5}$ and $4.3<\operatorname{Pr}<11.1$.

2. When $E=\frac{T_{p} \cdot c \cdot-T_{b}}{T_{w}-T_{b}}>1$, the variation of the properties of isobutane was least severe. The heat transfer coefficient for this range of $E$ and with $2.3 \times 10^{4}<\operatorname{Re}<2.0 \times 10^{5} ; 4.3<\operatorname{Pr}<5.5$ was discussed in Chapter 4. The experimental Nusselt numbers were found to be correlated to $\pm 15 \%$ by Petukhov's correlation. The Grashof number for these results ranged from $4.5 \times 10^{7}$ to $9.0 \times 10^{8}$. The analytical result of Futagami and Abe indicated an augmentation of Nusselt number, due to free convection, from $15 \%$ to $60 \%$ in this range of Grashof number. However, a comparison of the experimental result with Futagami and Abe's analytical result was hindered by the inapplicability of their correlation, derived for $\operatorname{Pr}=0.7$, to the higher Prandtl number obtained in this experiment. As already indicated, Petukhov's correlation seemed satisfactory and he indicated no free convection effect on the peripherally-averaged Nusselt number.

3. The data for runs with $E=\frac{T_{p} . c .-T_{b}}{T_{w}-T_{b}}$ less than unity, i.e. when the bulk fluid temperature approached or exceeded the pseudocritical temperature, over the exchanger length, were discussed in two parts in Chapter 5. Part a considered the results for conditions with 
$0.1<E<1.0$ over the exchanger length. Part $\underline{b}$ contained dáta for conditions with $-3.0<E<0.1$, and $E=0$ was obtained at some point along the length of heat exchanger.

(a) The average of the Nusselt numbers for $0.1<E<1.0$ were about $10 \%$ less than those obtained from runs with $E>1.0$, and they could be correlated to $=15 \%$ by the Sieder-Tate correlation or to $\pm 15 \%$ by Petukhov's correlation. The value of $\mathrm{Gr} / \mathrm{Re}^{2.7}$ varied from $5.4 \times 10^{-6}$ to $1.8 \times 10^{-4}$, and there was no apparent influence of free convection or of property variation, other than that already acccunted for by the Sieder-Tate correlation, on the heat transfer.

(b) For those results with $0.1>E>-3.0$, none of the proposed correlations could correlate the results. For $0.1>E>-0.1$, almost all of the experimental Nusselt numbers were less than the prediction by siederTate correlation, some by as much as $50 \%$. In addition there was some, but not conclusive, evidence that such reduction in NuEXP seemed to be dependent on E. For $E<-0.1$, the ratio of experimental Nusselt number to the Nusselt number predicted by Sieder-Tate correlation seemed to approach unity for decreasing E. However, the scatter of data points was too great to afford any conclusion. 


\section{REFERENCES}

1. Rogers Engineering Co., Inc: and Benham-Blair and Affiliates, 1974, "10 MW Experimental Geothermal Power Plant Conceptual Design:

Pre-Title I Report," San Francisco, Prepared for U.S. AEC/Lawrence Berkeley Laboratory, Sept., 1974.

2. Hall, W. B. and Jackson, J. D., "Heat Transfer Near the Critical Point," 6th International Heat Transfer Conference, Toronto, Aug. 1978, Keynote Papers V6, KS-27, pP. 377-392.

3. Hsu, Y. Y. and Graham, R. W., Transport Processes in Boiling and Two-Phase Systems, Including Near Critical Fluids, McGraw-Hill, New York, 1976.

4. Yamagata, K., Nishikawa, S., Hasegawa, T., Fujii, T. and Yoshida, S., "Forced Convective Heat Transfer to Supercritical Water Flowing in Tubes," Int. J. Heat Mass Transfer, Vol. 15, pp. 25752593, 1972.

5. Bourke, P. J., Pulling, D. J., Gill, L. E. and Denton, W. H., "Forced Convective Heat Transfer to Turbulent $\mathrm{CO}_{2}$ in the

Supercritical Region," Int. J. Heat Mass Transfer, Vol. 13, pp. $1339-1348,1970$.

6. Shiralkar, B. S. and Griffith, P., "Deterioration in Heat Transfer to Fluids at Supercritical Pressure and High Heat Fluxes," J. of Heat Transfer, pp. 27-36, Feb., 1969.

7. Brassington, D. J. and Cairns, D. N. H., "Measurements of Forced Convective Heat Transfer to Supercritical Helium," Int. J. Heat Mass. Transfer, Vol. 20, pp. 207-214, 1977.

8. Adebiyi, G. A. and Hall, W. B., "Experimental Investigation of Heat Transfer to Supercritical Pressure Carbon Dioxide in a Horizontal Pipe," Int. J. Heat Mass Transfer, Vol. 19, pp. 715-720, 1976.

9. Hsu, Y. Y. and Smith, J. M., "The Effect of Density Variation on Heat Transfer in the Critical Region," J. of Heat Transfer, pp. 176182, May, 1961.

10. Bringer, R. P. and Smith, J. M., "Heat Transfer in the Critical Region," A.I.Ch.E. Journal, Vol. 3, No. 1, pp. 49-55, 1957.

11. Hess, H. L. and Kunz, H. R., "A Study of Forced Convection Heat Transfer to Supercritical Hydrogen," J. of Heat Transfer; pp. 4148, Feb., 1965. 
12. Schnurr, N. M., Sastry, V. S. and Shapiro, A. B., "A Numerical Analysis of Heat Transfer to Fluids Near the Thermodynamic Critical Point Including the Thermal Entrance Region," J. of Heat Transfer, pp. 609-615, Nov., 1976.

13. Swerison, H. S., Carver, J. R. and Kakarala, C. R., "Heat Transfer to Supercritical Water in Smooth-Bore Tubes," J. of Heat Transfer, pp. 477-484, Nov., 1965.

14. McAdams, W. H., Heat Transmission, 3rd ed., McGraw-Hill, New York, 1954.

15. Futagami, K. and A.be, E., "Forced and Free Combined Convective Heat Transfer in an Inclined Tube (2nd Report, Turbulent Region)," in Japanese, Trans. of the Japen Society of Mechanical Engineering, Vol. 41, No. 347, 1975.

16. Petukhov, B. S., Polyakov, A. F., Kuleshov, V. A. and Sheckter, Yu. L., "Turbulent Flow and Heat Transfer in Horizontal Tubes with Substantial Influence of Thermogravitational Forces," Proceedings of 5 th Int. Heat Transfer Conference, Tokyo, Paper No. NC 4.8, 1974.

17. Hanley, H. J. M., "Prediction of the Viscosity and Thermal Conductivity Coefficients of Mixtures," Cryogenics, pp. 643-651, Nov. , 1976.

18. American Society of Heating, Refrigerating, and Air-Conditioning Engineers, ASHRAE Thermodynamic Properties of Refrigerants, 1969.

19. Gonzalez, M. H. and Lee, A. L., "Viscosity of Isobutane," Journal of Chemical and Engineering Data, Vol. 11, No. 3, pp. 357-359, July, 1966.

20. American Petroleum Institute, Technical Data Book - Petroleum Refining, 2nd ed., 1970.

21. Chun, K. R. and Seban, R. A., "Heat Transfer to Evaporating Liquid Films,".J. of Heat Transfer, pp: 391-396, Nov., 1971.

22. Kutateladze, S. S., Fundamentals of Heat Transfer, Arnold Publishing Co., English Translation, 1963.

23. Milora, S. L. and Combs, S. K., "Thermodynamic Representations of Ammonia and Isobutane," ORNL/TM-5847, May, 1977.

24. Hougen, 0.A., Watson, K.M. and Ragatz, R.A., Chemical Process Principles, Part II, 2nd ed, John Wiley and Sons, Inc., New York, 1967.

25. Hougen, O.A. and Watson, K.M., Chemical Process Principles Charts, John Wiley and Sons, Inc., New York, 1948. 
26. Sleicher, C.A. and Rouse, M.W., "A Convenient Correlation for Heat Transfer to Constant and Variable Property Fluids in Turbulent Pipe Flow", Int. J. Heat Mass Transfer, Vol. 18, Pp. 677-683, 1975.

27. Eckert, E.R.G. and Drake, R.M., Heat and Mass Transfer, 2nd ed., Mcgraw-Hill, New York, 1959. 
121

LIST OF SYMBOLS

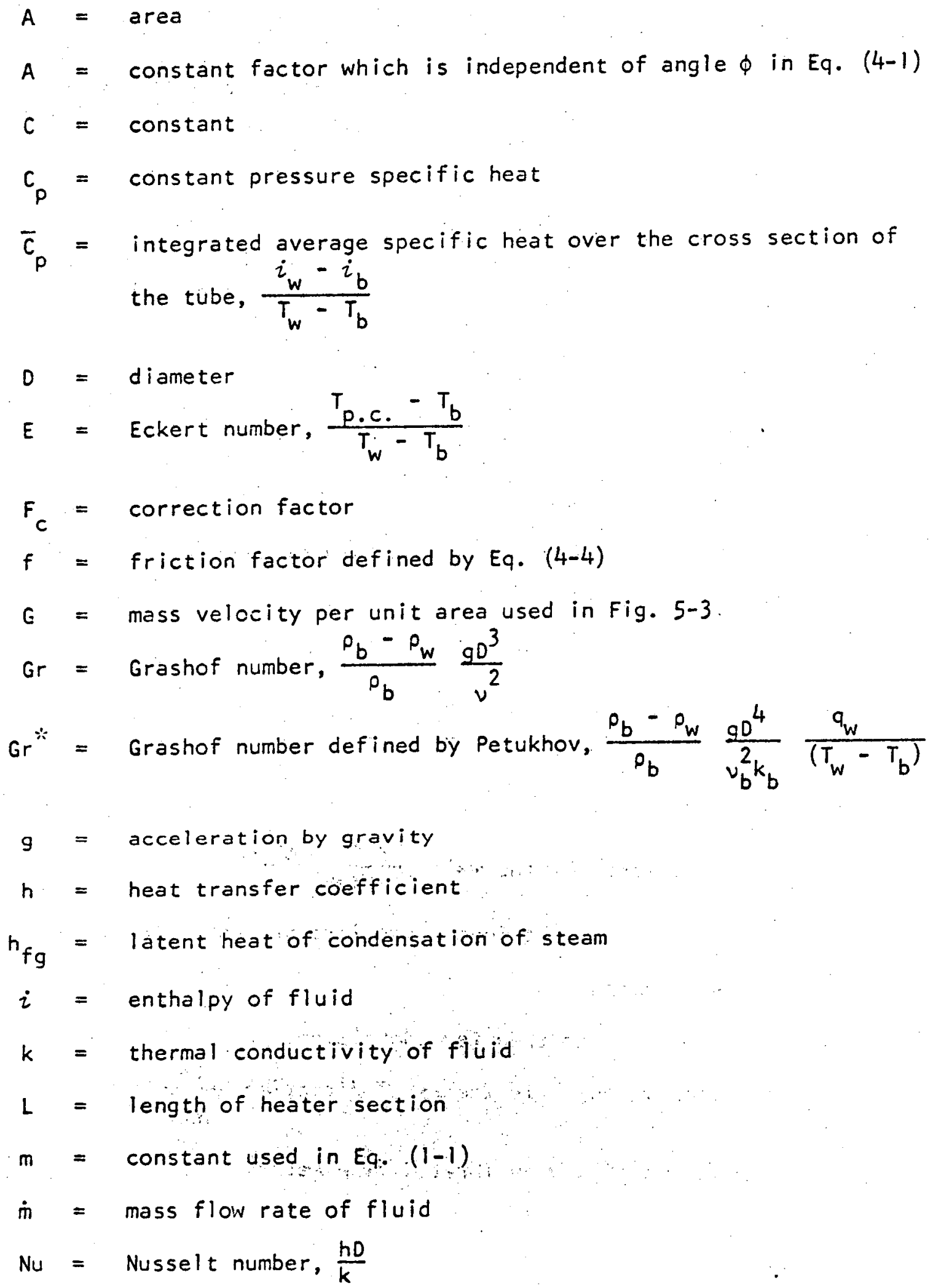




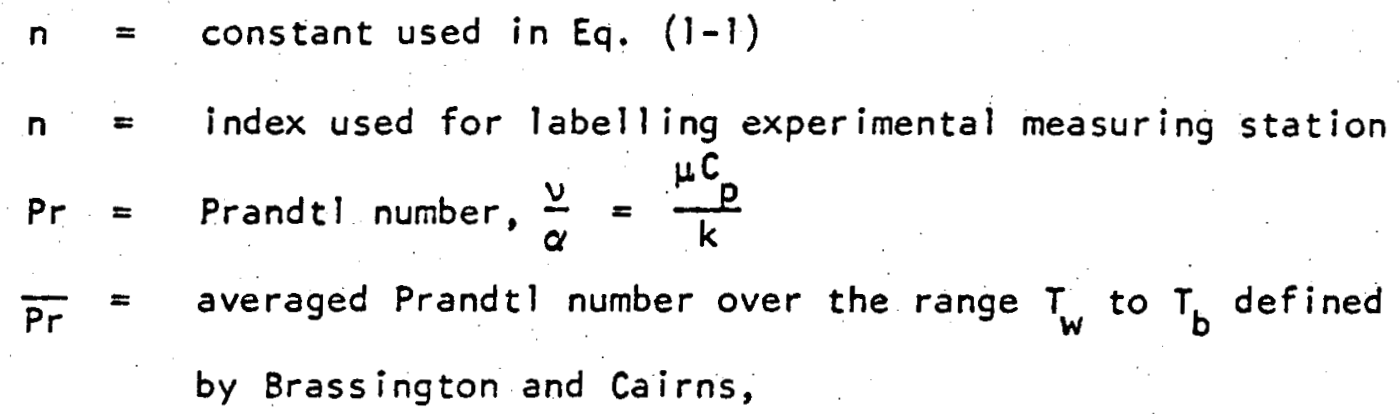

$$
\left[\frac{1}{T_{w}-T_{b}} \int_{T_{b}}^{T_{w}} \frac{1}{\operatorname{Pr}(T)} d T\right]^{-1}
$$

$Q=$ heat rate

$q=$ heat flux, $O / A$

$q_{c}=1$ imiting heat flux, used in Eq. $(5-10)$

Ra $=$ Raleigh number, Gr $\mathrm{Pr}$

$R a^{*}=$ Raleigh number defined by Futagami and Abe,

$$
\frac{99_{b} r^{4}\left|\frac{d T_{w}}{d x}\right|}{a_{b} v^{2}}=\frac{G r N u}{4 R e}
$$

$\operatorname{Re}=$ Reynolds number, $\frac{\rho m^{D}}{\mu}=\frac{4}{\pi} \frac{\dot{m}}{D_{\mu}}$

$r=$ radius

$r_{w}=$ resistance of the wall, $\frac{A_{i} \ln \left(r_{0} / r_{i}\right)}{2 \pi k L}$

$T=$ temperature (various subscripts are used, see section on subscripts)

$U=$ overall heat transfer coefficient

$u_{m}=$ mean velocity in the axial direction, $\frac{4 \dot{m}}{\rho \pi D^{2}}$

$v=$ volume of the calibrated flow meter

$v=$ specific volume, $1 / \rho$ 
$w=$ mass rate of condensate collected

$x=$ axial distance from the beginning of the horizontal run at the heater

Greek Symbols

$\alpha=$ thermal diffusivity, $k / \rho C_{p}$

$\alpha^{\prime}=$ angle of inclination of the tube as defined by futagami and Abe

$\beta=$ isobaric compressibility of fluid, $\frac{1}{v}\left(\frac{\partial v}{\partial T}\right)_{p}$

$\Gamma^{\prime}=$ mass rate of condensate collected per unit length

$\mu=$ absolute viscosity of fluid

$v=$ kinematic viscosity of fluid, $\mu / \rho$

$0 \quad=$ density of fluid

$\phi .=$ angle measured from the top of the heater tube

\section{Subseripts}

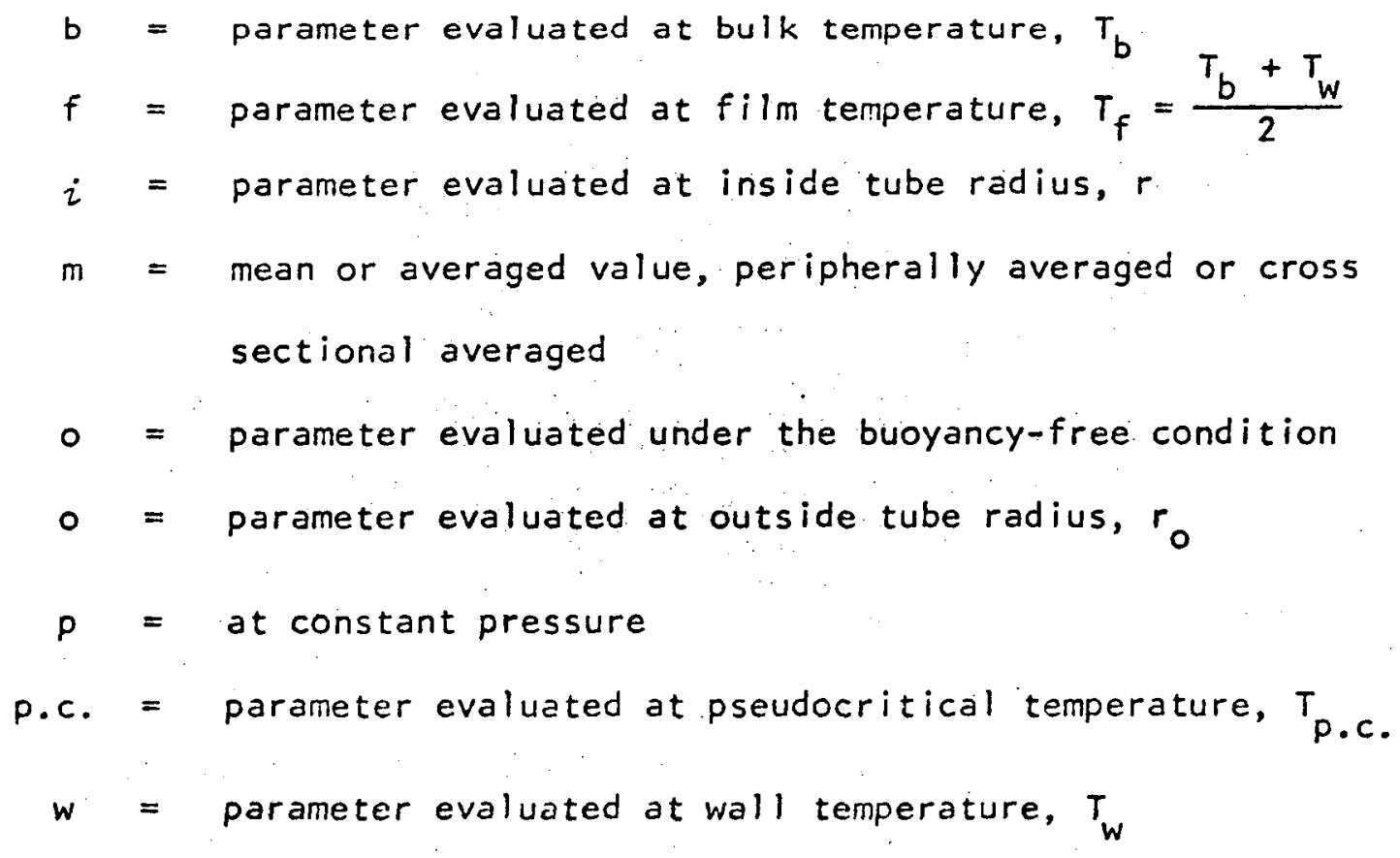




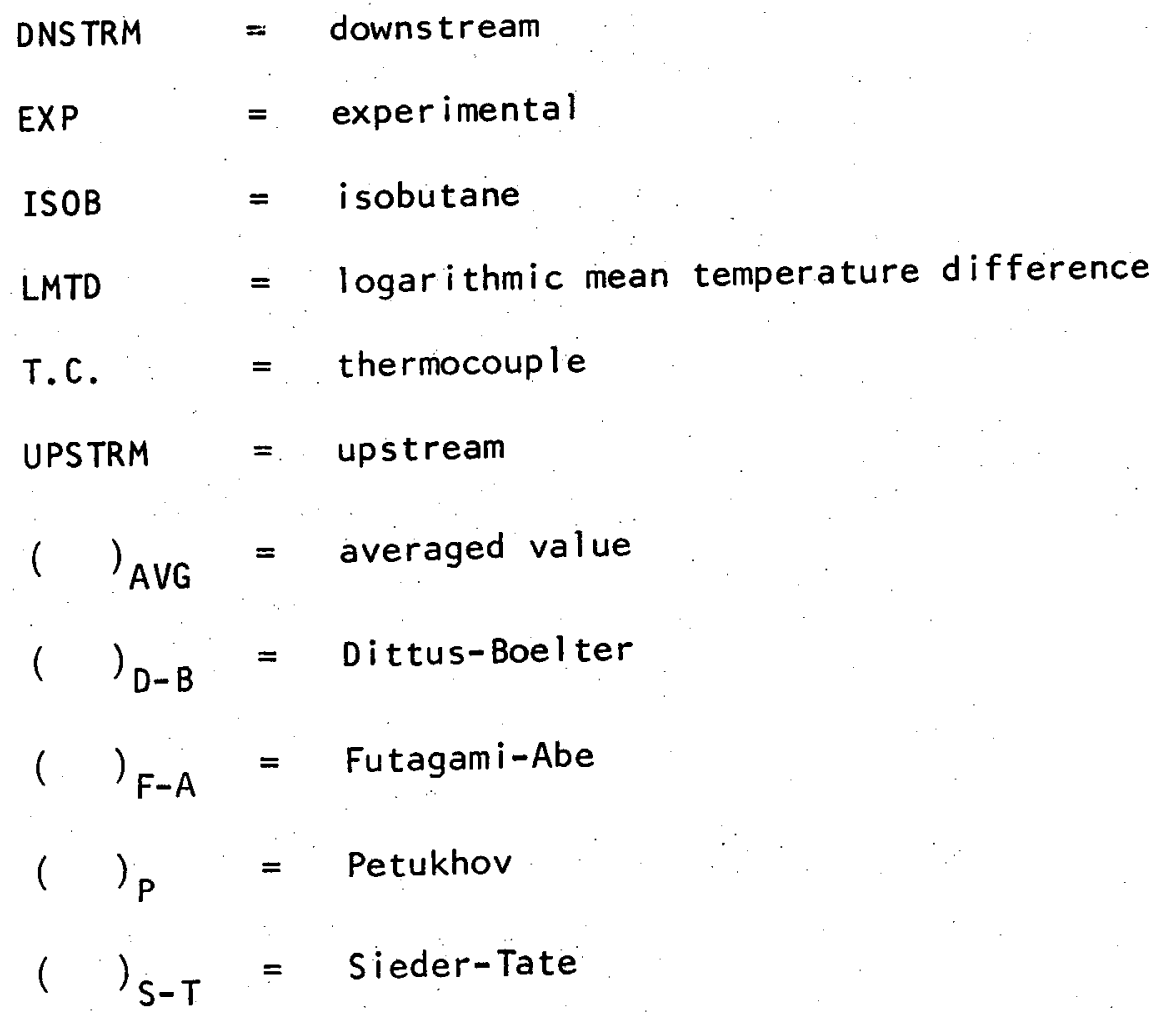

Superscript

$$
\text { ( ) = peripherally averaged value }
$$


APPENDIX A

THERMODYNAMIC AND TRANSPORT PROPERTIES OF ISOBUTANE AT $4.14 \mathrm{MPa}$ (600 PSIa)

The thermodynamic and transport properties of isobutane employed in the analysis of experimental data are plotted against temperature on Fig. A-1. The values of these properties were calculated by Dr. L. Silvester of Lawrence Berkeley Laboratory and furnished to this project. The thermodynamic properties were calculated based on Starling's equation of state and the transport properties were calculated based on the method suggested by Hanley, et al [17].

The properties of isobutane were also investigated by the author and the results compared with those furnished by $\mathrm{Dr}$. Silvester. From the ASHRAE Thermodynamic Properties of Refrigerants [18] the enthalpy of isobutane at 600 psia was tabulated on Table 50 against temperature. These values of enthalpy were compared with those furnished by $\mathrm{Dr}$. Silvester on Fig. A-2. The two values almost matched each other with respect to variation with temperature, except in the range of $135-145^{\circ} \mathrm{C}$ or in the range encompassing the pseudocritical temperature. These two sets of enthalpy values were compared in even more detail by computing the specific heat, $C_{p}$, from them for comparison. The specific heat is defined as

$$
c_{p}=\left(\frac{\partial i}{\partial T}\right)_{p}=\left(\frac{\Delta i}{\Delta T}\right)_{p}
$$

The results were plotted on Fig. A-3. Additional values of $C_{p}$ were also plotted on the figure from various other sources. From 
Fig. A-3, the pseudocritical temperature of isobutane at 600 psia was determined to be at $142.5^{\circ} \mathrm{C}$.

In conclusion, the thermodynamic properties of isobutane calculated by Dr. Silvester has been checked with the results calculated or obtained by the author from other published sources and found to be accurate.

Fig. A-4 shows the variation of isobaric compressibility of isobutane, 8, at 600 psia against temperature. The definition of $\beta$ is:

$$
B=\frac{1}{v}\left(\frac{\partial V}{\partial T}\right)_{P}=\frac{1}{v_{M E A N}}\left(\frac{\Delta V}{\Delta T}\right)_{P}
$$

where $\quad v=\frac{1}{\rho}=$ specific volume.

The values of $\beta$ were used in the calculation of Grashof number.

The transport properties of isobutane, viscosity and thermal conductivity, were more difficult to find in the published literature. The viscosity of isobutane was reported by Gonzalez and Lee [19] over a range of temperature of $100^{\circ} \mathrm{F}$ to $460^{\circ} \mathrm{F}$ and pressure from atmospheric to $8000 \mathrm{psia}$. The author also calculated some values of viscosity using the method described in Chapter 11 of the American Petroleum Institute, Technical Data Book, 1970 [20]. All of these values of viscosity are plotted on Fig. A-5 for comparison. The values calculated by Silvester are about $20 \%$ higher than those obtained by author and Gonzalez and Lee. Because the data points published by Gonzalez and Lee were few, the values of viscosity provided by Silvester were used in the data reduction.

The thermal conductivity, $k$, of isobutane was not found in the published literature. The author was able to calculate some values of $k$ 
using the procedures described in Chapter 12 of [20]. These values of $k$ are plotted on Fig. A-6 for comparison with those furnished by Silvester and the two sets of values do not agree very well. The values of thermal conductivity furnished by Silvester were used in the data reduction.

At this point, the following conclusions can be stated:

(a) Thermodynamic properties of isobutane calculated by L. Silvester and used in the data reduction have been checked by author with the published data and his calculated values. The comparison has shown that Silvester's data are accurate.

(b) Transport properties of isobutane calculated by Silvester have been checked also using the same approach as before but the results do not match very well. To be consistent with the thermodynamic properties, the values by Silvester are accepted and used in the data reduction. 


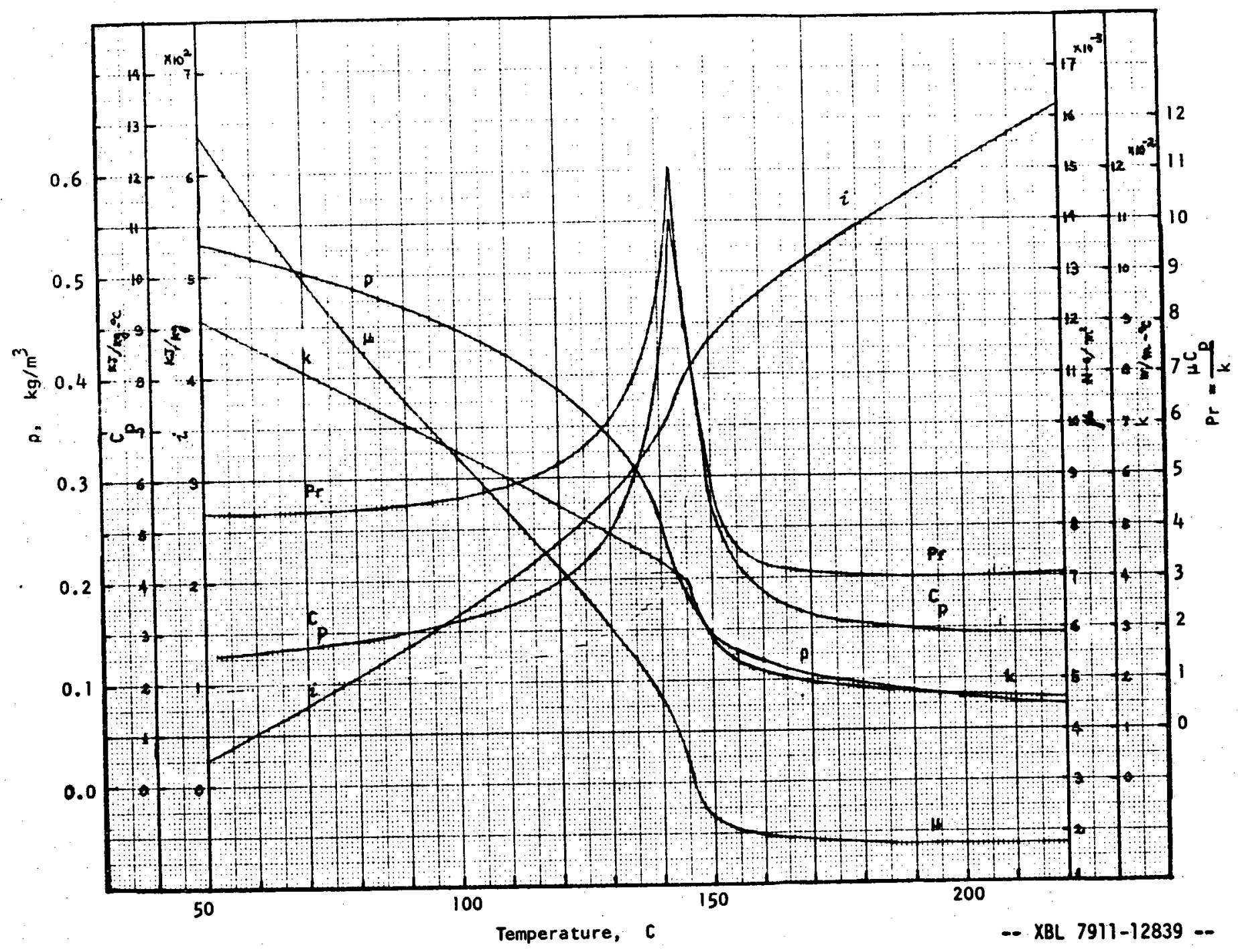

Fig. A-1. Properties of isobutane at $4.14 \mathrm{MPa}$ (600 psia). 


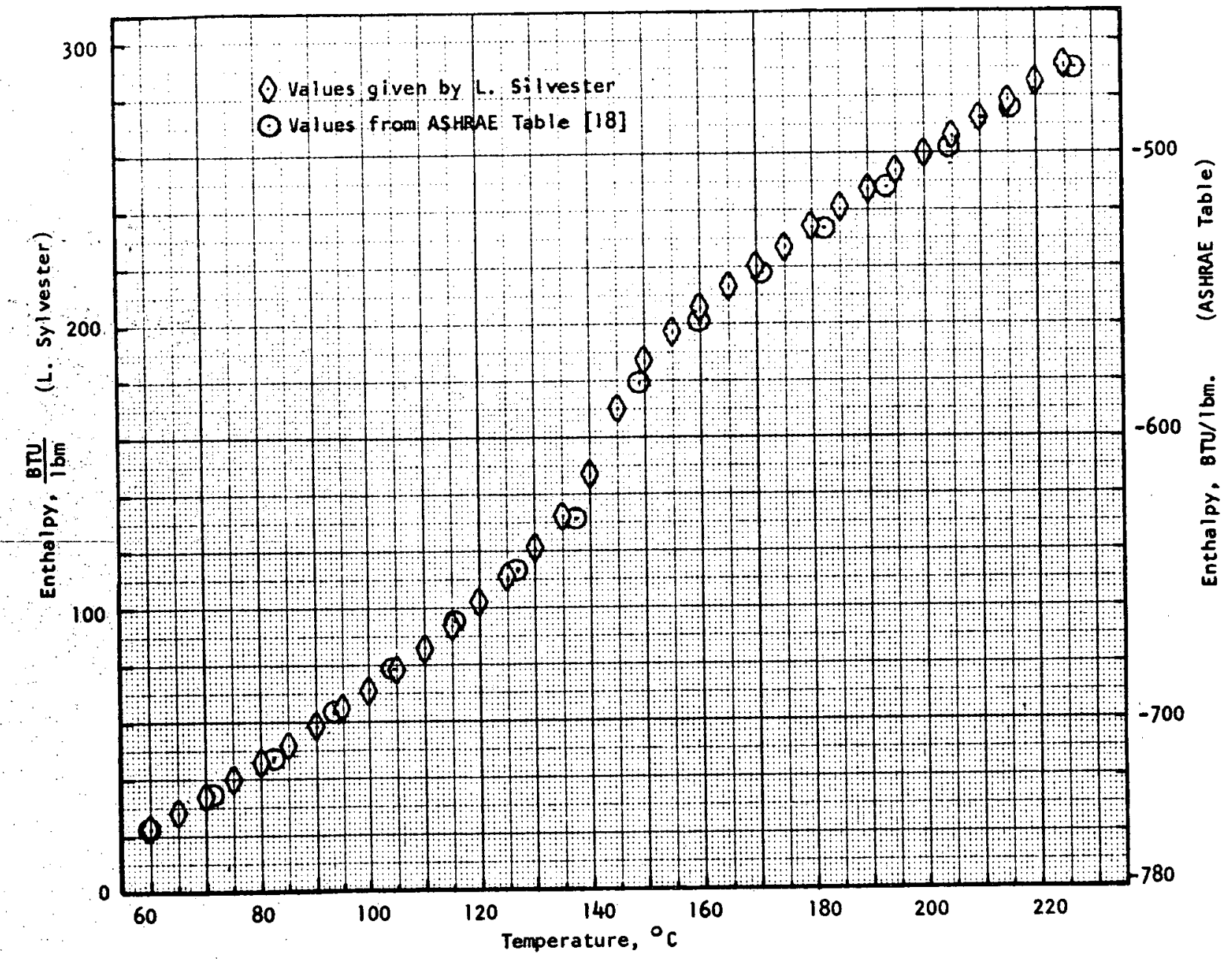

Fig. A-2. Comparison of enthalpy of isobutane at $4.14 \mathrm{MPa}$ obtained from two sources. 


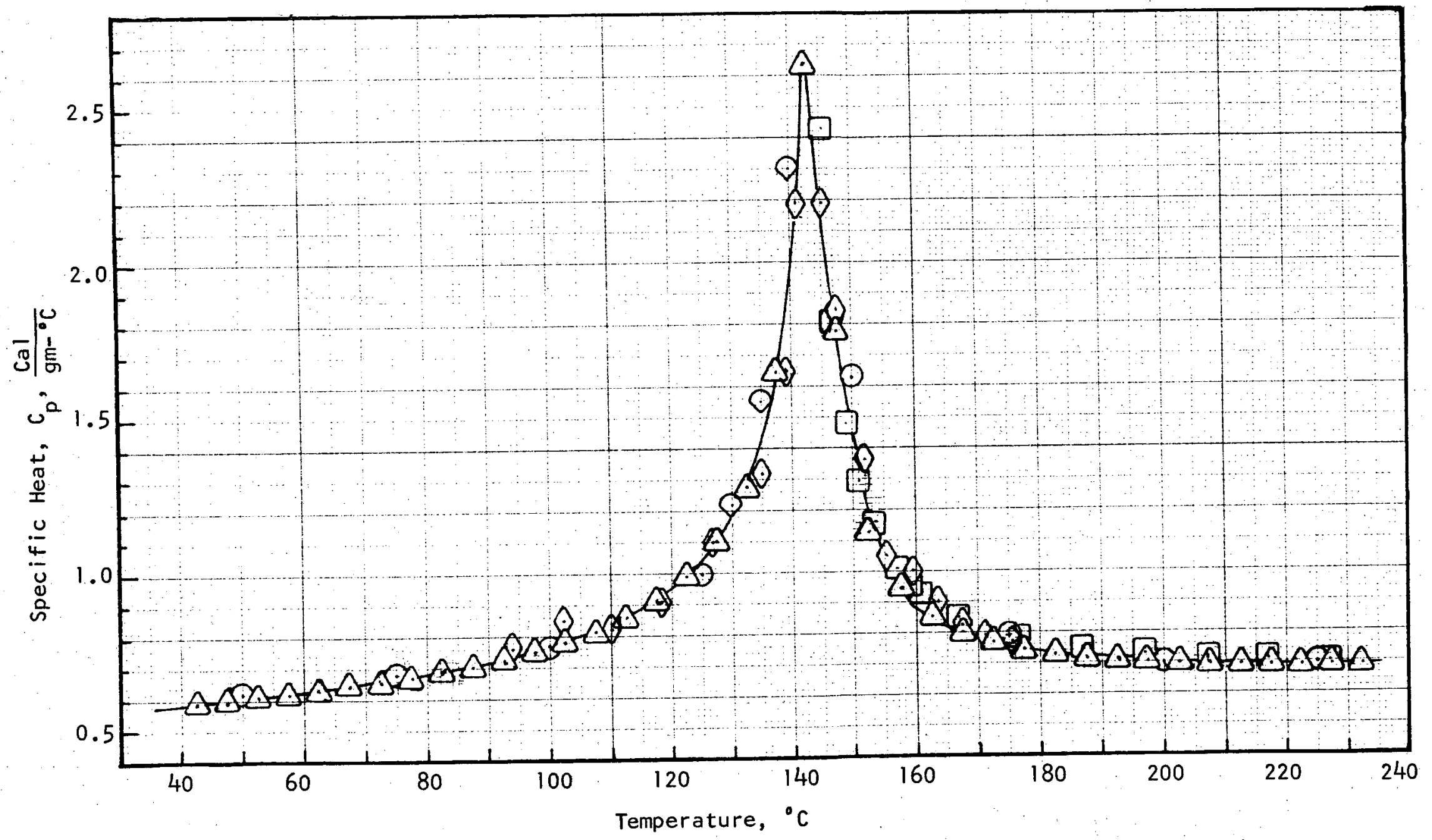

Fig. A-3. Comparison of Specific Heat of Isobutane at $4.14 \mathrm{MPa}$ (600 psia) Obtained From Various Sources. 


\section{(Continuation of Figure $\mathrm{A}-3$}

\section{from previous page)}

$\triangle$ Values calculated from enthalpy of isobutane given by L. Silvester.

$\rightarrow$ Values calculated from Hougen, Watson and Ragatz [24].

$\odot$ Values from Table 50, pp. 266, of [18].

$\odot$ Values calculated from interpolation of $\left(C_{p}-c_{p}^{*}\right)$ vs. $P_{r}$, pp. 108 of Chemical Process Principles Chart by Hougen and Watson [25].

$\square$ Values calculated from API Research Project 44, Table 23$2-(1.2005)-j j$, June 1970. 


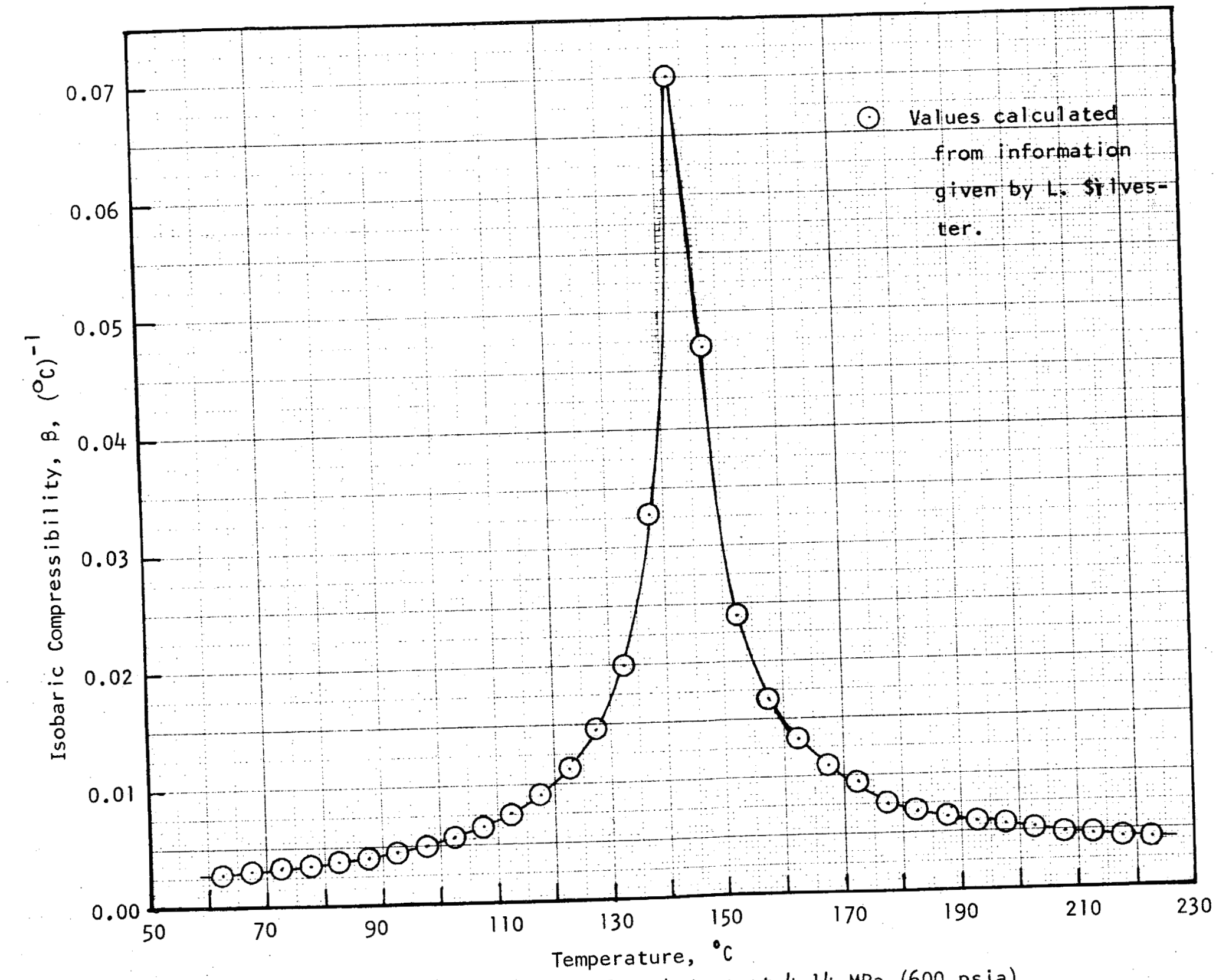

Fig. A-4. Isobaric Compressibility of Isobutane at $4.14 \mathrm{MPa}(600 \mathrm{psia})$. 


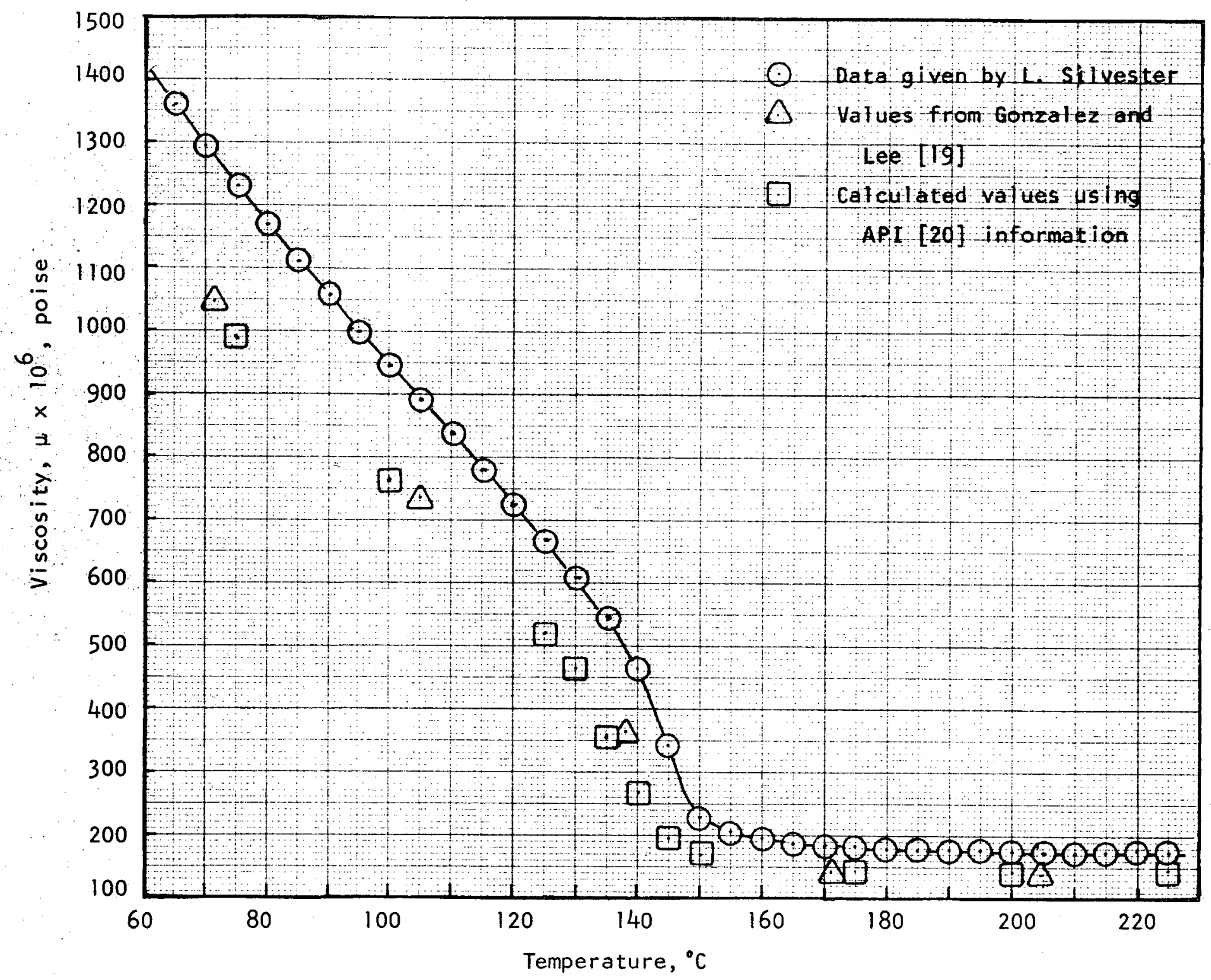

Fig A-5. Viscosity of Isobutane at $4.14 \mathrm{MPa}$ (600 psia). 


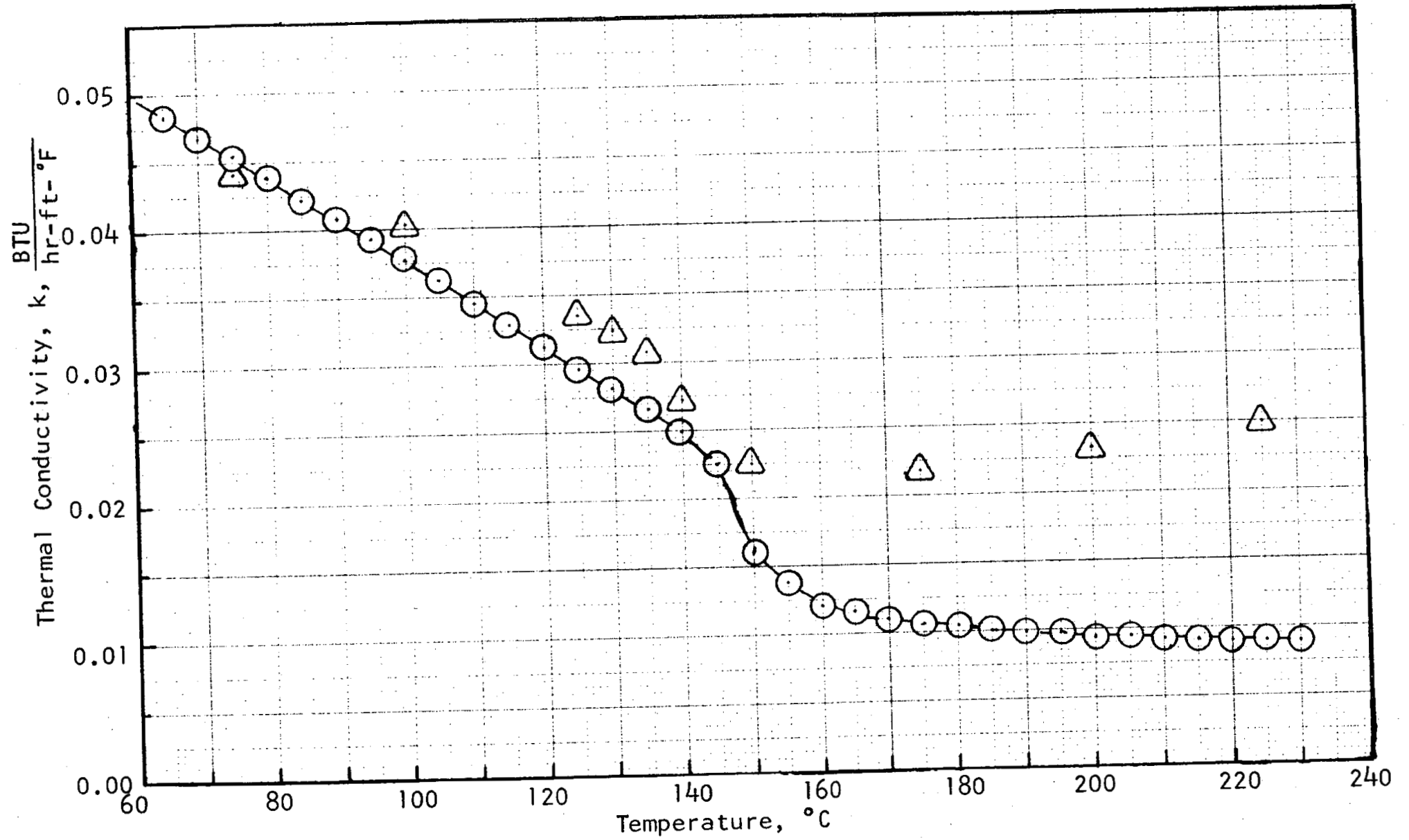

Fig. A-6. Thermal Conductivity of Isobutane at $4.14 \mathrm{MPa}$ (600 psia).

$$
\begin{aligned}
& \odot \text { Values calculated by } L \text {. Silvester. } \\
& \triangle \text { Values calculated by API } \\
& \text { Information }[20] \text {. }
\end{aligned}
$$

$\dot{\omega}$ 


\section{APPEND IX B}

\section{EXPER IMENTAL DATA}

The experimental data are presented in this appendix in three tables:

(1) Table B-1 contains runs with $E>1$ at almost all the temperature measurement stations.

(2) Table $8-2$ contains runs with $0.01<E<1.0$ at all the temperature measurement stations.

(3) Table 8-3 contains either those runs with $E$ changing from positive to negative along the length of the exchanger tube or those runs with E negative at all the temperature measurement stations.

Within each table, the experimental runs are tabulated in increasing order of Reynolds number, $\mathrm{Re}_{b}$, at Section $\mathrm{H}$, column 8, of each table. 


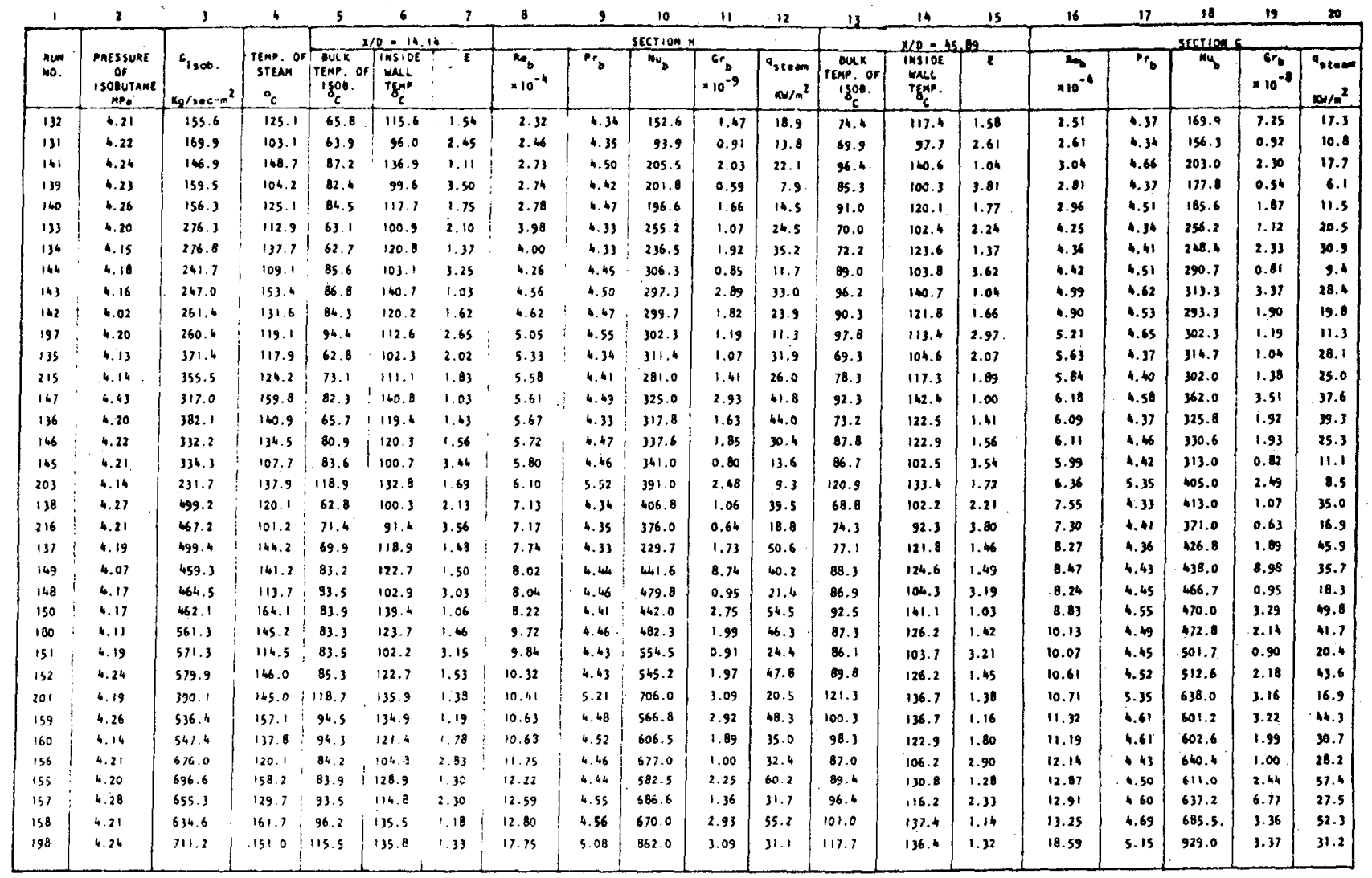

\begin{tabular}{|c|c|c|c|c|c|c|c|c|c|c|c|c|c|c|c|c|c|c|c|}
\hline & 21 & 22 & 23 & 24 & 25 & 26 & 27 & 28 & 29 & 30 & 31 & 32 & 33 & 34 & 35 & 36 & \multirow{2}{*}{\multicolumn{3}{|c|}{$37 \quad 38$}} \\
\hline \multirow[b]{2}{*}{$\begin{array}{l}\text { MUN } \\
\text { No. }\end{array}$} & & $\angle D_{-}=\| 1$ & & & & We & & & \multicolumn{3}{|c|}{$x / 0=109.38$} & \multicolumn{5}{|c|}{ Skcrion } & & & \\
\hline & 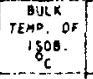 & 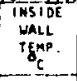 & $\overline{\boldsymbol{E}}$ & $\times 10^{-4}$ & $P_{0}$ & $\because 5$ & $110^{-8}$ & siteam & $\begin{array}{c}\text { remp. of } \\
\text { 's gos. }\end{array}$ & $\begin{array}{c}\text { WhSTDE } \\
\text { UALL } \\
\text { TEMP. } \\
\text { Ge }\end{array}$ & $E$ & $\begin{array}{r}748 \\
\times 10^{-4}\end{array}$ & $P_{r_{b}}$ & & $\begin{array}{l}G^{-6} \\
\times 10^{-8}\end{array}$ & 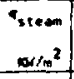 & 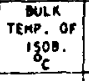 & $\begin{array}{c}\text { INSIDEE } \\
\text { MALL } \\
\text { TEMP. }\end{array}$ & E \\
\hline 132 & 82.0 & 119.3 & 1.62 & 2.69 & 4.46 & 163.8 & 1.79 & $\longdiv { 3 . 8 }$ & 88.4 & 120.7 & 1.67 & 2.86 & 4.50 & 178.9 & 1.79 & 12.5 & 93.8 & 121.7 & 1.75 \\
\hline 131 & 74.6 & 98.9 & 2.79 & 2.72 & 4.36 & 150.0 & 0.93 & 9.3 & 78.6 & 99.7 & 3.03 & 281 & 4. 38 & 166.9 & 0.84 & 8.2 & 8:.9 & 100.0 & 3.15 \\
\hline 141 & 103.8 & 141.9 & 1.02 & 13.24 & 4.80 & 219.4 & 2.28 & 15.1 & 110.0 & 142.5 & 1.00 & 3.50 & 4.98 & 234.7 & 2.34 & 13.6 & iis." & 142.9 & 0.98 \\
\hline 139 & BB. 1 & 101.1 & 4.19 & 2.88 & 4.46 & 183.4 & 0.50 & 5.3 & 90.2 & 101.6 & 4.57 & 2.95 & 4.50 & 191.0 & 0.45 & 4.5 & 92.7 & 101.9 & 5.60 \\
\hline 140 & 96.2 & 121.3 & 1.85 & 3.13 & 4.59 & 199.4 & 1.85 & 10.0 & 100.5 & 121.7 & 1.98 & 3.26 & 4.72 & 212.4 & 1.81 & 8.6 & 104.6 & 121.9 & 2.18 \\
\hline 133 & 75.3 & 103.9 & 2.35 & 4.46 & 4.34 & 259.4 & 1.12 & 17.7 & 80.0 & 105.3 & 2.47 & 6.64 & 4.38 & 267.9 & 1.20 & 16.0 & 83.8 & 106.9 & 2.54 \\
\hline 134 & 30.7 & 126.3 & 1,36 & 4.75 & 4.39 & 253.2 & 2.77 & 26.9 & 87.9 & 127.9 & 4.37 & 5.11 & 4.51 & 284.0 & 2.97 & 24.6 & 93.9 & 128.7 & 140 \\
\hline 144 & 916 & 104.6 & 3.90 & 6.51 & 4.49 & 291.9 & 0.76 & 8.2 & 93.7 & 105.2 & 4.26 & 4.50 & 4.52 & 298.2 & 0.11 & 1.4 & 95.6 & 105.9 & 4. 48 \\
\hline 143 & 103.6 & 162.8 & 0.99 & 5.42 & 4.08 & 283.6 & 3.85 & 25.1 & 109.8 & 144.4 & 0.95 & 5.86 & 4.61 & 340.5 & 4.47 & 23.1 & 185.7 & (45.) & 0.90 \\
\hline 142 & 95.4 & 123.3 & 1.69 & 5.15 & .60 & 293.1 & 1.98 & 17.2 & 99.7 & 124.4 & 1.73 & 5.34 & 4.65 & 329.2 & '.99 & 16.9 & 102.1 & 125.1 & 1.76 \\
\hline 197 & 99.7 & 114.2 & 2.95 & 5.21 & 4.65 & 324 & 1.15 & 10.6 & 102.7 & 1.15 .1 & 3.21 & 5.38 & 4.74 & 323.1 & 1.09 & 8.0 & 104.8 & 115.9 & 3. 18 \\
\hline 135 & 74.6 & 106.7 & 2.12 & 5.92 & 4.36 & 314.8 & 1.18 & 21.2 & 79.6 & 107.9 & 2.22 & 6.21 & (4.63 & 337.6 & 1.17 & 22.3 & 83.7 & 108.6 & 2.36 \\
\hline 215 & 81.6 & 113.7 & 1.90 & 6.18 & 4.46 & 303.0 & 1.50 & 21.1 & 89.3 & 115.1 & 2.06 & 6.57 & 4.51 & 342.0 & 1.49 & 19.3 & 94.4 & 116.4 & 2.18 \\
\hline ib7 & 100.2 & 144.3 & 0.96 & 6.69 & 6.68 & 375.0 & 4.04 & 32.5 & 107.4 & 146.1 & 0.91 & 7.52 & 4.80 & $\$+2.0$ & 4.70 & 00.0 & 116.5 & (4) .9 & 0.83 \\
\hline 136 & Bo. 4 & 125.3 & 1,38 & 6.53 & 4.54 & 333.3 & 2.06 & 34.7 & 26.9 & 127.3 & 1.38 & 6.53 & 4.54 & 361.9 & 2.22 & 31.9 & 92.9 & 128. & 1.40 \\
\hline 146 & 93.0 & 124.3 & 1.58 & 6.45 & 4.55 & 361.1 & 2.07 & 23.4 & 98.2 & 125.2 & 1.64 & 6.86 & 4.65 & 284.2 & 2.06 & 20.3 & 103.6 & 126.1 & 1.33 \\
\hline 165 & 89.2 & 103.3 & 3.77 & 6.11 & 4.56 & 318.0 & 0.74 & 9.8 & 91,3 & 103.6 & 4.15 & 6.26 & 4.52 & 365.0 & 0.72 & 6.9 & 93.5 & $103 . \%$ & 4.74 \\
\hline 203 & 122.7 & 134,2 & 1.73 & 6.59 & 5.45 & 394.0 & 2.42 & 7.0 & 125.4 & 134.8 & 1.82 & 6.96 & 5.73 & $406: 0$ & 2.36 & 5.9 & 121.6 & 135.5 & 1.88 \\
\hline 138 & 13. 8 & 104.3 & 2.25 & 7.93 & 4. 34 & tos. 3 & 1.15 & 30.5 & 78.2 & 106.2 & 2. 30 & a. 34 & 4.37 & 456.2 & 1.22 & 30.3 & 82.1 & 101.7 & 2.36 \\
\hline 216 & 76.2 & 93.6 & 3.85 & 7.48 & 4.41 & 350.0 & 6.56 & 14.7 & 79.1 & 94.4 & 4.14 & 1.70 & 0.36 & 348.0 & 0.62 & 12.9 & 11.3 & 95.4 & 4. 14 \\
\hline 131 & 83.5 & 124.6 & 1.46 & 8.72 & 4.36 & 626.8 & 1.89 & 45.9 & 88.9 & 126.6 & 1.62 & 9.23 & 4.50 & 461.4 & 2.14 & 38.0 & 96.1 & 121.8 & 1.44 . \\
\hline 149 & 104.6 & 126.7 & 1.72 & 8.96 & 4.52 & 424.9 & 2.18 & 30.2 & 98.7 & 128.2 & 1.49 & 9.49 & 4.65 & 488.2. & 2.40 & 28.7 & 103.9 & 129.6 & $1.50^{\circ}$ \\
\hline $16 \mathrm{~A}$ & 88.5 & 105.7 & 3.15 & 8.40 & 4.52 & 411,4 & 0.93 & 15.6 & 91.1 & 106.5 & 3.33 & 8.64 & 4.51 & $=41.5$ & 0.89 & 14.5 & 93.4 & 106.8 & 3.66 \\
\hline 150 & 96.9 & 143.3 & 0.98 & 9.50 & 4.65 & 676.0 & 3.66 & 43.9 & 104.4 & 145.3 & 0.93 & 10.51 & 4.67 & 570.0 & 4,45 & 42.2 & 113.4 & 147.2 & 0.86 \\
\hline 180 & 92.0 & 1286 & $1.3 \mathrm{a}$ & 10.68 & 4.55 & 466.6 & 2.31 & 36.5 & 97.1 & 130.2 & 1.37 & 11.35 & 4.62 & 526.2 & 2.48 & 34., & 102.6 & 131.1 & 1.0 \\
\hline 151 & 86. 3 & 105.0 & 3.25 & 10.26 & 4. 48 & .75 .4 & 0.91 & 10,1 & 90.2 & 105.9 & 3,34 & 10.45 & 4.52 & 487.0 & 0.89 & 17.3 & 91.3 & 106.2 & 3.4h \\
\hline 152 & 91.6 & 128.4 & 1. 30 & 18.03 & 4.55 & 482.0 & 2.29 & 34.2 & 96.6 & 129.7 & 1.39 & 11.92 & 4.83 & 569.6 & 2.65 & 35.9 & 106.6 & 129.7 & 1.51 \\
\hline 201 & 122.8 & 137.6 & 1.33 & 11.18 & 5.46 & 604.0 & 3.25 & 14.4 & 125.4 & 138.6 & 1,31 & 11.67 & 5.11 & xot.0 & 3.22 & 14.1 & 128.2 & 139.1 & 1.29 \\
\hline 159 & 105.7 & 198.8 & 1.11 & 12.05 & 6.31 & 615.0 & 3.63 & 39.2 & 110.1 & 160.6 & 1.06 & 12.75 & 4. 39 & 332.0 & 3.8 & 31.3 & 114.9 & 162.1 & 1.01 \\
\hline 160 & 101.6 & 126.5 & 1. 79 & 11.56 & $\therefore 64$ & 574.7 & 2.16 & 26.8 & 104.7 & 125.8 & 1.79 & 11.95 & 6.13 & 598.1 & 1,00 & 25.1 & 107.6 & 123.1 & 1.79 \\
\hline 156 & 89.6 & 107.6 & 2.94 & 1263 & 6.50 & 615.3 & 0.99 & 24.9 & 91. & 108.7 & 3.01 & 17.61 & 4.52 & 626.4 & 1.03 & 23.4 & 93.1 & 100.7 & 3.26 \\
\hline 1ss & 93.3 & 133.3 & 1.23 & 13.59 & 4.52 & 601.2 & 2.75 & 51.5 & 99.0 & 135.7 & 1.19 & 14.39 & 4.73 & 622.6 & 3.04 & 4.0 & 104.6 & 131.8 & 1.14 \\
\hline 157 & 98.2 & 117.6 & 2.28 & 13.25 & $4.8 !$ & 609.5 & 1.48 & 26.3 & 101.2 & 118.6 & 2.38 & 13.69 & 4.69 & 651.1 & 1.45 & 27.1 & 103.6 & 119.2 & 1.4 \\
\hline 158 & 106.0 & 139.6 & 1.01 & 13.86 & 6.79 & 68.3 & 3.54 & 46.7 & 109.1 & 141.3 & 1.06 & 14.96 & 4.81 & 759.9 & 6.01 & H. 5 & 116.8 & 142.8 & 0.99 \\
\hline 198 & 119.4 & 137.4 & 1.28 & 19.25 & 5.17 & 968.3 & 3.47 & 28.5 & 123.2 & 138.2 & 1.28 & 20.09 & 5.49 & 1123.7 & 3.46 & 27.6 & 125.6 & 130.2 & 1.34 \\
\hline
\end{tabular}

TABLE B-1. TABULATION OF EXPERIMENTAL DATA FROM RUNS WITH E $>1$. 


\begin{tabular}{|c|c|c|c|c|c|c|c|c|c|c|c|c|c|c|c|c|c|c|c|}
\hline 1 & 2 & 3 & 4 & 5 & $\underline{c}$ & 1 & $\underline{3}$ & 9 & 10 & 11 & 12 & 13 & 14 & 15 & 16 & 17 & 18 & 19 & 20 \\
\hline \multirow[b]{2}{*}{$\begin{array}{l}\text { Rum } \\
\text { No. }\end{array}$} & \multirow[b]{2}{*}{$\begin{array}{l}\text { PRESSURE } \\
\text { OF } \\
\text { I SOBUTANE } \\
\text { MPP }\end{array}$} & \multirow[b]{2}{*}{$\begin{array}{c}{ }^{6} / \mathrm{sob} \\
\mathrm{Kg} / \mathrm{sec}-\mathrm{m}^{2}\end{array}$} & \multirow[b]{2}{*}{$\begin{array}{c}\text { TEMP: OF } \\
\text { STEAH } \\
{ }^{\circ} \mathrm{C}\end{array}$} & \multicolumn{3}{|c|}{$x / 0=14.4$} & \multicolumn{5}{|c|}{ ECrION } & \multicolumn{3}{|c|}{$x / 0=45.89$} & \multicolumn{5}{|c|}{ SECTION G } \\
\hline & & & & $\begin{array}{c}\text { OWRK } \\
\text { TEMP. OF } \\
\text { ISOB. } \\
{ }^{\circ} \mathrm{C}\end{array}$ & $\begin{array}{l}\text { TNSTDE } \\
\text { WRLL } \\
\text { TEAP. } \\
\text { OC }\end{array}$ & $E$ & $\begin{array}{r}R e_{b} \\
\times 10^{-4}\end{array}$ & $\mathrm{Pr}_{\mathrm{b}}$ & $\mathrm{Nu}_{\mathrm{b}}$ & $\begin{array}{r}G r_{b} \\
\times 10^{-8}\end{array}$ & $\begin{array}{l}q_{\text {steam }} \\
\mathrm{kW} / \mathrm{m}^{2}\end{array}$ & $\begin{array}{l}\text { BULK } \\
\text { TEMP. OF } \\
\text { ISOB. }\end{array}$ & $\begin{array}{l}\text { THSTOE } \\
\text { HALL } \\
\text { TEMP. } \\
\text { OC }\end{array}$ & 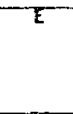 & $\begin{array}{r}R_{b} \\
\times 10^{-4}\end{array}$ & $P_{b}$ & $w_{b}$ & $\begin{array}{l}6 r_{D} \\
\times 10^{-8}\end{array}$ & $\begin{array}{l}q_{\text {steam }} \\
\mathrm{kH} / \mathrm{m}^{2}\end{array}$ \\
\hline 185 & 4.16 & 159.2 & 156.3 & 118.6 & 148.2 & 0.81 & 4.34 & 5.39 & 361.9 & 5.84 & 17.2 & 125.1 & 149.2 & 0.72 & 4.78 & 5.71 & 389.5 & 6.79 & 15.0 \\
\hline 195 & 4.10 & 281.7 & 191.3 & 100.1 & 169.2 & 0.61 & 6.12 & 4.64 & 379.8 & 6.56 & 50.7 & 110.8 & 171.2 & 0.52 & 6.77 & 4.87 & 414.0 & 8.29 & 47.2 \\
\hline 181 & 4.12 & 327.4 & 217.3 & 96.8 & 187.4 & 0.50 & 6.87 & 4.67 & 369.5 & 7.82 & 67.4 & 108.8 & 190.4 & 0.41 & 7.96 & 5.08 & 454.6 & 11.70 & 66.7 \\
\hline 184 & 4.12 & 277.0 & 168.2 & 117.7 & 154.7 & 0.67 & 7.44 & 5.36 & 497.9 & 7.09 & 30.9 & 123.7 & 156.6 & 0.57 & 8.25 & 5.65 & 528.4 & 8.93 & 27.2 \\
\hline 182 & 4.04 & 354.2 & 178.3 & 115.9 & 159.3 & 0.61 & 9.31 & 5.22 & 571.7 & 7.83 & 42.6 & 121.9 & 160.6 & 0.53 & 10.08 & 7.67 & 629.2 & 9.08 & 39.1 \\
\hline 153 & 4.27 & 558.8 & 176.1 & 84.3 & 142.4 & 1.00 & 9.91 & 4.46 & 522.7 & 3.06 & 69.1 & 91.3 & 145.7 & 0.94 & 10.74 & 4.54 & 563.6 & 3.50 & 66.0 \\
\hline 175 & 4.50 & 519.3 & 219.1 & 95.7 & 180.1 & 0.55 & 10.50 & 4.62 & 514.9 & 6.61 & 91.5 & 104.1 & 183.9 & 0.48 & 11.74 & 4.94 & 555.5 & 9.01 & 84.6 \\
\hline 174 & 4.20 & 552.4 & 184.9 & 94.4 & 152.3 & 0.83 & 11.00 & 4.60 & 572.3 & 4.27 & 71.1 & 101.7 & 157.1 & 0.74 & 12.02 & 4.75 & 604.2 & 5.34 & 66.0 \\
\hline 183 & 4.35 & 404.3 & 179.2 & 120.8 & 158.4 & 0.58 & 11.14 & 5.61 & 716.2 & 8.27 & 44.7 & 125.4 & 159.9 & 0.50 & 12.23 & 5.98 & 765.2 & 10.18 & 41.4 \\
\hline 154 & 4.19 & 652.3 & 179.3 & 37.1 & 143.0 & 0.99 & 11.88 & 4.54 & - & 3.15 & - & 93.7 & 146.3 & 0.93 & 12.79 & 4.55 & 648.6 & 3.75 & 72.8 \\
\hline 176 & 4.14 & 613.3 & 223.6 & 96.6 & 180.3 & 0.55 & 12.67 & 4.74 & 597.5 & 7.01 & 101.4 & 106.6 & 182.8 & 0.47 & 14.20 & 4.90 & 702.2 & 9.36 & 100.5 \\
\hline 177 & 4.36 & 627.2 & 187.7 & 96.3 & $151.3^{\circ}$ & 0.84 & 12.85 & 4.65 & 670.3 & 4.39 & 75.9 & 105.2 & 155.7 & 0.74 & 13.90 & 4.80 & 721.7. & 5.63 & 72.7 \\
\hline 186 & 4.39 & 496.3 & 181.4 & 117.5 & 157.5 & 0.63 & 13.15 & 5.40 & 809.3 & 7.42 & 54.4 & 123.2 & 158.5 & 0.55 & 14.13 & 5.67 & 853.0 & 8.48 & 50.0 \\
\hline 189 & 4.18 & 528.0 . & 206.1 & 118.7 & 175.4 & 0.42 & 14.29 & 5.65 & 740.2 & 11.62 & 69.6 & 124.6 & 176.1 & c. 35 & 15.85 & 6.10 & 848.3 & 15.56 & 68.6 \\
\hline
\end{tabular}

\begin{tabular}{|c|c|c|c|c|c|c|c|c|c|c|c|c|c|c|c|c|c|c|c|}
\hline \multirow[b]{3}{*}{$\begin{array}{l}\text { nun } \\
\text { No. }\end{array}$} & 21. & 22 & 23 & 24 & 25 & 26 & 22 & 28 & 32 & 30 & 31 & 32 & 31. & 34 & 35. & 36 & 32 & $3 B$ & 39 \\
\hline & \multicolumn{3}{|c|}{$\quad x / \mathrm{D}=72.63$} & \multirow{2}{*}{\multicolumn{2}{|c|}{$\mathrm{Pr}_{\mathrm{b}}$}} & \multirow{2}{*}{$\mathrm{ECLILOK}_{\mathrm{Nu}_{\mathrm{b}}}$} & \multirow[b]{2}{*}{$\begin{array}{r}6 r_{b} \\
\times 10^{-8}\end{array}$} & \multirow[b]{2}{*}{$\begin{array}{l}a_{5 t c a m} \\
\mathrm{nu} / \mathrm{m}^{2}\end{array}$} & \multicolumn{3}{|c|}{$\quad x / 0=109.38$} & \multicolumn{5}{|c|}{ SECTION E } & \multicolumn{3}{|c|}{$x / 0=141.12$} \\
\hline & $\begin{array}{l}\text { BULX } \\
\text { TEMP. OF } \\
\text { ISOB: } \\
\text { OC } \\
\end{array}$ & $\begin{array}{l}\text { IWSIDE } \\
\text { YALL } \\
\text { TEMP } \\
\text { OC } \\
\end{array}$ & $\varepsilon$ & & & & & & $\begin{array}{c}\text { BULK } \\
\text { TEMP. OF } \\
\text { tSOB. } \\
\text { OC } \\
\end{array}$ & $\begin{array}{c}\text { INSIDE } \\
\text { WALL. } \\
\text { TEMP. } \\
\text { OC }\end{array}$ & $\varepsilon$ & $\begin{array}{l}\text { Re } \\
\times 10^{-4}\end{array}$ & $\mathrm{Pr}_{\mathrm{b}}$ & $\mathrm{Nu}_{\mathrm{b}}$ & $\begin{array}{l}G_{b} \\
\times 10^{-8}\end{array}$ & $\begin{array}{l}q_{\text {steam }} \\
\mathrm{kW} / \mathrm{m}^{2}\end{array}$ & $\begin{array}{c}\text { BULK } \\
\text { TEMP. OF } \\
\text { ISOQ. } \\
\text { OC. }\end{array}$ & $\begin{array}{l}\text { INSIOE } \\
\text { WALL } \\
\text { TEMP. } \\
\text { OE: }\end{array}$ & $E$ \\
\hline 185 & 127.9 & 150.3 & 0.65 & 5.06 & 6.07 & 378.7 & 7.67 & 12.5 & 132.6 & 151.4 & 0.53 & 5.66 & 6.56 & 446.7 & 10.04 & 11.7 & 137.1 & 152.5 & 0.35 \\
\hline 195 & 115.9 & 173.5 & 0.46 & 7.52 & 5.14 & 431.2 & 10.64 & 42.3 & 124.4 & 175.7 & 0.35 & 9.17 & 6.31 & 584.1 & 15.10 & 41.7 & 138.3 & 177.8 & 0.11 \\
\hline 181 & 120.5 & 193.7 & 0.30 & 9.53 & 5.79 & 524.7 & 18.82 & 60.9 & 131.7 & 196.2 & 0.17 & 12.10 & 7.45 & 644.3 & 40.42 & 57.8 & 141.8 & 198.2 & 0.01 \\
\hline 184 & 129.4 & 158.1 & 0.46 & 9.26 & 6.48 & 562.9 & 11.80 & 23.3 & $135 . !$ & 159.1 & 0.31 & 10.64 & 7.76 & 727.5 & 16.39 & 23.3 & 140.3 & 159.6 & 0.11 \\
\hline 182 & 127.8 & 162.1 & 0.43 & 11.42 & 6.26 & 724.1 & 12.35 & 36.6 & 134.1 & 163.2 & 0.29 & 13.09 & 7.33 & 911.4 & 18.04 & 37.0 & 139.1 & 164.4 & 0.13 \\
\hline 153 & 98.9 & 148.9 & 0.87 & 11.70 & 4.68 & 603.7 & 4.17 & 60.2 & 106.8 & 151.1 & 0.81 & 12.94 & 4.99 & 716.7 & 5.27 & 56.5 & 115.6 & 152.1 & 0.74 \\
\hline 175 & 114.5 & 187.6 & 0.33 & 13.67 & 5.35 & $626.4^{\circ}$ & 13.31 & 77.2 & 125.4 & 190.2 & 0.26 & 16.91 & 6.39 & 801.8 & 23.69 & 74.5 & 137.4 & 190.7 & 0.10 \\
\hline 174 & 109.6 & 160.1 & 0.65 & 13.30 & 5.06 & 634.0 & 6.92 & 51.1 & 117.8 & 161.6 & 0.56 & 15.01 & 5.37 & 779.3 & 8.62 & 54.2 & 126.5 & 162.3 & 0.45 \\
\hline 183 & 130.3 & 161.4 & 0.39 & 13.63 & 6.57 & 855.6 & 13.26 & 38.6 & 135.7 & 162.3 & 0.26 & 15.85 & 8.03 & 1125.9 & 28.32 & 39.3 & 141.6 & 163.0 & 0.04 \\
\hline 154 & 100.5 & 149.6. & 0.86 & 13.89 & 4.73 & 642.4 & 4.42 & 62.2 & 107.9 & 151.6 & 0.79 & 15.28 & 5.02 & 822.0 & 5.40 & 64.1 & 116.0 & 152.6 & 0.72 \\
\hline 176 & 115.7 & 186.4 & 0.38 & 16.37 & 5.23 & 734.9 & 13.12 & 88.2 & 124.9 & 189.6 & 0.27 & 19.32 & 6.01 & 936.1 & 21.03 & 92.3 & 134.3 & 192.7 & 0.14 \\
\hline in & 109.3 & 158.2 & 0.68 & 14.80 & 5.02 & 755.4 & 6.42 & 67.3 & 116.2 & 159.4 & 0.61 & 16.74 & 5.45 & 966.6 & 7.90 & 66.5 & 125.3 & 159.9 & 0.50 \\
\hline 186 & 126.4 & 159.9 & 0.49 & 15.35 & 6.01 & 910.3 & 10.68 & 47.0 & 131.6 & 161.3 & 0.37 & 17.50 & 6.94 & 1143.9 & 14.76 & 47.2 & 138.2 & 162.5 & 0.18 \\
\hline 189 & 130.4 & 177.3 & 0.26 & 17.86 & 6.67 & 918.3 & 21.02 & 63.6 & 136.1 & 178.2 & 0.15 & 21.05 & 8.21 & 1199.5 & 34.52 & 68.5 & 141.8 & 178.7 & 0.02 \\
\hline
\end{tabular}

TABLE B 2. TABULATION OF EXPERIMENTAL DATA FROM RUNS WITH $0.01<$ E $<1.0$ 


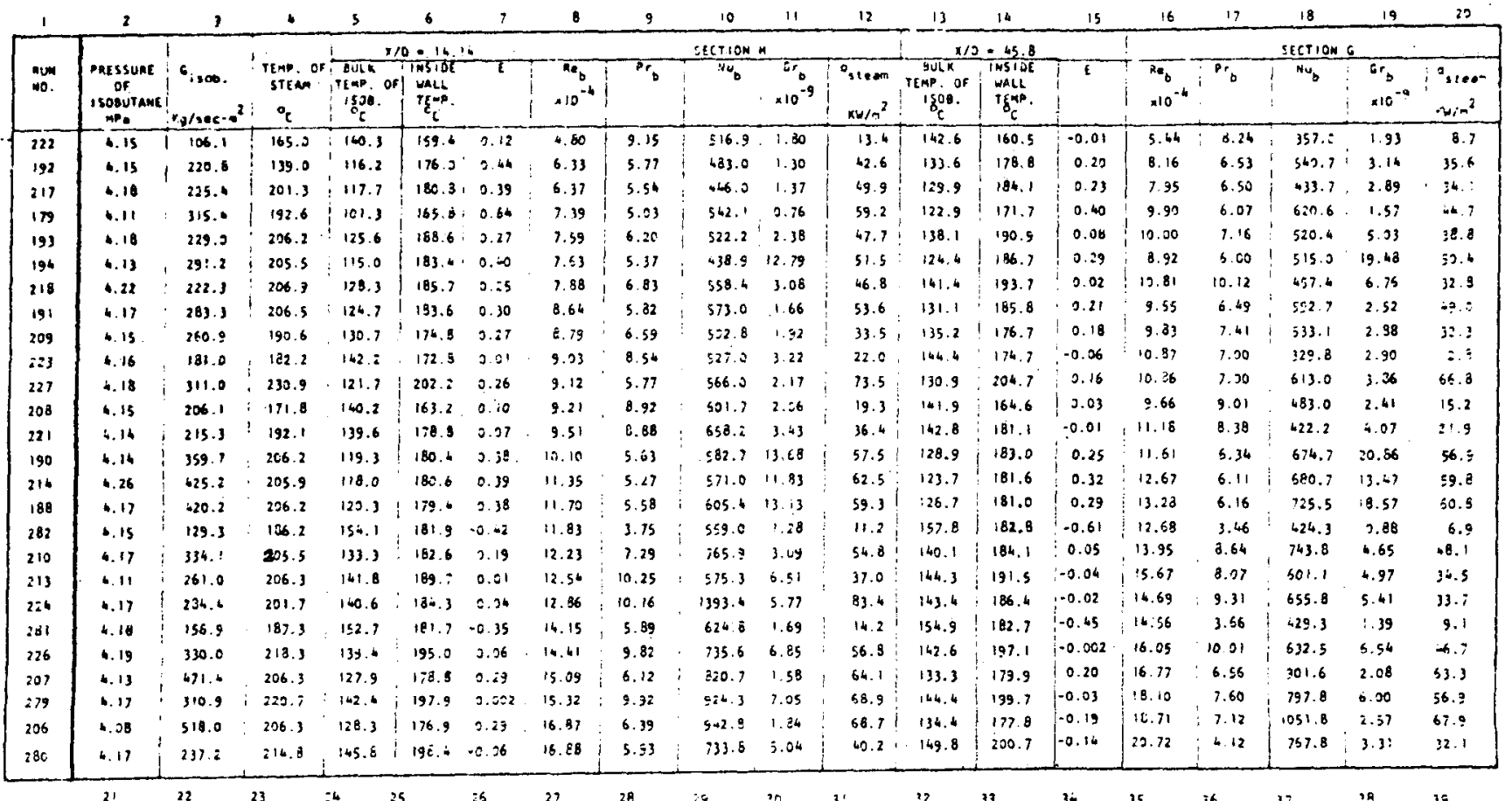

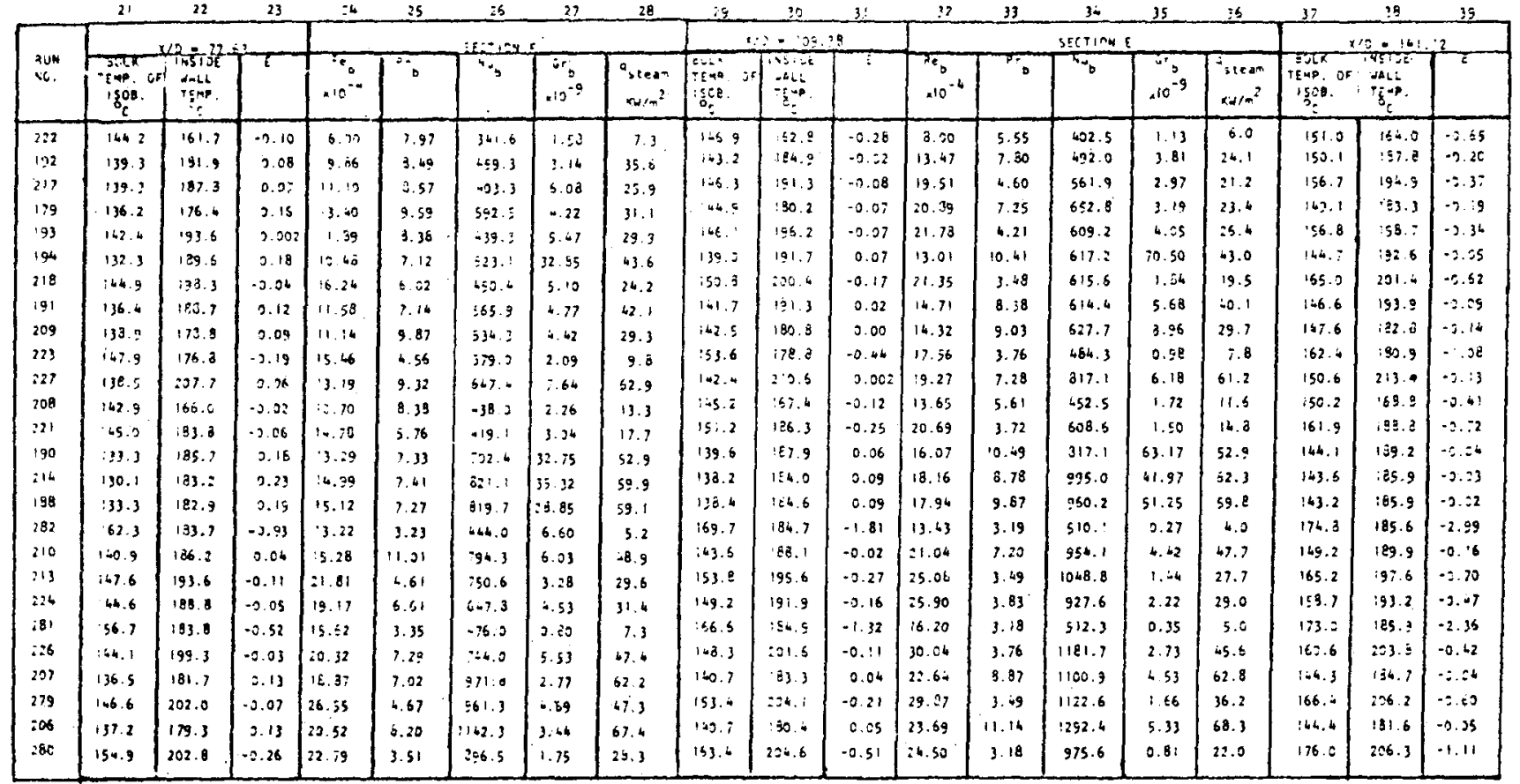

TABLE B-3. TABULATION OF EXPERIMENTAL DATA FROM RUN WITH E. CHANGING FROM POSITIVE TO NEGATIVE. 


\section{APPENDIX C}

\section{DER IVATION OF EQUATIONS FOR DATA REDUCTION}

The derivation of the equations used in the data reduction are presented in this appendix.

C-1. The Calculation of the Inside and Outside Heater Tube Wall Temperatures from Experimental Measurements.

The imbedded wall thermocouples measured the temperatures of the wall at $r_{1}$ and $r_{2}$ but the temperatures of the wall at $r_{i}$ and $r_{0}$ were required for data reduction as shown on Fig. C-1. (Refer to Table F-1, Appendix $F$, for values of $r_{1}, r_{2}, r_{i}$ and $r_{0}$ at the five temperature measurement stations.)

Under.steady state-conditions, the governing equation for temperature distribution inside the wall of the heater tube is:

$$
\frac{\partial^{2} T}{\partial r^{2}}+\frac{1}{r} \frac{\partial T}{\partial r}+\frac{1}{r^{2}} \frac{\partial^{2} T}{\partial \phi^{2}}+\frac{\partial^{2} T}{\partial x^{2}}=0
$$

Assuming one dimensional heat conduction in r-direction only and neglecting any peripheral and axial heat flux, Equation $C-1$ can be simplified to:

$$
\frac{\partial^{2} T}{\partial r^{2}}+\frac{1}{r} \frac{\partial T}{\partial r}=0
$$

The boundary conditions are:

$$
\begin{array}{ll}
T=T_{i} & \text { at } r=r_{i} \\
T=T_{0} & \text { at } r=r_{0}
\end{array}
$$


Depending on the method of non-dimerisionalization, one solution can be written as:

$$
\frac{T-T_{0}}{T_{0}-T_{i}}=\frac{\ln \left(r / r_{0}\right)}{\ln \left(r_{0} / r_{i}\right)}
$$

However, the value of $T_{0}$ and $T_{i}$ are still unknown but $T_{1}$ at $r=r_{1}$ and $T_{2}$ at $r=r_{2}$ are measured by the imbedded thermocouples. Thus

$$
\begin{aligned}
& \frac{T_{1}-T_{0}}{T_{0}-T_{i}}=\frac{\ln \left(r_{1} / r_{0}\right)}{\ln \left(r_{0} / r_{i}\right)} \\
& \frac{T_{2}-T_{0}}{T_{0}-T_{i}}=\frac{\ln \left(r_{2} / r_{0}\right)}{\ln \left(r_{0} / r_{i}\right)}
\end{aligned}
$$

Dividing Eq. $(\mathrm{C}-6)$ by $(\mathrm{C}-7)$ :

$$
\begin{aligned}
& \frac{T_{1}-T_{0}}{T_{2}-T_{0}}=\frac{\ln \left(r_{1} / r_{0}\right)}{\ln \left(r_{2} / r_{0}\right)} \\
& T_{0}=\frac{T_{1} \ln \left(r_{2} / r_{0}\right)-T_{2} \ln \left(r_{1} / r_{0}\right)}{\ln \left(r_{2} / r_{1}\right)}
\end{aligned}
$$

Another solution can be written as:

$$
\frac{T-T_{i}}{T_{i}-T_{0}}=\frac{\ln \left(r / r_{i}\right)}{\ln \left(r_{i} / r_{0}\right)}
$$




$$
\text { Again at } \begin{aligned}
& r=r_{1}, T=T_{1} \\
& r=r_{2}, T=T_{2} \\
& \frac{T_{1}-T_{i}}{T_{i}-T_{0}}=\frac{\ln \left(r_{1} / r_{i}\right)}{\ln \left(r_{i} / r_{0}\right)} \\
& \frac{T_{2}-T_{i}}{T_{i}-T_{0}}=\frac{\ln \left(r_{2} / r_{i}\right)}{\ln \left(r_{i} / r_{0}\right)}
\end{aligned}
$$

Dividing Eq. $(C-10)$ by $(C-11)$

$$
\begin{aligned}
& \frac{T_{1}-T_{i}}{T_{2}-T_{i}}=\frac{\ln \left(r_{1} / r_{i}\right)}{\ln \left(r_{2} / r_{i}\right)} \\
& T_{i}=\frac{T_{1} \ln \left(r_{2} / r_{i}\right)-T_{2} \ln \left(r_{1} / r_{i}\right)}{\ln \left(r_{2} / r_{1}\right)}
\end{aligned}
$$

C-2. Calculation of Steam Condensate Rate and $Q_{\text {STEAM }}$.

The steam condensate rate is calculated from the equation

$$
\dot{m}_{\text {STEAM }}=\frac{\rho V}{T_{A V G}}
$$

Where

$$
\begin{aligned}
\dot{\mathrm{m}}_{\text {STEAM }=} & \text { Steam condensate rate. } \\
V & \text { Volume of the calibrated condensate flow meter. } \\
& \text { The volumes of the eight condensate flow meters } \\
& \text { are listed in Table F-2. } \\
= & \text { Averaged time required to fill the calibrated } \\
& \text { flow meter. } \\
{ }^{A} \text { AVG } \quad & \text { Density of the steam condensate. }
\end{aligned}
$$


The steam heat rate, $Q_{\text {STEAM, is calculated as: }}$

$$
Q_{\text {STEAM }}=\dot{m}_{\text {STEAM }} h_{f g}
$$

where

$$
\begin{aligned}
h_{f g}= & \text { Latent heat of condensation of steam corresponding } \\
& \text { to the saturated vapor temperature, TSTEAM. }
\end{aligned}
$$

C-3. Calculation of Heat Rate, Q $Q_{\text {ISOB }}$.

The heat absorbed by isobutane flowing through the heater tube in between two bulk temperature measurement stations is calculated from:

$$
\begin{aligned}
Q_{I S O B}= & \dot{m}_{I S O B} \Delta i=\dot{m}_{I S O B}\left(i_{n+1}-i_{n}\right) \quad(c-15) \\
\dot{m}_{I S O B}= & \text { Mass flow rate of isobutane through the heater } \\
& \text { tube. } \\
i_{n+1}, i_{n}= & \text { Enthalpy of isobutane corresponding to the } \\
& \text { bulk temperature measured at station }(n+1) \text { or } n .
\end{aligned}
$$

C-4. Calculation of Local Heat Transfer Coefficient.

The local heat transfer coefficients can be evaluated by two methods:

$$
\text { (1) } h=\frac{Q_{\text {STEAM } / A_{i}}}{\left(T_{w}-T_{b}\right)_{A V G}}
$$

$$
\begin{aligned}
Q_{S T E A M} / A_{i}= & \text { Heat flux per unit inside tube area. } \\
\left(T_{W}-T_{b}\right)_{A V G}= & \text { Averaged difference between the inside wall } \\
& \text { temperature of the tube, } T_{w}, \text { and the bulk } \\
& \text { temperature of isobutane, } T_{b}, \text { in the } 2 \mathrm{ft} . \\
& \text { section of the heater tube for which the }
\end{aligned}
$$


evaluation was made. This term was redefined in the data reduction as a logarithmic mean temperature difference for the pan section as:

$$
\left\{\frac{\left(T_{w, U P S T R M}-T_{b, U P S T R M}\right)-\left(T_{w, D N S T R M}-T_{b, D N S T R M}\right)}{\ln \left[\frac{T_{w, U P S T R M}-T_{b}, \text { UPSTRM }}{T_{w, D N S T R M}-T_{b, D N S T R M}}\right]}\right\}
$$

(2) The overall heat transfer coefficient for each pan section is evaluated first:

$$
U_{i}=\frac{Q_{\text {STEAM }} / A_{i}}{\left(T_{\text {STEAM }}-T_{b}\right)_{\text {AVG }}}
$$

where

$$
U_{i}=\text { Overall heat transfer coefficient based on } A_{i} \text {. }
$$

$$
\left(T_{\text {STEAM }}-T_{b}\right)_{\text {AVG }}=\text { Averaged difference between the steam temperature }
$$
and the bulk temperature of isobutane in the $2 \mathrm{ft}$. section of the heater tube for which the evaluation was made. This term was redefined as a logarithmic mean temperature difference for the pan section as $\left\{\frac{T_{b, \text { ONSTRM }}-T_{b, U P S T R M}}{\ln \left[\frac{T_{\text {STEAM }}-T_{b} \text { UPSTRM }}{T_{\text {STEAM }}-T_{b, \text { DNSTRM }}}\right]}\right\}$

The local heat transfer coefficient of isobutane is related to the overall heat transfer coefficient by:

$$
\frac{1}{U_{i}}=\frac{1}{h}+\frac{A_{i} \ln \left(r_{0} / r_{i}\right)}{2 \pi k L}+\frac{A_{i}}{A_{0}} \frac{1}{h_{0}}
$$




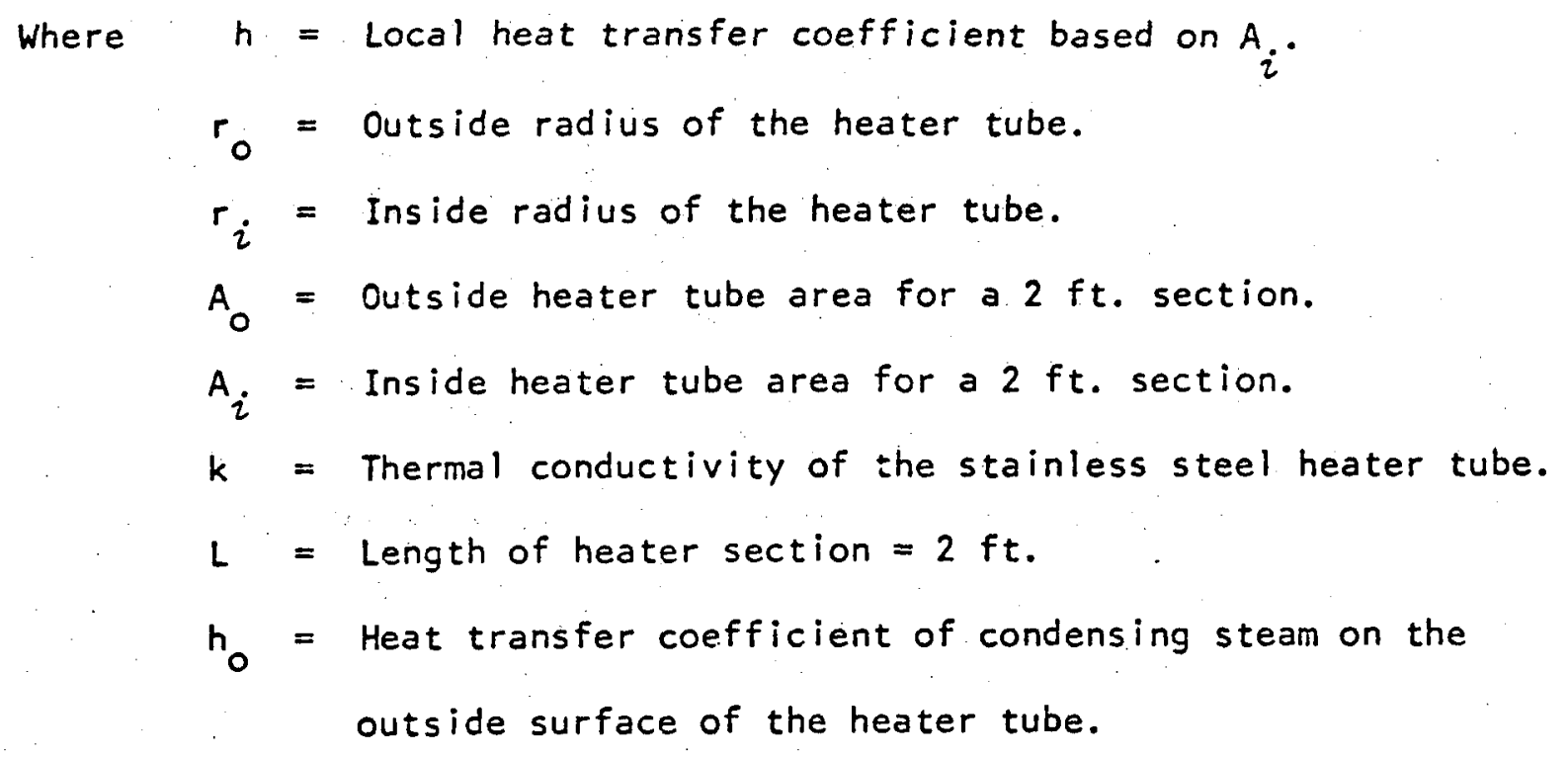

\section{C-5. Calculation of Heat Transfer Coefficient of Condensing Steam}

Using Nusselt's Equation.

The heat transfer coefficient of steam condensing on the outside of a single horizontal tube can be predicted by Nusselt's equation as:

$$
n_{0}\left(\frac{\mu_{f}^{2}}{k_{f}^{3} 0_{f}^{2} g}\right)^{1 / 3}=1.51\left(\frac{4 \Gamma^{\prime}}{\mu_{f}}\right)^{-1 / 3}
$$

$$
\begin{aligned}
& \text { Where } h_{0}=\text { Peripheral mean heat transfer coefficient over the } \\
& \text { outside of the horizontal tube. } \\
& I^{\prime}=\frac{W}{L} ; w \text { is the mass rate of condensate collected } \\
& \text { under the length of exchanger tube section, } L \text {, which } \\
& \text { is } 2 \mathrm{ft} \text {. long. } \\
& \mu_{f}=\text { Viscosity of condensate film at the film temperature } \\
& T_{f}=T_{\text {s. . . }}-\frac{3}{4} \Delta T \text {. } \\
& T_{\text {s.v. }}=\text { Temperature of the saturated vapor. } \\
& \Delta T=T_{\text {S.V. }}-T_{W A L L, O}
\end{aligned}
$$




$$
\begin{aligned}
& k_{f}=\text { Thermal conductivity of condensate at } T_{f} . \\
& \rho_{f}=\text { Density of condensate film at } T_{f} . \\
& g=\text { Acceleration due to gravity. }
\end{aligned}
$$

This equation is only valid for laminar flow of the condensate film over the horizontal tube surface. The criterion for laminar flow is that the value of $\frac{4 \Gamma^{\prime}}{\mu}$ can not exceed 4200 . 


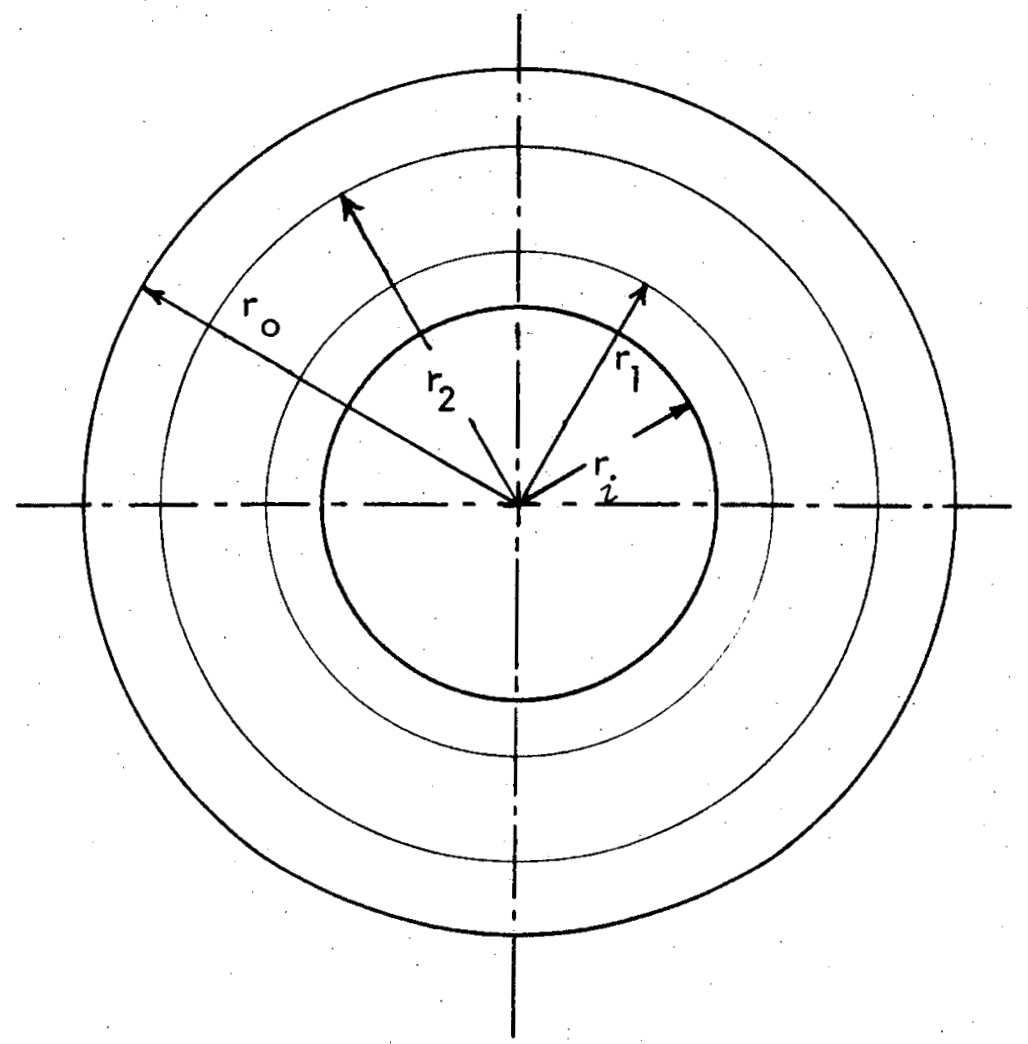

FIG. C-1. DEFINITION OF RADII USED IN SECTION C-1.

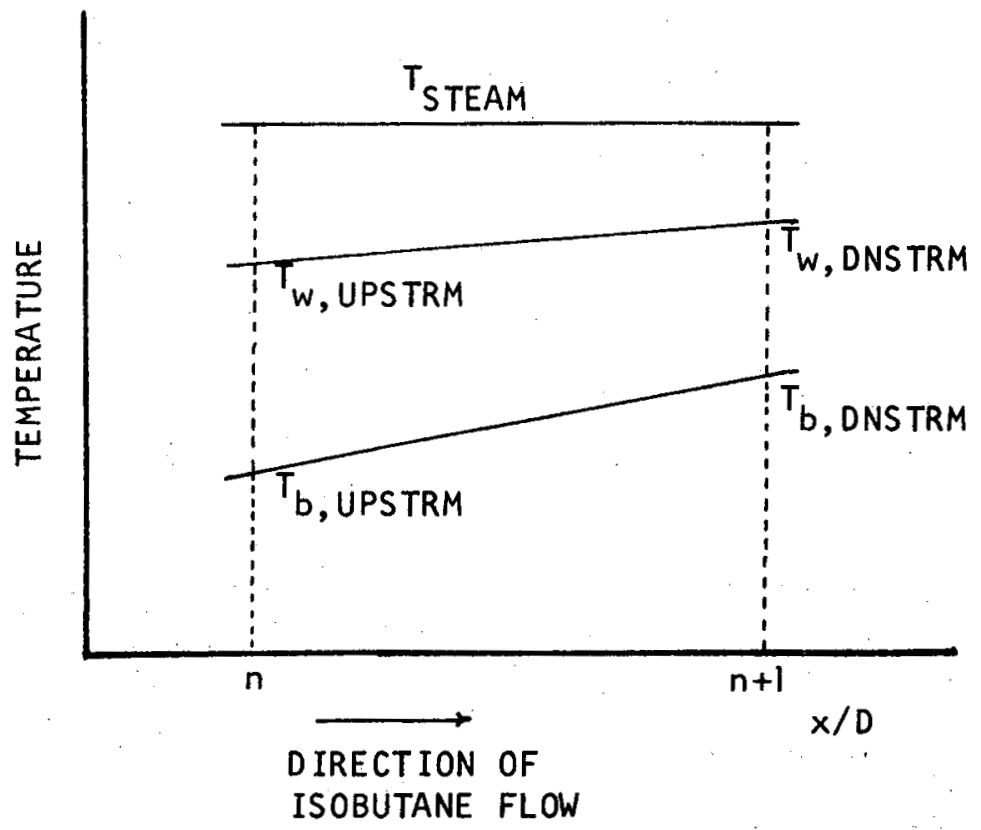

FIG. C-2. DEFINITION OF TEMPERATURES USED IN EQUATIONS $(C-16)$ and $(C-17)$. 
APPEND IX O

\section{EXPER IMENTAL RESULTS FOR LOW GRASHOF NUMBER RUNS}

In Chapter 4, the experimental heat transfer coefficients were compared with those correlations given by Petukhov and Futagami for possible effect of buoyancy on the heat transferred to isobutane. The result suggested that the experimental data had little apparent dependence on Grashof number. However, in the comparison with Futagami and Abe's result, the range of the values of $\frac{\operatorname{Ra}}{\operatorname{Pr}^{2 / 3} \operatorname{Re}^{3 / 2}}$ varied from 3.5 to 80 and these values all exceeded the criterion given by futagami and Abe for the onset of free convection effect. Therefore, some special experimental runs were performed, in addition to those tabulated in Appendix B, to gather data in the very low Grashof number range.

Those low Grashof number runs required a low temperature difference between the condensing steam and the bulk isobutane temperatures in the heater tube. This low temperature difference influenced the rate of condensation of steam on the outside of the heater tube causing the time taken to fill the condensate flow meters to increase to more than 4000 seconds. This exceedingly long time required to fill each flow meter made the recording of several such stopwatch times impractical for each run. Therefore, the heat rate $Q$ used for the calculation of local heat transfer coefficient was calculated from the heat flux measured by the imbedded thermocouples, multiplied by the outside heater tube area, $A_{0}$, for the section.

The results of these special runs are compared with the SiederTate and Petukhov correlations on Fig. D-1 and D-2 for comparison with Fig. 4-5 and 4-6 in Chapter 4. 
Fig. D-l shows most of the data points are above the Sieder-Tate correlation line similar to the data points on fig. 4-6. The data can be correlated by a new Sieder-Tate correlation with constant coefficient being 0.0362 to within $\pm 20 \%$ when the data points for RUN 171 are excluded. This new constant coefficient is about $21 \%$ larger than the one obtained from Fig 4-5 for the data with E>l.

Fig. D-2 shows the comparison of data with Petukhov correlation. The range of Prandtl number for the data points varies from 4.5 to 4.8 , but the data points are widely scattered on the figure.

Fig. D-3 shows the plot of experimental data in terms of (Nu/ $\mathrm{Nu}, F A$ ) against $\left(\frac{\mathrm{Ra}}{\mathrm{Pr}^{2 / 3} \mathrm{Re}^{3 / 2}}\right)$. The experimental data are mostly higher than unity while the prediction of Futagami and Abe indicates the values should be about unity. The data points are consistent with those shown on Fig. 4-9 and the data points failed to follow the prediction by Futagami and Abe.

At this point it can be concluded that the experimental data obtained for these low Grashof number runs showed little dependence on Grashof number and failed to follow the prediction by futagami and Abe. 


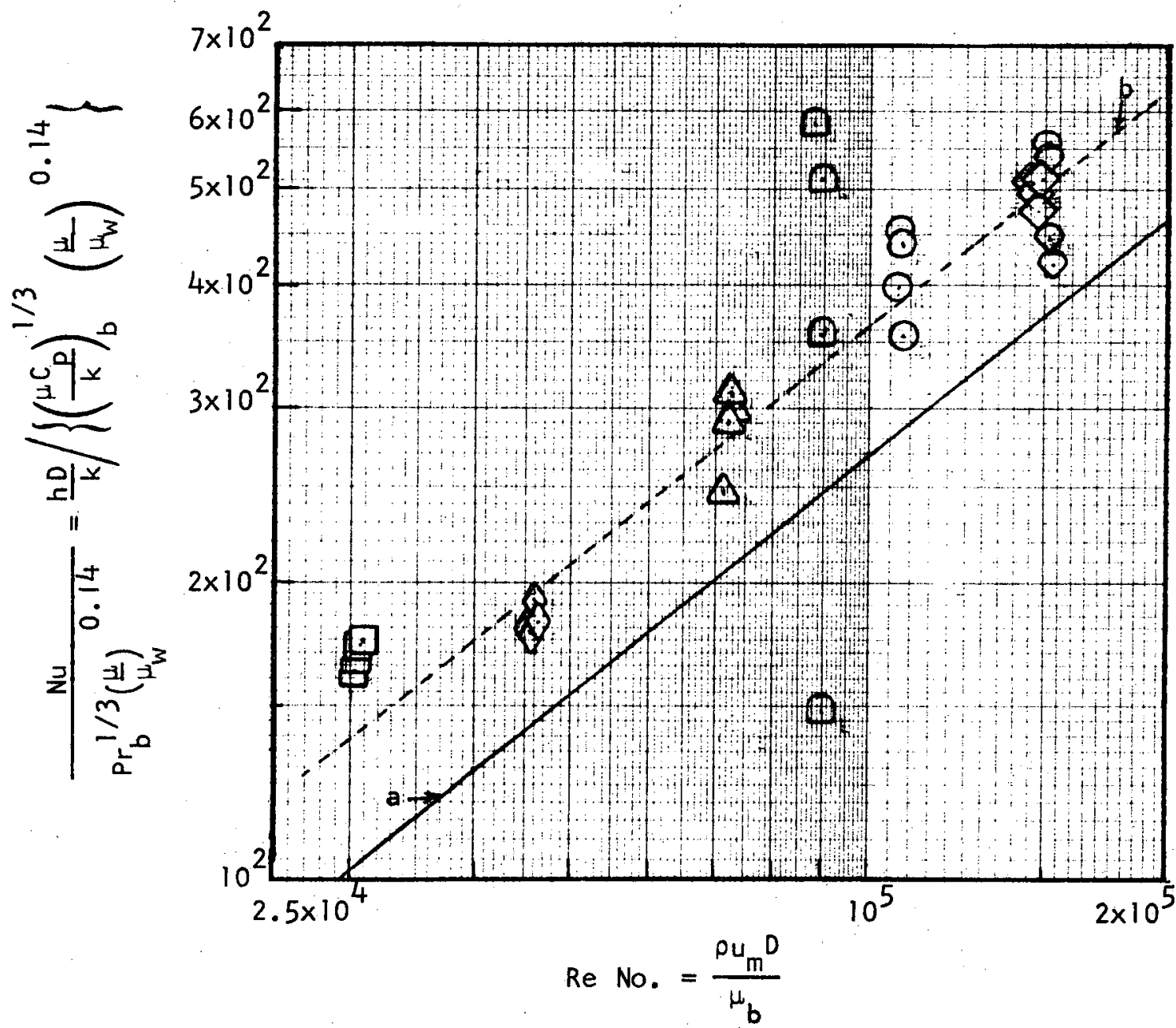

Fig. D-1. Comparison of experimental data obtained from low Grashof Number runs with Sieder-Tate Correlation.

Line a: $N u=0.027 \operatorname{Re}^{0.8} \operatorname{Pr}^{1 / 3}\left(\frac{\mu}{\mu_{w}}\right)^{0.14}$
Line $b: \quad N u=0.0362 \operatorname{Re}_{b}^{0.8} \operatorname{Pr}_{b} 1 / 3\left({ }_{\mu_{w}}\right)^{0.14}$ 


\section{(Continuation of Figure D-1 from previous page)}

$\odot \quad \operatorname{Run} 301, \quad G r / R e^{2.7}=2.79 \times 10^{-7} \sim 3.01 \times 10^{-7}$

$\odot$ Run 300, Gr/Re $e^{2.7}=5.85 \times 10^{-7} \sim 6.21 \times 10^{-7}$

$\triangle \quad \operatorname{Run} 305, \quad G r / \operatorname{Re}^{2.7}=1.82 \times 10^{-6} \sim 2.54 \times 10^{-6}$

$8 \quad \operatorname{Run} 306, \mathrm{Gr} / \mathrm{Re}^{2.7}=6.6 \times 10^{-6} \sim 8.47 \times 10^{-6}$

0 Run 163, Gr/Re $\mathrm{Re}^{2.7}=1.34 \times 10^{-5} \sim 1.99 \times 10^{-5}$

(2) Run 165, Gr/Re $\operatorname{Re}^{2.7}=1.42 \times 10^{-7} \sim 1.55 \times 10^{-7}$

$\odot \operatorname{Run} 171, \mathrm{Gr} / \operatorname{Re}^{2.7}=9.86 \times 10^{-7} \sim 1.29 \times 10^{-6}$ 


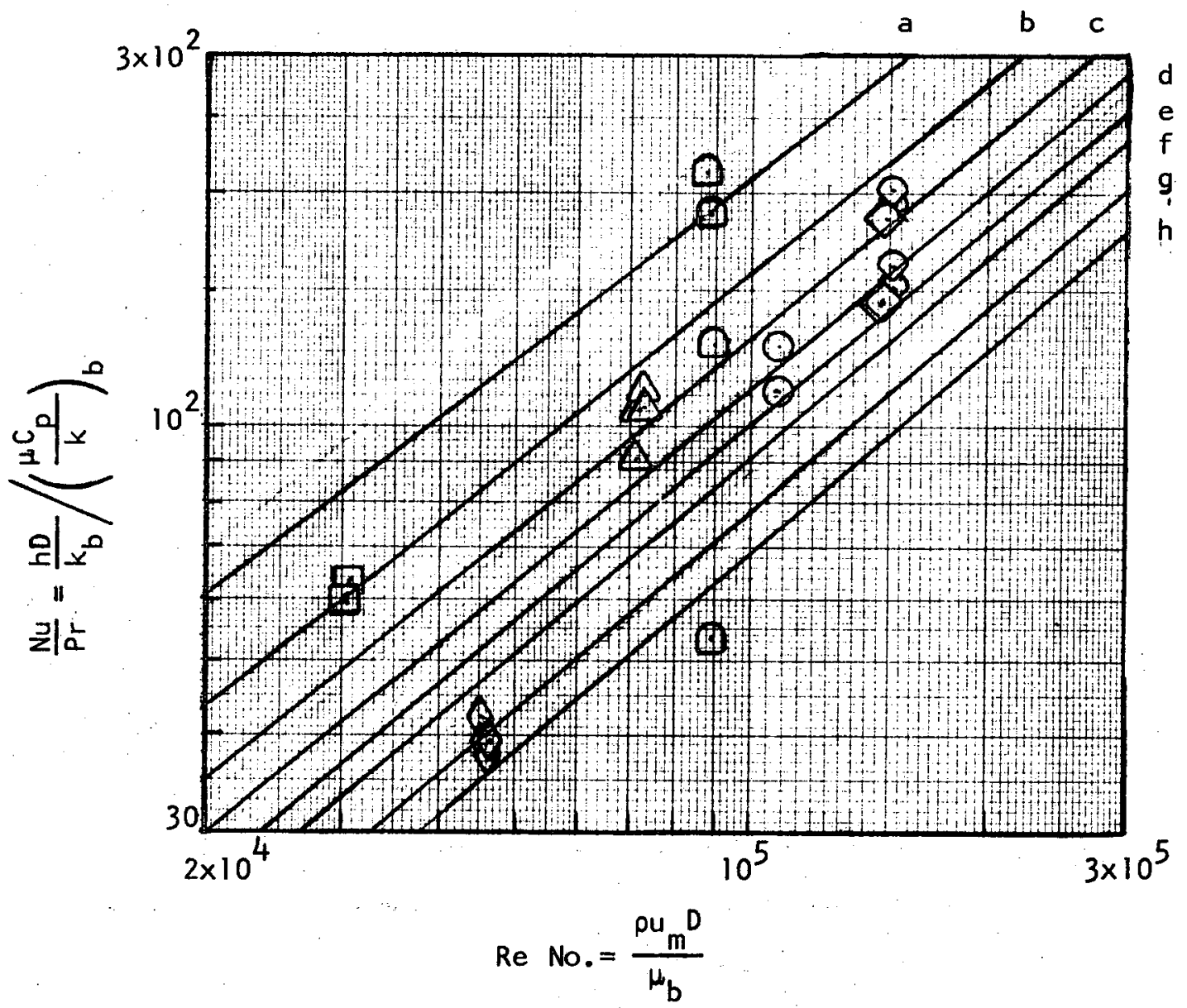

Fig. D-2. Comparison of experimental data with Petukhov Correlation. Line a: $\operatorname{Pr}=1.0$
Line $b: \operatorname{Pr}=2.0$
[. Run 163
Line $c: \operatorname{Pr}=3.0$
- Run 165
Line $d: \operatorname{Pr}=4.0$
$\odot$ Run 171
Line e: $\operatorname{Pr}=5.0$
(P) Run 300
Line $f: \operatorname{Pr}=6.0$
(-) Run 301
Line $g: \operatorname{Pr}=8.0$
$\triangle$ Run 305
Line $h: \operatorname{Pr}=10.0$
$\vartheta$ Run 306

Petukhov Correlation:

$\frac{\mathrm{Nu}}{\mathrm{Pr}}=\frac{\operatorname{Re}(\mathrm{f} / 8)}{1.07+12.7\left(\mathrm{Pr}^{2 / 3}-1\right) \sqrt{\mathrm{f} / 8}}$
$f=(1.82 \log \operatorname{Re}-1.64)^{-2}$

Note: $4.5<\operatorname{Pr}<4.8$ for all data points. 


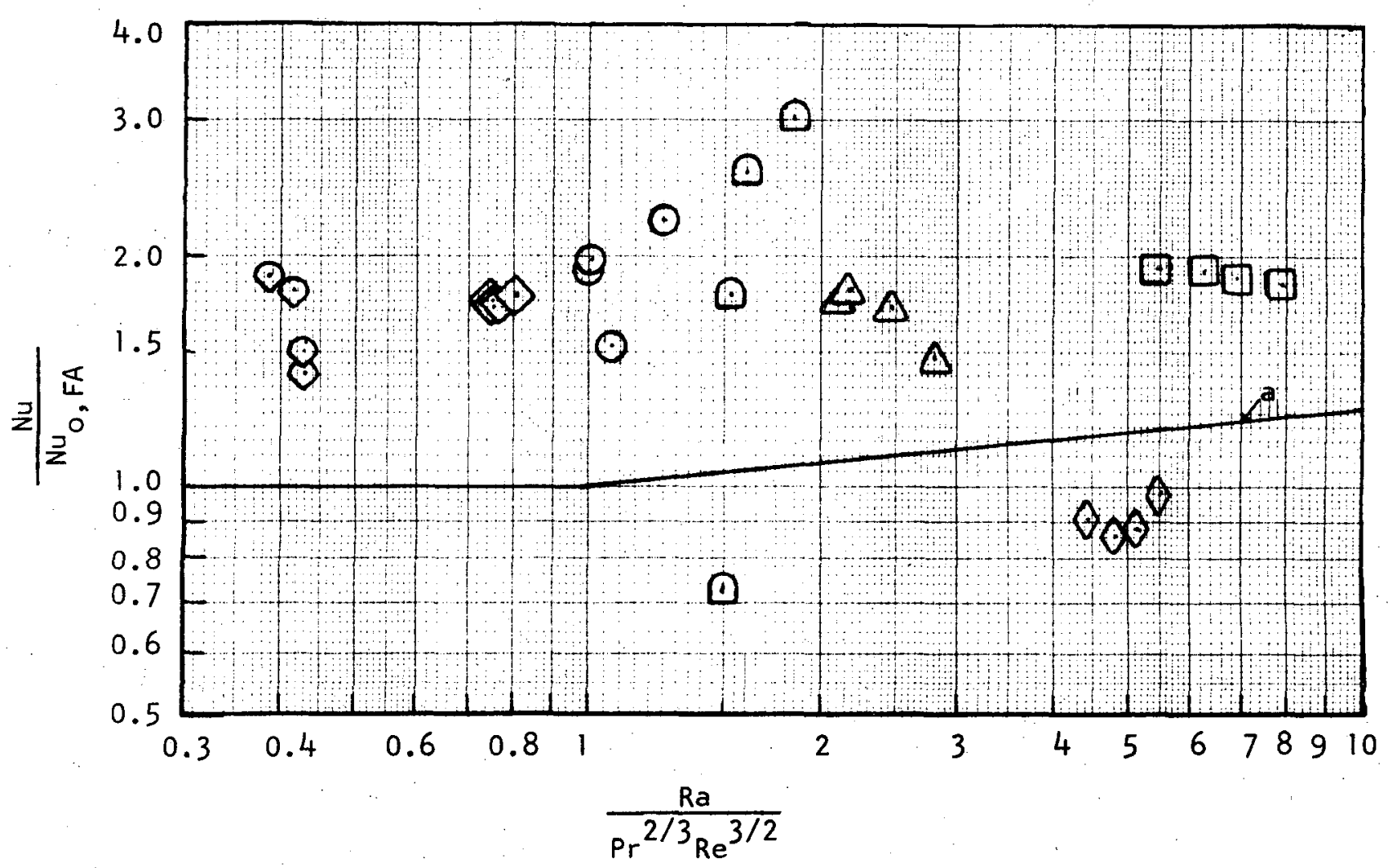

Fig. D-3. Comparison of experimental data with the prediction by Futagami and Abe on the effect of free convection to heat transfer in the horizontal tube.

Line a: $\frac{\mathrm{Nu}}{{ }_{\mathrm{Nu}}, \mathrm{FA}}=1.008\left(\frac{\mathrm{Ra}}{\operatorname{Pr}^{2 / 3} \mathrm{Re}^{3 / 2}}\right)^{0.1}$

๑. Run 163

$\odot$ Run 165

(2) Run 171

$\odot$ Run 300

$\odot$ Run 301

$\triangle$ Run 305

$\odot$ Run 306 


\section{APPENDIX E}

\section{PRELIMINARY RESULTS ON THE CONDENSATION OF ISOBUTANE ON A HOR IZONTAL TUBE}

The experimental results presented in this appendix on the condensation of isobutane on a horizontal tube at the condenser should be considered as preliminary results. The data were obtained from those experimental runs with the imbedded thermocouples in the condenser tube at Configuration A. After the heater and the condenser tubes were rotated to Configuration $B$, the main effort of this study was directed at obtaining data on the heater side. Consequently, the data on the condenser side are not completely reduced for analysis and the raw data are available at SWCL.

For those experimental data already reduced, the data are plotted on Fig. E-1 for comparison with Nusselt correlation for condensation on a single horizontal tube. The Nusselt correlation is:

$$
\begin{aligned}
& h_{m}\left(\frac{\mu_{f}^{2}}{k_{f}^{3} \rho_{f}^{2} g}\right)^{1 / 3}=1.51\left(\frac{4 \Gamma_{1}}{\mu_{f}}\right) \\
& h_{m} \quad=\text { Peripheral mean heat transfer coefficient } \\
& \text { over the outside of the horizontal tube. } \\
& \text { I' } \quad \text { Mass flow rate of condensate per unit } \\
& \text { length of condenser tube. } \\
& \mu_{f}=\text { Absolute viscosity of condensate film } \\
& \text { at the film temperature } T_{f}=T_{s . v .}-\frac{3}{4} \Delta T \text {. }
\end{aligned}
$$

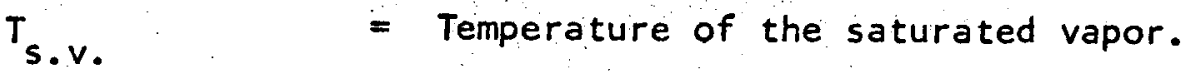

$$
\begin{aligned}
& \Delta T \quad=T_{\text {s.v. }}{ }^{-T} \text { WALL,O }
\end{aligned}
$$




$$
\begin{array}{ll}
k_{f} & =\text { Thermal conductivity of condensate at } T_{f^{*}} \\
\rho_{f} & =\text { Density of condensate film at } T_{f} . \\
g & =\text { Acceleration due to gravity. }
\end{array}
$$

The correlation given by Zazuli [21] for "wavy laminar" solution condensate flowing down the vertical tube is also added on Fig. E-l. The correlation is:

$$
h_{m}\left(\frac{\mu_{f}^{2}}{k_{f}{ }^{3} \rho_{f}^{2} g}\right)^{1 / 3}=0.606\left(\frac{\Gamma^{\prime}}{\mu_{f}}\right)^{-0.22}=0.822\left(\frac{4 \Gamma^{\prime}}{\mu_{f}}\right)^{-0.22}
$$

The experimental data points almost all lie on or above the prediction lines. At high values of $\frac{4 \Gamma^{\prime}}{\mu}$ the data points seem to follow Zazuli's prediction for a "wavy laminar" flow of condensate film around the condensing tube. The Reynolds number of the condensate film for the horizontal tube is:

$$
\operatorname{Re}_{f}=\frac{2 \Gamma i}{\mu_{f}}
$$

The critical Reynolds number for transition from laminar to turbulent flow is 2100 corresponding to $\frac{4 \Gamma 1}{\mu_{f}}$ of 4200 for a horizontal tube. The values of $\frac{4 \Gamma^{\prime}}{\mu_{f}}$ for this experimental study were less than 1000.

In conclusion, the preliminary data obtained on the condensation of isobutane on a horizontal tube give heat transfer coefficient that are equal to or above, by as much as $60 \%$, than the Nusselt's and Zazuli's predictions. 


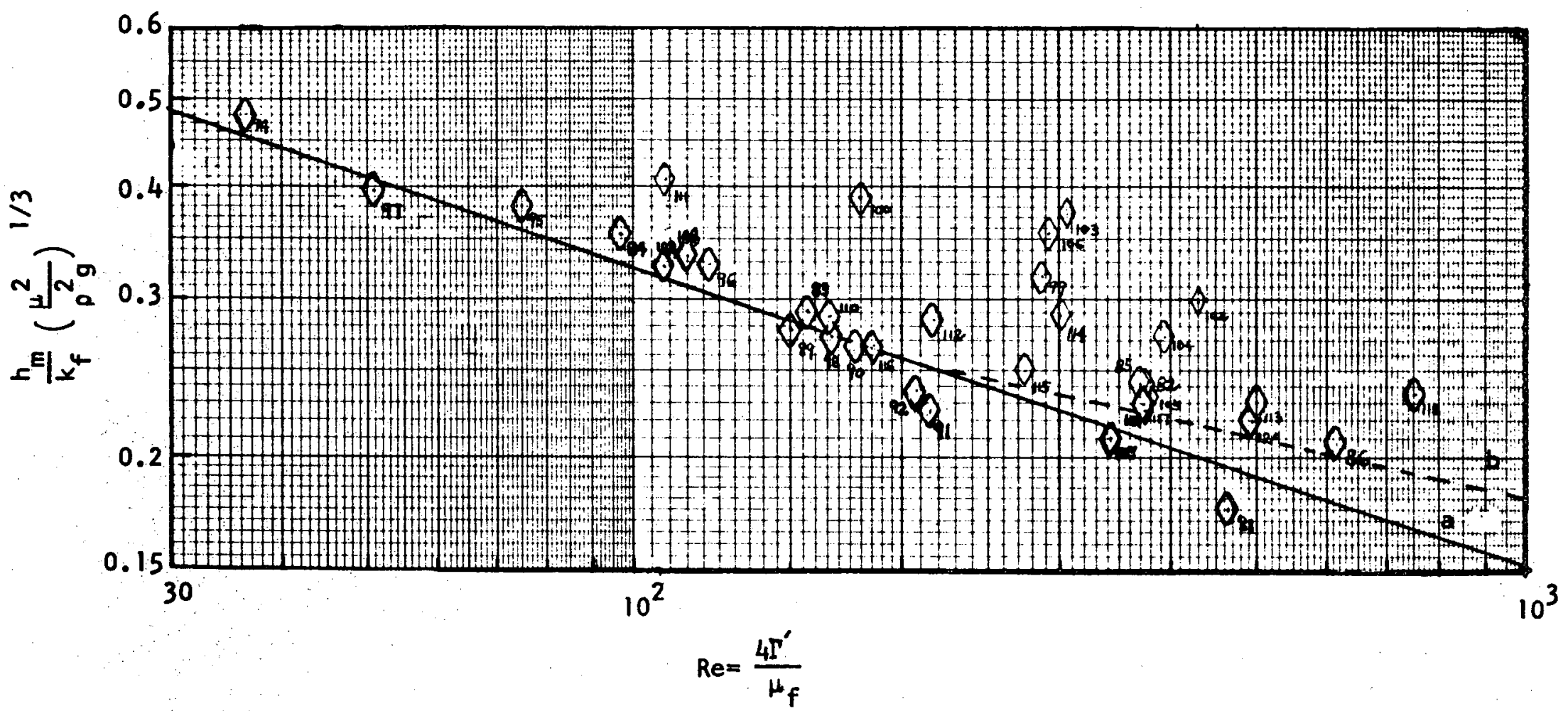

Fig. E-1. Preliminary data correlation for condensation of isobutane on a horizontal tube.

Curve a: Nusselt correlation:

$$
\frac{h_{m}}{k_{f}}\left(\frac{\mu^{2}}{\rho^{2} g}\right)^{1 / 3}=1.51\left(\frac{4 \Gamma^{\prime}}{\mu_{f}}\right)^{-1 / 3}
$$

Curve b: "Wavy Laminar" solution by Zazuli for vertical tube:

$$
\frac{h_{m}}{k_{f}}\left(\frac{\nu^{2}}{g}\right)_{f}^{1 / 3}=0.822\left(\frac{4 \Gamma^{i}}{\mu_{f}}\right)^{-0.22}
$$

$\odot_{110}$ Experimental data with run number. 


\section{APPENDIX F}

LOCATIONS AND CONFIGURATIONS OF IMBEDDED THERMOCOUPLES IN THE INSTRUMENTED TUBES

Table $\mathrm{F}-\mathrm{l}$ is a tabulation of the axial and radial locations of the imbedded thermocouples in the heater and condenser tubes.

Table F-2 is a tabulation of the calibrated volumes of the condensate flow meters.

Figure $\mathrm{F}-\mathrm{l}$ is an illustration of the imbedded thermocouples in Configuration $A$.

Figure $\mathrm{F}-2$ is an illustration of the imbedded thermocouples in Configuration $B$. 


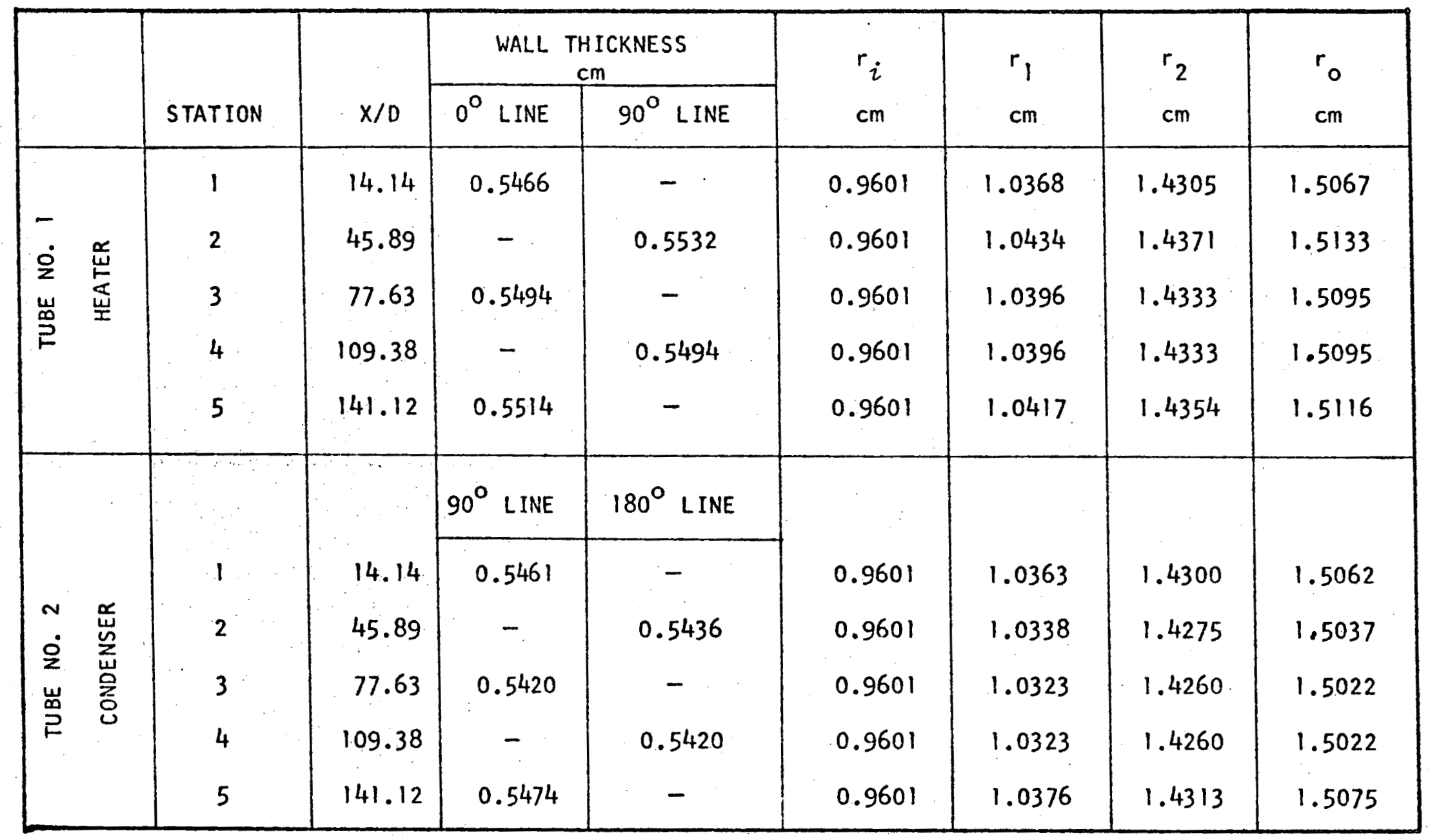

$D_{i}=1.92 \mathrm{~cm}=0.756 \mathrm{in}$.

TABLE F-1. TABULATION OF AXIAL LOCATION, WALL THICKNESS AND RADII OF THE IMBEDDED THERMOCOUPLES AT THE INSTRUMENTED TUBES. 


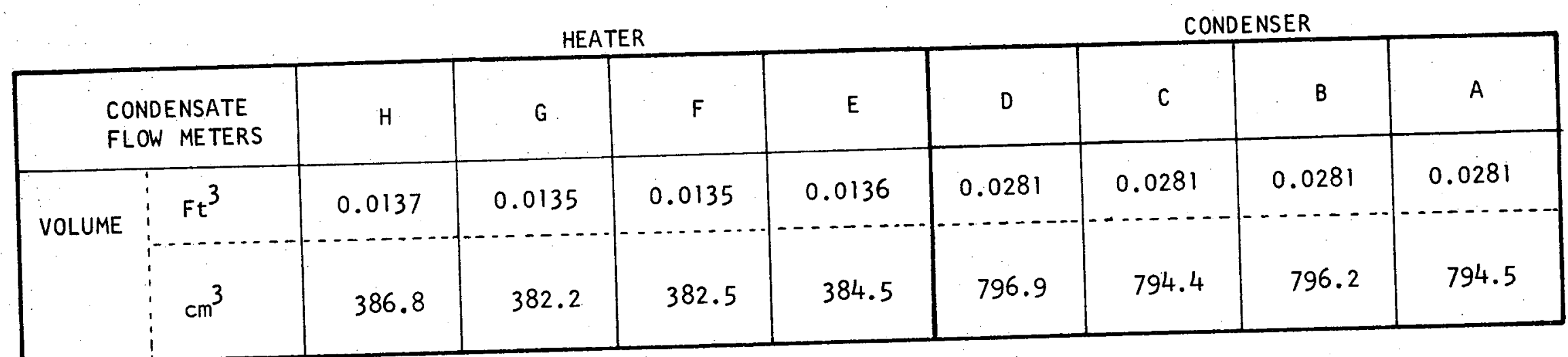

TABLE F-2. CALIBRATED VOLUMES OF CONDENSATE FLOW METERS. 


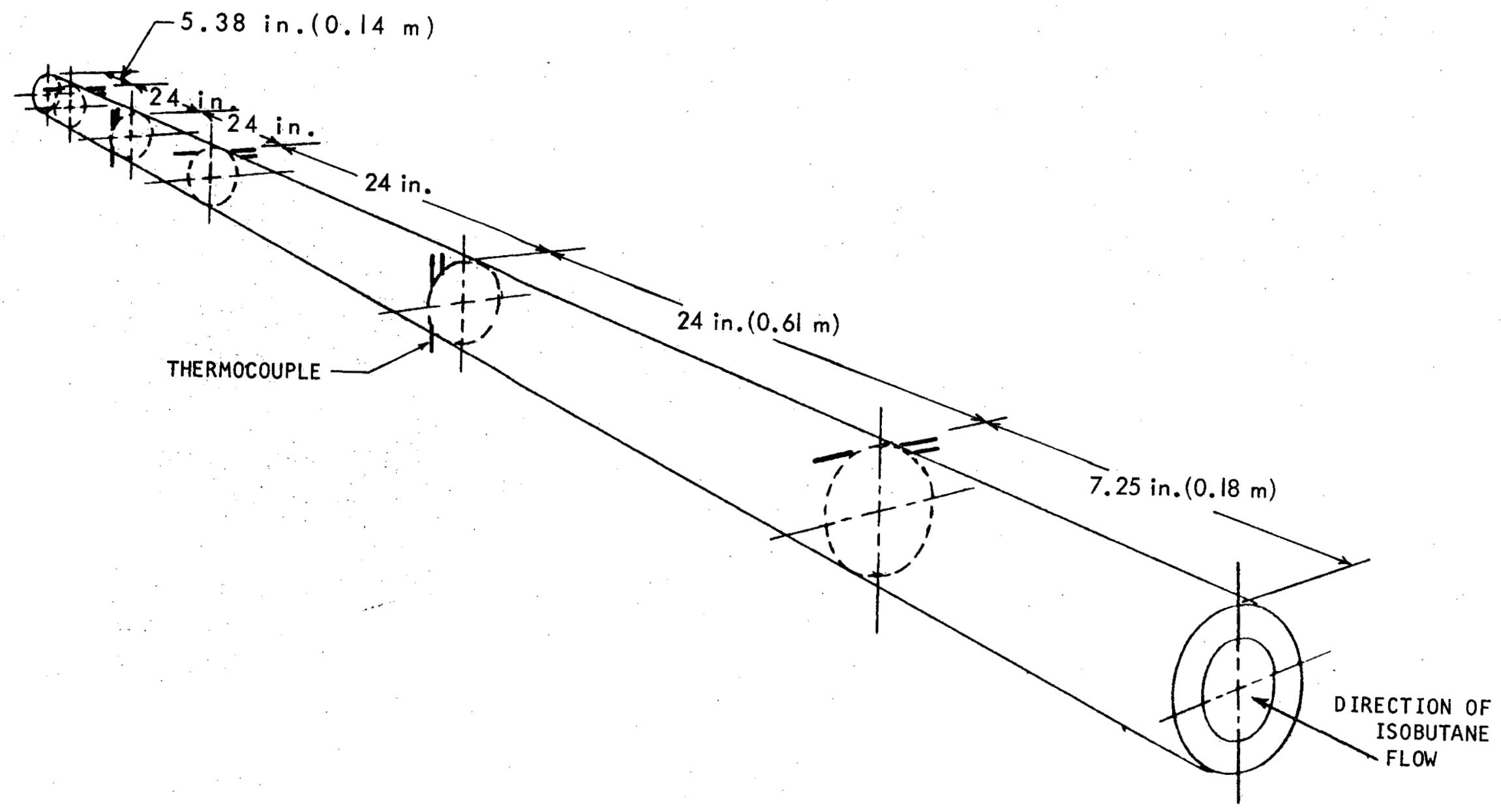

FIG. F-1. LOCATION OF THERMOCOUPLES IN THE HEATER AND CONDENSER TUBES: CONFIGURATION A. 


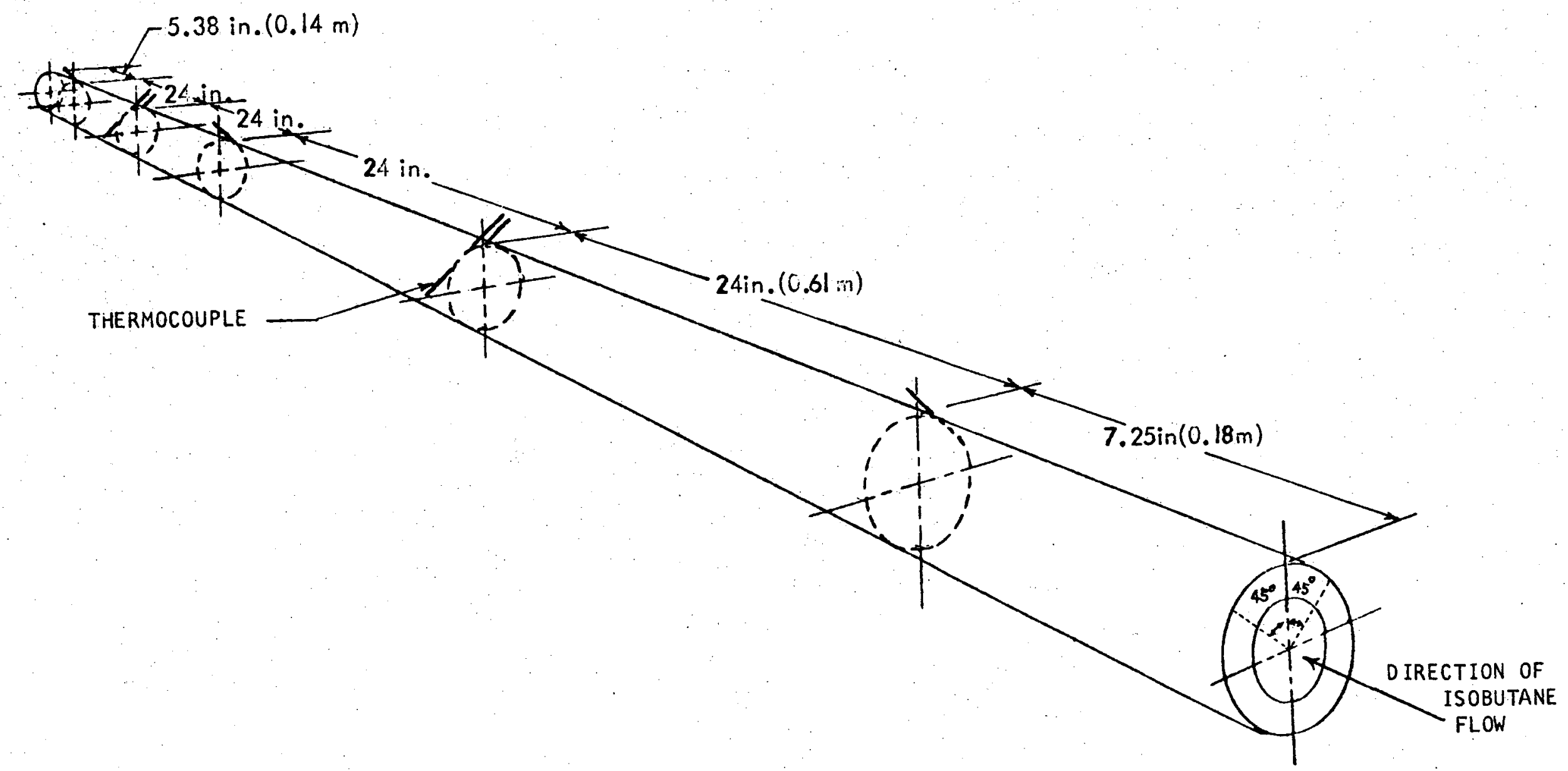

FIG. F-2. LOCATION OF THERMOCOUPLES IN THE HEATER AND CONDENSER TUBES: CONFIGURATION B. 